\title{
MANAGEMENT AND ORGANIZATION
}

\section{CONCEPTS, TOOLS AND APPLICATIONS}

Editors:

Csaba Bálint Illés Maria Nowicka-Skowron Anna Dunay 
MANAGEMENT AND ORGANIZATION

\author{
CONCEPTS, TOOLS \\ AND APPLICATIONS
}




\section{( \\ Pearson}

At Pearson, we have a simple mission: to help people make more of their lives through learning.

We combine innovative learning technology with trusted content and educational expertise to provide engaging and effective learning experience that serve people wherever and whenever they are learning.

We enable our customers to access a wide and expanding range of market-leading content from world-renowned authors and develop their own tailor-made book. From classroom to boardroom, our curriculum materials, digital learning tools and testing programmes help to educate millions of people worldwide - more than any other private enterprise.

Every day our work helps learning flourish, and wherever learning flourishes, so do people.

To learn more, please visit us at: www.pearson.com/uk 


\title{
MANAGEMENT AND ORGANIZATION
}

\author{
CONCEPTS, TOOLS \\ AND APPLICATIONS
}

Editors:

Csaba Bálint Illés

Maria Nowicka-Skowron

Elena Horská

Anna Dunay

2017

\section{P Pearson}


Pearson Education Limited

\section{Edinburgh Gate}

Harlow

Essex CM20 2JE

And associated companies throughout the world

Visit us on the World Wide Web at:

www.pearson.com/uk

(C) Csaba Bálint Illés; Maria Nowicka-Skowron; Elena Horská; Anna Dunay 2017

This book is published with the support of:

Szent István University, Faculty of Economics and Social Sciences

and

Agrár Management Alapítvány

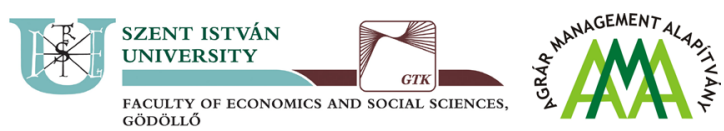

Editors:

Csaba Bálint ILLÉS

Maria NOWICKA-SKOWRON

Elena HORSKÁ

Anna DUNAY

Reviewers:

Anna Albrychiewicz-Słocińska, PhD

Felicjan Bylok, PhD

Helena Chládková, PhD

Anna Dunay, $\mathrm{PhD}$

Csaba Bálint Illés, CSc

Dorota Jelonek, PhD

József Káposzta, CSc

József Lehota, DSc

All rights reserved. No part of this publication may be reproduced, stored in a retrieval system, or transmitted in any form or by any means, electronic, mechanical, photocopying, recording or otherwise, without either the prior written permission of the publisher or a licence permitting restricted copying in the United Kingdom issued by the Licensing Agency Ltd, Saffron House, 6-10 Kirby Street, London EC1N 8TS.

ISBN 978-1-78726-048-1

DOI: 10.18515/dBEM.M2017.n02

Printed and bound in Great Britain by Clays Ltd, Bungay, Suffolk.

First Edition; Publishing Layout B5; Circulation: 300 copies 


\section{TABLE OF CONTENTS}

FOREWORD

\section{CHAPTER 1}

Changing economy - changing concepts

1.1. Competing in a smart world: the need for digital agriculture

György Bőgel

1.2. Oil-price volatility and external risk: Implications for the macroeconomies of Central and Eastern europe

Scott William Hegerty.

1.3. The issue of resource theory and corporate social responsibility

Maria Nowicka-Skowron, Helena Koscielniak

1.4. Counterproductive behaviour in organizations: Theoretical background and empirical implications

Leszek Cichobłaziński..

1.5. Key elements of corporate governance and the functioning of state-owned enterprises in Kosovo

Metë Beqiraj

1.6. The lean effect of the $5 \mathrm{~S}$ and standard work development in different automated machine process standardization

István Vajna, Anita Tangl.

\section{CHAPTER 2}

Management tools in modern organizations

2.1. Relationship between organisational justice and organisational citizenship behaviour: Examining the mediating role of job satisfaction

Hooi Lai Wan

2.2. Quality and management - Tools for continuous and systematic improvement of processes

Csaba Bálint Illés, Csaba Szuda, Anna Dunay

2.3. Evaluation of the results of a production simulation game with different DEA models

Tamás Koltai, Judit Uzonyi-Kecskés

2.4. Public relations in the management of a modern enterprise - Solutions for crisis situations

Anna Karczewska, Magdalena Bsoul

2.5. How can corporate social responsibility be perceived in multinational companyies? - A case study

Iveta Ubrežiová, Elena Horská, Andrzej Krasnodębski 
2.6. Problematic methodological questions of investment project evaluation Mária Illés

2.7. The evolution of e-recruitment: The introduction of online recruiter Beniamin G. Boşcai....

\section{CHAPTER 3}

Applications and innovative methods

3.1. Organizational culture assessment - A case study of Hungary and Austria Anna Dunay, Zoltán T. Nagy, Csaba Bálint Illés

3.2. Knowledge sharing behaviour - Impacts of trust climate and attachment to knowledge

Sathya Narayanan Sivaprakasam, Manikandan Velrajan

3.3. Knowledge management in innovative and social processes of enterprises Beata Skowron-Grabowska

3.4. Innovation - The importance of knowledge networks Árpád Bak, Imre Kovács, Miklós Daróczi

3.5. Consumer behaviour at the impulse product with product defect Adrienn Hegyi, Tünde Kuti, Zsófia Kertész, András Sebők, Sara De Pelsmaeker, Xavier Gellynck, József Lehota

3.6. Short communication: The effect of social media on customer behaviour and firms' activities

Seyyed Amir Vafaei, Mária Fekete-Farkas

3.7. Applying alternative metrics in quantification of news

Márk Molnár, Zsuzsanna Naár-Tóth 


\section{FOREWORD}

The book, "Management and Organization: Concepts, Tools and Applications" was designed to make an overview on the most recent questions of modern management issues. The editors' aim was to summarize the relevant concepts, tools and applications which might help in the successful operation of different organizations. The international group of authors presented a wide variety of topics from different fields and functions of management.

The challenge of this book was to distill the knowledge and findings of authors from different countries and to interpret their experiences to be useful at international - or rather global - level.

The book starts with the introduction of the changes and challenges of our world: the changes in the natural and economic environment, which generate new theories, methods and needs.

The second chapter provides an outlook on the most recent management tools of production processes, quality management, human resource management, public relations and corporate social responsibility based on the experiences and research results of authors from different countries.

The third chapter summarizes some applications and innovative methods by which the management of any organization is able to follow the accelerated rate of technological and social development processes.

Our book was written by an international group of authors for a wide audience, so it provides a unique source of knowledge for academics, researchers, students and professionals in different fields of the economy: business sphere, education and the public sphere.

We believe that the work and results of our authors will lead the reader to see the new concepts, tools and applications in contemporary management issues and to find the possibilities and opportunities for using them in the future.

Prof. Dr. Csaba Bálint ILLÉS

Hungary

Prof. Dr. Maria NOWICKA-SKOWRON

Poland

Prof. Dr. Ing. Elena HORSKÁ

Slovakia

Dr. habil. Anna DUNAY

Hungary 



\section{CHAPTER 1}

\section{Changing economy - changing concepts}





\title{
György BÖGEL
}

\subsection{COMPETING IN A SMART WORLD: THE NEED FOR DIGITAL AGRICULTURE}

\begin{abstract}
Summary
As the real and the virtual worlds are converging and Big Data is flooding everywhere in society, science, and business, new opportunities appear on the radar screen of active and would-be entrepreneurs. Agile ventures may disrupt existing markets and can create new ones. Thanks to sensors, unlimited computing capacities, clever algorithms, machine intelligence and many other technical tools, smart systems are built everywhere. A new entrepreneurial space is emerging where business opportunities can be identified and described by the help of an activity-sector matrix. The logic of this framework is explained in this study, practical examples demonstrate how the "smart ecosystem" is evolving, and how small and mediumsized companies compete in that arena. Special attention is paid to agriculture, a sector in the early phase of its digital transition. Farmers, small and large agricultural ventures must learn how to build and manage smart systems, how to acquire and harness digital capabilities, and how to collaborate and compete in the new environment. Business organizations, large incumbents and young ventures, government agencies, research centers and other stakeholders must develop strategies for succeeding in the new digital and data-rich world, must take care of their digital capabilities, and last but not least, have to demonstrate strong leadership in planning and execution.
\end{abstract}

Keywords: smart systems, Big Data, strategy, entrepreneurship, information technology, smart agriculture, precision agriculture

\section{Digital transformation: masters and laggards}

In their book "Leading Digital", authors George Westerman, Didier Bonnet, and Andrew McAfee describe how digital technologies change the business landscape, and how companies and entire industries try to adapt to the new opportunities and market conditions (Westerman et. al., 2014). Their findings and recommendations are based on a rigorous and extensive research study of 400 companies in 30 countries.

Two dimensions are used to describe this transformation. The first is for digital capabilities: what kind of digital infrastructure is available at the companies, the quality of hardware and software they use, and the knowledge and skills of their people. The second represents leadership capabilities required to develop a vision and execute on it, to initiate and launch critical projects, to manage change, build momentum and ensure that all employees follow through.

The firms that excel at both dimensions are called digital masters: they have cuttingedge technology, relevant and unique knowledge, and are able to harness what they have for improving their productivity and competitiveness. Digital mastery, as described by the authors, can be achieved in various forms of technology-driven business reinvention. For example, masters may reengineer their processes, launch better products or services, develop their quality, reduce cycle time, may create new 
digital businesses and distribution channels, improve customer relationships, rethink their value proposition, and compete by a radically new business model.

Research findings presented in the book highlight that digital masters do exist, but they are rare. Many companies are in the other corners of the matrix stretched by the two dimensions. Fashionistas are technology fans with impressive digital capabilities; they are ready to buy the most innovative (and expensive) technologies, but their leadership capabilities necessary for a real digital transition are weak, their business models are not changed in harmony with new technical tools, processes are not streamlined, and because of this, members of this group waste of much they spend, remain the same behind the curtain. Conservatives follow technical development slowly, they are unconcerned about new technical gadgets, build only limited digital capabilities. Firms in this third group are good in execution, but may fall in the governance trap paying too much attention to controls and rules. They move ahead slowly, are not ready to make radical steps, prefer to keep the status quo.

The fourth group called beginners are at the start of digital transformation. Companies in this group have only basic digital capabilities, many of them work by a "wait-andsee" infocommunications strategy or do not have a digital strategy at all. When asked about it, they look for excuses for inaction, find negative cases quickly, mention repeatedly the risks and the mistakes made by digital pioneers.

Regarding the benefits of digital mastery, the three authors draw a simple data-based conclusion: profitability of digital masters is significantly higher than that of the other three groups. The worst case is that of the beginners, with many firms in the red. The position of fashionistas and conservatives is better but they also drop well behind the masters.

The researchers also analysed digital mastery by industry and found significant differences. Just to mention a few examples, many high tech companies are digital masters (it cannot be a surprise), together with financial institutions and retail firms; the telecom industry is a fashionista, and utilities are conservative, while many manufacturing and pharmaceutical companies are beginners.

Despite its obvious importance, agriculture as an industry is not on this two dimensional map. We know that the economic significance of agriculture within the economy (measured as a ratio in GDP) has been in almost continuous decline over the last 50 years, but this lack of interest cannot be explained only with this unquestionable fact. When digital capabilities are discussed, agriculture is frequently regarded as a field where one might least expect a technology revolution. Regarding digital mastery, the industry is described as a beginner at best by many observers, lagging well behind others.

Fortunately, agribusiness is also changing, its digital transformation is in progress, the industry shows signs of technology innovation, exciting cases illustrate how digital technologies may improve the performance of plant cultivation and livestock breeding. The digital revolution in agriculture based on information technology started in the 1980s. One of the first steps was the introduction of a yield meter by an American company called Massey Ferguson at the beginning of that decade; yields could be continuously recorded for the first time. Global Positioning System (GPS) became 
available on tractors in the early $1990 \mathrm{~s}^{1}$ but its accuracy was not good enough for precise mapping. The main goal of recording yield and using GPS mapping was to identify spatial variations and to gain insight into the factors affecting yield such as landscape, moisture, soil content and structure, etc.

The term precision agriculture, together with GPS-guided tractors, also appeared in the early 1990s. Its fundamental principles were well known by farmers since the early days of agriculture (Brase, 2005; Srinivasan, 2006; Tamás, 2001). Plant producers divided their land into smaller parts and tried to grow crops where the specific conditions were the most suitable. They did it because they were forced to do it, if they wanted to produce enough food for their families. Although this practice was based on accumulated personal experience, was rather rough, low resolution, and lacking scientific evidence, it highlighted the importance of understanding field and microclimate variations. It suggested that decision-making must be based on three main components: obtaining relevant data, acquiring insight through analysis, generate and execute efficient management response. Its central notion is the empirical fact that both soil and microclimate vary spatially and temporally. The logic of precision agriculture dictates that production inputs like fertilizers, pesticides, and water should be applied only where and when they are needed ${ }^{2}$. It became obvious that fast developing information technology can raise precision agriculture to a higher level, but it may take a few years to fulfil this promise.

Precision agriculture developed at varying pace geographically (Zhang et al., 2002). The U.S., Canada and Australia are the traditional pioneers, the United Kingdom and France were the door openers in Europe, just like Argentina and Brazil in South America. Large visionary companies have ample resources to design and manage this transformation successfully, but technology innovation always opens the door for disruptive and agile new ventures experimenting with the new tools and solutions, using modern technology as a weapon in competition.

Despite early efforts, the sector's digital progress was slow. It takes time to asses and evaluate the short and long term effects of this kind of innovation, but we can assume that it will follow the same trajectory as that of other industries, but apparently slower. The technical revolution of precision agriculture looks to be unfinished, e.g. penetration of $11 \%$ was reported in Hungary recently, and this figure may be overestimated because of sampling reasons (Lencsés, 2013; Lencsés et al., 2014). Although the U.S. is a leader in precision agriculture, the country's Department of Agriculture reported that the technology is applied on less than $20 \%$ of corn fields (Lowenberg-DeBoer, 2015). Industry observers express the concern that adoption of agricultural software solutions is slow, penetration is much lower than predicted, digital systems' capabilities are underutilized, many producers use them only to prepare simple tables, to-do-lists, and working schedules.

\footnotetext{
1 The U.S. government opened its Global Positioning System (GPS), a satellite-based navigation program for civilian use in 1983.

${ }^{2}$ The core issue of precision agriculture is the identification of management zones defined as subfield regions with homogenous soil, landscape, etc. condition. Chang et al. (2014) describe how management zones were delineated using a special sensor technology on a tobacco field.
} 
At the same time, the need for modern efficient, productive and sustainable agriculture cannot be overemphasized. Here are a few ideas and data to illustrate this point.

Let us discuss the demand side first. The world population more than tripled during the 20th century from about 1.65 billion in 1900 to 5.97 billion in 1999. Growth did not stop: the United Nations projects a world population of 9.15 billion in 2050 . Population growth is especially high in some poor Third World countries, while some developed ones face the problem of demographic stagnation and aging population. Urbanization of the world is a massive migration trend, the majority of the world's population lives in towns now, huge megacities are emerging generating burning problems for food supply chains. Adding all these trends together, it is highly probable that we will need to grow $50-100 \%$ more food $^{3}$ within a few decades to meet the needs of the growing population.

While demand is growing, land size available for agricultural purposes is decreasing because of a few reasons like urbanization, highway building, climate change, scarcity of clean water, and environmental pollution. In many parts of highly populated Asia almost all cultivated land is already in use. In Brazil, where it is possible to extend the size of cultivable land, this can be done at the expense of native forests, a key component of the world's biological ecosystem. One should not forget that by FAO's estimation more than $75 \%$ of the Earth's land is unsuitable for rain-fed agricultural production. Decisions to produce biofuels on agricultural land also increased the pressure.

When demand is growing and sources are limited, productivity becomes the decisive factor of long term development. The analysis of agricultural labour productivity is a difficult task. The key indicator is the ratio of gross value added in agriculture per annual work units. To calculate the denominator, namely the labour input, part-time and seasonal work must be taken into account, both of which are widespread in agriculture. There are high geographic differences in production structure what may influence the comparability of productivity figures, e.g. production of fruits and vegetables is more labour-intensive than that of arable crops. Agricultural labour productivity can be influenced by quite a few factors such as average farm sizes (e.g. farms in eastern and southern Europe are generally much smaller than in northern Germany where average farm size is the highest in the EU), the level of mechanization, and the share of production for on-farm consumption.

Reliable and comparable productivity figures are rare but it is obvious that there is a huge gap between developed nations and Third World countries. European statistics also show a stark divide in relation to agricultural productivity: highest productivity is recorded in The Netherlands and some regions of France and the United Kingdom where gross value added per annual work unit reached EUR 45000 in 2011, while it was at or below EUR 5000 in some regions of Romania, Slovakia, Portugal, and Latvia (Eurostat, 2014).

Besides productivity, waste and pollution are also hot issues of agriculture. The sector is now a major force behind many environmental hazards. Agriculture occupies about $40 \%$ of Earth's terrestrial surface, rain-fed agriculture is the world's largest user of

\footnotetext{
${ }^{3}$ Variability of predictions is high, but typical figures are within the range of $50-100 \%$.
} 
water. Food production has important negative externalities such as release of greenhouse gases, chemical pollution, soil degradation, loss of biodiversity, and ecosystem disruption. Nitrogen consumption is a good example. Nitrogen is used by many farmers to influence plant growth and improve crop yields, but the use of a nitrogen fertilizer also has environmental impact. The cost of nitrogen fertilizers increased fast in the recent past, having a negative effect on plant producers' bottom line. In the United States, agriculture is the largest source of nitrogen compounds entering the environment. Nitrogen fertilizer consumption is the highest in China, a country with dreadful pollution problems.

Fertilizers are usually applied uniformly, consequently some parts of the field are likely to be more depleted in nutrients than required. There are regions where less than $50 \%$ of the fertilizers used on the fields actually goes to the plants, much of the rest leaks into the environment. Pesticides are generally sprayed evenly on large pieces of land without any differentiation and optimization, what is expensive and environmentally hazardous. The same can be said about water consumption for irrigation. A major challenge is to identify the fields which need more or less of the chemicals or irrigation water.

Growing demand, limited resources, huge productivity gap, need for sustainability agriculture faces all these problems. Farmers and firms must try to produce more from less land, protect the environment, ensure food security ${ }^{4}$, and answer legal quality and safety requirements at the same time. Agriculture must be intensified to raise production, but growth is constrained by the finite resources of the Earth. The ultimate goal is not maximum productivity, but the joint optimization of production, environment protection and social justice.

This need is not new and producers have done a lot to improve their output. Crop yields increased significantly in the second half of the $20^{\text {th }}$ century, e.g. global production of major cereals doubled. This growth came mainly from developed countries and without adding more land. It was the result of multiple factors like more irrigation, better machinery, greater use of herbicides, pesticides, and fertilizers, improved crop varieties, more efficient process management and monitoring.

Some of these efforts have their limits, face the law of diminishing returns, increase input costs and may pollute the environment. Advances based on traditional solutions are slowing. Average global crop yields increased by 56\% between 1965 and 1985, and only by $20 \%$ from 1985 to 2005 , and this growth was driven mainly by increased inputs of non-renewable resources (Foley 2011). Yields have plateaued or declined in some important food-producing regions (Grassini et.al., 2013) . $^{5}$.

Organic farming may solve some problems but it also has some drawbacks and cannot promise to feed the growing population. There is wide geographic variation in agricultural productivity even across regions having similar climate conditions. Yield

\footnotetext{
${ }^{4}$ By Maplecroft, a leading British risk management agency, the top 5 counties with the highest food security risk were Yemen, Somalia, Afghanistan, Pakistan, and Iraq (report on 2013, published in 2012). ${ }^{5}$ Research findings of Grassini, Eskride, and Cassman (2013) indicate that as yields move up towards the potential threshold during the adoption phase of new farm management practices, it becomes more difficult and expensive to push de gain ahead, and the associated marginal costs may outweight the benefits.
} 
gaps, defined as a difference between realized productivity and the best that could be achieved using up-to-date materials and technologies, are experienced in many parts of the world. The advent of precision agriculture technology opened the yield gap; this gap is still open in many places, whilst productivity frontiers are pushed ahead again by forces of innovation.

Although there are a few ways available for increasing production limits without much environmental damage ${ }^{6}$, he question raised in the present study is how technological innovation and digital transformation, as described by the aforementioned book of Westerman, Didier, and McAfee, can change agriculture's present and future productivity trajectory. Before focusing on agriculture again, let us discuss the main technology development trends especially the proliferation of data-based smart systems, the general structure of the new entrepreneurial space, and how companies compete for profitable positions in it.

\section{Big Data, smart systems and the new entrepreneurial space}

Mu Sigma Inc. is one of the fastest growing companies of the world now. It was founded by the former consultant Dhiraj C. Rajara in 2004. The company's name is derived from the statistical symbols „Mu” (mean) and „Sigma” (standard deviation).

The name is a message for the market: the company is a master of data-driven analytics and related decision support systems. Mu Sigma, headquartered in Chicago and operating its main delivery centre in Bangalore (India), works for many Fortune 500 companies nowadays. By the help of its analytical services, customers can make better predictions about future demand for their products, can increase the efficiency of their processes, the insight generated by data-based models help them to identify and manage risks, to implement growth strategies and to reduce costs. Mu Sigma is active in many industries including airline, entertainment, healthcare, retail, technology, telecom, etc. It managed to attract the interest of investors, raised its first institutional investment round of \$30 million from FTVentures and the second one of \$25 million from Sequoia Capital, the flagship venture fund of Silicon Valley.

$\mathrm{Mu}$ Sigma represents a new breed of knowledge-based private ventures of the fast developing Big Data world. 2004, the year when it was founded, closed the "nuclear winter" of the IT industry, a period after the dotcom crisis when many internet companies went bankrupt and technology investment hit the bottom. Fortunately technological progress did not stop in this period, technology entrepreneurs and investors learned a lot from the crisis and company failures (Bögel, 2015, chapter 6). The widespread enthusiasm of the late nineties did not return, business thinking became more realistic and cautious, but pessimism gave way to optimism, and the vital role modern information technology and innovation may play in business strategy became really apparent for many decision makers.

The content of business strategies has also changed: as the economy has been moving out of the financial crisis by the end of the new century's first decade, the focus is no longer on cost savings and economic efficiencies but rather on growth and

\footnotetext{
${ }^{6}$ E.g. roughly $30-40 \%$ of food in both the developed and developing worlds is lost to waste (Godfray et al. 2010, p. 816), consequently waste reduction measures are of high importance.
} 
technology's potential for business transformation (Davenport, 2014). Technology innovation, lessons learned during the crisis, and new growth opportunities - all these factors mixed together generate a fertile environment for ambitious SMEs like $\mathrm{Mu}$ Sigma.

Some technologies have matured enough to enable traditional and new businesses in many areas. Let us see just a few examples. Computers are more powerful now, networking is global and ubiquitous. Companies, especially new ones do not have to build and maintain their own ICT infrastructure because cloud computing became an accepted platform. Instead of buying expensive server farms companies can simply rent computing and storing capacities from huge data centers and pay by usage. Capacity and service prices are decreasing continuously thanks to competitive forces. Service models combined with mobile tools increase business flexibility and adaptability. Digitization is a massive trend everywhere, more and more physical objects, tools, machines and other devices are equipped with electronics, computing and communication capabilities (Gleick, 2011). The "internet of things" is growing faster than the "internet of people", billions of cars, production tools, household devices, sensors, etc. will be connected to the network in the near future, connectivity and data will get cheap and globally accessible. Many organizations have already built their "digital nervous system", installed ERP, CRM, SCM and other company applications, streamlined their processes by digitalizing transactions. Sensor and identification technology has developed a lot.

Datafication of the world is in progress, and this process looks to be unstoppable (Andreessen, 2011; Baker, 2008). Progress in infrastructure and software improved the ability to collect data throughout the enterprise and complex international supply chains. Virtually every part of modern organizations and their environment is open now to data collection. This almost unlimited availability of data has led to the so called Big Data phenomenon and raised the interest in methods for extracting useful information and knowledge from huge and permanently growing datasets of enormous volumes and high variety (Barabási, 2010).

Data became a key business asset, data management and analysis are business capabilities of high importance. Companies and other organizations try to exploit data for competitive advantage, better customer understanding, designing and launching new products and services. The data-centered convergence of important digital technologies has given rise to modern data science and powerful data-mining techniques (Fajszi et al., 2013).

The main promise of the Big Data phenomenon is the ability to build smart systems everywhere (Mayer et al., 2013; The Economist 2010). Smartness stems from a combination of comprehensive, relevant and real-time data, sophisticated analytical algorithms, efficient decision support, fast and effective execution. Cutting-edge smart systems are not only smart but capable for learning and self development. Smart systems pop up everywhere, more and more things get a "smart" prefix before their name: smart commerce, smart manufacturing, smart agriculture, smart town, smart commerce, etc.

The potential for designing and building smart systems opens a new entrepreneurial space. Many of these opportunities will be spotted and utilized by new ventures which 
will start to compete with industry incumbents. Smartness, namely the ability to collect and digest Big Data for insight, prediction, innovation and improvement may have a transformative impact on many sectors, may change the nature of competition and even disrupt some industries.

The aforementioned company, Mu Sigma is focusing on statistical analysis and modelling, as key components of this new entrepreneurial space. Its fast growth properly illustrates the market's potential. This opening and growing space can be described as a two dimensional matrix of activities and sectors.

The first dimension represents the following logically ordered imbedded activities of functioning smart systems:

- Selecting a subject and identifying its problems or needs for improvement

- Translating the problems to the language of data science

- Collecting relevant data on the system and its environment

- Mixing the collected data with other accessible relevant and valuable data

- Transferring the data to a place where the necessary computing power, storage capacity and data management knowledge is available

- Analyzing (mining) the data, acquiring insight, building decision-support models

- Using the models for decision support, presenting findings and recommendations to decision makers.

- Implementing the decisions, changing and developing the selected system, measuring and evaluating the results.

- Closing the loop by using the acquired experience for learning, improving the activities listed above.

Figure 1: Simplified model of building and operating smart systems

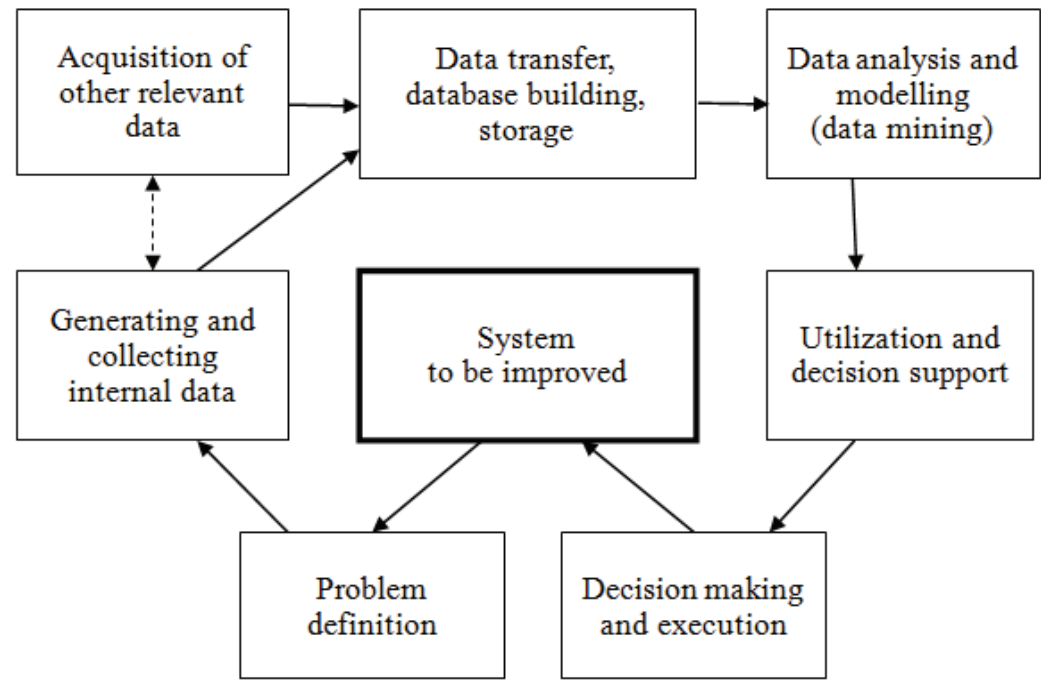

Figure 1 presents a simplified model of the activity loop above. The whole loop is liable to innovation because of the fast development of its components. 
The second dimension is for the sectors which may benefit from the development and spreading of smart technologies: trade, manufacturing, finances, government, healthcare, agriculture, education, marketing, etc.

Many companies and other organizations (e.g. university departments, research labs, consultants) try to find a good position in the activity-sector matrix matching the new opportunities with their financial, technological and intellectual capabilities.

Big incumbents like IBM may occupy almost all the horizontal (activities) and vertical (sectors) portions of the entrepreneurial space. Some of them design and build complete smart towns with many modern data-based smart services like transport, healthcare, education, government services (Townsend, 2014). One of the leading examples is Santander, a Spanish coastal town where thousands of installed sensors feed the smart algorithms providing support to the city's inhabitants. The systems' main designer and operator is Telefónica, a Spanish broadband and telecommunications provider with a global presence. Cisco's test field is the town of Songdo in South Korea, IBM is especially active in Portland. In Hungary, the large ICT incumbent Hungarian Telkom is building the infrastructure for smart town services in Szolnok and Nyíregyháza.

One of the most attractive sectors is energy where smart meters may generate a huge amount of data what can be used for reducing consumption, and managing the complexity of modern multi-source energy systems. Healthcare is also very promising; precision agriculture's healthcare tally is individualized medicine that is tailoring of medical treatment to the individual characteristics of each patient. By the help of cutting-edge digital diagnostics tools, high-capacity data centers, sophisticated machine learning systems, and artificial intelligence it is possible to obtain multiple layers of data for any individual, recognize patterns, making predictions and develop personalized treatment (Topol, 2014). General Electric is using Big Data to produce smarter turbines: intelligent machines equipped with hundreds of sensors can communicate their operating data to help the machines, their operators and maintenance staff to work better. The company opened Predix, its cloud-based Big Data analytics platform for software developers in 2014, connecting people machines and data through the industrial internet

Small and medium-sized companies, and especially startups try to focus on specific activities or vertical subsectors. Mu Sigma, a venture mentioned at the beginning of this section concentrates on data analytics and modelling in the activity loop, but otherwise it is sector-neutral that is it may serve anybody who has a problem which can be approached with data analytics tools (Provost - Fawcett 2013). To find a meaningful and exploitable niche, new ventures and R\&D groups may increase the granularity of the activity-sector matrix. Energy supply of special sensors may be a good example: it is technically impossible or very expensive to change the exhausted batteries in sensors used e.g. inside a living organism or spread over a large field, consequently special batteries must be developed which can draw energy from their environment. 


\section{Innovation for smart agriculture}

Agriculture is a vertical sector of the entrepreneurial space outlined above. Its progress on the "smartness trajectory" looks to be relatively slow, but its development potential is high. By the help of modern technology many decision factors can be translated to rich digital data sets what can be fed into sophisticated algorithms providing insight and suggesting decisions. Innovation is essential for this kind of transformation and it is coming in many forms and from many sources.

Grand visions are evolving about modern digital agriculture where sensors and drones collect and transfer real time data on everything, cloud-based data centers digest Big Data and build sophisticated and self-learning decision-support models, recommendations are sent to farmers' mobile devices or directly to automated selfdriving machines (robots) which take care of perfect execution. In the last section of this study we will use a few examples to illustrate how agriculture may get closer to this vision and buy its ticket to the club of digital masters.

Just like in other industries, some big companies, large incumbents looking for new growth opportunities and climbing up the value chain may figure out technology's transformative potential quickly. They can leverage their large R\&D budget, accumulated knowledge base, and extended partner network for building complex smart systems and to position themselves as system integrators and vertical providers of smart services.

Monsanto $^{7}$, a multinational agrochemical and agricultural biotechnology corporation headquartered in the US, launched the trial version of its prescriptive-planting system called FieldScripts in 2013, and it went on sale in some states in 2014 (The Economist 2014). The system is based on precision farming principles: using data-based decisionmaking support and modern equipment, farmers can plant the sections of their fields with different seed varieties at different spacing and depths. This practice is called variable rate planning, what means using different plant populations across an entire field. It may replace static rate planting, i.e. planting a uniform population everywhere. The ultimate goal is to take into consideration the complete yield environment that is all the interacting factors that may impact the yield from a field, e.g. weather conditions, soil type, disease history.

Monsanto's FieldScripts is an algorithm-based smart system using Big Data, telling farmers with high precision which seeds to plant and where, and how to cultivate them. Monsanto had to acquire and mix databases from different sources to feed its models. The company itself has a library of hundreds of thousands of seeds and their yields. To add an appropriate soil and weather database, it acquired Climate Corporation in 2013, a firm founded by to former Google employees in Silicon Valley in 2006. Climate Corporation uses remote sensing and sophisticated cartographic techniques for mapping millions of fields in America. Their database, originally planned to sell crop

\footnotetext{
${ }^{7}$ Monsanto is a pioneer of genetically engineered seeds. The company's policies and practices are frequently criticized for several reasons.
} 
insurance, is growing very fast, by 2010 it contained 150 billion soil observations and 10 trillion weather-simulation points ${ }^{8}$.

The third crucial component of the system came from Precision Planting, also acquired by Monsanto in 2012. This firm makes seed drills and other agricultural devices pulled by tractors. Modern planters use GPS and some of them can steer themselves. Loaded with data the machines can adapt to soil and weather microenvironments and can plant a field with different seed varieties.

This kind of data-based precision planting has become a competitive field by now. To manage complexity, alliances are built and acquisitions are initiated. Another global seed producer, $\mathrm{Du}$ Pont Pioneer fashioned an alliance with farm-machinery manufacturer John Deere ${ }^{9}$ in the recent past. In 2013, Land O'Lakes, a leading agribusiness and food industry company, announced the acquisition of Geosys, a global technology company providing satellite imaging services to agribusiness. Machinery producer Case IH and high-tech equipment maker Ag Leader are also early adopters of precision agriculture technologies and predictive analytics solutions.

Large-scale, complex and ambitious smart agriculture projects need partners who can provide the necessary domain knowledge and technology components. In Hungary, Széchenyi István University teamed up with the local unit of Hewlett-Packard, Hungarian Academy of Sciences' Institute for Computer Science and Control, and internet research venture eNET to launch the AgroDat.hu research project. The partners aim to create an agricultural information system and knowledge depository using big data technologies. By the project's blueprint, special low-energy agricultural sensors are grouped and installed above and under the surface at many field observation points. These sensors generate high volume data on many factors, e.g. humidity, water content, temperature, vapor pressure, radiation, leaf wetness, ice formation, carbon-dioxide concentration, electric conductivity ${ }^{10}$, wind direction. Data is sent to central servers (supercomputers) via GSM network where, after mixed with other data, predictive and prescriptive models are built and constantly fine-tuned. Users can access this database and the related decision-support services through and interactive and personalized web portal (Paller et.al., 2014) ${ }^{11}$.

Large companies may assume very complicated and challenging tasks. Most of agriculture is directly driven by weather, consequently "holy grail" of smart or

\footnotetext{
${ }^{8}$ To make the picture complete, Climate Corporation bought the soil analysis business line of Solum, and agriculture technology venture in February 2014.

${ }^{9}$ A farm management and decision support software called APEX is an integral part of John Deere's product line.

${ }^{10}$ Electric conductivity correlates with salt content, salt influences plan growth.

${ }^{11}$ Collecting and processing relevant data and building a database large enough for statistical analysis is a real challenge. A significant barrier to the utilization of Big Data's full potential and to the adoption of smart technologies is the incompatibility of data formats through various platforms and farmers' understandable concerns about data ownership, security, and privacy. One of the initiatives aiming to find a solution is the Open Ag Data Alliance founded in early 2014. The long-term goal of this open standards group is to create a data a knowledge sharing backbone, a platform where farmers, engineers, scientists, and others can share their data, ideas, code, and technologies easily and safely. Some of the members: Purdue University, OnFarm, The Climate Corporation, Granular, Geosys, Monsanto, Ayrstone, AgReliant.
} 
precision agriculture is accurate, automated, and continuous weather forecast. IBM's Deep Thunder system, based on high-performance computing aims to improve shortterm local, high resolution weather forecasting customized to weather-sensitive operations. Yamaha is a leading supplier of agricultural drones. As Japan faces the problem of a rapidly aging population, these automated machines may help to ease the hard work of farmers. Yamaha's drone business is a small portion of the group's sales now, but high growth is predicted for connected and automated agricultural drones capable to collect field and crop data, and to execute activities like pesticide spraying. The network of cooperating partners may be very colourful. Customers of Airinov, a French venture founded in 2010, a remote sensing pioneer, use a drone for collecting real-time high resolution data about their crops, while the results of the analysis is fed into the computer of their multipurpose John Deere tractors for direct execution.

Small and medium-sized companies, and especially startups try to focus on specific activities or vertical subsectors. Some of them develop really innovative and sometimes disruptive technologies. Blue River Technology, established by a group of university students, built an automated machine for lettuce thinning. The machine, moving rather fast over straight rows of small lettuce plants collects data via digital photographs, then a smart algorithms decides what to keep and what to cut. Execution is also automated: unnecessary plant are killed with precisely aimed shots of fertilizers. The Hungarian QuantisLabs' SmartVineyard system is predicting grape diseases with modern tools of data collection and data-based decision support. The system captures real-time microclimatic data with a set of sensors. The data is transferred to the cloud where smart, scientifically tested algorithms calculate the probability and the intensity of local grape diseases, then properly visualized real-time forecasts and alerts are presented to vine-growers, who can expect higher productivity and lower costs. Human decision-making and intervention (e.g. spraying chemicals) is an integral part of this system, but data collection, transfer and analytics is automated.

Dacom is a venture of about two dozen people in The Netherlands. Its customers are farmers who try to improve their business efficiency and to reduce risk. Dacom combines sensor technology, data analysis and internet connectivity to optimize agricultural production. It develops and sells hardware and software that measure weather conditions in farm field, which means rainfall, humidity and soil moisture content. Its sensors are very easy to install, farmers can do it without help, and they can also switch them on by their cellphones. All the data from the sensors are collected and consolidated in the cloud where Dacom processes and analyses it, then sends the results to customers' smartphones. Farmers can use the raw data and the results of data analysis in their daily routines, plus share it with their partners as necessary for optimizing harvest and productivity. By the help of this smart systems, farmers can manage irrigation problems on a day-to-day basis, can see from their home offices if crops need water, receive alerts by the smartphone app when to go to the field and check it personally. Precious human time is saved this way, farmers have to go to the field only when it is necessary.

A Hungarian venture called Moow.farm developed a special device made of durable materials for measuring cattle's rumen acidity levels and temperature. Detected irregularities may indicate a disease or problems in foraging. The device is put in 
the rumen of the cattle and data is transmitted directly and automatically to a base station and then to the cloud where analysis is conducted and alerts are sent out to farmers and veterinarians. This case illustrates how smart system may appear and evolve in livestock breeding, and how "smart stalls" can be built ${ }^{12}$. The device was developed in cooperation with a design venture called Maform, automation expert Cubilog, and the University of Pécs.

At the indoor vertical farms of Green Sense Farms sensor systems control and optimize energy, water, and fertilizer consumption. Pesticides and herbicides are not used at all. AeroFarms is also building large high-tech indoor vertical farms with financial backing from Goldman Sachs and Prudential. The Japanese Mirai, founded in 2004 after an earthquake and a tsunami caused food shortages in the country, teamed up with General Electric to develop LEDs generating light in wavelengths adapted to plant growth in its half-automated vertical greenhouses. A startup called BioCarbon Engineering uses remote sensing, automated mapping, and high-velocity, air-fired planting systems for industrial scale reforestation.

Sensor technology, a key component of smart agricultural systems, develops very fast $^{13}$. Farmers can measure a crop's nitrogen requirement with the British Yara company's tractor-mounted N-sensors as the tractor passes across their fields, and vary the fertilizer application rate accordingly. A team based at the University of California, Santa Barbara, develops an implantable microfluidic-electrochemical sensor capable of providing continuous, real-time tracking of drug levels in animals. An MIT group works on a nanotube which, when implanted below the surface of an animal's skin, can detect levels of nitrit oxide to monitor inflammation. Special biosensors developed at Georgia Institute of Technology are powered from the hydraulic force of the bloodstream. ${ }^{14}$

OnFarm, founded in California, is a firm providing an internet-of-things platform that integrates farm hardware technologies into a single user-friendly management and decision platform. Farmers get access to agronomic information from any device or location through customizable dashboards.

We can expect that a growing number of old and new ventures, research spin-offs will realize the opportunity, consequently competition will get tougher, massive competitive advantages must be built and maintained for success. New ventures are hungry for capital, but unfortunately, as numbers on Table 1 indicate, agriculture, for obvious reasons, is not on the radar screen of typical venture funds. Venture investment in agricultural firms was zero in Hungary in 2013 and 2014, and European figures are also very low (Table 1).

\footnotetext{
${ }^{12}$ Bewley, J. (2012) provides a long list of data which can be collected by modern technologies for the purpose of precision dairy farming (PDF): milk yield, milk conductivity, body weight, odor, glucose, acoustics, body temperature, animal positioning and activity, ruminal $\mathrm{pH}$, feeding behaviour, etc. The author defines PDF as ,the use of technologies to measure physiological, behavioural, and production indicators on individual animals to improve management strategies and farm performance" (p. 65).

${ }^{13}$ Liaghat and Balasundram (2010) analyse the agricultural utilization of remote sensing technologies including aerial, satellite, and spacecraft observation tools.

${ }^{14}$ Sensors, an open access, peer-reviewed journal, provides up-to-date information on sensor technology innovation, with sections dedicated to biosensors, chemical sensors, physical sensors, remote sensors, and sensor networks.
} 
Table 1: Venture capital investments in Europe by sector, 2012 (\% of total VC investment)

\begin{tabular}{|l|c|}
\hline \multicolumn{1}{|c|}{ Sector } & \% of VC investment \\
\hline Life sciences & 28.4 \\
\hline Computer and consumer electronics & 19.0 \\
\hline Communications & 18.2 \\
\hline Energy and Environment & 11.0 \\
\hline Consumer goods and retail & 5.7 \\
\hline Consumer services & 4.8 \\
\hline Financial services & 4.1 \\
\hline Business and industrial products & 3.5 \\
\hline Business and industrial services & 1.7 \\
\hline Chemicals and materials & 1.5 \\
\hline Transportation & 1.1 \\
\hline Construction & 0.3 \\
\hline Agriculture & 0.3 \\
\hline Real estate & 0.2 \\
\hline Unclassified & 0.1 \\
\hline Total & $100 \%$ \\
\hline
\end{tabular}

Source: European Private Equity and Venture Capital Association (2015)

Interest may grow in the future, especially for high-tech ventures building smart agricultural systems or developing their critical components. The number of promising examples is growing. AgTech Innovation Fund, a venture capital fund investing in early-stage food- and agricultural-technology companies in North America, managed to raise $\$ 50$ million in the recent past. By its mission statement, it supports ventures which are developing innovative solutions to improve productivity, increase sustainability, streamline supply chains, and create innovative products. Another fund, Cultivian Ventures focuses on the US Midwest, a region with the highest concentration of public and private R\&D spending for agribusiness. One of the fund's portfolio companies, AquaSpy develops intelligent water monitoring systems, another one, Divergence, applies data-intensive genomics to identify compounds, proteins, and genes to control parasitic infections in plants and animals.

High-tech opinion leaders and celebrities may point the way forward. Google Chairman Eric Schmidt' Innovation Endeavors VC fund invested in a Silicon Valleybased ag-tech company called CropX, a venture selling sensors and software designed to help farmers to decide how much water to use in different parts of their fields. The firm claims, famers can use up to $25 \%$ less water by the help of their solution. What makes this venture even more interesting is an unusual collaboration between genomics researchers from Israel and irrigation technologists from New Zealand. One of the founders is a medical doctor who launched life-science firms in Israel. He saw an opportunity in applying the same basic technologies his genomics company used to provide personalized medicine to generate location-specific irrigation recommendations to farmers.

As Big Data and analytics becomes the driver of agricultural growth, some data-driven companies try to facilitate the diffusion of innovative ideas and knowledge sharing. One of the investors behind the startup called Farmers Business Network is Google. 
This venture, launched in 2014, aims to help farmers to learn from each other had data on 7 million acres of farmland across 17 states in the U.S. in early 2015.

High-tech smart solutions can be combined with other agricultural innovations. One of China's fastest growing companies, Tony's Farm, focuses on the new urban elite of the country, producing and distributing organic vegetables. The company operates large computer-controlled greenhouses full of sensors, its fields are spanning thousands of acres across eight Chinese provinces. The country feels double pressure as its population raises to 1.47 billion projected for 2030, and this demographic trend coincides with soil degradation, climate change, water shortage, and extremely high pollution levels. Experiments demonstrate how smart farming techniques may improve yields while taking care of the environment.

Chinese experience may be especially instructive for the rest of the world (Zhang et al., 2013). The country managed to increase its cereal production by approximately $32 \%$ in the period of 2003-2011, largely by improving the productivity of its farms. This improvement is impressive but far from being enough to meet the growing demand on the long run. Spare land is sparse, water shortages are normal, fertilizer usage has reached its limits, the country has more than 200 million very small farms, typical farm widths is only a few meters. Among other things, modern agronomics combined with information technology is needed to push yields closer to biological limits. Scientists are studying fields as ecosystems, they are tracking various inputs and outputs and develop algorithms to optimize production and achieve the greatest yields. This approach provides insight into the optimal times to add chemicals, planting dates and densities. Genetic plant varieties and field management processes recommended by the decision support models are tested in experimental plots, results are used for fine-tuning of the models. The centralized political system of the country supports the efforts to build nationwide monitoring networks and to restructure agricultural systems on a nationwide scale. The country's government has more than tripled its agricultural research investment between in the first decade of the new century.

Farmers everywhere in the world, who are perfectly aware of the unique natural context of their fields, are practicing experimentalists who can be and must be involved in innovation efforts. To support bottom-up innovation, the EU launched the European Innovation Partnership for Agricultural Productivity and Sustainability (EIPAGRI). It aims to promote joint research and development projects by linking farmers, researchers, businesses and other stakeholders into groups looking for solutions to shared problems and disseminating the results.

Collective learning, knowledge sharing, and bottom-up initiatives are critical factors of innovations' diffusion. Botanicals, created by a grassroots project of technologists and artists, is a do-it-yourself kit with a sensor was developed that goes a flowerpot to measure moisture in it. When it gets too dry, the sensor sends an alert to the owner's mobile phone, and its sends a grateful "thank you" when the plant gets watered. The number of users grew very fast, and techno-gardening hobbyist started to build more sophisticated automated gardening systems by the help of small, simple, and cheap 
microcontrollers ${ }^{15}$ like the Arduino ${ }^{16}$ developed in Italy. This easy-to-use device may receive signals from many sensors and may control lights, motors, etc. It is built on an open-source electronics platform, so a complete development platform is available. These projects and tools may teach many people how to connect a plant to the internetof-things, how a sensors work, and how to build a closed control loop, plus they get a picture of the economics of smart systems. Fast diffusion of innovations and intensive knowledge sharing may require new knowledge management approaches and institutions. Besides top-down advisory services, many industry observers highlight the importance of horizontal networks, social learning and participative solutions (Busse, 2014; Nemes and High, 2013; European Union, 2014, p. 45).

\section{Conclusions}

Due to world population trends and the rise of a new middle class, demand for agricultural products is continuously growing. Obtaining bigger yields with limited resources and without destroying the natural environment, exploiting soil, polluting air and water is a challenge everywhere in the world. Agriculture of the future must be efficient and sustainable, problems of intensive yet environmentally safe production must be solved.

Digital mastery managed to raise efficiency, productivity, and profitability in many industries. From this perspective, agriculture appears to be a laggard because of a few reasons. However, the sector's digital transformation started decades ago, as precision agriculture, an information-intensive management system emerged in the 1980s thanks to the advent of such technologies as computers and global navigation satellite systems. It was originally used for optimizing fertilizer distribution and irrigation to varying soil and weather conditions, i.e. to apply right treatment in the right place at the right time.

Together with other innovations, precision agriculture put the industry on a new development trajectory, pushing ahead efficiency and productivity thresholds. It highlighted that gains in yields will depend ever more on innovating in context, datafication of key factors, statistical analysis and decision-support algorithms.

Although the technical revolution of precision agriculture appears to be unfinished and its market penetration is low in many parts of the world, fast technological innovation opens up new opportunities. New hardware and software tools, combined or supported by innovative service solutions appear everywhere, revolutionize complete industries and sectors. Among others, exponentially increasing computing capacity and speed, general connectivity, the internet-of-things, mobile tools, sensor technology, automation and robotics, drones, imaging satellites, machine learning, artificial intelligence, parallel processing of Big Data, cloud computing, miniaturization, nanotechnology, progress in machine-human interface, optical pattern recognition, software as a service, etc. open a new entrepreneurial space. Large companies, small ventures and other stakeholders are looking for competitive and profitable positions.

\footnotetext{
15 Microcontrollers are small computers on a single integrated circuit board with programmable input/output peripherals.

${ }^{16}$ Szilágyi and Toth (2015) analyse Arduino's agricultural data collecting capabilities.
} 
The complexity of many problems to be solved requires an all-embracing approach, intensive cooperation and the emergence of complete innovation ecosystems.

The new technologies and tools mentioned above will influence directly and indirectly the development of agriculture. Many stakeholders, large and small companies, research and development centers realize the opportunity and contribute to the digital development of the sector. The number of developers and users is growing, experience and knowledge is accumulating, there are many promising cases and results, but further research is needed to decide where the new potential efficiency and productivity thresholds are, what kind of factors will influence diffusion and adoption patterns, what will be the intended and the unintended consequences, how the environmental footprint of agriculture is changing. One thing is sure: besides digital tools, leadership capabilities are also essential to initiate and support this transformation.

Acknowledgements. For advice, information, ideas, and comments, the author is especially grateful to Judit Karsai (Institute of Economics, Hungarian Academy of Sciences - HVCA), Paul Marer (CEU Business School), Péter L. Molnár (Maform), Balázs Weibel (Cubilog, Moow.farm), Borbála Báló (Corvinus University), Balázs Huszty (QuantisLabs), Gábor Élő (Széchenyi István University), Achilles Georgiu (IBM Hungary - CEU Business School), Attila Oláh (ESRI Hungary), Károly Stipsicz (Haszon Magazine), and CEU Business School's MBA students Yan Liu, Tamás Nagy, Viktor Andrusik, Rachael Corr, Celestine Gandu, János Mészáros, Stanislav Rubin, Mirjam Simpson-Logonder, Balázs Vincze, who participated in "smart agriculture" projects.

\section{References}

1. Andreessen, M. (2011): Why Software is Eating the World. The Wall Street Journal, 20 August

2. Baker, S. (2008): The Numerati. Jonathan Cape, Random House, London

3. Barabási, A. L. (2010): Villanások. Nyitott Könyvmühely, Budapest

4. Bewley, J. (2012): How precision dairy technologies can change your world. November 13, 2012 Penn State Dairy Cattle Nutrition Workshop Proceedings. Grantville, PA. pp. 65-74.

5. Bőgel, Gy. (2015): A Big Data ökoszisztémája. Typotex Kiadó, Budapest

6. Brase, T (2005): Precision Agriculture. Delmar Cengage Learning, Independence, Kentucky

7. Busse, M.; Doernberg, A.; Siebert, R.; Bokelmann W. (2014): Innovation Mechanisms in German Precision Farming. Precision Agriculture, 15(4) pp. 403-426. DOI: 10.1007/s11119013-9337-2

8. Chang, D.; Zhang, J.; Zhu, L.; Ghe S-H.; Li, P-J.; Liu, G-S. (2014): Delineation of management zones using an active canopy sensor for a tobacco field. Computers and Electronics in Agriculture, 109, pp. 172-178. http://dx.doi.org/10.1016/j.compag.2014.09.019

9. Davenport, T. (2014): Big Data@ Work. Harvard Business School Publishing, Boston

10. European Union (2014): Precision Agriculture: An Opportunity for EU Farmers. DirectorateGeneral for Internal Policies, Agriculture and Rural Development

11. Eurostat (2014): Agriculture statistics at regional level. Eurostat statistics explained, (http://ec.europa.eu/eurostat/statistics-explained/)

12. Fajszi B.; Cser L.; Fehér T. (2013): Business Value in an Ocean of Data. Alinea Kiadó with TSystems, Budapest 
13. FAO, IFAD, WFP (2015). The State of Food Insecurity in the World 2015. Meeting the 2015 international hunger targets: taking stock of uneven progress. Rome, FAO.

14. Foley, J. et al. (2011): Solutions for a cultivated planet. Nature, 478, 20 October, pp. 337-342. DOI:10.1038/nature10452

15. Gleick, J. (2011): The Information. Fourth Estate, London

16. Godfray, C. et al. (2010): Food Security: The Challenge of Feeding 9 Billion People. Nature, 12 february, Vol. 327, pp. 812-818. DOI: 10.1126/science.1185383

17. Grassini, P.; Eskride, K.; Cassman, K. (2013): Distinguishing between yield advances and yield plateaus in historical crop production trends. Nature Communications, 17 December

18. ITU (2013): Big Data: Big today, normal tomorrow. ITU-T Technology Watch Report

19. Lencsés, E. (2013): A precíziós (helyspecifikus) növénytermelés gazdasági értékelése. Doctoral thesis, Szent István University, Gödöllö

20. Lencsés E.; Takács I.; Takács-György K. (2014): Farmers’ Perception of Precision Farming Technology among Hungarian Farmers. Sustainability, 25 November, pp. 8452-8465 (Special Issue Towards Sustainability: Selected Papers from the Third World Sustainability Forum)

21. Liaghat, S.; Balasundram, S. (2010): A Review: The Role of remote Sensing in Precision Agriculture. American journal of Agricultural and Biological Sciences. 5(1), pp. 50-55

22. Lowenberg-DeBoer, J. (2015): The Precision Agriculture Revolution. Foreign Affairs, MayJune

23. Mayer-Schönberger, V.; Cukier, K. (2013): Big Data: A Revolution That Will Transform How We Live, Work, and Think. Houghton Mifflin, New York

24. Nemes G.; High, C. (2013): Old institutions, new challenges: the agricultural knowledge system in Hungary. Studies in Agricultural Economics, 115, pp. 76-84

25. Paller G.; Szármes P.; Élő G. (2014): Az AgroDat.hu szenzorhálózat kommunikációs/távközlési rendszerének tervezési tapasztalatai. Hiradástechnika, HTE Infokom különszám, pp. 58-63

26. Provost, F.; Fawcett, T. (2013): Data Science for Business. O’Reilly Media, Sebastopol

27. Schmidt, E.; Cohen, J. (2013): The New Digital Age. Alfred A. Knopf, New York

28. Srinivasan, A. (2006): Precision Agriculture: Principles and Applications. CRC Press, London

29. Szilágyi R.; Tóth M. (2015): Development of an open source agricultural mobile data collector system. Journal of Agricultural Informatics. Vol. 6, No. 2, pp. 54-61

30. Tamás J. (2001): Precíziós mezőgazdaság. Szaktudás Kiadó Ház Rt., Budapest

31. The Economist (2010): It's a smart world. A special report on smart systems. 6 November

32. The Economist (2014): Digital disruption on the farm. 24 May, p. 62

33. Topol, E. (2014): Individualized Medicine from Prewomb to Tomb. Cell 157, March 27, pp. 241-253

34. Townsend, A. (2014): Smart Cities. W.W. Norton\&Company, New York

35. Westerman, G.; Bonnet, D.; McAfee, A. (2014): Leading Digital. Harvard Business Review Press, Boston

36. Zhang, F.; Chen, X.; Vitousek, P. (2013): Chinese agriculture: An experiment for the World. Nature, 2 May, Vol 497, pp. 33-35. DOI:10.1038/497033a

37. Zhang, N.; Wang, M.; Wang, N. (2002): Precision agriculture - a worldwide overview. Computers and Electronics in Agriculture, 36, pp. 113-132. http://dx.doi.org/10.1016/S01681699(02)00096-0 


\title{
1.2. OIL-PRICE VOLATILITY AND EXTERNAL RISK: IMPLICATIONS FOR THE MACROECONOMIES OF CENTRAL AND EASTERN EUROPE
}

\begin{abstract}
Summary
In an era of increased global risk and the possibility of international "contagion," managers worldwide must be cognizant of the role that various types of volatility might have on their countries and regions. In particular, statistical analysis can provide estimates of the macroeconomic implications of shocks to foreign asset and commodity prices. This study performs such an analysis, applying time-series econometric modelling to analysis of four Central European countries (Bulgaria, Croatia, Hungary, and Poland), as well as Russia and Ukraine.

Using monthly data and applying Vector Autoregressive (VAR) time-series methods, this study first models oil-price volatility and real effective exchange-rate volatility. We then study the effects of these volatility terms and of changes in U.S. stock prices on credit growth, output growth, and the currency markets of our set of European countries. Overall, Granger Causality tests and Impulse Response Functions show that risk does have a strong impact on the region's economies, but that the effects differ from country to country. For example, U.S. stock-price declines uniformly put pressure on the region's currencies. At the national level, oil-price volatility puts pressure on the złoty (PLN) and also contributes to Polish growth, and also hurts Russian growth. Our findings therefore offer the region's industries insights into their exposure to global risk and the global macroeconomy.
\end{abstract}

Keywords: Commodity prices, volatility, Central Europe, Eastern Europe, time series

\section{Introduction}

Following a decade of large increases and decreases on global markets, commodity prices began to drop significantly in 2014. While the resulting revenue losses can hurt emerging-market commodity exporters, oil-price declines may help lower costs and boost profits for manufacturers, particularly in Central and Eastern European (CEE) nations. At the same time, however, large swings in commodity prices create volatility that might be detrimental; increased risk hurts individual businesses and the overall macroeconomy. This paper investigates the impact of oil-price volatility on the exchange markets of six CEE nations, as well as interactions with macroeconomic variables. Using time-series methods, we find important effects that differ from country to country.

This study focuses on a measure of Exchange-Market Pressure (EMP), which captures exchange-rate depreciations as well as central-bank measures to combat these depreciations. This monthly measure is then modelled as a function of U.S. stock prices and key macroeconomic variables. These include domestic credit growth, the growth rate of government borrowing, GDP growth, and inflation. Previous research, by Phylaktis and Ravazzolo (2005), Van Poeck et al. (2006), Stavárek (2011), Koseoglu and Cevik (2013) and others shows these variables to be significant determinates of EMP and currency crises in the CEE region. And while Hegerty (2012, 
2014a, 2014b) examines the link between commodity price changes and EMP in Latin America, Russia, and the Baltics, he does not include price variability in any specification. This study, therefore provides a key addition to this important branch of the literature, providing business leaders with increased ability to understand and mitigate this risk.

\section{Methodology}

In this study, monthly data for all variables are taken from the International Financial Statistics of the International Monetary Fund. The timespan differs from country to country, but generally begins in the mid-1990s and ends in late 2014. First, we calculate EMP as a function of exchange-rate depreciations (an increase in the number of units per U.S. dollar), reserve losses (as a percentage of the lagged monetary base), and the change in the interest-rate differential (money-market rate) vis-à-vis the United States:

$$
E M P_{t}=\frac{1}{\sigma_{\Delta e}}\left(\ln E_{t}-\ln E_{t-1}\right)-\frac{1}{\sigma_{\Delta R E S}} \frac{\Delta R E S_{t}}{M B_{t-1}}+\frac{1}{\sigma_{\Delta r}} \Delta\left(r_{t}-r_{t}^{U S}\right)
$$

Each component is deflated by its own standard deviation. Oil-price volatility is next calculated as the standard error of a rolling AR(1) regression (of the price on its lagged value), with 12-month windows. A similar calculation is carried out with the real effective exchange rate (REER), which represents a country's competitiveness versus a broad range of trade partners. This volatility, therefore, represents another type of external risk.

After plotting these time series, we then conduct Vector Autoregressive (VAR) analysis to test for spillovers among variables. These allow for any variable in the specification to have an impact on any other; for example, EMP and growth might have effects on each other. We first perform a bivariate Granger Causality test between oil-price and REER volatility to see whether the addition of one variable to a regression of the other on its own lagged values increases the regression's explanatory power; if so, it has a significant impact. Our main test, however, is this test's multivariate version, applied to the following vector:

\section{$[$ EMP,CRG, GOVGGROWTH,INF, d $\ln U S P S$, POIL VO]}

The lag length of each VAR is chosen by minimizing the Schwarz goodness-of-fitcriterion. In addition, we make sure that each variable in our analysis is stationary by performing a set of Phillips-Perron (1988) stationary tests, and taking first differences of any variable for which we are unable to reject the null hypothesis of nonstationarity. We therefore proceed with VARs that contain different mixes of differenced and level variables, all of which are stationary. Once proper VARs are estimated, significant Granger Causalty/Block exogeneity statistics suggest that one variable has an effect on the variable of interest.

We also generate a number of Impulse-Response Functions (IRFs) following the Generalized VAR methodology of Pesaran and Shin (1998). These functions plot the time path of one variable after a shock to another, as well as significance bands to 
show whether these responses differ from zero. While the "orthogonal" VAR approach of Sims (1980) depends on the proper ordering of variables in the system, the "generalized" approach does not. In an additional analysis, we re-estimate Equation (2) with volatility of the REER in place of oil-price volatility, for a total of 12 separate estimations.

Our Granger Causality results and Impulse Response Functions are shown below. Overall, we find that not only does each of the six countries in our analysis behave differently from one another for almost every variable, but that REER volatility and oil-price variability also generate surprisingly different results.

\section{Results}

Figure 1 shows the calculated time series of in the price of U.K. Brent and its volatility from 1990 to 2014. We see increases in volatility throughout the sample period, but the largest "spike" occurs immediately before and during the 2008 Global Financial Crisis. At the same time, EMP increased during this period, as did real exchange-rate volatility for these CEE countries. Our goal is to test empirically the causes and interlinkages of these movements.

Figure 1: Oil Prices (U. Brent) and their volatility

POILB (log changes in U.K. Brent price) VOLPOILB (volatility in oil price)

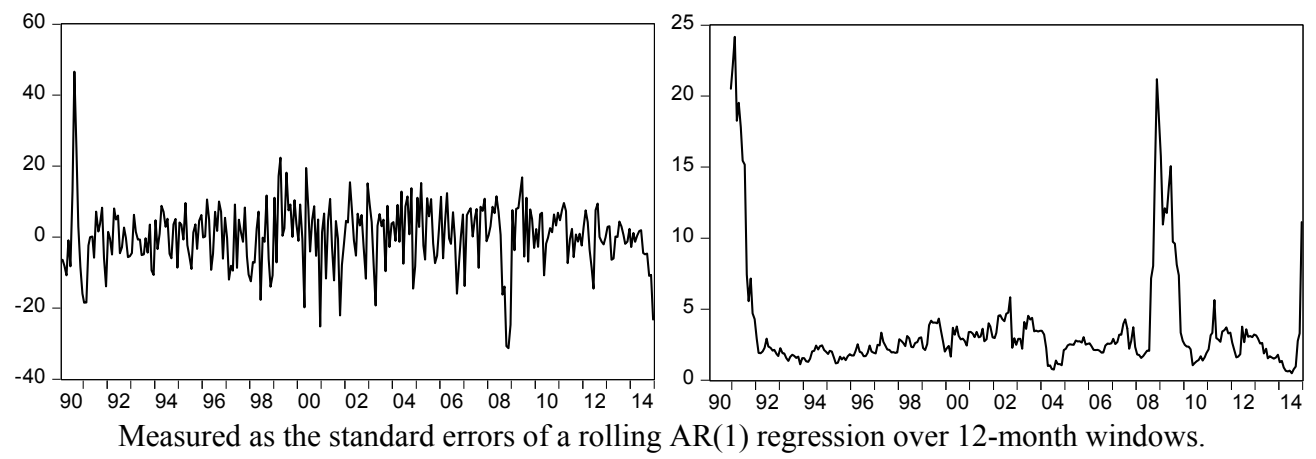

The left side of Figure 2 shows our generated EMP series. Market pressure increased during the 2008 crisis - note the behaviour of the złoty, for example - but this pattern is similar across countries. Each country has its own "idiosyncratic" behaviour as well, which represents it unique internal conditions (Bulgaria, for example, behaves differently from the others). On the right side is REER volatility. Again, there are "common" events, such as the 2008 crisis, as well as individual movements (Hungary's stands out during 2012). 
Figure 2: Exchange market pressure indices (left side) and REER volatility (right side)

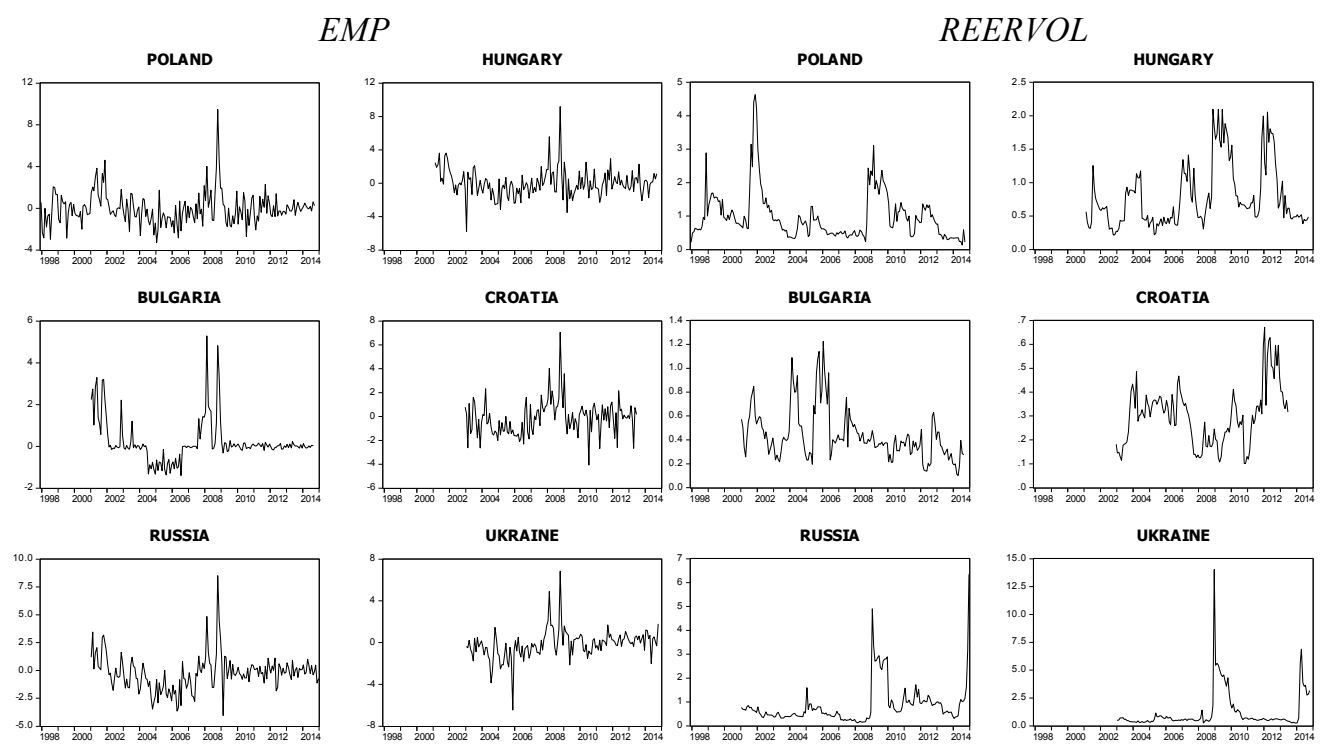

Before proceeding with our econometric analysis, we first conduct the Phillips-Perron (1988) stationarity test.

Table 1: Phillips-Perron stationary test results

\begin{tabular}{lllllll} 
Variable & Bulgaria & Poland & Hungary & Croatia & Russia & Ukraine \\
\hline EMP & -5.126 & -9.143 & -9.805 & -8.726 & -6.771 & -7.123 \\
& $(0.000)$ & $(0.000)$ & $(0.000)$ & $(0.000)$ & $(0.000)$ & $(0.000)$ \\
CRG & -2.063 & -2.453 & -2.066 & -2.277 & -2.730 & -1.490 \\
& $(0.260)$ & $(0.127)$ & $(0.258)$ & $(0.180)$ & $(0.069)$ & $(0.538)$ \\
GOVG & -14.089 & -3.474 & -2.475 & -2.948 & -12.456 & -8.598 \\
& $(0.000)$ & $(0.009)$ & $(0.122)$ & $(0.040)$ & $(0.000)$ & $(0.000)$ \\
GROWTH & -3.167 & -6.038 & -4.011 & -5.087 & -3.168 & -2.063 \\
& $(0.022)$ & $(0.000)$ & $(0.001)$ & $(0.000)$ & $(0.022)$ & $(0.260)$ \\
INF & -2.102 & -2.513 & -2.022 & -2.437 & -2.263 & -1.735 \\
& $(0.244)$ & $(0.112)$ & $(0.277)$ & $(0.132)$ & $(0.184)$ & $(0.413)$ \\
DLNUSPS & -10.406 & & -10.423 & -8.674 & -10.671 & -9.310 \\
& $(0.000)$ & & $(0.000)$ & $(0.000)$ & $(0.000)$ & $(0.000)$ \\
VOLPOILB & -2.909 & -3.297 & -2.913 & -2.634 & -2.904 & -2.734 \\
\multirow{2}{*}{ REERVOL } & $(0.044)$ & $(0.015)$ & $(0.044)$ & $(0.086)$ & $(0.045)$ & $(0.068)$ \\
& -4.460 & -4.034 & -4.034 & -3.157 & -1.473 & -4.968 \\
& $(0.000)$ & $(0.001)$ & $(0.001)$ & $(0.023)$ & $(0.547)$ & $(0.000)$ \\
\hline
\end{tabular}

$\mathrm{P}$-values in parentheses. $\mathrm{H}_{\mathrm{o}}=$ the variable is nonstationary.

Macroeconomic variables are often "nonstationary," rising or falling over time. This makes traditional statistical inference difficult, so one solution is to difference the variables when necessary and to include only changes over time in our analysis. The 
results of our test, which tell us which variables need to be differenced and which do not, are presented in Table 1.

EMP, for example, is always stationary without differencing, while credit growth must be differenced for all six countries (and would be labelled "DCRG" to reflect this adjustment). GDP growth must be differenced for Ukraine, but not Poland, for example.

We next test for direct spillovers between volatility measures using a bivariate Granger-causality test. The results are provided in Table 2.

Table 2: Bilateral Granger causality test results (p-values in parentheses)

\begin{tabular}{lllllll} 
& Poland & Hungary & Bulgaria & Croatia & Russia & Ukraine \\
\hline \multirow{2}{*}{ REER $\rightarrow$ POILB } & 0.288 & 3.774 & 0.360 & 2.502 & 0.457 & $\mathbf{3 . 9 8 9}$ \\
& $(0.599)$ & $(0.054)$ & $(0.549)$ & $(0.116)$ & $(0.500)$ & $\mathbf{( 0 . 0 4 8 )}$ \\
POILB $\rightarrow$ REER & $\mathbf{6 . 6 4 5}$ & $\mathbf{1 0 . 6 4 4}$ & 0.016 & 0.435 & $\mathbf{8 . 8 4 4}$ & $\mathbf{4 2 . 2 4 5}$ \\
& $\mathbf{( 0 . 0 1 1 )}$ & $\mathbf{( 0 . 0 0 1 )}$ & $(0.898)$ & $(0.511)$ & $\mathbf{( 0 . 0 0 3 )}$ & $\mathbf{( 0 . 0 0 0 )}$ \\
\hline
\end{tabular}

Bold = significant at 5 percent. $\mathrm{H}_{\mathrm{o}}=$ the left-hand variable does not Granger-cause the righthand one.

We see that in four of the six countries, increased oil-price variability spills over to the real effective exchange rate. In other words, oil price risk leads to risk in the "terms of trade," or the competitiveness of the CEE region. Only in Ukraine is the other direction of causation significant at 5 percent. Perhaps world markets are sensitive to events in this relatively small, but highly influential country.

Table 3 shows the main Granger causality/Block exogeneity test results. Variables are differenced based on stationarity tests results that are available upon request.

Table 3: Bilateral Granger causality test results (p-values in parentheses)

\begin{tabular}{|c|c|c|c|c|}
\hline Poland & EMP & DCRG & GROWTH & DINF \\
\hline EMP & & $0.578(0.447)$ & $14.785(0.000)$ & $0.604(0.437)$ \\
\hline DCRG & $0.116(0.733)$ & & $7.790(0.005)$ & $7.696(0.006)$ \\
\hline GROWTH & $0.572(0.449)$ & $1.349(0.245)$ & & $6.097(0.014)$ \\
\hline DINF & $0.063(0.802)$ & $14.217(0.000)$ & $9.793(0.002)$ & \\
\hline DGOVG & $1.182(0.277)$ & $0.156(0.693)$ & $2.077(0.150)$ & $1.227(0.268)$ \\
\hline DLNUSPS & 2.526( & $0.666(0$. & 0.31 & $0.070(0.791)$ \\
\hline DVOLPOILB & $0.777(0.378)$ & $6.892(0.009)$ & $0.241(0.624)$ & $0.212(0.645)$ \\
\hline All & $5.138(0.526)$ & $25.643(0.000)$ & $28.004(0.000)$ & $18.152(0.006)$ \\
\hline Hungary & EMP & DCRG & DGROWTH & DINF \\
\hline EMP & & $1.901(0.168)$ & 0.30 & $0.136(0.712)$ \\
\hline DCRG & 1.9 & & $0.145(0.703)$ & $0.000(0.993)$ \\
\hline DGROWTH & $0.143(0.705)$ & $0.058(0.810)$ & & $2.393(0.122)$ \\
\hline DINF & $0.035(0.851)$ & $3.233(0.072)$ & $0.38(0.538)$ & \\
\hline DGOVG & $2.365(0.124)$ & $2.187(0.139)$ & $3.793(0.052)$ & 0.179 \\
\hline DLNUSPS & $1.629(0.202)$ & $0.252(0.616)$ & $0.131(0.717)$ & $2.881(0.090)$ \\
\hline DVOLPOILB & $0.410(0.522)$ & $0.803(0.370)$ & $2.489(0.115)$ & $0.343(0.558)$ \\
\hline All & $4.928(0.553)$ & $12.316(0.055)$ & $13.958(0.030)$ & $7.815(0.252)$ \\
\hline
\end{tabular}




\begin{tabular}{|c|c|c|c|c|}
\hline Bulgaria & EMP & DCRG & DGROWTH & DINF \\
\hline EMP & & $0.557(0.456)$ & $3.634(0.057)$ & $0.336(0.562)$ \\
\hline DCRG & $0.830(0.362)$ & & $0.008(0.927)$ & $0.456(0.500)$ \\
\hline DGROWTH & $0.965(0.326)$ & $0.494(0.482)$ & & $0.357(0.550)$ \\
\hline DINF & $0.250(0.617)$ & $0.635(0.425)$ & $0.148(0.701)$ & \\
\hline GOVG & $0.000(0.993)$ & $0.136(0.712)$ & $0.315(0.575)$ & $0.063(0.802)$ \\
\hline DLNUSPS & $6.018(0.014)$ & $7.991(0.005)$ & $0.152(0.696)$ & $5.156(0.023)$ \\
\hline DVOLPOILB & $1.051(0.305)$ & $0.011(0.916)$ & $0.003(0.957)$ & $0.001(0.979)$ \\
\hline All & $9.207(0.162)$ & $9.461(0.149)$ & $4.927(0.553)$ & $6.496(0.370)$ \\
\hline Croatia & EMP & DCRG & GROWTH & DINF \\
\hline EMP & & $0.092(0.762)$ & $0.771(0.380)$ & $0.213(0.645)$ \\
\hline DCRG & $1.270(0.260)$ & & $0.001(0.974)$ & \\
\hline GROWTH & $0.449(0.503)$ & $0.003(0.957)$ & & $0.608(0.435)$ \\
\hline DINF & $0.324(0.569)$ & $1.599(0.206)$ & $0.491(0.484)$ & $0.725(0.394)$ \\
\hline DGOVG & $1.105(0.293)$ & $0.048(0.827)$ & $0.825(0.364)$ & $0.475(0.491)$ \\
\hline DLNUSPS & $1.634(0.201)$ & $0.267(0.605)$ & $0.428(0.513)$ & $0.084(0.772)$ \\
\hline DVOLPOILB & $0.558(0.455)$ & $4.633(0.031)$ & $0.159(0.690)$ & $9.475(0.002)$ \\
\hline All & $4.423(0.620)$ & $9.790(0.134)$ & $4.492(0.610)$ & $11.50(0.074)$ \\
\hline Russia & EMP & DCRG & DGROWTH & DINF \\
\hline EMP & & $1.099(0.295)$ & $4.986(0.026)$ & $0.437(0.508)$ \\
\hline DCRG & $0.007(0.933)$ & & $3.484(0.062)$ & $0.001(0.978)$ \\
\hline DGROWTH & $1.794(0.180)$ & $2.947(0.086)$ & & $2.585(0.108)$ \\
\hline DINF & $0.701(0.402)$ & $2.200(0.138)$ & $0.802(0.371)$ & \\
\hline DGOVG & $0.332(0.565)$ & $1.623(0.203)$ & $0.090(0.764)$ & $0.192(0.662)$ \\
\hline DLNUSPS & $2.832(0.092)$ & $0.503(0.478)$ & $4.546(0.033)$ & $0.026(0.871)$ \\
\hline DVOLPOILB & $0.729(0.393)$ & $0.886(0.347)$ & $4.415(0.036)$ & $0.175(0.676)$ \\
\hline All & $5.804(0.446)$ & $9.916(0.128)$ & $25.082(0.000)$ & $3.105(0.796)$ \\
\hline Ukraine & EMP & DCRG & DGROWTH & DINF \\
\hline EMP & & $1.280(0.258)$ & $2.023(0.155)$ & $0.754(0.385)$ \\
\hline DCRG & $2.172(0.141)$ & & $0.040(0.841)$ & $1.630(0.202)$ \\
\hline DGROWTH & $1.340(0.247)$ & $9.834(0.002)$ & & $6.294(0.012)$ \\
\hline DINF & $0.748(0.387)$ & $4.783(0.029)$ & $1.262(0.261)$ & \\
\hline GOVG & $0.214(0.644)$ & $2.849(0.091)$ & $2.094(0.148)$ & $0.020(0.887)$ \\
\hline DLNUSPS & $1.152(0.283)$ & $0.187(0.665)$ & $4.785(0.029)$ & $3.277(0.070)$ \\
\hline DVOLPOILB & $0.252(0.616)$ & $0.036(0.849)$ & $0.487(0.485)$ & $0.172(0.678)$ \\
\hline All & $6.789(0.341)$ & $26.01(0.000)$ & $14.872(0.021)$ & $14.232(0.027)$ \\
\hline
\end{tabular}

Our key item of interest is the effect of oil-price volatility on EMP, credit growth, GDP growth (proxied by log changes in the monthly index of industrial production), and CPI inflation. Our main finding is that CEE exchange markets are less affected by commodity-price risk than are other variables. Oil-price volatility has a significant impact on credit growth in Poland and Croatia and on GDP growth in Russia. U.S. stock-price movements significantly affect EMP growth in Poland and Croatia and industrial-production (GDP) growth in Russia. U.S. stock-price movements significantly affect EMP, credit growth, and GDP growth in Poland and Croatia, and GDP growth in Russia. U.S. stock-price movements significantly affect EMP, credit growth, and inflation in Bulgaria, and GDP growth in Russia and Ukraine. The other 
macroeconomic variables (such as the linkage between inflation and credit growth and Poland) have important effects as well.

These results are confirmed by our Generalized IRF results, which are presented in Figure 3. It is important to note that the IRFs on the far right of each column come from a set of separate estimations (which replace oil-price volatility with REER volatility). Since all but the "replacement" variables' IRFs will be the same, to avoid redundancy and to conserve space, only the REERVOL IRFs are depicted. We can easily see the differences in response to shocks in each variable. Also, only those responses that are more than two standard errors from zero (using the error bands) are considered to be significantly positive or negative.

Our main conclusion from the IRFs is that macroeconomic variables respond differently to oil-price and REER shocks. In many cases, higher U.S. stock prices reduce EMP (and falling prices put pressure on the region's currencies); high stock prices are often beneficial to the region's growth. While there is a vast amount of information in these graphs, we can focus on some key results, country by country. In Poland, for example, oil-price volatility raises EMP and increases credit growth, while REER volatility reduces credit growth. Here, we see that the two types of external risk - oil-price variability and REER volatility — do indeed have different effects.

In Hungary, REER volatility reduces EMP as well as credit growth, but oil prices have less of an effect. Oil-price volatility increases Croatian credit growth, but REER volatility does not have the same effect. For Bulgaria, only limited effects are observed overall. Neither oil-price variability nor REER volatility generate significant impulse responses for any of Bulgaria's key macroeconomic variables in our study. Perhaps differences in the country's exchange-rate regime (it alone has a currency-board-type fixed exchange rate; others have floating currencies) might explain these differences.

Turning to the two countries that are most closely tied to energy prices, we arrive at some interesting conclusions. In Russia, oil-price volatility increases EMP and reduces industrial production growth, confirming that recent fluctuations in global energy markets will help destabilize not only the ruble (RUB), but also Russia's real economy. At the same time, increased REER volatility leads to higher growth, which demonstrates the differences in responses to these two risk measures. In Ukraine, oilprice volatility increases credit growth, while REERVOL reduces the same macroeconomic variable. The hryvnia is not affected the way the ruble was in our analysis.

These findings bring us to two key conclusions. First, business leaders and policymakers must be wary of the role that commodity-price fluctuations have on the macroeconomies of the countries in which they operate. But, since this role varies from country to country, a "one size fits all" policy is not recommended, and policies must therefore be tailored depending on the importance of oil prices and the impact that risk has on each particular economy. 
Figure 3: Impulse-response functions (with \pm 2 standard error bands)

\section{Poland}
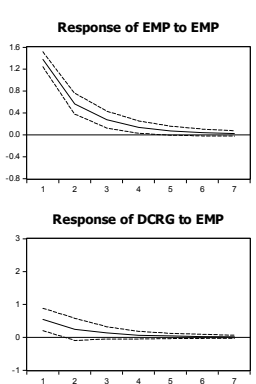

Response of GROWTH to EMP

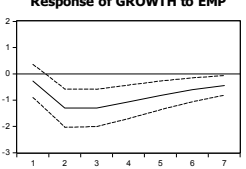

\section{Hungary}
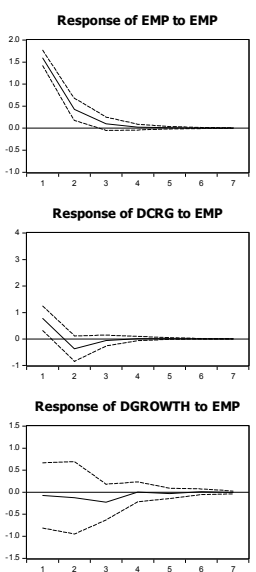

\section{Croatia}
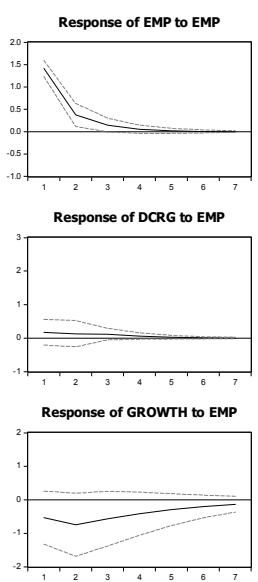

Response to Generalized One S.D. Innovations \pm 2 S.E. Response of EMP to DCRG

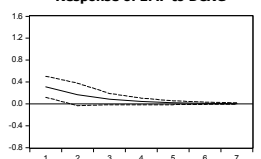

Response of DCRG to DCRG

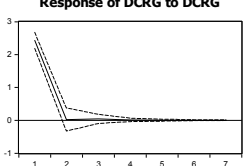

Response of GROWTH to DCRG

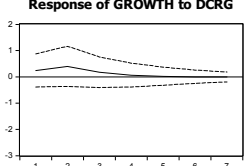

Response to Generalized One S.D. Innovations \pm 2 S.E.

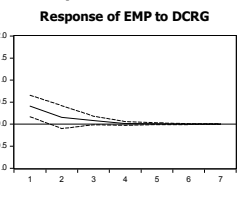

Response of DCRG to DCRG

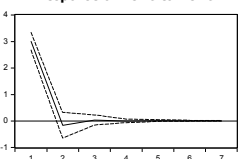

Response of DGROWTH to DCRG
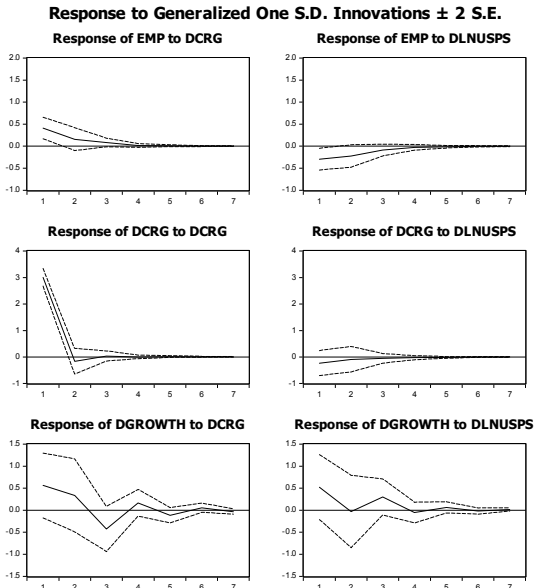

Response of DCRG to DLNUSPS

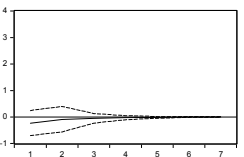

Response of DGROWTH to DLNUSPS

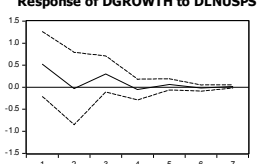

Response of EMP to DLNUSPS

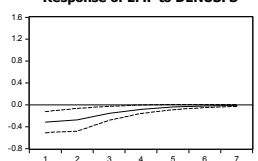

Response of DCRG to DLIUSPS

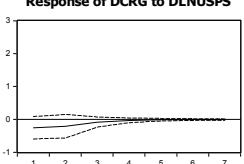

Response of GROWTH to DLNUSPS
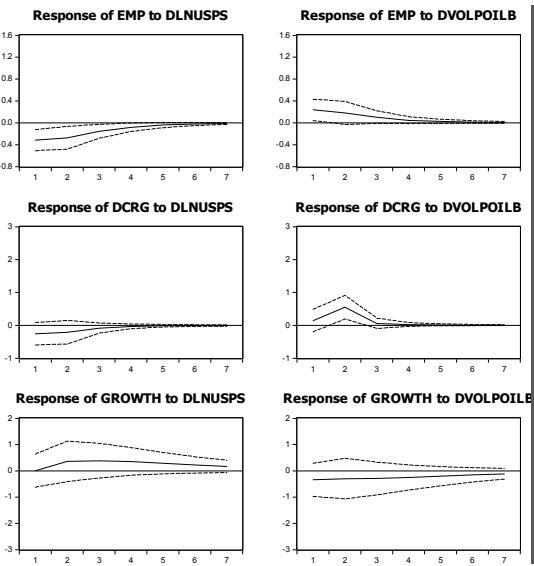

Response of DCRG to DVOLPOILB
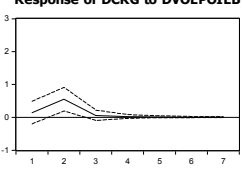
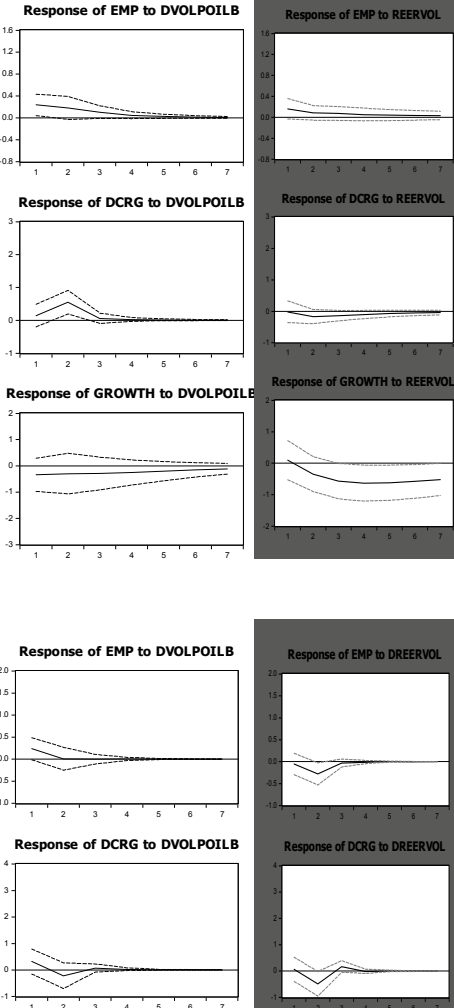

Response of DGROWTH to DVOLPOIL

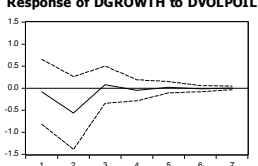

Response to Generalized One S.D. Innovations \pm 2 S.E.
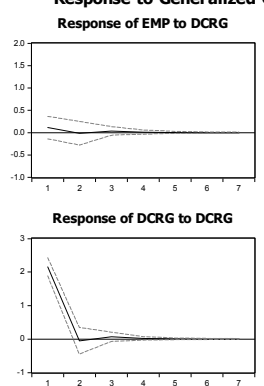

Response of GROWTH to DCRG

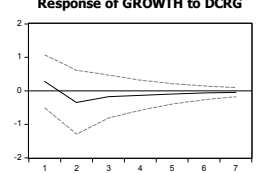

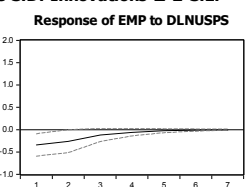

Response of DCRG to DLNUSPS

Response of EMP to DVOLPOIL

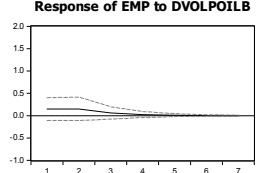

Response of DCRG to DVOLPOILB

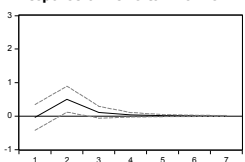

Response of GROWTH to DVOLPOIL

Response of GROWTH to DLNUSPS

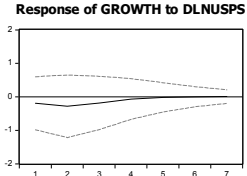

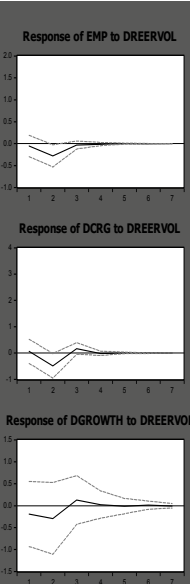

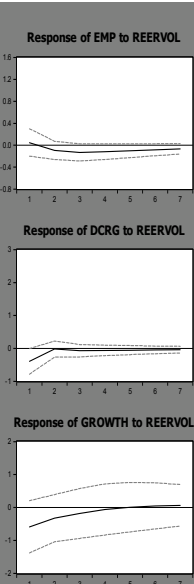




\section{Bulgaria}
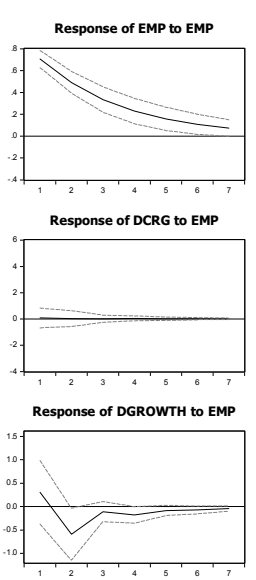

\section{Russia}
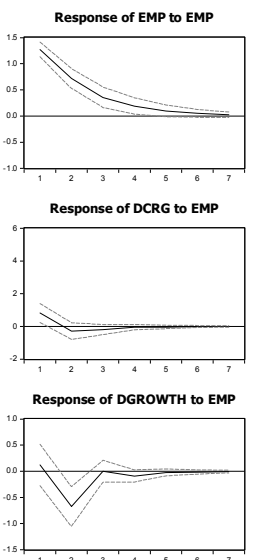

\section{Ukraine}
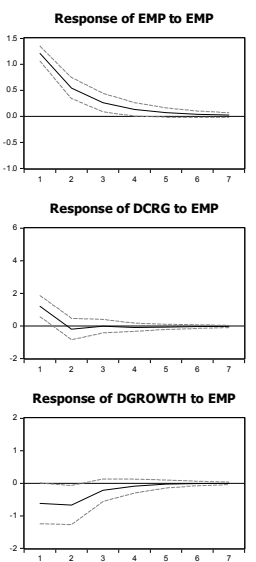

Response to Generalized One S.D. Innovations \pm 2 S.E. Response of EMP to DCRG
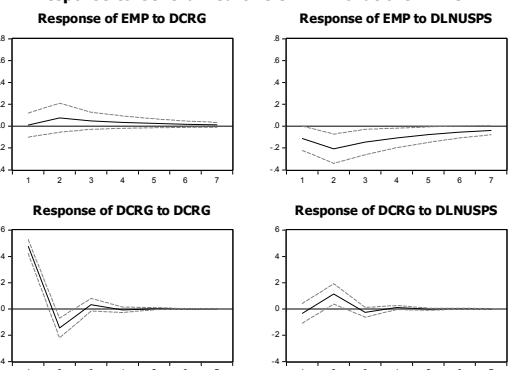

Response of DGROWTH to DCRG
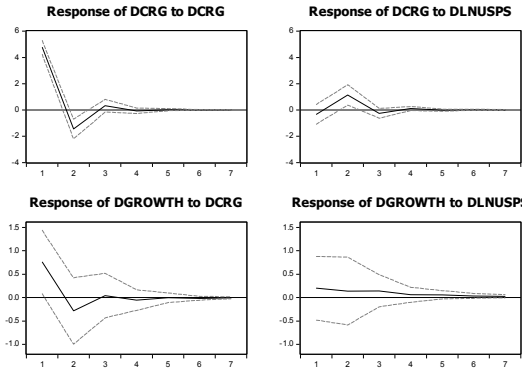

Response to Generalized One S.D. Innovations \pm 2 S.E. Response of EMP to DCRG

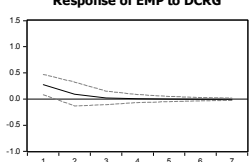

Response of DCRG to DCRG

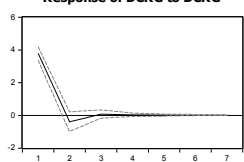

Response of DGROWTH to DCRG

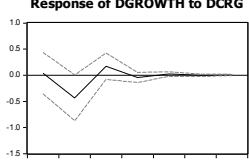

Response of DGROWTH to DLNUSPS
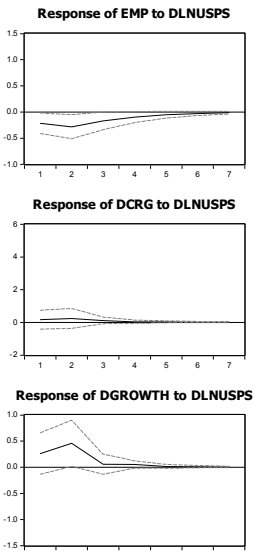

Response to Generalized One S.D. Innovations \pm 2 S.E. Response of EMP to DCRG
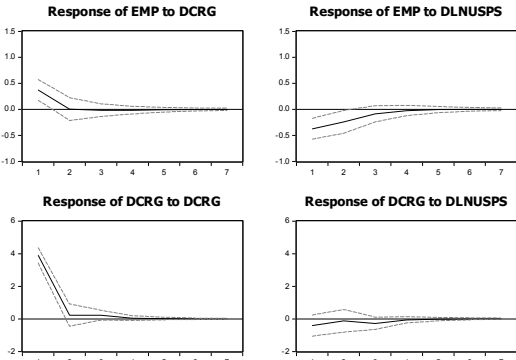

Response of DGROWTH to DCRG

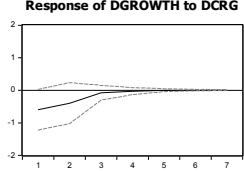

Response of DCRG to DLNUSPS

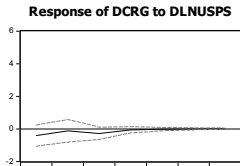

Response of DGROWTH to DLNUSPS

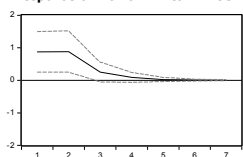

Response of DCRG to DVOLPOILB

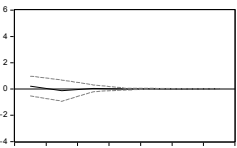

Response of DGROWTH to DVOLPOILE
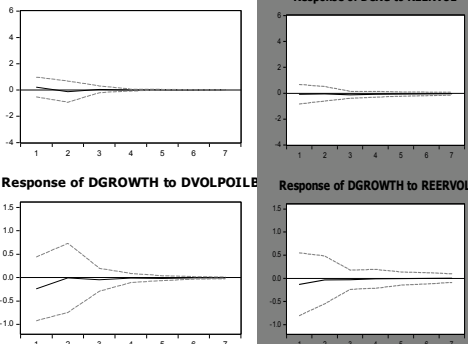

Response of EMP to DVOLPOILB

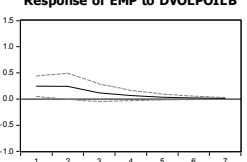

Response of DCRG to DVOLPOILB

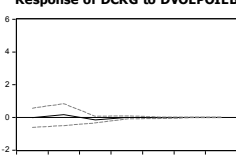

Response of DGROWTH to DVOLPOILE
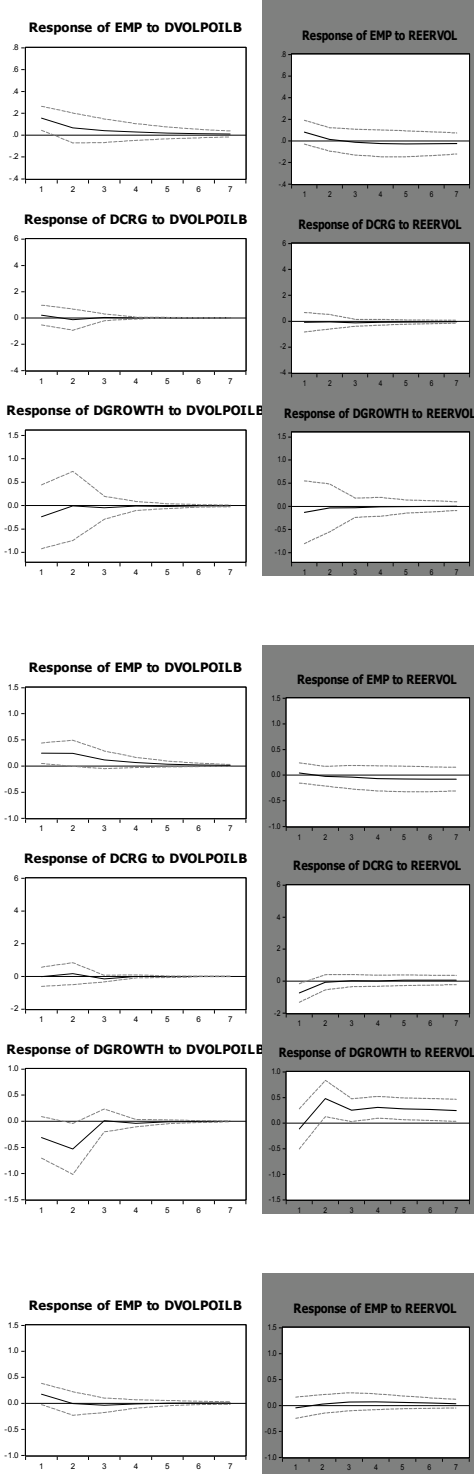

Response of DCRG to DVOLPOILB

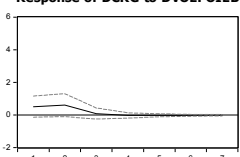

Response of DCRG to REERVOL

Response of DGROWTH to DVOLPOI
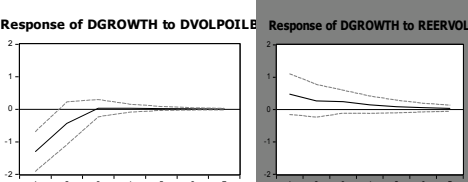


\section{Conclusion}

Commodity-price volatility, which has increased over the past year with the recent plunge in oil prices, has the potential to introduce risk into the business environment. In particular, CEE countries might find the costs of this risk to outweigh the benefits brought by high energy prices. Therefore, those who conduct business in the region must be aware of how risk affects each variable in the macroeconomy, and how these effects differ from country to country.

This study models oil-price and real effective exchange rate (REER) risk for six CEE economies before using Vector Autoregressive (VAR) methods to test for spillovers between risk and a set of macroeconomic variables. First, a measure of Exchange Market Pressure (EMP) is created for each country to obtain a measure of currency movements and central bank interventions combined. Risk in oil prices and the REER is also calculated using statistical methods, and these variables are used alongside a number of macroeconomic variables in our empirical analysis.

We test our hypothesis using Granger causality tests and by generating Impulse Response Functions. Our results show that oil-price and REER volatility have differing effects on our set of macroeconomic variables, and that overall the results differ from country to country. In general, U.S. stock price decreases put pressure on the region's currencies. We find that credit growth and output growth are most affected by oil-price risk, but not for every country in the study. In particular, oil-price risk puts pressure on the złoty and leads to increased credit growth in Poland, while REER volatility has more of an impact on Hungary's economy. Russia, the region's major oil exporter, experiences not only pressure to depreciate, but also reduced GDP growth, when oilprice risk increases. We conclude that differences in economic performance in the region are real, and that policymakers and business leaders must take these differences into account when planning their strategies.

\section{References}

1. Hegerty, S.W. (2012): How Integrated are the Exchange Markets of the Baltic Sea Region? An Examination of Market Pressure and its Contagion, Baltic Journal of Economics, 12(2), pp. 109-122. http://dx.doi.org/10.1080/1406099x.2012.10840520

2. Hegerty S.W. (2014a): Exchange Market Pressure, Commodity Prices, and Contagion in Latin America, Journal of International Trade \& Economic Development, 23(1), pp. 56-77. http://dx.doi.org/10.1080/09638199.2012.679292

3. Hegerty, S.W. (2014b): Exchange Market Pressure and Price Spillovers in Russia, Ukraine, and Belarus, Applied Econometrics and International Development, 14(2).

4. Koseoglu, S.D.; Cevik, E.I. (2013): Testing for Causality in Mean and Variance Between the Stock Market and the Foreign Exchange Market: An Application to the Major Central and Eastern European Countries, Czech Journal of Economics and Finance (Finance a uver), 63(1), pp. 65-86

5. Pesaran, M.H.; Shin, Y. (1998): Generalised Impulse Response Analysis in Linear Multivariate Models, Economics Letters, 58, pp.17-29. http://dx.doi.org/10.1016/s01651765(97)00214-0

6. Phillips, P.; Perron, P. (1988): Testing for a Unit Root in Time Series Regression, Biometrica, 75, pp. 335-346. http://dx.doi.org/10.1093/biomet/75.2.335 
7. Phylaktis, K.; Ravazzolo, F. (2005): Stock Prices and Exchange Rates Dynamics, Journal of International Money and Finance, 24(7), pp. 1031-1053.

8. Sims, C.A (1980): Macroeconomics and Reality, Econometrica 48, pp. 1-48. http://dx.doi.org/10.2307/1912017

9. Stavárek, D. (2011): Comparison of Exchange Market Pressure Across the New Part of the European Union, Emerging Markets Finance and Trade, 47, iss. sup 3. http://dx.doi.org/10.2753/ree1540-496x4704s302

10. Van Poeck, A.; Vanneste, J.; Veiner, M. (2006): Exchange Market Pressure in the Formerly Planned Central and Eastern European Countries: The Role of Institutions, Tijdschrift voor Economie en Management, 51(3), pp. 309-46. 



\title{
1.3. THE ISSUE OF RESOURCE THEORY AND CORPORATE SOCIAL RESPONSIBILITY
}

\begin{abstract}
Summary
In this paper, the problematic issues have been undertaken with regard to the management of intangible resources in an enterprise. There has been an indication of the changes in an enterprise as the consequence of functioning in a turbulent environment. The environment forces the social approach of enterprises. The significance of organizational culture in the process of creating the social approach of enterprises has also been emphasized, while simultaneously acknowledging organizational culture as one of the intangible resources. In the further sections, models of the relations between enterprises and institutions have been presented, coupled with an illustration of the social approaches.
\end{abstract}

Keywords: intangible resources, culture of organization, social approach of enterprises

\section{Introduction}

The functioning of enterprises requires the possession of resources. Their structure indicates a significant differentiation and generally speaking, the tangible resources and intangible resources are distinctive. In the resource theory, the focus is being increasingly moved from the tangible resources to the intangible resources. In this group of resources the competitive potential of an enterprise functioning on a global market is perceived. The intangible resources are termed as a catalyser for the activation of the tangible resources. In terms of the intangible resources their usefulness is illustrated. Of all the varied forms, the usefulness of intangible resources evolves in the direction of creating the social approaches of enterprises. In the sphere of the issues of the social approaches of enterprises, there is an indication of organizational culture in terms of ontological, semantic and nomological notions. Organizational culture has been included in the organizational creation, constituting a base for the strategies of enterprises. The differentiation of the forms of organizational activity has become the basis of the generalization presented in business models. The social basis of enterprises has been taken into consideration as an element of the intangible resources.

\section{Processes of changes in management of intangible resources}

In the process of the functioning of enterprises, there is an indication of change as an intrinsic element of the activities of an organization. Their very nature and scope indicates great differentiation, while Krzakiewicz claims that the contemporary world of business favours those organizations that may display that their activities are tried and trusted and may appraise its activities in a rational way. Selection within the framework of the organizational populations usually eliminates organizations of a low reliability and a lack of social responsibility (Krzakiewicz, 2014) By way of continuing deliberations in this sphere of change, it is possible to refer to the premise 
of their introduction. The fundamental premise is that of competitiveness. Gawron (2014) claims that with the aim of increasing the competitiveness of an enterprise, improving the economic results, increasing the market value and increasing productivity, the management of the organization should implement changes that will make the development of the enterprise dynamic. The development of enterprises is currently being determined to an increasingly wider scope by intangible resources.

Intangible resources have become a significant base of the functioning and development of enterprises. Their essence places them in the resource theory, by indicating their usefulness and effectiveness in terms of the business activities of enterprises (Krupski, 2012). It is claimed that intangible resources constitute a catalyser for the activation of the tangible resources (Rzemieniak, 2013). The structure of intangible resources indicates a high level of complexity and variation. This fact causes the case whereby the analysis of the intangible resources in terms of various aspects is carried out, one of which is that of its usefulness (see Table 1).

On the basis of the afore-mentioned data as results of empirical research, it is possible to state that knowledge illustrates the highest level of usefulness of the intangible resources. Following this, it is possible to distinguish the worker approaches and behaviour. Non-formalized relations are also significant. The employees determine the development of an enterprise by means of creativity and innovativeness. The features of the employees of knowledge mentioned above enable the competitive advantage of enterprises (Myjak, 2014). These features also constitute the base for implementing change to the nature of the social approaches of enterprises. In the process of change, arising out of a turbulent environment, but also caused by the implementation of new technologies, an enterprise is forced into the realization of the strategic aims as derivative of the business activities on a global scale (Borowiecki, 2013).

The competitiveness and requirements of society in terms of the social approaches of enterprises in the sphere of the social approaches of enterprises force enterprises to base on key competences and the processes systematically supplemented, updated and intangible resources created. As a result of the aforesaid change, the enterprises adjusting to the environs undergo a transformation into a learning organization that adjusts to the economic and social needs and requirements (Nogalski and Niewiadomski, 2014).

In making an evaluation in terms of the sphere of change in enterprises, it is necessary to emphasize the growth in the importance of intangible resources, while also the increasing trend of the occurrence of the social approaches of enterprises. It would seem to be justifiable to acknowledge the social approach of enterprises as one of the newly forming intangible resources.

\section{Culture of organization as an element of social approach of enterprises}

The problems of organizational culture are inextricably connected with the functioning of enterprises. The scope and forms of impact on an enterprise have however undergone significant change over time. In the past few years, the growth in significance and interest in the culture of the organization of an enterprise has been noticeable in terms of various aspects. 
Table 1: Usefulness of intangible resources in cross-section of types of activity of enterprises (Results of empirical research)

\begin{tabular}{|c|c|c|c|c|c|}
\hline $\begin{array}{l}\text { Types of } \\
\text { activity }\end{array}$ & $\begin{array}{c}\text { Usefulness of intangible } \\
\text { resources }\end{array}$ & Comments & $\begin{array}{l}\text { Types of } \\
\text { activity }\end{array}$ & $\begin{array}{c}\text { Usefulness of intangible } \\
\text { resources }\end{array}$ & Comments \\
\hline $\begin{array}{l}\text { Strategic } \\
\text { level }\end{array}$ & $\begin{array}{l}\text { 1. Knowledge }(3,80) \\
\text { 2. Non-formalized } \\
\text { relations }(1,00) \\
\text { 3. Formalized relations } \\
(0,89) \\
\text { 4. Image of firm }(0,76) \\
\text { 5. Worker approaches and } \\
\text { behaviour }(0,16)\end{array}$ & $\begin{array}{l}\text { Decisively } \\
\text { greatest use } \\
\text { is with } \\
\text { knowledge }\end{array}$ & $\begin{array}{l}\text { Replica- } \\
\text { tion }\end{array}$ & $\begin{array}{l}\text { 1. Knowledge }(4,13) \\
\text { 2. Formalized relations } \\
(1,39) \\
\text { 3. Worker approaches and } \\
\text { behaviour }(0,59) \\
\text { 4. Non-formalized } \\
\text { relations }(0,37) \\
\text { 5. Image of firm }(0,07)\end{array}$ & $\begin{array}{l}\text { Decisively } \\
\text { greatest use } \\
\text { is with } \\
\text { knowledge }\end{array}$ \\
\hline $\begin{array}{l}\text { Operatio- } \\
\text { nal level }\end{array}$ & $\begin{array}{l}\text { 1. Worker approaches and } \\
\text { behaviour }(2,66) \\
\text { 2. Knowledge }(2,08) \\
\text { 3. Formalized relations } \\
(0,84) \\
\text { 4. Non-formalized } \\
\text { relations }(0,74) \\
5 . \quad \text { Image of firm }(0,35)\end{array}$ & $\begin{array}{l}\text { Decisively } \\
\text { greatest use } \\
\text { is with } \\
\text { worker } \\
\text { approachesb } \\
\text { ehaviour } \\
\text { and } \\
\text { knowledge }\end{array}$ & $\begin{array}{l}\text { Competi- } \\
\text { tion }\end{array}$ & $\begin{array}{l}\text { 1. Knowledge }(3,47) \\
\text { 2. Non-formalized } \\
\text { relations }(0,86) \\
\text { 3. Image of firms }(0,85) \\
\text { 4. Formalized relations } \\
(0,69) \\
5 . \quad \text { Worker approaches and } \\
\text { behaviour }(0,43)\end{array}$ & $\begin{array}{l}\text { Greatest use } \\
\text { is with } \\
\text { knowledge }\end{array}$ \\
\hline $\begin{array}{l}\text { Availing } \\
\text { of } \\
\text { opportu- } \\
\text { nities }\end{array}$ & $\begin{array}{l}\text { 1. Non-formalized } \\
\text { relations }(2,63) \\
\text { 2. Knowledge }(2,49) \\
\text { 3. Formalized relations } \\
(1,21) \\
\text { 4. Worker approaches and } \\
\text { behaviour }(0,35) \\
5 . \quad \text { Image of firm }(0.06)\end{array}$ & $\begin{array}{l}\text { Greatest use } \\
\text { is with non- } \\
\text { formalized } \\
\text { relations } \\
\text { and } \\
\text { knowledge }\end{array}$ & $\begin{array}{l}\text { Coopera- } \\
\text { tion with } \\
\text { competi- } \\
\text { tors }\end{array}$ & $\begin{array}{l}\text { 1. Knowledge }(2,87) \\
\text { 2. Formalized relations } \\
(1,33) \\
\text { 3. Image of firm }(0,56) \\
\text { 4. Non-formalized } \\
\text { relations }(0,55) \\
\text { 5. Worker approaches and } \\
\text { behaviour }(0,36)\end{array}$ & $\begin{array}{l}\text { Greatest use } \\
\text { is with } \\
\text { knowledge }\end{array}$ \\
\hline $\begin{array}{l}\text { Avoidance } \\
\text { of threats }\end{array}$ & $\begin{array}{l}\text { 1. Worker approaches and } \\
\text { behaviour }(2,60) \\
\text { 2. Knowledge }(1,80) \\
\text { 3. Formalized relations } \\
(1,39) \\
\text { 4. Non-formalized } \\
\text { relations }(1,06) \\
5 . \quad \text { Image of firm }(0,09)\end{array}$ & $\begin{array}{l}\text { Decisively } \\
\text { greatest use } \\
\text { is with } \\
\text { worker } \\
\text { approaches } \\
\text { and } \\
\text { behaviour }\end{array}$ & $\begin{array}{l}\text { Acquisi- } \\
\text { tion of } \\
\text { clients }\end{array}$ & $\begin{array}{l}\text { 1. Knowledge }(2,98) \\
\text { 2. Image of firm }(2,33) \\
\text { 3. Non-formalized } \\
\text { relations }(0,69) \\
\text { 4. Formalized relations } \\
(0,41) \\
5 . \quad \text { Worker approaches and } \\
\text { behaviour }(0,26)\end{array}$ & $\begin{array}{l}\text { Decisively } \\
\text { greatest use } \\
\text { is with } \\
\text { knowledge } \\
\text { and image } \\
\text { of firm }\end{array}$ \\
\hline $\begin{array}{l}\text { Develop- } \\
\text { ment of a } \\
\text { firm }\end{array}$ & $\begin{array}{l}\text { 1. Knowledge }(3,51) \\
\text { 2. Non-formalized } \\
\text { relations }(1,21) \\
\text { 3. Worker approaches and } \\
\text { behaviour }(0,89) \\
\text { 4. Image of firm }(0,32) \\
5 . \quad \text { Formalized relations } \\
(0,27)\end{array}$ & $\begin{array}{l}\text { Decisively } \\
\text { greatest use } \\
\text { is with } \\
\text { knowledge }\end{array}$ & $\begin{array}{l}\text { Mainte- } \\
\text { nance of } \\
\text { clients }\end{array}$ & $\begin{array}{l}\text { 1. Knowledge }(2,67) \\
\text { 2. Image of firm }(2,49) \\
\text { 3. Worker approaches and } \\
\text { behaviour }(0,67) \\
\text { 4. Non-formalized } \\
\text { relations }(0,54) \\
5 . \quad \text { Formalized relations } \\
(0,41)\end{array}$ & $\begin{array}{l}\text { Decisively } \\
\text { greatest use } \\
\text { is with } \\
\text { knowledge } \\
\text { and image } \\
\text { of firm }\end{array}$ \\
\hline $\begin{array}{l}\text { Existence } \\
\text { of a firm }\end{array}$ & $\begin{array}{l}\text { 1. Worker approaches and } \\
\text { behaviour }(2,53) \\
\text { 2. Knowledge }(2,12) \\
\text { 3. Formalized relations } \\
(0,69) \\
\text { 4. Non-formalized } \\
\text { relations }(0,63) \\
5 \text {. Image of firm }(0,53)\end{array}$ & $\begin{array}{l}\text { Decisively } \\
\text { greatest use } \\
\text { is with } \\
\text { worker } \\
\text { approachesb } \\
\text { ehaviour } \\
\text { and } \\
\text { knowledge }\end{array}$ & $\begin{array}{l}\text { Realiza- } \\
\text { tion of } \\
\text { processes }\end{array}$ & $\begin{array}{l}\text { 1. Knowledge }(3,89) \\
\text { 2. Worker approaches and } \\
\text { behaviour }(1,96) \\
\text { 3. Formalized relations } \\
(0,94) \\
\text { 4. Image of firm }(0,18) \\
\text { 5. Non-formalized } \\
\text { relations }(0,04)\end{array}$ & $\begin{array}{l}\text { Decisively } \\
\text { greatest use } \\
\text { is with } \\
\text { knowledge }\end{array}$ \\
\hline $\begin{array}{l}\text { Innova- } \\
\text { tions }\end{array}$ & $\begin{array}{l}\text { 1. Knowledge }(3,25 \\
\text { 2. Worker approaches and } \\
\text { behaviour }(2,22) \\
\text { 3. Formalized relations } \\
(0,48) \\
\text { 4. Non-formalized } \\
\text { relations }(0,19) \\
5 . \quad \text { Image of firm }(0,04)\end{array}$ & $\begin{array}{l}\text { Decisively } \\
\text { greatest use } \\
\text { is with } \\
\text { knowledge, } \\
\text { worker } \\
\text { approaches } \\
\text { and } \\
\text { behaviour }\end{array}$ & $\begin{array}{l}\text { Realiza- } \\
\text { tion of } \\
\text { results }\end{array}$ & $\begin{array}{l}\text { 1. Knowledge }(3,29) \\
\text { 2. Worker approaches and } \\
\text { behaviour }(2,62) \\
\text { 3. Image of firm }(0,53) \\
\text { 4. Formalized relations } \\
(0,48) \\
5 . \quad \text { Non-formalized } \\
\text { relations }(0,18)\end{array}$ & $\begin{array}{l}\text { Decisively } \\
\text { greatest use } \\
\text { is with } \\
\text { knowledge } \\
\text { worker } \\
\text { approaches } \\
\text { and } \\
\text { behaviour }\end{array}$ \\
\hline
\end{tabular}


One of these is the direction of the culture of an organization towards the social approach of an enterprise. In order to indicate the aforesaid relation, it is necessary to refer to the genesis of the culture of an organization. Hence, it is necessary to place the culture of an organization under analysis in terms of ontological, semantic and nomological notions.

The systemic aspect constitutes the basis of acknowledging the ontological approach to organizational culture in terms of a collection of employees, coupled with the existing relations in the creation of the organizational structure. The semantic context however indicates that the culture of an organization in constituting a set of culture-creating processes requires the adding of mutual ties, together with the exchange of information via the system. The nomological context displays the culture of an organization in a system of elements that are first and foremost complex relations (Leśniewski, 2013). The processes of analysing organizational culture in an enterprise confirm the level of importance of this issue in terms of the management of economic units. It is significant to encompass activities in the sphere of organizational culture into the strategies of an enterprise with the aim of emphasizing the various consequences accepted or planned patterns of procedure (Gajewska and Kubański, 2014). In organizational culture, a premise of the effective management of an enterprise is sought after (Bubel, 2014). Empirical research confirms the significance of organizational culture in terms of improving the effectiveness of management. Likewise, the significance of the social approaches of enterprises is growing.

By way of example, we may refer to the research of enterprises which revealed that social capital and organizational culture in enterprises may be acknowledged as the pro-effectiveness factor of development. Thus, enterprises shall be able to achieve success by encompassing organizational culture into the built-up networks of the organization. Simultaneously, the social approaches of enterprises are shaped.

The afore-mentioned activities appeal to the requirements of clients, the qualifications of employees and the strategies of enterprises. Bylok highlighted that "the selection of highly qualified employees enables the appropriate realization of the strategy of a firm in a situation when the market requirements are first and foremost taken into consideration, or in other words, when employees shall display the skills to satisfy the needs of clients" (Bylok, 2013). In these activities, the relations in management in terms of the legislative and social aspects are important (Dziwiński and Barcik, 2014). The fundamental problem is thus becoming the definition of the role of humanistics in the development of management and shaping the social approaches of enterprises. The marking out of the ontological and epistemological assumptions, as well as the scope of the applied research methods are characterized by complexity, while simultaneously creating the opportunities of development. In this context, it is necessary to pose the question relating to the range of values that humanistics contribute to management. By way of answering this question, it is essential to indicate two fundamental reasons for the interest in humanistics. One of them is identified as the fundamental role of humanistics in the teachings of management. The second reason involves the provision of the model patterns of science by means of an inherent interdisciplinarity and non-paradygmatics (Prawelska-Skrzypek and Lenartowicz, 2013). Referring to the aforementioned reasons marks out the framework in terms of organizational creativity. 
Organizational creativity is activity aimed at the generation of new and useful concepts in the form of a multi-dimensional construction. Following the execution of empirical research in the field of indicators, the characteristic dimensions of organizational creativity, as Bratnicka defines that Hypothesis 1 has been confirmed, namely by stating that organizational creativity has two dimensions- novelty and usefulness (Bratnicka, 2014). Further deliberations have led to the case whereby the author formulated questions relating to the direction and field of research on organizational creativity in the future (Bratnicka, 2014). In this creativity, it is necessary to adopt the direction of the creation of the social approaches of enterprises as the creation of values is to be perceived there (Kaplan and Norton 2006). This is simultaneously the indication of the necessity to update the strategies of enterprises by taking account of new value that is the result of the social approaches of economic units. The social approach constitutes one of the intangible resources of the enterprises.

\section{Models - intangible resources - social approach of enterprises}

The model formulation of the concept of the intangible resources is related to the general relations in a community. Likewise, it is also connected with the dependencies between enterprises, public institutions and consumers. Each of these groups realizes different aims, although they create an integrated set of a socio-economic nature. By way of conclusion, the essence of these relations, the determinants of success and the boundary conditions are reflected in the general models of organization. (Czekaj and Ziębicki, 2014) The scope of identification of the business model in terms of the social aspects is presented in Table 2 .

Table 2: Business entrepreneur vs. social entrepreneur

\begin{tabular}{|l|l|l|}
\hline & Business Entrepreneur & Social Entrepreneur \\
\hline Economic value & Priority & Secondary \\
\hline Social value & Secondary & Priority \\
\hline $\begin{array}{l}\text { Origin of project's } \\
\text { "vision" }\end{array}$ & Individual or a small group & Associative \\
\hline Concept of" client" & Unique and clear definition & $\begin{array}{l}\text { Presence of "user" or "double } \\
\text { clientele" }\end{array}$ \\
\hline $\begin{array}{l}\text { Origin of business " } \\
\text { know-how" }\end{array}$ & $\begin{array}{l}\text { Radical innovation, imitation } \\
\text { or adaptation }\end{array}$ & $\begin{array}{l}\text { Based on knowledge and } \\
\text { experience from advanced societies }\end{array}$ \\
\hline $\begin{array}{l}\text { Degree of business } \\
\text { innovation }\end{array}$ & Limited to high & High \\
\hline $\begin{array}{l}\text { Expectation of personal } \\
\text { economic rewards }\end{array}$ & $\begin{array}{l}\text { Moderate at the beginning } \\
\text { and make related later on }\end{array}$ & $\begin{array}{l}\text { Secondary issue: presence of } \\
\text { "psychological salary" }\end{array}$ \\
\hline
\end{tabular}

Source: (de Pablo Lopez 2014)

The characteristics of the model reveals each of them bases itself on the organization that is identified from the subjective and action notions. The determinants of success are of great importance as the functioning of each model of an organization is directed towards the achievement of success thanks to the utilization of the resources of the enterprises. These models are thus becoming a significant pattern of activity in the strategies of enterprises and regions (Bojar, 2009). 


\section{Business entrepreneur vs. social entrepreneur}

Social entrepreneurs, unlike business entrepreneurs, are more concerned with creating social change. Profit seems to be of secondary importance here. Business entrepreneurs set up a venture and expect to make as much profit as possible, and social entrepreneurs expect to profit as much as the previously mentioned group, however, the difference is that the latter does not consider generating profit in the money-making sense-profit as a condition for achieving success and an indication of business activity efficiency.

Table 3: Features of HR management and human capital management

\begin{tabular}{|c|c|c|}
\hline Feature & Human resource management & $\begin{array}{c}\text { Human capital management based on } \\
\text { commitment }\end{array}$ \\
\hline Effects & - productivity & $\begin{array}{l}\text { - innovations } \\
\text { - quality } \\
\text { - customer satisfaction } \\
\end{array}$ \\
\hline $\begin{array}{l}\text { Organizational } \\
\text { culture }\end{array}$ & $\begin{array}{l}\text { - individualism } \\
\text { - specialization } \\
\text { - autocratic management }\end{array}$ & $\begin{array}{l}\text { - collective approach } \\
\text { - universalism-flexibility } \\
\text { - leadership }\end{array}$ \\
\hline $\begin{array}{l}\text { Development } \\
\text { of employee } \\
\text { activity }\end{array}$ & $\begin{array}{l}\text { - occasional } \\
\text { - system of incentives and } \\
\text { suggestions }\end{array}$ & $\begin{array}{l}\text { - process } \\
\text { - proper attitude } \\
\text { - commitment }\end{array}$ \\
\hline $\begin{array}{l}\text { Labour } \\
\text { organization }\end{array}$ & $\begin{array}{l}\text { - tight control } \\
\text { - detailed job description } \\
\text { - competence } \\
\text { - stand procedures }\end{array}$ & $\begin{array}{l}\text { - lax control } \\
\text { - autonomous groups } \\
\text { - project teams } \\
\text { - assessment of objective fulfilment }\end{array}$ \\
\hline Communication & - vertical (up-down) & - multi-dimensional \\
\hline Assessment & $\begin{array}{l}\text { - individual goals } \\
\text { - assessment made by controller } \\
\text { - main criterion for the } \\
\text { assessment -financial success }\end{array}$ & $\begin{array}{l}\text { - team goals } \\
\text { - assessment made by customers } \\
\text { - priority given to improvement in the } \\
\text { quality of customer service }\end{array}$ \\
\hline Motivation & $\begin{array}{l}\text { - competition } \\
\text { - financial remuneration }\end{array}$ & $\begin{array}{l}\text { - cooperation } \\
\text { - rewards for teams } \\
\text { - financial and non-financial rewards }\end{array}$ \\
\hline Training & $\begin{array}{l}\text { - Job related skills: } \\
\text { a) functional } \\
\text { b) technical }\end{array}$ & $\begin{array}{l}\text { - Wide range of skills: } \\
\text { a) cross-functional } \\
\text { b) diagnostic } \\
\text { c) problem solving } \\
\text { d) quality-oriented } \\
\text { e) interpersonal } \\
\end{array}$ \\
\hline $\begin{array}{l}\text { Career } \\
\text { development }\end{array}$ & $\begin{array}{l}\text { - narrow skills } \\
\text { - development based on } \\
\text { individual achievements } \\
\text { - vertical career tracks } \\
\end{array}$ & $\begin{array}{l}\text { - interdisciplinary nature } \\
\text { - development based on team } \\
\text { achievements } \\
\text { - horizontal career tracks } \\
\end{array}$ \\
\hline
\end{tabular}

Source: (Czernachowicz, 2011)

In the "customer", or "client" aspect, business entrepreneurs consider such people as customers who bring them profit, and social entrepreneurs prefer to address social needs and focus on the positive impact of a business on a society. A client is a user and a person who benefits from business operations, not a money-maker from the business 
entrepreneur's point of view. Finally, business entrepreneurs prefer to take their "know-how" from slightly unknown sources, betting on unknown, radical and innovative ideas, often adapted from other businesses, while social entrepreneurs are rather methodical and base their business strategy of knowledge and experience.

The problem of human resources requires the illustration of the conditions, essence and relations in terms of the aspect of management (see Table 3 ).

Employee commitment can only be achieved if a staff member is treated more like "capital" rather than a "resource" and while a resource is constantly used, capital is to be grown and increased. If an employee is treated as an asset, namely an individual who is worth investing in, there is also a sense of stabilization that is being developed, that is, belonging to the organization and identification with the values that the company represents. Employees in the human capital management model are most likely to work in groups and take collective responsibility for their actions. The model notion of the intangible resources in the context of the social approaches of enterprises is the basis ofdeliberations and construction of the appreciation of new resource elements.

\section{Summary}

In the herein paper, the aspects of intangible resources in the process of shaping the social approaches of enterprise have been presented. On the basis of the cited empirical research, the usefulness of the intangible resources have been indicated in terms of the cross-section of the types of activities of enterprises. Particular usefulness was indicated by such intangible resources as knowledge, worker approaches and behaviour, as well as non-formalized relations. Resource usefulness is leading to the growth in the level of competitiveness of enterprises. The usefulness of intangible resources is also a social determinant in terms of the approaches of enterprises. The reflection of the social approaches of enterprises has been presented in business models. The model elements and the mutual ties between them confirm the level of importance of intangible resources in terms of the creation of the social approaches of enterprises.

\section{References}

1. Borowiecki, R. (2013): The challenges and dilemmas in corporate management in the conditions of economic uncertainty and instability. In: Contemporary economies in the face of new challenges. Economic, social and legal aspects. Ed. R. Borowiecki, A. Jaki, T. Rojek. Cracow University of Economics, Cracow, pp. 127-139.

2. Bratnicka, K. (2014): Twórczość organizacyjna: zdefiniowanie i operacjonalizacja nowego konstruktu. In: Nowe kierunki w zarządzaniu przedsiębiorstwem - wiodące orientacje. Ed. J. Lichtarski, S. Nowosielski, G. Osbert -Pociecha, E. Tobaszewska-Zajbert, Nr 340, Wrocław University of Economics, Wroclaw, pp. 27-36. http://dx.doi.org/10.15611/pn.2014.340.02

3. Bubel, D. (2014): Intellectual capital management as an element of strategy of small and medium-sized enterprises in Germany. In: Current problems of maintenance of electrical equipment and management. Ed. M. Kolcun, L. Borowik, T. Lis, Technical University of Kosice, Kosice, pp. 235-244.

4. Bylok, F. (2013): Personnel Strategy in SMEs as a Factor Determining Market Success. In: People Knowledge and Modern Technologies in the Management of Contemporary Organizations. 
Theoretical and Practical Approaches, Ed. C. B. Illes, Szent Istvan Eqyetemi, Hungary, Gödöllö, pp. 102-114.

5. Czekaj J.; Ziębicki B. (2014): Współczesne modele biznesu w świetle rozwoju teorii organizacji i zarządzania. In: Zarządzanie przedsiębiorstwem w warunkach współczesnych wyzwań gospodarczych. Modele - metody - procesy. Ed. R. Borowiecki, J. Kaczmarek, Uniwersytet Ekonomiczny w Krakowie, Kraków, pp. 17-26.

6. Czernachowicz, B. (2011): Selected problems of the development of human capital, eds. R. Borowiecki,T. Rojek Developmental Challenges of Contemporary Economies. Management Finance - Restructuring, Cracow University of Economics, Cracow,pp. 110-119.

7. Dziwiński, P. \& Barcik, A. (2014): The compliance mechanism in management of the company in terms of European Competition Policy. In: Management and Managers Facing Challenges of the 21st Century. Theoretical background and practical applications. Ed. F. Bylok, I. Ubrežiova, L. Cichobłaziński, Szent Istvan Egyetemi Kiadó, Gödöllö, pp.140-147.

8. Gawron, J. (2014): Restrukturyzacja zasobów kadrowych a patologie w organizacji. In: Zarządzanie przedsiębiorstwem w warunkach współczesnych wyzwań gospodarczych. Modele - Metody - Procesy. Ed. R. Borowiecki, J. Kaczmarek Uniwersytet Ekonomiczny w Krakowie, Kraków, pp. 160-168.

9. Gajewska, P.; Kubański, M. (2014): Wpływ kultury organizacyjnej na efektywność przedsiębiorstwa. In: Etyka, Kultura organizacyjna i społeczna odpowiedzialność biznesu w kształtowaniu potrzeb i relacji z klientami. Ed. H. Howaniec, Z. Malara, W. Waszkiewicz. ATH Bielsko-Biała, pp.75-88.

10. Kaplan, R. S.; Norton, D. P. (2006): Alignment Using the balanced Scorecard to create corporate synergies. Harvard Business School Press , Boston, 302 p.

11. Krupski, R. (2012): Rozwój szkoły zasobów zarządzania strategicznego. "Przegląd Organizacji" 4, pp. 3-7.

12. Krupski, R.; Osyra, M. (2014): Badanie użyteczności zasobów niematerialnych w wyodrębnionych obszarach aktywności przedsiębiorstw. Przegląd Organizacji 8, pp. 4-8.

13. Krzakiewicz, K. (2014): Zmiany w organizacji i strukturalna inercja. In: Nowe kierunki w zarządzaniu przedsiębiorstwem - wiodące orientacje. Ed. J. Lichtarski, S. Nowosielski, G. Osbert-Pociecha, E. Tabaszewska Zajbert. $\mathrm{Nr}$ 340. Wydawnictwo Uniwersytetu Ekonomicznego we Wrocławiu, Wrocław, pp. 450-460

14. Lopez, I. de Pablo (2014): Strategic approach for non-profit organizations. In: Third Sector Theoretical and empirical approach. Eds. R. Borowiecki, M. Dziura, Cracow University of Economics, Cracow pp. 87-94.

15. Leśniewski M. A. (2013): Kultura w systemie organizacji. In: Zachowania przedsiębiorstw w obliczu nowych wyzwań gospodarczych Restrukturyzacja - Zarządzanie - Analiza, Ed. Borowiecki et al. Uniwersytet Ekonomiczny w Krakowie, Kraków, pp. 81-95.

16. Myjak, T. (2014): Pracownicy wiedzy jako źródło konkurencyjności przedsiębiorstw na przykładzie wybranych mikrofilm w branży budowlanej. In: The Intelectual and Innovative Potential In Management Or Organization. Ed. J. Dudzik-Lewicka, H. Howaniec, J. Klisiński, W. Waszkielewicz. ATH University of Bielsko-Biała, pp. 199-207.

17. Nogalski, B.; Niewiadomski, P. (2014): Elastyczność w obliczu wyzwań globalnej gospodarki - kontekst dopasowania rynkowego. In: Restrukturyzacja w obliczu wyzwań gospodarki globalnej. Ed. R. Borowiecki, A. Jaki. Uniwersytet Ekonomiczny w Krakowie, Kraków, pp.123-138.

18. Prawelska-Skrzypek, G.; Lenartowicz, M. (2013): Badanie organizacji i zarządzania na gruncie humanistyki. „Problemy zarzadzania” vol. $11 \mathrm{nr}$ 4(44). Wydział Zarządzania, Uniwersytet Warszawski, Warszawa, pp.45-57.

19. Rzemieniak, M. (2013): Zarządzanie niematerialnymi wartościami przedsiębiorstw. Dom Organizatora, TNOiK, Toruń. 343 p. 


\title{
1.4. COUNTERPRODUCTIVE BEHAVIOUR IN ORGANIZATIONS: THEORETICAL BACKGROUND AND EMPIRICAL IMPLICATIONS
}

\begin{abstract}
Summary
Problems related to counterproductive behaviour within organizations can be included in sciences on management and organization, namely in organizational behaviour. Human aspect of company functioning is difficult to overemphasize, as the regularities that steer human behaviour within a company must take into account the so-called humanistic factor (the whole symbolic sphere where a man exists, a sphere which is an inherent element of organizational reality). This sphere influences the decision making process to a great extent, what according to some authors is an essence of management.

The analysis will be based on the following definitions of dysfunctional behaviours within an organization 'dysfunction and pathology which drive men are a state of disappearance or not establishing social norms like legal, ethical or professional. They refer to individuals and broader structures, where individuals transfer harmful behaviours (both intended and not intended). They may contribute to induction of unexpected behaviours. The actions which are contrary to the expected ones, in other words - referring to the praxeological terminology - are counterproductive and they prevent organizations from reaching their goals.

The aim of the analysis is to create a theoretical model that would explain the emergence of counterproductive actions within organizations existing in a turbulent environment. The second aim is to indicate methods of management allowing prevention of organizational pathologies. The pro-productive organization model will be approached from the perspective of strategic management, which is targeted mainly at achieving and maintaining competitive supremacy. The outcome of the analysis is to indicate directions of empirical research and to pose research worth-testing hypothesis.
\end{abstract}

Keywords: strategic management, counterproductive behaviour, organizational misbehaviour, ethical leadership

\section{Introduction}

In the present study, attention will be focused on the problem of counter-productive and dysfunctional behaviours within an organization. This issue will be covered from the perspective of strategic changes in an organization forced to act in conditions of discontinuous environmental changes. There is a common belief that the source of the largest turbulence within an organization comes from its environment. Even violent internal changes within an organization i.e. owner change, conflict or crisis within organizational leadership - these are always, to some extent under control of its members and can be mastered before disclosing their destructive power. External changes are different. The organization has no control over them, it cannot be predicted when changes may occur nor the nature of these changes (Romanowska, 2010). Extremely competitive and changing environment requires the organization to have the previously unknown competences involving rapid response to signals coming from the environment. The ability to undertake such actions and making decisions in 
conditions where it's difficult to estimate the risk - these are the sources of numerous tensions, which are a subject of both system of social organizations and the people who work there. A man who acts in a constantly uncertain environment is looking for something certain, some niche, where he would feel safe. If the organization does prepare mechanisms to counteract such tensions, then counterproductive behaviour begins to perform this function, especially informal groups of interest.

This issue is important for several reasons. Firstly, from the perspective of organization employing workers who manifested a counterproductive behaviour. It happens that such behaviours are transferred from the outer environment, i.e. from the culture of a local community. Secondly, this issue is also important from the point of view of an employee, as counterproductive behaviours are often a form of adaptation to an organizational pathology and can cause moral conflicts, especially when they are forced by a group of employees. Counterproductive Work Behaviour can be recognized in the context of the organizational stress theory, according to which organizational tensions, interpersonal conflicts and the visible injustice are stressors and the counterproductive actions are just an adaptive response (Fox, Spector and Miles 2001. p. 291). At this point, it is worth to emphasize the importance of sense of justice in organizations and its impact on productivity (Macko, 2009).

\section{Counterproductive behaviours - a theoretical background}

Problems, which are related to the counterproductive behaviour in the organization, include the area of sciences on management and organization, which is called the organizational behaviours. The human aspect of the organization is difficult to overestimate, as the regularities which drive human behaviour in a company must include the so-called humanistic factor, primarily the entire symbolic sphere (where a man is immersed) and which is an integral element of the organizational reality. This sphere substantially affects the decision-making process, which according to some authors is an essence of management.

Considering the nature of the management one may enumerate the following dimensions (Bhattacharyya, 2009, pp. 5-6):

- productivity orientation - Frederick Winslow Taylor and John F. Mee were the pioneers of this approach. In terms of this approach an increase in productivity is the main goal of management.

- human relations orientation - pioneers: Lawrence A. Appley and Harold Kootz. In this approach, attention is focused mainly on the interpersonal relations within an organization.

- Decision-making orientation - the essence of management comes down to making decisions. Pioneers: Ross Moore and Stanley Vance.

- leadership orientation - according to this orientation leadership is the most important part of management. Pioneers: Donald J. Clough and Ralph C. Davis.

- process orientation - management is seen as a process. Even the organization itself is rather a process than a structure (Czarniawska, 2010).

It should be emphasized that the perspective of human relationships does not treat those a subject of management. Objectives are always outside the organization. It is assumed, however, that relationships are one of the vital resources of an organization. 
They are a key to the effectiveness of the entire management process, and shaping them deliberately and purposefully brings the organization closer to the success. Pathologies in this area - on the other hand - they are dysfunctional and move away from the organization's objectives. However, in accordance with the functional paradigm, the question should be raised about the function of pathologies. Every human action in this paradigm has a particular role. The distinction between function and dysfunction is relative. It means that calling any action functional or dysfunctional depends on whether it leads to the objective, to achieve the goal for which the company was established, or maybe completely different, when it leads to a goal which is contrary to the intended one. This understanding of functions and dysfunctions in management determines the role of the manager. "(...) manager's essential skill is a correct diagnosis of the company's condition, sources of difficulties and successes, future opportunities and risks of development, the strengths and weaknesses of the company." (Romanowska, 1995, p. 10)

Organizational pathologies represent the weaknesses of the company and are one of the main sources of difficulties in achieving the objectives and at the same time they are a significant barrier limiting the development, which is a key indicator of health of any organization. The ability to diagnose organizational pathologies and to prevent them is an important aspect of managerial functions.

This analysis will be based on the following definitions of dysfunctional behaviour within the organization - "dysfunction and pathology of leadership are a state of decay or failure in establishing legal, ethical, professional norms, and more generally social norms and apply to both individual people and the wider structures, where individuals carry adverse effects both knowingly and unknowingly. They may contribute to induce of a contrary behaviour to the expected one." (Chmal, 2007, p. 9) Behaviour, which is contrary to the expected ones, is - referring to the praxiological terminology - a counterproductive behaviour, it does not allow an organization to achieve its goals. Kieżun has a less complex definition of pathology in an organization (the term of dysfunction and pathology will be used interchangeably in this paper): "Pathology of the organization is relatively permanent disability of an organization, which results in the waste exceeding the limits of a social tolerance." (Kieżun, 1997, p. 376) According to this definition, pathological decisions are the ones which determine behaviour whose effect is an excessive consumption of resources in achieving organizational goals, or even in extreme cases, consumption of these resources without achieving the goals. In order to properly assess the "excessive resource consumption", one should have a reference point allowing the comparison of two management processes, both requiring a similar amount of resources. The reference point is not required in case of the total ineffectiveness, meaning when the target has not been achieved in the slightest degree. Without seeking the reference point, even a minor consumption of resources can be called a waste. Can we immediately call every single waste a pathology and an effect of counterproductive behaviour? It seems not. It is difficult to talk about the wastefulness if resources are wasted due to a non-culpable managers lack of knowledge, or due to making decisions in high-risk conditions. This phenomenon occurs when dysfunctional behaviours become "needed" (in its own way) in the organization, when they have specific functions that are in conflict with the 
basic function. This happens, for example, when some of the functions and structures in management are a subject of autonomous processes. Reporting is a good example, as people complain on it in almost every organization. Its purpose is to serve each organization, especially the process of achieving goals, but sometimes it becomes an "art for art's sake", when it gives certain organizational units a control over the organization as a whole. A lot of information is collected 'just in case' and when someone is looking for such important data, it turns out that one needs create it from the beginning, just because this particular data was never collected before.

Organ and Bateman understand organizational behaviour as follows: OB refer to the behaviour of individuals and groups in an organizational environment. In organizations, people perform their duties, do business, gossip, tease others, make decisions, argue, and commit despicable and heroic deeds. When these behaviours a refer to an organization, when they influence the functioning of the organization and when are shaped by the organization. They can be incorporated into these phenomena, which are collectively referred to as an organizational behaviour. (Organ and Bateman, 1991, p. 5) According to this broad understanding of organizational behaviour, functional and dysfunctional behaviour can be added to this group. From the perspective of Organization Behaviour as an object of scientific analysis, both types of behaviour are equally interesting and important in the management of the organization. To sum up the deliberations on the counter-productive behaviour, it should be noted that its essence lies in the "intentional and harmful influence on the organization and its members. These include certain open activities, such as aggression and theft, as well as passive and intentional lapse in respecting the instructions or an inaccurate performing duties. (...) The common feature of all the counterproductivity definitions is the harm it makes to the organization as a whole by a direct negative influence on its functioning or its ownership, or hurting its employees in a way which reduces their effectiveness. (Fox, Spector and Miles, 2001, p. 292)

An overview of definitions made by Fox, Spector and Miles indicates three harmful areas of counter-productive behaviour : functioning of the organization, its property and welfare of its employees. Lack of respect for these three important aspects of functioning of the organization, conducted by a deliberate reduction of the effectiveness of the management process (i.e. Incorrect coordinating of actions), wasting property (i.e. lack of attention to equipment, or even theft) and activities to detriment the employees (i.e. unfair assessment or remuneration). In this paper the abovementioned actions will be referred to as a counterproductive behaviour. Such actions can be undertaken by both employees and employers/managers.

\section{The concept of a healthy organization}

The analysis of counterproductive behaviour carried out so far concentrated mainly on the phenomenon of organizational pathologies. It is worth to note a more constructive approach, namely the concept of a 'healthy organization'. Joseph Penc defined the term in the following way: "it seems that a healthy organization is an efficient organization in the praxeological sense. It is also capable of removing all the difficulties that stand or may stand in the way of its development and harmonious relationship with the environment of its actions. So this is an organization which is 
sensitive to innovation and change, it is able to generate and implement them, it competes due as if has more values to offer to the customer, it is friendly to both its employees and the environment." (Penc, 2001, p. 12) While the concept of organizational pathology became common in the subject literature, the concept of a healthy organization is still uncommon. Stocki $(2005$, p. 375) also uses this term, he writes about "the anatomy of a healthy organization." Medical analogies which increasingly emerge may focus the attention on the subject. Definition made by Penc is interesting, as it draws attention to the positive aspects of a 'healthy organization' (inter alia it is supposed to be able to the adaptive change) and not limited to the absence of a pathology. Kiezun writes about the 'health of an organization'. This raises a further semantic problem: what is the health of the organization, as we are always revolving around the considerations of an organization. We have a number of both US and Polish considerations. The concept presented by Bennis (1966) and Likert (1967) are particularly developed. According to Bennis a basic measure of organizational health is the ability to adapt to altering conditions and to changes in the environment. This ability is a function of the development of a spirit of research. (Kieżun, 1997, p. 375) Kieżun remains in the circle of adaptive changes, in other words, in the area of learning organizations. 'Learning' or a 'smart' organizational become the same model - an ideal type of a healthy organization. Adaptation means learning, therefore it one of the most important management functions in an organization. Dohasz, Fudaliński, Kosala and Smutek put it as follows: "Management should lead to the fact that the organization is capable of learning, in other words, to adapt to changing environmental conditions." (Dohasz et al., 2009, p. 47) Another important issue connected to the concept of healthy organization is trust but this subject needs separate elaboration. (Robak, 2013)

The issue of a healthy organization can be also seen in the context of organization's ethos. Lewicka and Guzik introduced the concept of the "anatomy of a healthy organization," and they define it as follows: A healthy organization as opposed to a pathological one is characterized by humanity, openness to employees and their needs, it allows the employees to learn from each other and from the managers. The managers do not subordinate the employees, but they cooperate with them, as the aim is to solve problems and act for the good of the company. They allow them to make mistakes, as the conclusions are drawn for the future. Managers also allow employees to take risks (within a certain extent) associated with i.e. new ideas. In a well-functioning and friendly staff, organization there is a principle of liability for both company and employees. There is no space for blame or denial; everyone takes responsibility for ones actions by doing their job as best as they can. A manager is not laissez-faire person, but he is the leader outstanding above the average, being a model to follow. (Lewicka and Guzik 2015)

At first, the introduction of such concepts as 'humanity' and 'openness to employees' sound naive in terms of economic efficiency which is the main criteria for company success. That is just why we should keep these issues in mind not only because human dignity is a fundamental value of a Western civilization, (Mitrus, 2015) but also as shown by numerous studies, recognition of these values in an organization fundamentally affects the efficiency of its employees. Ethical leadership directs 
members of the organization toward goals which are benefits for the organization, its members, stakeholders and the society. In other words, ethical leadership appears to be effective. (De Hoogh and Den Hartog, 2008).

It is worth noting that most publications devoted to assessments of the staff list four types of criteria: eligibility, efficiency, personality and behavioural. (Oleksyn, 2001) Ethical criteria, if presented, are in the groups of personality or behavioural criteria. Yet they are completely detached competences. What use the employer has with an excellent and professional accountant, if the man is dishonest or irresponsible? Some authors write about moral competences, enumerating as follows:

- Actions consistent with the principles, values and beliefs,

- Telling the truth,

- Insistence on what is right,

- Keeping promises,

- Taking responsibility for personal decisions,

- Admitting to mistakes and failures,

- Accepting the responsibility to serve others,

- Actual concern for others,

- An ability to accept one's own mistakes,

- An ability to accept mistakes others make. (Turek and Wojtczuk-Turek, 2011)

These competences are important not only for employees, but especially for the leaders.

\section{Conclusions}

Both management and employees manifest counterproductive behaviours. As the managers have a full authority, they are responsible for employees counterproductive behaviour. From the functional approach these behaviours have an adaptive function to the pathological work conditions.

People management is in a blatant contradiction with a toxic leadership, based on a Roman principle 'divide et impera' (divide and rule). According to this principle, it is the best to rule the subordinates who are conflicted with each other. This type of leadership treats people instrumentally only, what makes a teamwork (which is so important in the contemporary business) highly difficult, and sometimes even impossible.

The emphasis of the excessive and unjustified work competition, increases destructive conflicts and fosters the emergence of one of the largest pathologies in contemporary organizations, namely an organizational stress which is being a source of other pathologies.

\section{References}

1. Bhattacharyya, D.K. (2009): Organizational Behaviour. Concepts and Applications, Oxford University Press, Oxford - New York.

2. Chmal, Z. (2007): Pojęcie dysfunkcji i patologii w życiu społecznym, in: Dysfunkcje i patologie w sferze zarządzania zasobami ludzkimi, red. Z. Janowska, Wydawnictwo Uniwersytetu Łódzkiego, Łódź. 
3. Czarniawska, B. (2010): Trochę inna teoria organizacji, Poltext, Warszawa.

4. De Hoogh, A.H.B., Den Hartog, D. N (2008): Ethical and despotic leadership, relationships with leader's social responsibility, top management team effectiveness and subordinates' optimism: A multi-method study, The Leadership Quarterly no. 19.

5. Dohasz, M., Fudalinski, J., Kosala, M, Smutek, H. (2009): Podstawy zarządzania. Koncepcje strategie - zastosowanie, Wydawnictwo Naukowe PWN, Warszawa 2009.

6. Fox, S., Spector, P.E., Miles,. D. (2001): Counterproductive Work Behaviour (CWB) in Response to Job Stressors and Organizational Justice: Some Mediator and Moderator Tests for Autonomy and Emotions, Journal of Vocational Behaviour no. 59.

7. Hurta, H. (2014): Impact of the Crisis on Leader's Attitude, in: Illes A.B., Dunay A., Słocińska A., New Trends in Management in the $21^{\text {st }}$ Century, Wydawnictwo Wydziału Zarządzania Politechniki Częstochowskiej, Częstochowa.

8. Kieżun, W. (1997): Sprawne zarządzanie organizacją. Zarys teorii i praktyki, Szkoła Główna Handlowa, Warszawa.

9. Lewicka, D., Guzik, G. (2014): Wpływ dysfunkcyjnego zachowania managerów na jakość środowiska pracy $\mathrm{w}$ organizacji, http:/www.google.pl/url?url=http://irbis-nbuv.gov.ua/cgibin/irbis_nbuv/cgiirbis_64.exe\%3FC21COM\%3D2\%26I21DBN\%3DUJRN\%26P21DBN\%3D UJRN\%26IMAGE_FILE_DOWNLOAD\%3D1\%26Image_file_name\%3DPDF/VNULPM_20 14_797_26.pdf\&rct $=$ j\&frm $=1 \& q=\&$ esrc $=$ s\&sa $=$ U\&ei $=$ qYT $\bar{L}$ LVMizKNbzas7gguAJ\&ved $=\overline{0}$ CB MQ̄FjAA_\&sig2=Onay4Jxw4FhzQMrYCYMvxg\&usg=AFQjCNGgIOgSWe_cfmpt68QgkkBC2c3JA (12.01.2015)

10. Macko, M. (2009): Poczucie sprawiedliwości organizacyjnej a zachowania pracowników, Wydawnictwo Naukowe Wydziału Nauk Społecznych Uniwersytetu im. Adama Mickiewicza w Poznaniu, Poznań.

11. Mitrus, L. (s.d.): Godność jako podstawa aksjologiczna praw pracowniczych, https://prawo.amu.edu.pl/_data/assets/pdf_file/0010/175528/dr-hab.-Leszek-Mitrus.pdf (9.02.2015)

12. Oleksyn, T. (1991): Praca i płaca w zarządzaniu, Międzynarodowa Szkoła Menedżerów, Warszawa 2001.

13. Organ, D.W., Bateman, T.S. (1991): Organizational Behaviour, IRWIN, Homewood - Boston.

14. Penc, J. (2001): Kreowanie zachowań w organizacji. Konflikty i stresy pracownicze, zmiany i rozwój organizacji, Agencja Wydawnicza Placet, Warszawa.

15. Robak, E. (2013): The Importance of Organizational Trust Management for the Functioning of Enterprises, in: Illes C.B., Bylok F., Dunay A., Cichobłazinski L., People, Knowledge and Modern Organizations, Szent Istvan Kiadó Nonprofit K.ft., Godollo.

16. Romanowska, M. (2010): Przełomy strategiczne w przedsiębiorstwie, Studia i Prace Kolegium Zarządzania i Finansów, „Zeszyt Naukowy 98, Szkoła Głównia Handlowa W Warszawie”, Warszawa.

17. Romanowska, M. (1995): Zarządzanie strategiczne firmą, Centrum Informacji Menedżera, Warszawa.

18. Stocki, R. (2005): Patologie organizacyjne. Diagnoza i interwencja, Wydawnictwo Wolters Kluwer, Warszawa.

19. Turek, D., Wojtczuk-Turek A. (2011): Kompetencyjne uwarunkowania nieetycznego zachowania pracowników, „Problemy Zarządzania”, vol. 9, 4 (34). 



\title{
1.5. KEY ELEMENTS OF CORPORATE GOVERNANCE AND THE FUNCTIONING OF STATE-OWNED ENTERPRISES IN KOSOVO
}

\begin{abstract}
Summary
Public Enterprises (PEs) in Kosovo are of strategic importance for the country, employing about 14,000 workers and the impact on the economy over $20 \%$ of GDP over the past 5 years. Corporate Governance (CG) in Kosovo is a new concept and is in the process of continuous development and improvement. Government supported by the international community has made progress and has adopted laws based on best practices and international standards in general and the promotion of CG in particular, the challenge of enforcing the law in practice. The aim of the research is to analyse the mechanisms of CG and its legal framework in PE. CG in Kosovo as a result of the challenges of transition is closely related to the consolidation of the rule of law, ownership structure, as well as professional and institutional capacities. The basic hypothesis is that the weaknesses of the CG mechanisms affect the quality of the CG. Methodology: The research sample will be 17 PEs, 100\% owned by the government. The research method will be combined primary data with secondary ones such as annual reports, analysis of the legal framework and mechanisms of CG. For primary data is a used survey with key actors in the CG. Results of the survey will identify strengths and weaknesses in the nature and enforcement mechanisms at CG and in this way to strengthen policy dialogue that will identify reform priorities that lead to improved performance $\mathrm{CG}$ and economic.
\end{abstract}

Keywords: corporate governance, mechanisms, public enterprises

\section{Introduction}

Corporate Governance (CG) is one of the most debated issues in contemporary literature, and in the last decade has attracted and is receiving widespread attention across the globe, as well as in Kosovo. Empirical studies confirm that companies with good CG standard are valued higher in financial markets (McKinsey, 2002). Promoting CG has become a global movement developing wide array of standards, codes and criteria for evaluation. Countries and companies that have not addressed the problems of the $\mathrm{CG}$ are threatened to be left behind in the global race for capital. For investors, one of the most important aspects when making investment decisions is the level of implementation of the principles of CG (information disclosure, protection of shareholders rights and equal treatment of all shareholders and other stakeholders) and profit that provides return on their investment. PEs have multiple and contradictory objectives, influenced by excessive political interference and lack of transparency, considered the main problems facing PEs in Kosovo.

\section{Theories of Corporate Governance}

CG theme is becoming increasingly important on a global scale after the Asian financial crisis of 1997, Russian in 1998 and bankruptcy and scandals in the USA during 2001 and 2002 and the outbreak of the financial crisis that engulfed the global 
economy in 2008 (GCGF, 2012). In response to these scandals OECD developed a set of standards and guidelines on CG. OECD Principles on CG were accepted in 1999 and were reviewed in 2004. The OECD Principles are internationally recognized and treated by the entire CG framework. OECD Principles have served as a reference point for the development of a growing number of CG standards in different countries. After infamous scandals, many academic, expert and professional organizations presented their recommendations (Bech, 2005). Experiences show that the issue of salaries of managers and their relation to performance was at the centre of debates and literature from CG (Baker, 1988) and (Jensen and Murphy, 1990). OECD has developed guidelines on CG state enterprises, designed to meet the OECD principles on CG (OECD, 2005). OECD is seeking to push the implementation of the OECD principles on non-CG member countries by organizing round tables, such are organized in Asia, Latin America, Russia, Eurasia and Southeast Europe (OECD, 2003). PEs in Kosovo are government owned (Law No. 03/L-087, 2008), and may be subject to guidelines (OECD, 2005). PEs in Kosovo turned into corporations in 2005 where CG was adopted for the first time. Different authors define the concept of CG in different ways. Universally accepted definition of the term is derived from the ratio of CG Sir Adrian Cadbury, as the system by which the company is directed and controlled (Cadbury, 1992). Internationally accepted definition is given (OECD, 1999, 2004). CG in Kosovo is a new concept and is in the process of continuous development and improvement. Kosovo government supported by international institutions operating in Kosovo: International Development Agency of the United States (USAID), IFC, World Bank (WB), OECD, etc., has shown a commitment to CG improved. The Government of Kosovo has achieved inter alia approved the Law on Business Organizations (Law No. 02/L-123, 2007), the Law on PE (Law No. 03/L-087, 2008) which was amended later (Law No. 04/L-111, 2012), Code of Ethics and Corporate Governance for PE (2010), the amended and published in (July 2014), and has established, Policy and Monitoring Unit of PE (PMUPE). Since the CG implies a different set of relationships between management, board, shareholders and stakeholders, and establishing conditions for setting goals and means to achieve them, an important part of this process are the means to gain the control. CG mechanisms exist and work for this purpose.

There are two main mechanisms of control: internal and external mechanisms. Internal control refers to the direct monitoring of the owners at work management discipline. External control occurs when other interest groups influence mechanisms in defining and achieving company goals. Internal mechanisms of control are: 1) The Board of Directors 2) Compensation of Management 3) Concentration of ownership 4) Relationships with stakeholders 5) Financial transparency and disclosure of relevant information (corporate reporting). External mechanisms include: 1) The market for corporate control 2) legal infrastructure 3) protection of small shareholders and 4) Conditions for competition.

Internal mechanisms and their relationships are included in the CG of company's code. Foreign influence is observed mainly from the perspective of national level or from the perspective of belonging to a system of CG. Kosovo generally applies onelevel model, in which the impact of the internal control mechanisms prevail. One characteristic of $\mathrm{PE}$ is that the state ownership does not imply the existence of a 
corporate control market. Therefore, there is no opportunity to oversee the success of the company following the share price. Therefore, boards of directors, especially their structure, should have a key role in the CG of PE. Board of Directors (BD) is an instrument used by the government (shareholder) to influence the behaviour of PE management in Kosovo.

\section{Operation of the PEs}

PEs in Kosovo are of strategic importance for the country. PE provide vital services to people and employ about 14,000 workers, of whom 12.042 or $88 \%$ of men and only 1,607 or $12 \%$ are women. PEs are incorporated in December 2005 and operate under the $\mathrm{CG}$, based on the principles of the OECD for CG. Kosovo has a very large public sector which has significant impact on the economy of the country with an average of over 20\% of GDP over the past 5 years (Ministry of Finance, SAA, pp. 142-143). PEs have a high level of bad debts, high technical and commercial losses, and face low collection level, so PE continue to burden the government budget, due to the inability to achieve the appropriate level of financial sustainability (Figure 1).

\section{Figure 1: Financial support of the government for PE}

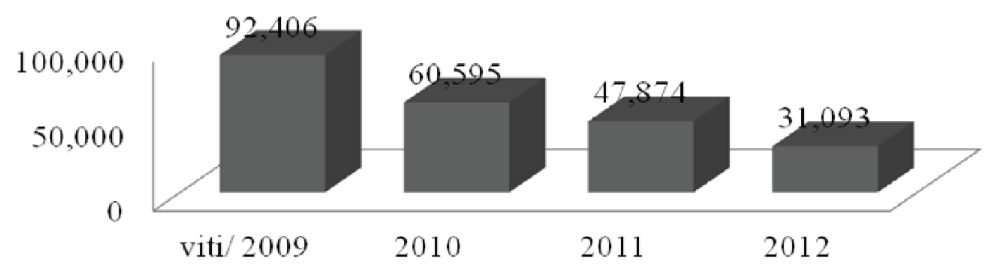

Source: Ministry of Economic Development, (PMUPE), PE performance reporting 2010 p. 10, 2011 p. 21, and 2012, p. 17.

Government policies for financial support to PE have a declining trend as a result of improved financial performance of companies. It is expected in the upcoming years that this government support would be even further reduced (PMUPE, 2010/2011). This is very important in terms of expected negotiations for a Stabilization and Association Agreement (SAA). Likewise, the level of collection from customers for provided services is very small, especially in the waste sector where the collection rate is about $62 \%$, in the water sector is about $68 \%$, (PMUPE).

\section{External mechanisms of CG}

According to the law, a set of one-level model of governance (Anglo-American model) is provided to all $\mathrm{PE}$, in which the impact of the internal control mechanisms prevails. External mechanisms include four factors: the market for corporate control, the legal infrastructure, the protection of small shareholders and the conditions for competition. 


\section{The market for controlling the corporate}

One of the most effective mechanisms for corporate control is the managers' market, which forces managers to operate effectively because they can always be replaced by other more effective managers. In case of CG in PE of Kosovo, the role of the market for corporate control of the company is performed by $\mathrm{BD}$.

\section{Legal and institutional basis}

Law on PE (Law No. 03/L-087, 2008), as amended and supplemented on 20.04.2012 (Law No. 04/L-111) is a foundation for the form of management, reporting and ownership, for all PE's. According to the law, the Government is obliged to supervise the management of these enterprises and report to Assembly on an annual basis.

Kosovo's legislation is largely in line with the EU because of the considerable technical assistance provided by the United Nations (UN) and the EU in recent years (EBRD, 2013). However, the level of implementation of this legislation is less advanced. Some of these laws are:

- Law (No. 02/L-123) on Business Organizations, September 27, 2007.

- Law (No. 03/L-087) on Publicly Enterprises, June 13, 2008.

- Law (No. 04/L-006) on Amending and Supplementing the Law No. 02/L-123 on Trade Associations, June 23, 2011.

- Law (No. 04/L-111) on Amending and Supplementing the Law No. 03/L-087 on Public Enterprises, May 30, 2012.

- Establishing of PMUPE

- Code of Ethics and CG (June 2010), amended and revised (July 2014).

- Instructions on becoming a director of PE (April 2010), and

- Government's Decision No. 01/119, date 13/03/2013, on remuneration of PE directors

The means of this Law established a legal framework for governing the exercise of property rights in $\mathrm{PE}, \mathrm{CG}$ of enterprises in accordance with internationally recognized principles of CG of PE's, and effective reporting structures and responsibility to allow proper supervision of PE activities have been set. According to the Law on PE, Article 4, item 4.1, all PE's shall be organized as a joint stock company (JSC) in accordance with applicable laws on commercial companies (Law No. 02/L-123). According to the Law on PE, Article 40, paragraph 40.1 if an enterprise is or becomes less than $50 \%$ owned, directly or indirectly, by the Government, this enterprise is not a PE and the remaining shares are governed by the Law on Trade (Law No. 02/L-123).

\section{Code of Ethics and Corporate Governance}

Law on PE, Article 35 (35.1) states: Every PE shall prepare, adopt and implement a mandatory code of ethics and CG. According to the law, PMUPE has compiled and published the model code of ethics and CG which was distributed to all PE. This model establishes the code of ethics and standards of CG expected from PE, its employees, officers and directors. CG code in Kosovo was developed in cooperation with international institutions operating in Kosovo and technical support from the USAID and is in accordance with the law and largely meets international standards of $\mathrm{CG}$ as OECD principles. Above from the research shows that only 3 PEs have 
published a code of ethics in their web site and by all companies only (KOSTT JSC) has reported that it is implemented in practice this code.

\section{Internal Auditor}

Literature and many academics of $\mathrm{CG}$ argue that the internal audit function is an integral part of an effective system of CG. It is assumed that this is the first line of defense against misuse of company accountants. According to the OECD, the board of directors of an enterprise must necessarily define an internal audit function. Law sets internal audit as one of the senior most important officials of PE. Based on research, all PE (100\%) have established committees of internal auditors and held on average of $10 \div 13$ meetings during the year, whereas more complex PE, such as KEK and PTK have teams of auditors, who enhance significantly the internal control (PMUPE, 2011). The number of committees other than the audit committee established by enterprises is from $1 \div 6$ (one to six), and now the new Code has reduced them to three with a temporary 6-months mandate with the possibility of extension by the BD.

\section{External Audit}

Under Article 33.1 of the Law on PE, each PE shall be subject to an annual external audit by an objective, independent, competent and qualified auditor. External audit is conducted by the Office of the Auditor General (OAG), or elected by the public enterprise through a selection process based on criteria and conditions set out in the Public Procurement Law (PPL). Every PE has the external audit completed for 2011, 2012 and 2013. The reports resulted in opinions on the compatibility and consistency of financial statements and internal control processes with standards and legal requirements, and in comparison with previous years, recently there is a progress in the opinions of external auditors.

\section{Protecting the interests of shareholders}

That the system of corporate governance and best practices are still evolving, PE are still at risk due to non-transparency of operations, which reflect the position of shareholders as a whole, particularly the position of small shareholders. PE are owned by the government of Kosovo, and after the introduction of the private sector in these enterprises, it is necessary to ensure equality among shareholders, especially in matters of timely and accurate transactions etc. Law on PE, Article 13 stipulates that PE is subject to the same legal treatment as private enterprises. Law on PE, Article 12 stipulates that all shareholders shall be treated equitably. According to the law, an equal market for all stakeholders is intended, and this is in conformity with the principles of the OECD (2005) and it poses a challenge for the government to implement it in the future.

\section{Internal mechanisms CG}

Internal mechanisms of control are: 1) The Board of Directors 2) Compensation of Management 3) Concentration of ownership 4) Relationships with stakeholders and 5) Financial transparency and disclosure of relevant information (corporate reporting). 


\section{Composition of Board of Directors}

Law on PE (Law No. 03/L-087) defines the model as a one-tier board, known as the Anglo-American model. According to the Law on PE, Article 15, paragraph 15.1 the Board of Directors (BD) of a PE shall consist of five or seven directors. All directors, except one, shall be selected by the government and each such selected director shall have a 3-year term. The other director will be Executive Director (ED) of the PE and shall be selected by the Board of PE based on Article 21 of this Law. According to the Law on PE, Article 17, paragraph 17.2 all directors, except the ED, shall be independent; hence $82.5 \%$ of PE directors are independent and $17.5 \%$ ED. Article 37, paragraph 37.1 stipulates the establishment of PMUPE within the Ministry in order to support the Minister and the Government in exercising the responsibilities for PE which were conferred upon them by this law. PMUPE is responsible for organizing the training for directors of PE, and based on our research findings, such trainings, in collaboration with the International Development Agency of the United States (USAID) and the International Finance Corporation (IFC), were organized every year. The manner and criteria for selection of directors are defined by the same law. Some of these criteria are professional adaptability, political impartiality, conflict of interest and to not be prosecuted. So the issue of appointment of directors lies in the law. In practice, it turns out that the selection of the list of candidates that shall be voted on by the Assembly of Kosovo is non-transparent and politically influenced. Although defined by the law, the evaluation of the professionalism of the Board of PE still remains problematic because of the lack of transparency in the board nomination process.

The findings show that no data for the professional and biography of BD members are published, but we indirectly learn that all members of BD possess a university degree. Referring to the Law, all BD mandate have expired in December 2011, even after the announcement of the two competitions in 2012, no selection of board took place because of political interference. Selection of the Board of PE remains disputed issue with the opposition, non-governmental organizations and civil society. Criticism had to do with lack of transparency, political appointments, professionalism in boards and high fees. The research revealed that PE boards are even used as a sector where political party militants can be hired. Hiring the party militants enables political parties to have more impact on these companies so they can push forward their policies. It also gives more employment opportunities for even more politicized people at the lower ranks of the company.

In the past two years, BD were incomplete and non-functional, the situation at the beginning of 2015 shows that only two BD were selected, whereas other PE had no boards selected, and based on political agreement of the parties in power in January 2015 a competition for selection of BD was publicly announced, yet no board was selected. Research also shows that the average number of BD sessions is 12.6, and the audit committee held 10 meetings in 2012 and 2013, above the European average which is 9.4 meetings per year (Heidrick and Struggles, 2011, p.26).

In $17 \mathrm{PE}$ analysed, BD counted 97 members, of whom six are women (6.19\%) and 91 men $(93.81 \%)$. 
Based on research findings, only 2 out of 17 PE distributed dividends for the government, while 15 other PE are not financially viable. During 2012, PTK has declared and distributed dividends to the shareholder, amounting to 45 million euro's and 3.0 million euro's KOSTT (PMUPE, July, 2013).

\section{Remuneration of PE Directors}

Remuneration along with bonuses represent one of the instruments of internal governance that are used more often and are generally assumed to be a good motivational tool used to align the interests of the owner (maximization of profit) with management interests . Law No. 04/L-111 on Amending and Supplementing the Law No. 03/L-087 PE Article 12 (1) limits the performance incentive remuneration which is determined after the annual audit of the financial statements and the publication of reports on the performance of the regulatory offices.

This compensation (bonus) is now paid to directors, an amount up to $50 \%$ of the basic fee referred to in paragraph 2 of this article. Research findings show that the directors have received high bonuses without reaching the performance and also benefited from $\mathrm{PE}$ in other forms of use of vehicles, trips abroad and other illegal forms.

Research results show that many $\mathrm{BD}$ of $\mathrm{PE}$ so far were part of, or related to politics. Research also shows that wages and salaries that the directors of these boards receive are very high compared with the average wage of the country. The government's decision No. 01/119 dated 13.03.2013 that reverses previous decisions, adopt rules on the amount of compensation of PE board members. Research results points out that BD have illegally distributed bonuses before the end of calendar year and without assessing their performance. Members of the Board of PE in the past four years gained 3 million on behalf of salaries and bonuses (Newspaper Zëri, 09.05.2014).

Office of the Auditor General (OAG) in its report (August 2014) found that total compensation for members of the BD for the period $2009 \div 2012$ was $2,439,710$ $€$. From this value for BD meetings was $€ 1,691,304$, compensation for $€ 204.268$ audit committees, compensation for other committees and retroactive payment $€$ 528.368 payment of members of $\mathrm{BD} € 15.770$, whereas bonuses allocated in this period were in the amount of $€ 1,207,139$. Total compensation and bonuses for BD for the period $2009 \div 2012$ was $€ 3,646,849$. From the analysis of the OAG report it can be seen that the total payments to other committees from PE for the period $2009 \div 2012$ was $€ 528.368$ (OAG, 2014).

Directors, except representation in PE boards, are engaged in a primary work through private or public organizations. Except engagement as a regular member of the PE boards, participating in audit committees, directors are also engaged in several other committees within one month. The whole commitment of BD members in primary and secondary work indicates that boards may not be functional and cannot perform their job efficiently.

The above statements on PE distributed bonuses by PE did not meet the criteria for measuring the long-term performance of $\mathrm{PE}$ developments in order to win the right to compensation because these criteria are not consistent with the purpose of the law on 
incentive compensation. The provided statements show that only four PE have partly met the criteria.

PMUPE in its website published a consolidated annual statement on PE for 2012. The analysis above shows that only three PE did not distribute bonuses for BD.

\section{Concentration of ownership in PE}

The main hypothesis that prevails in nowadays literature on the CG is that corporate profitability is positively associated with the concentration of ownership. Although the concentration of ownership of large shareholders is considered a mechanism for reducing conflict between shareholders and management, it can be a potential source of conflict of interest between large and small shareholders (La Porta, Lopez-deSilanes, Shleifer and Vishny, 2000).

However, empirical evidence about the relationship between concentrated ownership and financial performance of the companies is unclear and unconvincing in different markets within the same market. In transition economies, characterized by underdeveloped capital markets, to understand the effects of ownership structure, the authors start off from the general assumption that the private property leads to improved performance (Frydman, Gray, Hessel and Rapaczynski, 1999).

In the case of Kosovo, the ownership structure of PE of Kosovo is focused on only one shareholder (the government, as $100 \%$ shareholder), which does not imply the existence of the market for corporate control, and therefore reflects the composition of $\mathrm{BD}$ which has a key role in CG of PE. PE in Kosovo continues to have low performance and delay in providing quality services to citizens. PE have been consistently followed by a series of negative phenomena such as mismanagement, corruption, weak and non-professional boards, political interference, non-transparency, having too many staffers and militants of rulers, budget deficit, etc. This made PE not attractive to investors. Kosovo's government has madeit clear to the introduction of the private sector in these sectors. Privatization of state-owned shares in certain PE has moved very slowly, which at the current level of their management and financial sustainability means relatively low quality of CG of PE in Kosovo. Moreover, it is rightly to assert that the best solution for $\mathrm{PE}$ in Kosovo is privatization and most effective way to improve the performance of these PE.

Pristina International Airport (PIA) was granted on concession for 20 years by the Government of Kosovo for the first time in 2010. Also the government of Kosovo in June 2012 awarded the company Limak and Calik to privatize the Distribution and Electricity Supply (KEDS) priced 26.3 million, whose ownership was transferred in May 2013. This process was not opposed with regard to transparency from the opposition, non-governmental organizations and the public at large.

The government failed several times in succession in the sale of $75 \%$ PTK shares stake and in enhancing new energy capacities. Research findings show that BD are politically influenced by the shareholders (the government) and exert a positive and significant effect on employment, while they negatively affect the performance of the PE. However, the practice confirms the existence of direct political interests that undermine the efforts of the Board of PE to achieve these objectives. 


\section{Relations with interest groups}

PE should recognize the importance of relations with interest groups, for the sound and financially stable companies. State ownership policy should fully recognize the PE responsibilities towards stakeholders and lay down demands that they report on relations with other stakeholders. It is necessary for PE to continue active cooperation with all stakeholders in order to create jobs, prosperity and the preservation of financial stability of the company.

\section{Reports based on Law on PE}

The existence of PE website and quality online reporting greatly facilitates the access to existing and potential investors with relevant and timely information for companies. The law obliges all PE to submit every 3 months certain reports. Based on research, from the total number of $17 \mathrm{PE}$ analysed, only 13 of them possess internet website. It is also noted that the maintenance of existing web-pages is insufficient. Results of the survey show that there are few relevant information to current and potential shareholders and other interested parties.

From 17 PE that were analysed, only 9 have published: mission, vision, annual business plan, organizational chart, financial statements and independent auditors' report, etc., for 2010-2013 periods on their website. PMUPE has published annual reports for the $17 \mathrm{PE}$ and the external auditor's report on its website for the year 20102013 for all PE but this site is poorly maintained and not all the reports can be opened, whereas in 2014 there is no reporting conducted, although the law requires 75 days after the end of the calendar year to report to the Assembly. The above delays in annual reports and insufficient information on the websites of companies and their non maintenance lowers level of public confidence, investors, and the quality of the CG.

\section{Conclusions}

Among the achievements of the Kosovo government worth of highlighting is the provision of legal and institutional framework, which largely meet the standards and principles of the OECD and other international experiences, but their implementation in practice remains a challenge. Weak enforcement of legal provisions and nonqualitative supervision of PE activity by the shareholder shows that there are delays in the delivery of quality services to citizens. It should reflect the positive effects of greater transparency and greater public access to information on the operation of the PE. As in other countries, in Kosovo effective governance of PE is a difficult and complex matter. Research analysis shows that the government as a shareholder is not that much interested to improve the performance of PE and political interference are highly influencing the appointment of directors and management. PE are responsible for the procurement of goods and services that are in fact the most corrupted practices in terms of tenders abuses by certain political groups and the governors who, beyond a shadow of a doubt, are a cancer to the health of PE in Kosovo. Political appointments of unqualified and inexperienced people ate the boards and management, but supported by certain political groups, weaken the quality of the CG. CG in PE of Kosovo has made progress over time but more efforts should be done and focus on enhancing the 
quality of the board of directors, whose members should be professionally trained, have better information about the company's operations, and should have greater independence and not be subject to political influence, because strengthening the role of the board of directors would allow high efficiency and win the company's reputation. These results reflect that the concept of CG in Kosovo is in the beginning stage. It is evolving and not well understood or applied. Research results show the need for raising awareness about the importance of the $\mathrm{CG}$ and its implementation.

\section{References}

1. Baker, G., Jensen, M., Murphy K. (1988): Compensation and Incentives: Practice vs. Theory, Journal of Finance, 43: 593-616.

2. Becht, M., Bolton, P., Roell, A. (2005): Corporate Governance and Control, European Corporate Governance Institute, Finance Working Papers No. 02/2002, updated August 2005.

3. Cadbury, A. (1992): Committee on Financial Aspects of Corporate Governance (the UK Cadbury Code), London.

4. Code of Ethics and CG (June 2010): amended and revised (July 2014).

5. European Bank for Reconstruction and Development (EBRD), 2013: Dokument i Bankës Europiane për Rindërtim dhe Zhvillim (BERZH), Strategji për Kosovën, Maj 2013.

6. Frydman, R., Gray, C., Hessel, M., Rapaczynski, A. (1999): When does privatization work? The impact of private ownership on corporate performance in the transition economies. The Quarterly Journal of Economics, Vol. 114, No. 4. pp. 1153-1191.

7. Global Corporate governance Forum IFC (2012): Corporate Governance Codes and Standards practice Group Meeting, May 17-18, 2012.

8. Jensen, M., Murphy, K., (1990): Performance Pay and Top Management Incentives, Journal of Political Economy, 98 (August):225-64.

9. La Porta, R., Lopez-de-Silanes, F., Shleifer, A., Vishny, R. (2000): Investor protection and corporate governance. Journal of Financial Economics, 58(1\&2), 3-27.

10. Law No. 03/L-087, On Publicly Enterprises (2008), as amended and supplemented on Law No. 04/L-111, (2012).

11. Law No. 02/L-123, On Business Organizations (2007), as amended and supplemented on Law No. 04/L-006, (2011).

12. McKinsey \& Company (2002): Global Investor Opinion Survey: Key Findings, London.

13. Ministry of Economic Development, Policy and Monitoring Unit of the PE (PMUPE), Reporting Performance PE for years $2010 \div 2012$.

14. OECD, (1999): Principles of Corporate Governance, Paris.

15. OECD, (2003): White Paper on Corporate Governance in South East Europe, Paris.

16. OECD, (2004): OECD Principles of Corporate Governance, Organization for Economic Cooperation and Development, Paris.

17. OECD, (2005): Guidelines on the Corporate Governance of State-Owned Enterprises, Paris.

18. Office of the Auditor General (OAG, 2014), The audit report for the BD of PE compensation for the years $2009 \div 2012$. 


\title{
1.6. THE LEAN EFFECT OF THE 5S AND STANDARD WORK DEVELOPMENT IN DIFFERENT AUTOMATED MACHINE PROCESS STANDARDIZATION
}

\begin{abstract}
Summary
The Standardized Work (SW) means to create wasteless process as much as possible and create the document of the current best practice to maintain the developed status. SW is the baseline for KAIZEN. As the standard is improved, the new standard becomes the baseline for further improvements, and so on. Improving standardized work is a never-ending process. In this

Our research shows how can be combined the $5 \mathrm{~S}$ and standard work. By the parallel implementation of the $5 \mathrm{~S}$ and Standard Work, the economic benefits are coming earlier.
\end{abstract}

Keywords: lean, standard work, 5S

\section{The Lean Concept origin}

All business-oriented company's primary goal is to gain profit even if it is a production or service provider company. Either the micro or multinational companies act in a characteristically and locally specialized but continuously changing business environment. Despite that, there is an open market by globalization for everyone, the immediate local economic, political, social, geographical, energetic, environmental factors strongly influence and define the market share. In one hand, the profitability of a company lays down the ability of effectiveness of the company's internal business processes and the adaptation capability to the external business environment, during the companies different lifecycle stages (Illés et al., 2015). On the other hand, this means that how much value is created during the transformation process and how much non-value added activity and waste is hidden in the value stream of the business. Waste means all activities that will not add value during the transformation process and service. The value added and waste ratio strongly define the income flow and quality as well as the costs. The costs directly decrease the profit. (Illés and Szuda, 2015; Al-zaidi and Dunay, 2015)

This thinking has roots in Arsenal of Venice in the 1450s at starting of mass production. This ship factory was capable of producing one fully equipped merchant or military vessel per day, whereas production of similar sized and featured ships elsewhere in Europe took several months. At the Arsenal, the modern concepts of standardized parts, assembly-line production, specialized work groups, and vertical integration were anticipated. The modern era's mass production systems started to develop in 1890s. In 1905, Henry Ford together with his chief construction and production inventor József Galamb designed the mobile assembly line for the Ford TModel. In 1937 in Japan, the Toyota Motor Corporation was founded by Kiichiro Toyoda, son of Sakichi Toyoda. Toyota adopted a new business paradigm for the 
profit realization and it was led by a strong process thinking in the manufacturing by entering in deep details, managing by facts on the Gemba. The basic principle was and it is the same in our time - is eliminating the 3MU, i.e. Mura (unevenness), Muri (overburden) and Muda (waste). (Shook and Marchwinski, 2014)

The concept and methodology was always perfected by Toyoda and by time it has been developed into an effective business system called Toyota Production System (TPS). The backbone of the business system stays in systematic method for the elimination of waste. Everything that does not add value for product or service from the perspective of the customer shall be considered as waste. All the things what are done by the human beings or by machines during the whole worktime and everything becomes the part of the so called value stream, or someone is doing value added work, or moving. In the business environment, there are many ways to increase productivity. In the Lean production there are two main approaches: the continuous improvement known as kaizen and innovation (buying new technology) or combination of these. The one of the most effective business philosophy is known as the Toyota Production System-TPS- published also in Toyota Way. The TPS is responsible for the production or service to ensure flow of quality and Kaizen (Imai, 2012).

\section{The Lean principles}

The key element of the Lean production is to be able to identify two things in your business activity area and business processes, namely the value itself, and to make difference between value and waste. Value is that for which the customer is willing to pay and all other things in the sense of the business result are to be considered as waste. Seven main waste (it is called 'Muda' in Japanese language) are differentiated:

1. Muda of Over-Production;

2. Muda of Waiting;

3. Muda of Transportation;

4. Muda in Processing (i.e. over-processing);

5. Muda in Inventory;

6. Muda of Motion, Movement;

7. Muda of Correction (scrap, defect).

In any corporations and business activities these wastes are always presented in some ratio. The best ratios in the world are connected to production companies with Toyota production where in the value stream during the total lead time the VA (value added) is $5 \%$ against the NVA (non-value added) activities what is 95\%. In the Japanese business sense this is a potential or possibility which may solve the problems gaining profit by sparing costs.

\section{The meaning of Lean manufacturing in practice}

The Lean manufacturing means to make effort day by day to recognize the value and the waste in processes and to apply in and in practice the five basic rules of the Lean production. (Womack and Jones, 2009)

1. Specifying value from the standpoint of the end customer by product family. Identifying the value for the customer. 
2. Identifying all the steps in the value stream for each product family, eliminating whenever possible those steps that do not create value.

3. Making the value-creation steps in tight sequence so the product will flow smoothly toward the customer

4. As flow is introduced, let customers pull value from the next upstream activity.

5. As value is specified, value streams are identified, wasted steps are removed, and flow and pull are introduced, begin the process again and continue it until a state of perfection is reached in which perfect value is created with no waste.

The total value stream means the observation of the business processes on different scale from the customer order until the payment of the service or the product. In order to find the problems which may stop the flow or decrease the quality the processes will need an investigation on different levels. The macro level is 10,000 foot view so a very broad overview of the business processes or even down to the micro level. The micro level means to analyse the work processes in the given work environment considered by the rules of $5 \mathrm{~S}$. After eliminating the Muda the more developed work process is called standardized work (SW) and standards are to be created in order to maintain the work operations time and quality.

\section{The problem solving by $O P P D C A$ and $5 S$}

The meaning of the problem is depending on the user community. The definition of the problem by the (Webster dictionary) is: a question raised for inquiry, consideration, or solution. In the Lean concept problem is any difference between the actual status and goal. To search and solve problems of the Muda is needed a basic project tool helping the team to act effectively. It was used the Deming PDCA cycle and the OPPDCA (OPPDCA stands for: Observation, Pre-check, Plan, Do, Check, Act). This is an extended methodology of the PDCA when is intensive Kaizen action to reduce the risk and increase result during the completion of the $5 \mathrm{~S}$ and $\mathrm{SW}$ development.

The 5S means the structured methodology to create and maintain the high quality workplace in 5 steps. 1S (Seiri) means to eliminate the unnecessary items 4M+ (Man, machine, Material, Method) and information. The 2S (Seiton) arrange everything in the right order for the process, 3S (Seisou) Clean and check everything, 4S (Seiketsu) set the most right rules, $5 \mathrm{~S}$ (Shitsuke) means to practice the $1 \mathrm{~S}$ to $4 \mathrm{~S}$ cycle like mindset. In the TPS system gives the stability and foundation for Kaizen is given by $5 \mathrm{~S}$ followed by the SW (Standardized Work) development (Vajna and Tangl, 2015).

\section{The elements of the standardized work and the Standard Work development}

Standardized Work has three main elements:

- Takt time - the quantity rate - at which products must be made in a process to meet customer demand

- Standard work sequence - precise balanced work sequence that operator performs within the takt time

- Standard WIP (SWIP) .e. Standard work in process or SWIS i.e. standard work in sequence is the inventory level of all units in the process (including machine) for smooth operation (Vajna and Tangl, 2013) 


\section{The current statement analysis}

The Standardized work development was five days. One day training followed by four days on shop-floor (Gemba in Japanese). The management decided to increase productivity of the manual operations of three operators at three different the low pressure system moulding machines. The PDCA cycle of the development process included the diagnosis and the treatment. After half-day observation and understanding the work elements and technology the standardized work study was continued with the deep numerical /statistical data collection. The independent data collection was made continuously by six persons (two in pair) trained and led by the Lean Kaizen expert on the shop-floor during the whole worktime. There were made minimum 240-250 cycle time measurement for each operator (Figure 1) for one batch processing processed by one operator on three different type machines and products.

Figure 1: Cycle measurement.

Cycle time variability MURA in case of 241 measurements at operator 1

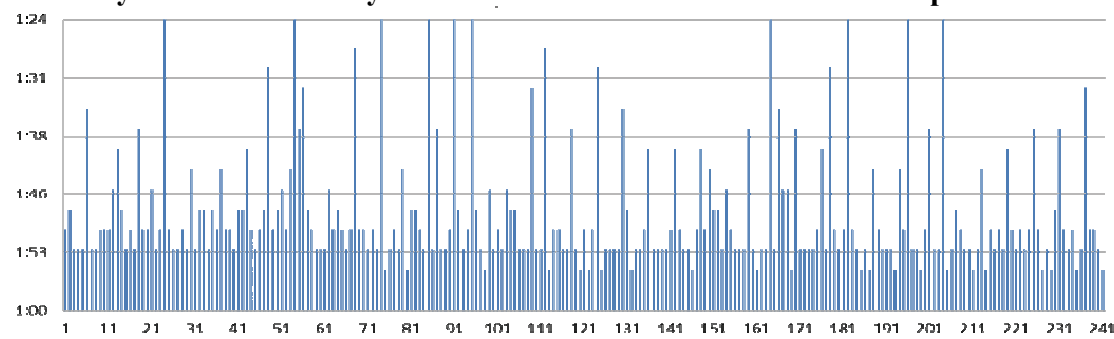

Source: own measurement

On next day the operators were interchanged between the machines, but during the whole workshop the operators were the same physical persons (Figure 2). The data collection included the machine operation and stability analysis. The data collection was run for 2.5 days. Out of some cycle time errors the process revealed that not the machine, were the key success point of the development but revealed some hidden improvement points, too.

Figure 2: Machine Cycle time on operator 1 and operator 2

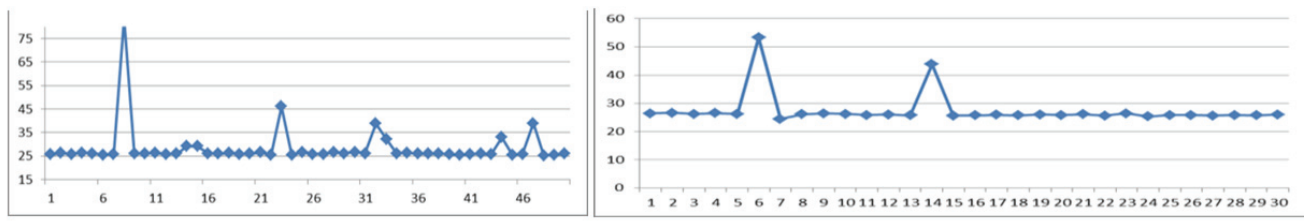

Source: own calculation

For data collection the standard for work time collection of data sheets, stopwatch and continuous video recording were used from three different axes to see both hands in operation, the work piece/tools, the machine operations and wastes during the processing. It were counted all inputs and outputs manually and cross-checked. The scraps were also registered. The workplace was also evaluated with $5 \mathrm{~S}$ point of view. The implementation phase took only 1,5 days including checking and corrective actions. The loss times is visualised in Figure 3. 
Figure 3: The loss times and the high inoperability ratio due to lack of SW during small batch processing

\begin{tabular}{|c|c|c|c|c|c|}
\hline son & Op1 LT1: 23:44. & & Op 1 LT5: 21:47 & & Op 1 LT2: 14:30 \\
\hline 0.23 .02 & & $0.21: 53$ & & $0: 17: 17$ & \\
\hline 0.2010 & $0: 10: 34$ & $\begin{array}{l}0.21: 30 \\
0: 21: 10\end{array}$ & & $0: 14: 24$ & nas:ie \\
\hline $\begin{array}{l}0: 17: 17 \\
0: 14: 24\end{array}$ & & $0.21: 01$ & $0.01: 11$ & 0:11:31 & $0.05: 18$ \\
\hline a:11:31 & & 0.20 .44 & & $0.08: 38$ & \\
\hline 0.08 .38 & $0.13: 10$ & $0.20: 27$ & & $0.05: 40$ & $0.09: 12$ \\
\hline $0.08: 40$ & & $0.20: 10$ & $0: 20: 30$ & 0.02 .53 & \\
\hline 000000 & & $0: 19.52$ & & 0.00 .00 & \\
\hline
\end{tabular}

Source: own calculation

\section{The process of creating standardized work}

After data collection, all data were visualized and analysed in graphs, pie and line charts, and was performed statistical measurements. The research on low pressure injection moulding machinery The general process of moulding product: 1 . raw material stock handling, 2. raw material transportation, 3. mixing raw materials 4. heating up, 5 . transportation to moulding machines, 6. the injection moulding by machine (VA) 7 . optical quality check by operator, 8. manual postproduction processes, 9. batch creation. The processes 6.,7.,8.,9 were examined in depth. In step 6, one moulding process resulted 4 to 6 pcs. of product depending on the moulding form. Each pieces were processed one by one to cut the roughness by the operator. The processing also resulted not only time waste but also quality problems. Produced good quality in one shift was 1892 with 916 scrap. The reusable raw material quantity and quality was not measured and considered at all thinking that after reheating and reprocessing will result good product, but not to after the right first. Operation 6 was the only one value added (VA) activity in all other 41 motion/transport, check and correction is waste. There were 11 different WIP locations with big quantity (total 89 pcs) of materials and always variable. After development the WIP was reduced to 5 locations (Figure 3.) with single piece (in 1. machine inside - transportation $\rightarrow 2$. machine outside, 3 . in operator hands, 4. packing box, 5. place for quality sample after each $500 \mathrm{pcs}$ ).

Figure 3: The WIP before and after improvement

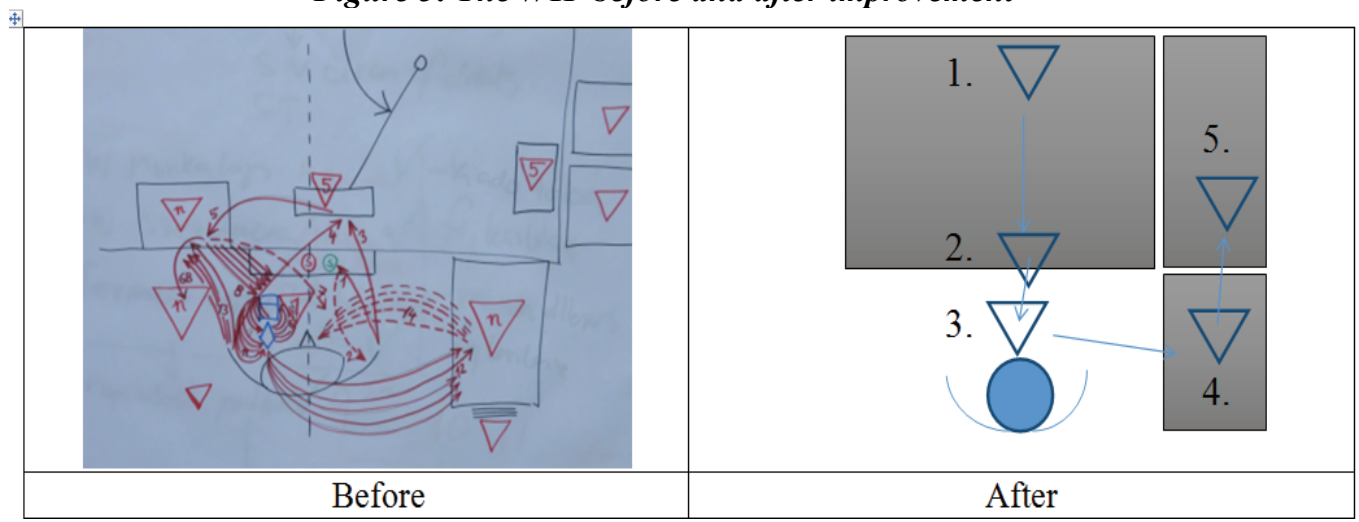

The comparison of the results of the $5 \mathrm{~S}$ and SW improvement in the before and after stage of development is in the Table 1. 
Table 1: Comparison of the results of the $5 S$ and $S W$ improvement in the before and after stage of development

\begin{tabular}{|l|l|}
\hline \multicolumn{1}{|c|}{ Before } & \multicolumn{1}{c|}{ After } \\
\hline Processes VA/41 NVA 0,00 & 1VA/ 8 NVA \\
\hline $\begin{array}{l}\text { Long and variable way of processing, no } \\
\text { visual standards and obstacles in work area. }\end{array}$ & $\begin{array}{l}\text { Direct POU to POU movements in small batch } \\
\text { check and processing in once. Stable manual } \\
\text { support and work sequence }\end{array}$ \\
\hline Not adequate and quality hand tools & High quality prechecked tools. \\
\hline 1892 psc. good with 916 scrap, (48\% scrap) & $\begin{array}{l}\text { Output: 2905 psc good+1313 better products }= \\
\text { total of 4218 pcs and 132 pcs scrap only }\end{array}$ \\
\hline Rework time and capacity loss & No cost of opening new shift, bo time delay \\
\hline Demotivated and nervous employees & $\begin{array}{l}\text { Motivated operator that without stess and effort } \\
\text { has better performance }\end{array}$ \\
\hline $\begin{array}{l}\text { From 2:05 operation hours 30 minutes total } \\
\text { lost time from forced stop of the machine }\end{array}$ & Continuos machine operation \\
\hline
\end{tabular}

Source: own calculation

The visualization of the time efficiency / and MURA of the three different operators work during the process observation before creating the SW. By selecting the best work sequences from each operator and combining in the right sequence resulted the waste elimination and improvement in productivity.

Figure 4: The visualization of the process efficiency in time of the three operators $(A, B, C)$ of during $S W$ observation
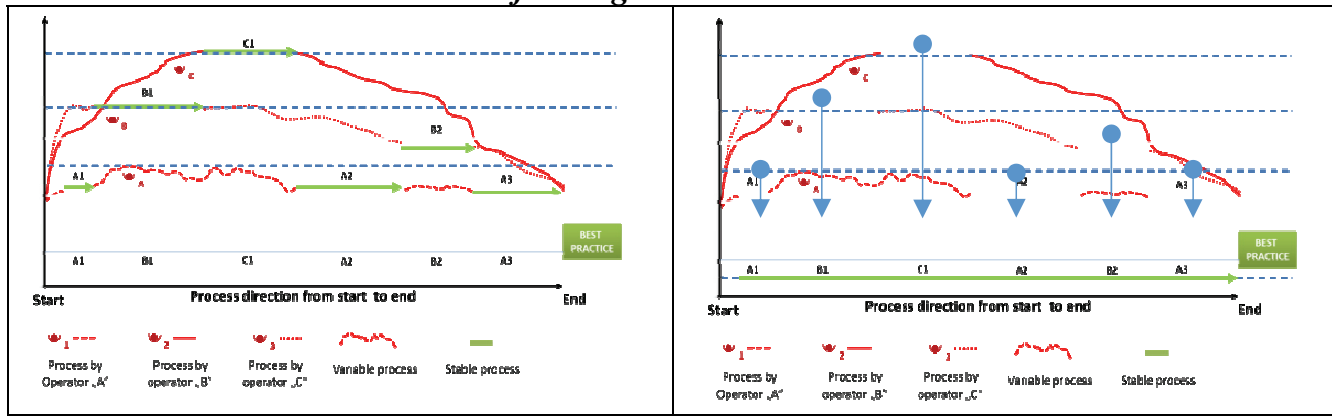

Source: own

The Figure 4 shows the visualization of the process efficiency in time $(\mathrm{x}, \mathrm{y})$ of the three different operators (A, B, C) of during the standard work observation. Creating the SW was performed by selecting the best operation elements from each operator work and combining into a new better practice gave a much better result than copying the best operator performance sequences. Later this analysis method was used to all kind of analysis of manual work such is Changeovers turning into quick changeover SMED (single minute exchange of die) process.

\section{Conclusions and benefits}

Standard work is known mostly to develop the human aspect of the work effectiveness improvement. In the Japanese thinking and acting the right way is to consider all the 
elements of the process because everything is related in the man-machine complex and environment. One data is true only in the moment of the analysis. During the development all possible parameters were registered and analysed. To get the best results it was necessary to use scientific methods. To improve empirically and observe only the best operator should not gave such results. The productivity of the "best one" process should limit the boundaries. The best performer does not mean the best opportunity. Age, sex, work-experience seems to have no significant effect on output. Even in the worst case of the analysis the productivity was raised to $222 \%$. Annually this gave extra 306.000 pcs. of product per product type for one operator.

$5 \mathrm{~S}$ and SW together are powerful Lean tools. Without implementing $5 \mathrm{~S}$ in these workplaces itself the analysis should not give such results. All unnecessary things were removed from the operator's range, the necessary tools were procured, the chair changed to adjustable chair for each operator. The surface of work area was improved by making more safe and ergonomic. The mechanical arm of machine was redesigned by operators and technicians for smoother operation that not dropped the WIP.

The work was standardized and was set new work standards on the shop floor:

- Operation balance chart

- Production capacity sheet and board

- Standard operation work chart

- Standard Combination Work Chart

- 5S method and clear visual standards were set

- Standard work Tools and cleaning tools were set up with a 2" rule availability

- All three operators were trained and could perform with 5\% variability all processes.

Besides the financial benefits the $5 \mathrm{~S}$ and SW improvement had more positive outputs:

1. Consistency (reduction of variation) among staff members performing the work balanced and in same way. Induction of Training development programs.

2. Reduction or elimination of errors and human mistakes (causes of defects)

3. Work process stability, reduced defects and waste in process

4. Increased employee safety (no even minor injuries)

5. The order can be fulfilled without extra shift

6. Operation with less cost on higher productivity

7. Employee involvement and empowerment to make changes based scientifically

8. Improved productivity without added stress in workplace

9. Encourages flexibility and creativity between the operators

10. Improved, and much higher quality

11. Improved cost management as wastes are removed,

12. Availability of a great tool for staff training

13. Visual management--managers and supervisors can see when processes are not operating normally.

14. Frees managers and leaders to focus on strategic objectives

15. Makes improvement easier and faster

16. Makes results predictable and measurable

The research shows clearly: there is not only one way to improve productivity using standard work. The empirical development hides costs and lack's the productivity by 
blinding the management from the real opportunities. The $5 \mathrm{~S}$ together with $\mathrm{SW}$ development has much stronger effect in Kaikaku way (intensive short time improvements) involving directly the stuff in cross-functional team. The standardization techniques application must be chosen by the local business environment and implemented immediately and re measured. The SW has to the QCD indicators direct effect. Setting up new work methods cost are six times less than in the empirical way. The results are indisputable. The audits can be performed much effectively and redesigning a process lead-time is shortened. The improvement ideas are given much wisely focusing on QCD elements. Monitoring the performance during the shift and reporting gives more accurate data and the visual control helps everyone in decision taking. Ensure the necessary measures are taken alerts support functions, by developing effective real training materials and defines performance of the improvement possibilities of human limits. Daily operation of SW ensure that standard less variable work gives much more stable output. The Combination of the existing scientific results can lead to better results. Where 5S and SW was extended the ROI was $50 \%$ higher. The problem solving can be founded and operated in a company with implementing easy to understand visual methods from operators to top management with common understanding towards the customer satisfaction.

\section{References}

1. Illés B. Cs., Hurta H. and Dunay A. (2015): Efficiency and Profitability Along the Lifecycle Stages of Small Enterprises. International Journal of Management and Enterprise Development, 14:(1) pp. 56-69. dx.doi.org/10.1504/ijmed.2015.069311

2. Illés, B. Cs., Szuda, Cs. (2015): Quality in manufacturing - is a management tool? In: Dunay, A. (ed.) Proceedings of the 5th International Conference on Management 2015. Management, leadership and strategy for SMEs' competitiveness. Szent István University Publishing House, Gödöllő, pp. 126-129. http://dx.doi.org/10.17626/dBEM.ICoM.P00.2015.p023

3. Imai, M. (2012): Gemba Kaizen: A Commonsense Approach to a Continuous Improvement Strategy, McGrow Hill, p.14.

4. Shook, J., Marchwinski, C. (2014): Lean Lexicon, 5th Ed. Lean Enterprise Institute, Inc. p.54.

5. Stoller, J. (2015): The lean CEO, McGraw Hill p. 352.

6. Vajna, I., Tangl, A. (2013): The Importance of Standard Work Processes in Increasing Productivity and its Financial Impacts, People, Knowledge and Modern Technologies in the Management of Contemporary Organizations - Theoretical and Practical Approaches, Szent István Egyetemi Kiadó Gödöllö, p. 204.

7. Vajna, I., Tangl, A. (2015): The comparison of the different ways of the introduction of the 5S method in practice and the effect on the productivity and the accounting information, In: Dunay, A. (ed.) Proceedings of the 5th International Conference on Management: Management, leadership and strategy for SMEs' competitiveness. Szent István University Publishing House, Gödöllö, pp. 119-125. http://dx.doi.org/10.17626/dBEM.ICoM.P00.2015.p022

8. Womack, J., Jones, D.T. (2009): Lean szemlélet, HVG Könyvek, p.71.

9. Al-zaidi, W. A. H., Dunay A. (2016): The role of re-use in reducing industrial costs. A case study in the general company for electrical industries, in Diyala, Iraq. Hungarian Agricultural Engineering (29) pp. 36-39. http://dx.doi.org/10.17676/HAE.2016.29.36 


\section{CHAPTER 2}

\section{Management tools in modern organizations}





\title{
2.1. RELATIONSHIP BETWEEN ORGANISATIONAL JUSTICE AND ORGANISATIONAL CITIZENSHIP BEHAVIOUR: EXAMINING THE MEDIATING ROLE OF JOB SATISFACTION
}

\begin{abstract}
Summary
The relationship between organizational justice perceptions, job satisfaction, and Organizational citizenship behaviour (OCB) from the responses of 267 employees in the manufacturing sector showed that interpersonal justice positively influenced all dimensions of OCB. Among the justice factors, informational justice had a greater influence on job satisfaction than distributive justice, procedural justice, or interpersonal justice. The effect of job satisfaction on OCB was most significant on civic virtue, followed by courtesy, altruism, conscientiousness, and sportsmanship. The mediation analysis showed that job satisfaction fully mediated the relationship between organizational justice and OCB. Therefore, job satisfaction is a stronger predictor of citizenship behaviours than justice perceptions.
\end{abstract}

Keywords: job satisfaction, manufacturing sector, organizational citizenship behaviour, organizational justice

\section{Introduction}

Globalization and the advancement of technology has triggered much interest in organizational researchers to study the discretionary behaviour of employees at the workplace. As baby boomers retire, the core workforce in most organizations are dominated by Generation $\mathrm{X}$ and Generation $\mathrm{Y}$, who generally are less likely to remain in an organization for their entire working life. Being more techno-savvy, these workforce have access to information that provides career advancement opportunities which increase the incidence of leaving. Therefore, research on organizational citizenship behaviour (OCB) has attracted much attention as discretionary and extrarole behaviours of organizational citizens are instrumental for employee retention, job performance (Greenberg, 1988) and the survival of many organizations (Fassina et al., 2008). To understand what enhances OCB, various predictors of OCB have been examined, and among the most robust attitudinal predictors of OCB are employees 'perceptions of fairness (e.g. Colquitt et al., 2001; Hassan and Mohd Noor, 2008; Lo et al., 2006; Moorman, 1991; Organ and Konovsky, 1989; Podsakoff et al., 2000) and job satisfaction (e.g. Bateman and Organ, 1983; Smith et al., 1983; Williams and Anderson, 1991). As perceptions of fairness have been associated with job performance and $\mathrm{OCB}$, and $\mathrm{OCB}$ with job satisfaction, facilitating organisational justice becomes crucial.

Perceptions of organizational justice are widely recognized as an influential factor in employee attitudes at the workplace (Ramamoorthy and Flood, 2004). Employees who perceive unfairness is likely to limit their commitment to citizenship, whereas employees who perceive equity will contribute to the system through continued citizenship (Moorman, 1991; Podsakoff et al., 2000). Basically, organizational justice 
concerns three distinct, but related components of justice, namely, distributive, procedural, and interactional justice (Colquitt et al., 2001; Folger and Konovsky, 1989;). Tansky (1993) posits that procedural justice (perceived justice of the decisionmaking procedures) and fair treatment from managers and supervisors (interactional justice) seem to be the most important component to the relationship between justice and OCB. Others affirm that procedural justice accounts for a linear relationship with altruism (Farh et al., 1990) and altruism, courtesy, sportsmanship, and conscientiousness (Moorman, 1991).

Likewise, Robinson and Morrison (1995) argue that employees are less likely to engage in civic behaviour if they perceive that their employer had failed to fulfill employment obligations. Moorman (1991) emphasizes that interactional justice is the sole dimension of fairness to significantly relate to OCB while Giap et al. (2005) stress that the only significant correlation is that between altruism and interpersonal justice (sincerity and respectfulness of authority communication). Additionally, DeConinck (2010) asserts that in order to increase interactional justice, it is imperative for the supervisor to explain the procedure as well as to take questions from the employee regarding the process. In essence, employees are more likely to exhibit OCBs if they perceive that their organizations treated them fairly. But, do perceptions of organizational justice have similar relationships with OCB in a collectivist orientation culture like Malaysia?

In the Malaysian context, there is limited study on organizational justice and OCB, specifically with job satisfaction as a mediator. Furthermore, the limited literature available show that the findings of prior studies are rather ambiguous. Hassan and Mohd Noor (2008) assert that there is no significant relationship between organizational justice and extra-role behaviour in a high power distance and collectivistic society like Malaysia. Othman et al. (2005) establish that justice perceptions moderated the relationship between psychological contract violation and OCB. Despite being a high power distance country, where open expression of dissatisfaction is much constrained, interest in research on organizational justice in Malaysia has increased. Mohd Nasurdin and Soon (2011) examine the links between organizational justice (distributive justice and procedural justice) and job performance (task performance and contextual performance) while Hassan and Hashim (2011) explore the role of organizational justice in shaping teaching faculties' attitude (job satisfaction and commitment) and behavioural intention (turnover intention). However, limited studies in Malaysia have researched the relationship between organizational justice perceptions, job satisfaction and OCB in the manufacturing sector. Considering the job switching habits of the current Malaysian workforce, the question of how employee perceptions of organizational justice would be related to job satisfaction and OCB remains to be addressed. That question is the focus of this study.

\section{Relationship between organizational justice and organizational citizenship behaviour}

According to many studies, organizational justice seems to be a key determinant of OCB (Colquitt et al., 2001; Farh et al., 1990; Moorman, 1991; Organ and Konovsky, 1989; Organ and Ryan, 1995; Podsakoff et al., 2000). Meta-analytic data show positive 
correlations between both procedural and distributive justice and OCB (Colquitt et al., 2001). Fair procedures move people to support the needs of the group and augment OCB (Moorman and Blakely, 1995). Likewise, perceptions of interactional justice are instrumental in predicting OCB (Hassan and Jubari, 2010; Lazar et al., 2007; Moorman, 1991). Organ and Moorman (1993). Assert that procedural justice rather than distributive justice or job satisfaction explains more of the variance in OCB. Additionally, some studies suggest that perceptions of fairness may relate more strongly to altruism than to other OCB dimensions (Farh et al., 1990).

Skarlicki and Latham $(1996,1997)$ reiterate the importance of organizational justice and emphasize that training leaders in the principles of justice increases levels of perceived fairness and OCB. Tyler and Blader (2003) stress that employee sense of belonging in teams enhances perceptions of fairness and encourage citizenship behaviours'. As valued members of the team, employees realized the importance of OCB in enhancing their association in the team. Bateman and Organ (1983) argue that people seek to reciprocate those who benefit them. Once the employer initiates fair treatment of its employees, especially in relation to procedural and interactional justice, employees feel obligated to reciprocate (Blau, 1964; Homans, 1961) and employees reciprocate by exhibiting extra-role behaviours' (Robinson and Morrison, 1995). On the contrary, employees may adhere to negative reciprocity norms in restraining OCBs and only fulfill contractual obligations if they perceive unfair treatment. Hence Hypothesis 1: Employee perceptions of organizational justice positively affect the dimensions of OCB.

\section{Relationship between organizational justice and job satisfaction}

Some researchers argue that perceptions of justice and job satisfaction are indistinguishable (Organ et al., 2006), and conceptualize that justice perceptions strongly influence satisfaction at the workplace (e.g. Organ, 1988b). In contrast, Fassina et al. (2008) assert that justice and job satisfaction are likely distinguishable from each other as evaluation of justice and job satisfaction attitudes are qualitatively different. Nonetheless, numerous studies affirm that procedural fairness enhances job satisfaction (e.g. Colquitt, et al., 2001; Hendrix et al., 1999; Hooi, 2011; Igbaria and Greenhouse, 1992; Latham and Pinder, 2005). Likewise, Ismail et al. (2011) maintain that interactional justice significantly correlates with job satisfaction. Schaubroeck et al. (1994) contend that procedural justice is more strongly related than distributive justice to job satisfaction. In a meta-analytic study, Colquitt et al. (2001) affirm that all three justice dimensions were related to job satisfaction and organizational commitment. Accordingly, Hypothesis 2: Employee perceptions of organizational justice positively influence job satisfaction.

\section{Relationship between job satisfaction and organizational citizenship behaviour}

Prior empirical studies (e.g. Bateman and Organ, 1983; Organ and Konovsky, 1989; Organ and Ryan, 1995), and the conceptual rationale proposed by Organ (1988a, 1990) reveal a positive relationship between job satisfaction and OCB. Some research show that job satisfaction enhances extra-role behaviour (Organ, 1977) while others assert that the relationship between job satisfaction and $\mathrm{OCB}$ is one of social exchange 
(Bateman and Organ, 1983; Organ et al., 2006). Employees experiencing job satisfaction reciprocate through OCB and withdraw citizenship behaviours if they are dissatisfied. Murphy et al. (2002) found a correlation of between .40 and .67 in the job satisfaction-OCB relationship while Smith et al. (1983) established a correlation of .33 between job satisfaction and altruism and .29 between job satisfaction and compliance (conscientiousness). Thus, Hypothesis 3: Job satisfaction positively influences the dimensions of OCB.

\section{The role of job satisfaction in the justice-citizenship relationship}

Examining the mediating effect of job satisfaction in the justice-citizenship relationship, earlier studies maintain that organizational justice rather than job satisfaction is a more important predictor of OCB (Moorman, 1991; Organ, 1988a, 1990). Tansky (1993) claims that job satisfaction on its own relates positively to courtesy, civic virtue, altruism, and sportsmanship, but as a mediator in the justicecitizenship relationship, it is insignificant in predicting altruism and sportsmanship. This is probably attributed to the sizable correlations

between types of perceived fairness and job satisfaction (Fassina et al., 2008). However, studies have also indicated significant correlations between job satisfaction and OCB (e.g. Smith et al., 1983). Fassina et al. (2008) assert that job satisfaction may relate to OCB because it is distinctive from justice as an antecedent (Organ and Ryan, 1995); it mediates fairness-OCB relationships (e.g. Tansky, 1993); or it shares fairness as a common predictor (Farh et al., 1990). The inconclusiveness of the findings have hindered contributions to theory and research on $\mathrm{OCB}$, and hampered practical implications for managers (Fassina et al., 2008). Understanding if job satisfaction is a direct predictor of OCB or a mediator in the job satisfaction-OCB relationship, is therefore, imperative for advancement of theory development on OCB. Additionally, it would help guide practitioners to encourage OCB by either enhancing antecedents of job satisfaction or promoting favorable levels of perceived fairness. Fassina et al. (2008) further posit that the relationships among perceived fairness, job satisfaction, and OCB may be dependent on the types of justice and the dimensions of OCB. If this is indeed true, then managers would have an array of options to enhance OCB. Therefore, the relationships among perceived fairness, job satisfaction, and OCB need to be further explored. It is hypothesized that justice and job satisfaction are likely distinguishable from each other in their relationships to OCB. Hence,

Hypothesis 4: Job satisfaction mediates the relationship between organizational justice and OCB.

\section{Organizational justice and organizational citizenship behaviour in the Malaysian context}

Research on organization justice and OCB in Malaysia is slowly gaining momentum despite the collectivist and high power distance culture at the workplace. This is probably due to the evolution of new work ethics among the current generation of workforce. Gone were the days where loyalty and commitment to an organization was the norm. As such, organizations are embarking on various programs to instill OCB to retain talent workers. This has generated much interest among practitioners and 
academicians to research on antecedents of OCB to help enhance sustainability. In Western societies, it has been verified that organizational justice has a significant influence on OCB. But, research in non-western societies remains limited. A number of Malaysian scholars (e.g. Asgari et al., 2008; Hassan and Hashim, 2011; Hassan and Mohd Noor, 2008; Ishak and Alam, 2009; Khalid and Ali, 2005; Leow and Khong, 2009; Lo et al., 2006; Mohd Nasurdin and Soon, 2011, Othman et al., 2005) have examined the relationship between organizational justice and various organizational outcomes. Nonetheless, the outcomes are varied and the findings of similar studies are ambiguous.

Mohd Nasurdin and Soon (2011) examined the moderating role of age in the relationships between organizational justice (distributive justice and procedural justice) and job performance (task performance and contextual performance). The results gathered from a sample of 136 customer-contact employees within the telecommunications industry of Malaysia demonstrated that distributive justice had a significant and positive relationship with task performance while procedural justice was found to be significantly and positively related to contextual performance. Age, however, did not moderate the justice-performance relationships.

Hassan and Hashim (2011) analysed the role of organizational justice in shaping teaching faculties' attitude (job satisfaction and commitment) and behavioural intention (turnover intention). The findings from a sample of Malaysian nationals with tenure appointments and expatriates with contractual appointments drawn from four public universities in Malaysia revealed that except for job satisfaction, where Malaysians recorded significantly higher endorsement compared to expatriates, no significant difference was found between the two groups on perception of distributive, procedural, and interactional aspects of organizational justice, as well as organizational commitment and turnover intention. Interactional and distributive justice promoted expatriates' organizational commitment and/or intention to stay with the organization while procedural justice contributed to local employees' job satisfaction, organizational commitment, and turnover intentions. Another study by Hassan and Mohd Noor (2008) that examined the relationship between organizational justice and extra role behaviour showed no significant relationship between organizational justice components and extra role behaviour in the Malaysian context.

Leow and Khong (2009) studied the relationship and tested the interaction effects of organizational justice (distributive, procedural, and interactional) on organizational commitment among auditors serving in audit firms across Malaysia. The results showed that distributive, procedural and interactional perceptions of organizational justice positively influenced affective-normative commitment. Asgari et al. (2008) explored the relationship between transformational leadership behaviours, organizational justice and $\mathrm{OCB}$, and found a direct significant relationship between the variables. Further to this, Lo et al. (2006) investigated the role of equality of the leader-member exchange in promoting OCB and reported a significant relationship from a sample drawn from executives and managers in Malaysian manufacturing organizations. Othman et al. (2005) explored the relationship between psychological contract violation and $\mathrm{OCB}$, with justice perception as a moderator and reported partial support for the model. 


\section{Methodology and sample}

Using stratified random sampling, survey questionnaires were administered to fulltime management staff of a sample of 100 manufacturing companies selected from the 2,571 manufacturing companies listed in the Federation of Malaysian Manufacturers Directory. Questionnaires were distributed to ten management staff from each of the 100 companies. Overall 267 valid cases were used for the analysis. Of the 267 respondents, 56.6 percent are male and 43.4 percent are females. The majority of the respondents are aged between 25 and 40 years $(67.8 \%)$ and about two thirds $(66.3 \%)$ are married. More than half of the respondents have at least a Bachelor degree $(68.5 \%)$ and slightly more than a third are managerial staff (36.3\%). Half of the respondents are either engineers or executives (50.9\%). About half of the respondents $(48.3 \%)$ have been with their current organization for between three to ten years.

Primary data were collected from questionnaires written in English, which were sent by post to the selected companies. A cover letter and a postage-paid, return envelope for respondents to mail back the completed questionnaires were sent together with the questionnaire. The cover letter explained the purpose of the study, and emphasized the importance of responding to the questionnaire. Assurances of anonymity and confidentiality were also stated. Two weeks later, follow-up letters were mailed to non-respondents, stressing the value of the survey and the importance of their participation.

Items for all the constructs were measured using scales ranging from (1) strongly disagree to (5) strongly agree. Organizational justice was measured using 20 items taken from the scale developed Colquitt (2001). An example of a statement is "The procedures used to arrive at the (outcome) have been free of bias." The Cronbach alpha for each component was 0.888 for procedural justice, 0.866 for informational justice, 0.914 for distributive justice, and 0.868 for interpersonal justice. Job satisfaction was measured using five items from a scale developed by Brayfield and Rothe's (1951) and used by Price and Mueller (1986, $\alpha$ ranging from 0.78 to 0.99), Moorman (1991, $\alpha=0.86$ ) and Lambert et al. (2005, $\alpha=0.82$ ). The Cronbach alpha for this study was 0.865 . One of the items was "I am very satisfied with my job." OCB was measured using 24 items developed by Podsakoff et al. (1990) in which internal consistency reliabilities for the OCB scales ranged from 0.70 for civic virtue and 0.85 for altruism. The Cronbach alphas for the current study were 0.872 for courtesy, 0.871 for sportsmanship, 0.845 for altruism, 0.789 for civic virtue and 0.767 for conscientiousness. An example of an item was "I always help others who have heavy workloads." Eight questions tapped the demographic data of the respondents as well as some characteristics of the organizations.

After the removal of outliers, a factor analysis rotated with Varimax was conducted to examine the factor structure of the scales. With eigenvalues set at 1.00 , items with communalities more than 0.50 were retained. For justice measures, the items formed four factors representing procedural justice ( 7 items), informational justice (5 items), distributive justice (4 items) and interpersonal justice (4 items). For job satisfaction, only one factor was extracted, explaining 71.2 percent of the variance. One item was dropped due to low loading (JS5). For OCB variable, all five factors, namely courtesy 
(5 items), sportsmanship (5 items), altruism (5 items), civic virtue (4 items), and conscientiousness (4 items), were included to represent the construct. One item (Con1) was dropped due to low factor loading.

Correlation analysis was then conducted to describe the strength and direction of the linear relationship between the variables. Before analyzing the structural models, confirmatory factor analysis was conducted to test for convergent and discriminant validity of the constructs. Then, the final model was assessed using structural equation modeling with the AMOS 18 program to analyse its validity. To provide evidence of model fit, five fit indices have been identified for the study - Chi-Square $\left(\chi^{2}\right)$, Goodness-of-Fit Index (GFI), Tucker-Lewis Index (TLI), comparative fit index (CFI), and Root Mean Square Error of Approximation (RMSEA).

\section{Results}

\section{Measurement Model Analysis}

To assess the validity of the measure, all four justice factors were subjected to confirmatory factor analysis (CFA). The results of the first-order CFA indicated an acceptable fitting model with $\chi^{2}=382.388 ; \mathrm{p}<.001 ; \mathrm{GFI}=.877$; TLI $=.922$; CFI $=$ .932 ; and RMSEA $=.071$. All items that represented organizational justice were significantly loaded into their intended factors with standardized loadings of more than 0.50 . Theorganizational justice construct was then subjected to second-order CFA. The results revealed an acceptable fitting model with $\mathrm{y}^{2}=391.822 ; \mathrm{p}<.001 ; \mathrm{GFI}=.874$; $\mathrm{TLI}=.920 ; \mathrm{CFI}=.930 ;$ and RMSEA $=.072$. The standardized factor loadings for all the items were more than 0.50 and were significantly loaded into their intended factors, indicating convergent validity.

Results of the first-order CFA for OCB signified an acceptable fitting model with $\mathrm{y}^{2}=$ 499.025; $\mathrm{p}<.001 ; \mathrm{GFI}=.862 ; \mathrm{TLI}=.889 ; \mathrm{CFI}=.903 ;$ and RMSEA $=.069$. Standardized factor loadings for all items ranged from 0.599 to 0.836 , and, therefore, no items were dropped. Second-order confirmatory factor analysis carried out implied an acceptable fitting model with $\mathrm{y}^{2}=520.290 ; \mathrm{p}<.05$; GFI $=.855$; TLI $=.885$; CFI $=$ .898 ; and RMSEA $=.070$. Except for sportsmanship, standardized factor loadings for all the other items were above 0.50 , thus, confirming convergent validity.

The results of the goodness of fit indices indicated a well-fitting measurement model with $\mathrm{y}^{2}=150.565 ; \mathrm{p}<.05 ;$ GFI $=0.916$; TLI $=0.915 ; \mathrm{CFI}=0.932$; and RMSEA $=$ 0.073 . The standardized regression weights showed that except for sportsmanship, all the items were significantly loaded into the intended factor with standard loadings ranging from 0.591 to 0.841 . There was no empirical or theoretical justification to modify or re-specify any of the existing relationships in the hypothesized model. The CFA results confirmed that the theoretical measurement model was valid.

To measure discriminant validity, a Chi square difference test was performed on the nested models. Four models that were specified provided evidence for discriminant validity. First, the three-construct model was specified where all constructs organizational justice, job satisfaction and organizational citizenship behaviour were treated as independent variables. Then, a two-construct model in which job satisfaction and organizational citizenship behaviour were loaded into one construct 
was specified. Finally, only one latent construct model was specified in which all 13 measured items were indicators. Each model was tested and its fit compared to the fit of the original three-construct model. As shown in Table 2, the model fits were significantly different, suggesting that the 13 items represent three separate constructs. Significant Chi square differences $\left(\Delta \mathrm{y}^{2}>3.84\right.$ for $\left.\mathrm{df}=1\right)$ were observed in all cases, thus, providing evidence of discriminant validity. In essence, the model has fulfilled the criterion of distinctiveness. Having confirmed the adequacy of the measurement model, subsequent testing in the structural form was possible (Table 1).

Table 1: CFA Comparison of the Measurement Models

\begin{tabular}{|lllll|l|l|r|}
\hline Model & $\chi^{\mathbf{2}}$ & df & GFI & TLI & & CFI & RMSEA \\
\hline 3-Factor Model & 150.565 & 62 & 0.916 & 0.915 & & 0.932 & 0.073 \\
2-Factor Model & 339.764 & 64 & 0.806 & 0.743 & & 0.789 & 0.127 \\
1-Factor Model & 433.349 & 65 & 0.767 & 0.662 & & 0.718 & 0.146 \\
\hline
\end{tabular}

Source: own research

\section{Summary of findings on hypothesized relationships}

\section{Hypothesis 1: Organizational Justice - Organizational Citizenship Behaviour} Relationship

As summarized in Table 2, the hypothesis relating employee perceptions of organizational justice to the dimensions of OCB was partially supported.

Table 2: Organizational Justice - Organizational Citizenship Behaviour

\begin{tabular}{|c|c|c|c|c|}
\hline Factors/Items & Std. Loading & S.E. & C.R. & $\mathbf{P}$ \\
\hline Courtesy $\leftarrow$ Procedural justice & -0.128 & 0.051 & -1.988 & 0.047 \\
\hline Sportsmanship $\leftarrow$ Procedural justice & -0.136 & 0.076 & -2.007 & 0.045 \\
\hline Altruism $\leftarrow$ Procedural justice & 0.101 & 0.054 & 1.497 & 0.134 \\
\hline Civic virtue $\leftarrow$ Procedural justice & 0.170 & 0.060 & 2.382 & 0.017 \\
\hline Conscientiousness $\leftarrow$ Procedural justice & -0.069 & 0.058 & -1.036 & 0.300 \\
\hline Courtesy $\leftarrow$ Informational justice & 0.177 & 0.071 & 2.656 & 0.008 \\
\hline Sportsmanship $\leftarrow$ Informational justice & 0.082 & 0.103 & 1.208 & 0.227 \\
\hline Altruism $\leftarrow$ Informational justice & 0.072 & 0.074 & 1.067 & 0.286 \\
\hline Civic virtue $\leftarrow$ Informational justice & -0.022 & 0.080 & -0.311 & 0.756 \\
\hline Conscientiousness $\leftarrow$ Informational justice & 0.045 & 0.079 & 0.675 & 0.500 \\
\hline Courtesy $\leftarrow$ Distributive justice & -0.029 & 0.043 & -0.467 & 0.640 \\
\hline Sportsmanship $\leftarrow$ Distributive justice & -0.113 & 0.064 & -1.705 & 0.088 \\
\hline Altruism $\leftarrow$ Distributive justice & -0.046 & 0.046 & -0.699 & 0.485 \\
\hline Civic virtue $\leftarrow$ Distributive justice & 0.153 & 0.051 & 2.207 & $\mathbf{0 . 0 2 7}$ \\
\hline Conscientiousness $\leftarrow$ Distributive justice & -0.109 & 0.050 & -1.647 & 0.100 \\
\hline Courtesy $\leftarrow$ Interpersonal justice & 0.389 & 0.077 & 5.206 & $* * *$ \\
\hline Sportsmanship $\leftarrow$ Interpersonal justice & 0.191 & 0.102 & 2.750 & 0.006 \\
\hline Altruism $\leftarrow$ Interpersonal justice & 0.334 & 0.082 & 4.324 & $* * *$ \\
\hline Civic virtue $\leftarrow$ Interpersonal justice & 0.327 & 0.087 & 4.183 & $* * *$ \\
\hline Conscientiousness $\leftarrow$ Interpersonal justice & 0.480 & 0.097 & 5.608 & $* * *$ \\
\hline
\end{tabular}

Source: own research

Distributive justice positively influenced civic virtue whilst informational justice had a significant positive effect on courtesy. Procedural justice positively influenced civic virtue, but had a negative effect on courtesy and sportsmanship. Employee perceptions of interpersonal justice, however, positively influenced all dimensions of OCB. 
Comparatively, interpersonal justice had a more significant effect on conscientiousness than on courtesy, altruism, civic virtue, or sportsmanship. The influence of interpersonal justice on civic virtue was stronger than the effect of procedural justice or distributive justice. Similarly, interpersonal justice was more significant on courtesy as compared to informational justice or procedural justice. Comparatively, interpersonal justice had a stronger influence on sportsmanship than procedural justice. Hypothesis 2: Organizational Justice - Job Satisfaction Relationship

As evidenced in Table 3, employee perceptions of organizational justice positively influenced job satisfaction. All dimensions of organizational justice were significantly related to job satisfaction. Among the justice factors, informational justice had a greater influence on job satisfaction than distributive justice, procedural justice, or interpersonal justice. Therefore, the hypothesis that employee perceptions of organizational justice positively influence job satisfaction was supported.

Table 3: Results on Organizational Justice - Job Satisfaction Relationship

\begin{tabular}{|c|c|c|c|c|}
\hline Factors/Items & Std. Loading & S.E. & C.R. & $\mathbf{P}$ \\
\hline Job satisfaction $\leftarrow$ Procedural justice & 0.229 & 0.065 & 3.460 & **** \\
\hline$\leftarrow$ Informational justice & 0.334 & 0.096 & 4.652 & **** \\
\hline Job satisfaction $\leftarrow$ Distributive justice & 0.273 & 0.056 & 4.203 & *** \\
\hline Job satisfaction $\leftarrow$ Interpersonal justice & 0.159 & 0.084 & 2.438 & 0.015 \\
\hline
\end{tabular}

Source: own research

\section{Hypothesis 3: Job Satisfaction-Organizational Citizenship Behaviour Relationship}

As evidenced in Table 4, job satisfaction positively influenced all dimensions of OCB. Thus, the hypothesis that job satisfaction positively influence OCB was substantiated. The effect of job satisfaction on organizational citizenship behaviour was most significant on civic virtue, followed by courtesy, altruism, conscientiousness, and sportsmanship.

Table 4: Job Satisfactions - Organizational Citizenship Behaviour Relationship

\begin{tabular}{|c|c|c|c|c|}
\hline Factors/Items & Std. Loadin g & S.E. & C.R. & $\mathbf{P}$ \\
\hline Courtesy $\leftarrow$ Job Satisfaction & 0.428 & 0.052 & 5.883 & $* * *$ \\
\hline Sportsmanship $\leftarrow$ Job Satisfaction & 0.155 & 0.070 & 2.215 & 0.027 \\
\hline Altruism $\leftarrow$ Job Satisfaction & 0.404 & 0.057 & 5.269 & \\
\hline Civic virtue $\leftarrow$ Job Satisfaction & 0.511 & 0.064 & 6.376 & $* * *$ \\
\hline Conscientiousness $\leftarrow$ Job Satisfaction & 0.396 & 0.059 & 4.943 & \\
\hline
\end{tabular}

Source: own research

Hypothesis 4: The Role of Job Satisfaction in the Justice-Citizenship Relationship

The possibility that the relationship between organizational justice and OCB was mediated by job satisfaction was analysed using a two-step process. At Step 1, the significant relationships between the constructs were established. For this, the correlations between constructs in the CFA model shown in Table 5 was referred. From the analysis of the correlations that were obtained after standardization, the interconstruct correlations were significant for all the four constructs. As shown in Table 5, organizational justice was significantly related to OCB (0.409), ensuring that 
the direct, unmediated relationship was significant. Organizational justice was also significantly related to job satisfaction (0.721) establishing relationship with the potential mediator. Finally, OCB was significantly related to job satisfaction (0.426), thus, supporting relationships between the mediator and the outcome variable.

Table 5: Construct Correlation Matrix (Standardized)

\begin{tabular}{|c|c|c|c|}
\hline & OJ & JS & OCB \\
\hline $\mathrm{OJ}$ & 1.000 & 0.520 & 0.167 \\
\hline JS & $0.721 * * *$ & 1.000 & 0.181 \\
\hline $\mathrm{OCB}$ & $0.409 * * *$ & $0.426 * * *$ & 1.000 \\
\hline
\end{tabular}

Significance Level: $*=0.05, * *=0.01, * * *=0.001$

Note: Values below the diagonal are correlation estimates among constructs, diagonal elements are construct variances, and values above the diagonal are squared correlations

Source: own research

Step 2 was to estimate the mediated model and assess the level of mediation. First, was to estimate the original model, which did not estimate the direct effect from organizational justice to OCB. Then, a revised model, with the added direct path between organizational justice and OCB was estimated. This was to assess if adding the direct effect would substantially change the model fit. The results in Table 6 showed that the revised model with the direct relationship had a slight decrease in Chi square $\left(\Delta \chi^{2}=3.024, \mathrm{df}=1, \mathrm{p}=0.000\right)$ and an insignificant path estimate for the organizational justice-OCB relationship. These indicated that there was complete mediation, that is, the existence of a fully mediated model. In the revised model, the path estimate between organizational justice (OJ) and the mediator (JS) was still significant. Job satisfaction still had a significant relationship with OCB (JS -, OCB is significant) at 0.05 significant level $(\mathrm{p}=0.02)$. As OJ -, JS -, OCB contained paths that were all significant, and the OJ -, OCB path estimate was not significant, the model supported full mediation.

Table 6: Testing for Mediation in the Justice-Citizenship Model

\begin{tabular}{|c|c|c|}
\hline Model Element & Original Model & Revised Model \\
\hline \multicolumn{3}{|l|}{ Model Fit } \\
\hline Chi square $\left(\chi^{2)}\right.$ & 153.589 & 150.565 \\
\hline Degrees of freedom & 63 & 62 \\
\hline Probability & 0.000 & 0.000 \\
\hline CMINDF & 2.438 & 2.428 \\
\hline RMSEA & 0.074 & 0.073 \\
\hline CFI & 0.931 & 0.932 \\
\hline \multicolumn{3}{|c|}{ Standardized parameter estimates } \\
\hline $\mathrm{OJ}$ & $0.727 * * *$ & $0.721 * * *$ \\
\hline $\mathrm{OCB}$ & $0.438 * * *$ & $0.272 *$ \\
\hline $\mathrm{OJ}$ & 0.000 & 0.213 \\
\hline
\end{tabular}

Source: own research

The magnitude of the mediating effect was demonstrated by breaking down the total effects into direct and indirect effects. A breakdown of the effects of OJ -, OCB both in the original model (no direct effects from OJ -, OCB) and the revised model (direct effect added for OJ -, OCB) is shown in Table 7. In the original model, 
substantial indirect effects were present, thus, supporting the presence of mediating effect of job satisfaction. Although the indirect effects decreased, the insignificant direct effect made this a full mediation situation.

Table 7: Assessing Direct and Indirect Effects in a Mediated Model

\begin{tabular}{ccc} 
Effects of $\mathbf{O J} \rightarrow$ OCB & $\begin{array}{c}\text { Original ModelRevised Model } \\
\text { (Only Indirect Effects)(Indirect and Direct Effects) }\end{array}$ \\
\hline Total effects & 0.319 & 0.409 \\
Direct effects & 0.000 & 0.213 \\
Indirect effects & 0.319 & 0.196
\end{tabular}

Source: own research

The results of the mediated relationship implied that job satisfaction fully mediated the relationship between organizational justice and OCB. In short, organizational justice had no direct effect on OCB, but was fully mediated by job satisfaction. Therefore, the hypothesis that job satisfaction mediates the relationship between organizational justice and OCB was supported.

\section{Discussion}

\section{Organizational Justice-Organizational Citizenship Behaviour Relationship}

The findings of the study affirm that there is indeed a positive relationship between organizational justice and OCB, albeit partially. The findings establish the strong influence of interactional justice, in particular, interpersonal justice on OCB. To a certain extent, the findings support the assertion that interactional justice is the sole dimension of fairness to significantly relate to OCB (Lazar et al., 2007; Moorman, 1991). It is, therefore, crucial that organizations ensure politeness and treat employees with respect and dignity (Colquitt, 2001) as employees are more willing to accept unfavorable outcomes (Deutsch, 2000).

Besides, only interpersonal justice relates significantly to sportsmanship. In short, employee perceptions of justice do not necessary encourage avoidance of negative behaviours and complaints. Employees avoid negative behaviours only if superiors treat them with respect and dignity. Equity in the distribution of outcomes, objectivity in decision procedures, as well as adequate and honest explanations do not deter pessimistic behaviours. To avoid negative behaviours from escalating, it is desirable that organizations provide adequate training to enhance interpersonal skills of superiors. Enhanced interpersonal skills improve social relations among employees and mitigates misunderstanding and conflict at the workplace. Additionally, organizations benefit from activities that promote workplace harmony, as such activities foster team work and increase employee morale. Well established grievance procedures are also likely to improve sportsmanship at the workplace.

Furthermore, the results establish that interactional justice has a significant effect on courtesy, but only interpersonal justice significantly affects the other dimensions of OCB. The association between interpersonal justice and altruism supports the findings of Giap et al. (2005) which affirm that employees do extra-role work to help when their supervisors treat them respectfully; akin to Organ's (1997) contention that employees contain extra-role behaviour if employees perceive injustice. Similarly, 
Sweeney and McFarlin (1993) assert that employee perceptions of injustice restrict employee willingness to help other employees. Informational justice enhances employees' obligation of cooperation with others and has no significant effect on other dimensions of OCB.

However, the current findings dispute prior studies that contend that procedural justice is an important determinant of OCB (e.g. Farh et al., 1990; Moorman, 1991; Tansky, 1993). The current findings are also incongruent with the findings of Nadiri and Tanova (2010) where distributive justice is a stronger predictor of OCB and that distributive justice is associated with altruism and conscientiousness (Organ and Konovsky, 1989). It further differs from meta-analytic data that show positive correlations between both procedural and distributive justice and OCB (Colquitt et al., 2001; Giap et al., 2005). The current study suggests that perceived fairness of interpersonal treatment by managers as well as adequate and sincere communication of procedures and outcomes rather than fairness of a firm's procedures would have a stronger impact on OCB. Based on the current study, to enhance OCB, managers may have to make a concerted effort to treat employees with greater respect and dignity.

In the current study, employee perceptions of procedural justice relate negatively to courtesy and sportsmanship. Hence, the results challenge prior research that contend the linear relationship between procedural justice and altruism (Farh et al., 1990); and altruism, courtesy, sportsmanship, and conscientiousness (Moorman, 1991). The inverse correlation indicates that employees have a tendency of containing cooperative behaviours and complain more if procedures in decision outcomes are perceived as fair. In essence, perceptions of procedural justice reduce employees' efforts in avoiding negative behaviours and not complaining in case of problems. Concisely, employees are less tolerant and tend to behave negatively when equity in decision outcome procedures exists. Additionally, procedural justice hinders helpful behaviours, as well as discourages team working and collaboration among employees. Such attitudes may be detrimental to organizations, as collaboration and consultation are sometimes instrumental in mitigating the severity of a foreseen problem.

The current study ascertains that distributive, procedural, and interpersonal justice, positively influence civic virtue. This confirms the findings of Robinson and Morrison (1995) that employee perceptions of fairness enhance civic behaviour. This indicates that organizational justice is a key determinant of whether employees take an interest in company affairs and developments, and make efforts that promote self as well as organization interest. Succinctly, organizational justice is a strong determinant of whether employees respond appropriately and responsibly to the political life of the organization. Fair procedures encourage employees to stay up-to-date with important issues of the organization and support the needs of the group (Moorman and Blakely, 1995). Awareness of happenings at the workplace not only helps employees respond quickly, but also promotes citizenship behaviours in the long run.

\section{Organizational Justice-Job Satisfaction Relationship}

The results of the study show that all dimensions of organizational justice positively influence job satisfaction. Informational justice has the most significant influence 
followed by distributive justice, procedural justice, and interpersonal justice. This is consistent with prior research that affirm the relationship between fairness and job. Specifically, distributive justice and procedural justice are related to job satisfaction (Colquitt et al., 2001; Lee et al., 2000; Sweeney and McFarlin, 1993) while interactional justice has a significant impact on both job satisfaction (Azman, et al., 2011; Colquitt, et al., 2001) and performance (Fernandes and Awamleh, 2006). Employees' perception of equity in distribution enhances employees' satisfaction with supervisors (Schaubroeck et al., 1994; Sweeney and McFarlin, 1993). Others concur that only procedural fairness enhances job satisfaction (Igbaria and Greenhouse, 1992). Nonetheless, the current study disagrees with other studies that indicate that procedural justice rather than distributive justice is more strongly related to job satisfaction (Hassan, 2011; Schaubroeck et al., 1994). In this study, distributive justice rather than procedural justice is a stronger predictor of job satisfaction.

The importance of informational justice among justice factors in enhancing job satisfaction suggests that organizational decisions are not perceived as transparent and impartial. If honest and adequate explanations for decisions were given, employees are unlikely to perceive informational justice as the key determinant of job satisfaction. As job satisfaction affects other organizational phenomena that may have an impact on organizational performance, it is of paramount significance that organizations ensure transparency in decisions. Employees tend to lose confidence in ambiguous and partial decisions that affect their career and tenure with the organization. Being in a high power distance environment, employees are unlikely to openly confront disputable decisions. Enduring in silence would probably aggravate employee feelings of discontentment and may result in unfavourable outcomes for the organizations. Therefore, organizations would probably benefit from investing in developing decision makers to effectively articulate organizational decisions. Alternatively, organizations can involve employees in decision making as participation in decision-making is likely to instill OCB. Opportunity to participate in decision-making enhances employees' perceptions of procedural justice (Organ, 1988a; Thibaut and Walker, 1975) and promotes social exchange relationships between employees and their supervisors (Organ,1988a). Based on the norm of reciprocity (Gouldener, 1960), employees are likely to reciprocate by exhibiting OCB (Organ, 1988a).

In contrast to prior studies, distributive justice rather than procedural justice has a more significant influence on job satisfaction. This suggests that employees are concerned about fairness in decision outcomes. Organisations, therefore, have to reward accordingly (Homans, 1961), and ensure that outcomes adhere to expectations (Blau, 1964). Employees are less concern with the fairness in procedures in the decision making process. As long as outcomes are consistent with implicit norms for allocation (Colquitt, 2001), employees experience job satisfaction. The results imply that employees in general tend to be materialistic. Regardless of the procedures involved, equality of outcomes is of prime concern. A lack of perceived fairness in procedures probably will not affect job satisfaction if employees perceive that rewards are contingent on the level of contribution (Yilmaz and Tazdan, 2009). Hence, organizations may have to focus on improving distributive justice to enhance job satisfaction. 
Interpersonal justice has the least effect on job satisfaction. Employees do not seem concerned with respectful treatment from their superiors. As long as explanations in decision procedures are honest and adequate; outcomes received meet expectations; and procedures in decision outcomes are fair, employees experience job satisfaction. On one hand, the indifferent attitude of employees towards the authorities implies that the superior-subordinate relationship in the organizations may not be strong. On the other hand, high interpersonal justice probably exists at the workplace, and, therefore, the impact on job satisfaction is not strong. Organizations in the former situation may have to work on strengthening the bond between superior and subordinates, and improving employee interest in the organization to foster greater employee commitment. In the latter case, organizations would probably benefit from improving other justice factors to enhance work performance.

\section{Job satisfaction-organizational citizenship behaviour relationship}

The hypothesis that job satisfaction positively influences the dimensions of OCB is supported. In order of importance, job satisfaction, has a significant effect on civic virtue, courtesy, conscientiousness, altruism, and sportsmanship. The findings support empirical studies that show a significant association between job satisfaction and some dimensions of OCB (e.g. Bateman and Organ, 1983; Foote and Tang, 2008; Murphy et al., 2002; Tansky, 1993). Smith et al. (1983) affirm the influence of job satisfaction on altruism and conscientiousness while Williams and Anderson (1991) emphasize the effect on conscientiousness. The current study, on the contrary, shows a stronger correlation between job satisfaction and civic virtue, and courtesy. In essence, job satisfaction increases employee interest to participate appropriately and responsibly in company matters to enhance corporate governance. Proactive, responsible participation in the political life of the organization improves employee awareness of the affairs and developments at the workplace. Employees are likely to go for self-improvement to enhance competencies to stay up-to-date with important issues of the organization.

Results of the study further emphasize the importance of job satisfaction on courtesy. As courtesy concerns undertaking and carrying out the obligation of cooperation with others, increased job satisfaction would probably enhance team working, create a more disciplined and committed workforce, and improve behaviours and attitude at the workplace. As these worker attitudes and behaviours enhance productivity, creativity, innovation, performance, and openness to change (Mathieu and Zajac, 1990), it would be beneficial for organizations to improve job satisfaction. Such supportive behaviours encourage communication and collaboration at the workplace to alleviate the intensity of job-related problems. Besides, it promotes social interaction, mutual understanding, team spirit, and harmony at the workplace. Problems of diversity at the workplace which could escalate into discrimination, harassment, hostility, conflicts, and social alienation could be better managed.

As job satisfaction has a significant effect on conscientiousness, organizations would profit from leveraging employee conscientiousness for achieving organizational goals. For organizational effectiveness, employees' sincere devotion to the organization and respect for company policies beyond the organization's requirements (Eskew, 1993; 
Tansky, 1993) is fundamental. Organizational effectiveness is essential for sustainability, and the importance of positive work behaviours is indisputable. Therefore, measures to ensure that employees contribute beyond roles specified in the job description are crucial. Introducing incentive programs to reward employees that adhere to organizational rules, procedures, and regulations is a way to motivate employees to display characteristics of conscientiousness. Considering the damaging consequences of negative work behaviours, it may be worthwhile for organizations to invest in grooming conscientious workers. Conscientious workers naturally are role models to be exemplified and could be a source of motivation for other employees. A motivated and productive workforce would translate to better quality of goods, which in turn would enhance not only job satisfaction, but also customer satisfaction and loyalty.

Since job satisfaction also influences altruism, improving job satisfaction becomes increasing important. Organizations stand to gain if altruism is present at the workplace, as productivity and performance are likely to improve. The voluntary behaviour of helping co-workers in the organization in work-related matters not only promotes prosocial, helpful behaviours and neighbourliness among employees, but also expedite completion of work-related tasks. Such discretionary behaviours have positive effects for the organization, and may even be instrumental for a company's survival. To avoid distracting and showing supervisors their lack of competence, employees may engage in knowledge sharing. Employees reap benefits from both knowledge donation and knowledge collection, which may in turn inspire them to further acquire new knowledge. A knowledgeable workforce in a learning organization is valuable for gaining competitive advantage in an uncertain, challenging global environment.

Thus, it would be advantageous for organizations to improve job satisfaction to garner the benefits of OCB. Enhancing job satisfaction may entail increasing salaries and improving working conditions (Nadiri and Tanova, 2010). Flexitime and working remotely may also enhance job satisfaction. Increased job satisfaction together with effective training has the potential to contribute significantly to the bottom line of any organization. Furthermore, as job dissatisfaction causes anxiety (Spector et al., 1988), depression (Bluen et al., 1990), lower affective organizational commitment (Meyer et al., 2002), poorer in-role performance (Judge et al., 2001), and contextual performance (Podsakoff et al., 2000), ignoring job satisfaction may be detrimental to organizational effectiveness. Therefore, it is recommended that organizations implement policies and practices that augment job satisfaction. Job satisfaction is of utmost importance as it is significantly related to all dimensions of OCB. Organizations may have to focus on job satisfaction to enhance OCB.

\section{The role of job satisfaction in the justice-citizenship relationship}

It is hypothesized that job satisfaction and leader-member exchange mediate the relationship between organizational justice and OCB. The findings reveal full mediation for job satisfaction, and therefore, hypothesis 4 is substantiated. However, this contradicts extant literature that asserts that employee perceptions of fairness, and not job satisfaction is the main determinant of OCB if job satisfaction and perceptions of fairness were both measured (Moorman, 1991; Nadiri and Tanova, 2010; Organ, 
1988b, 1990). Organ (1988b, 1990) further reiterates that the relationship between job satisfaction and OCB probably reflects employee perceptions of organizational justice. Nadiri and Tanova (2010) contend that though employees may be satisfied, employees will not demonstrate OCBs if employees do not perceive organizational justice. Tension escalates in response to perceive injustice, and this translates into lower citizenship behaviours. Moreover, employees that favor social exchange are more likely to demonstrate OCBs if equity exists. Despite the importance of organizational justice rather than job satisfaction in determining OCBs, the current study shows that job satisfaction is a more significant predictor.

Full mediating effect of job satisfaction in the organizational justice-OCB relationship demonstrates that job satisfaction is indeed an important predictor. Thus, in contrast, organizational justice may not be as significant on OCB as expounded in prior studies. This implies that practitioners should aim to improve OCB through improved job satisfaction. The effect on OCB would be minimal if practitioners were to focus on improving organizational justice. Increased job satisfaction would probably enhance morale, motivation, and team working; create a more disciplined and committed workforce; and improve behaviours and attitude at the workplace. These would likely engage employees in civic behaviour, generating renewed interest in happenings in the organization. Employees' concern and attention in organizational affairs augments OCB. The results of the study suggest that organizations need to pay more attention to programs and policies that encourage job satisfaction if OCB is the priority of management. Nonetheless, organizations need to focus on overall justice to enhance job satisfaction, and hence, OCB. As organizational justice has a significant influence on job satisfaction, it is crucial for organizations to manage fairness effectively to enhance OCB. The current study shows that the relationship between organizational justice and job satisfaction is more significant than the organizational justice-OCB relationship. To further justify the need to improve overall justice, the study concurs with the assertion that positive justice perceptions possibly reinforce affirmative citizenship perceptions, and, therefore, the more robust organizational citizenship perceptions are, the more positive the organizational justice perception will be (Yilmaz and Tasdan, 2009).

\section{Managerial implications and contributions}

From a practical perspective, this study has important implications for managers and organizations. Of utmost significance is the indication of the importance of each justice factors on job satisfaction and the dimensions of OCB. This is useful for managers to monitor a wide range of employee behaviours that may be detrimental to organizational effectiveness. The current findings reveal explicitly which justice factor to focus on to enhance job satisfaction, and each dimension of OCB. Previous studies have offered one-dimensional analysis of the effect of organizational justice on job satisfaction and OCB (e.g. Yilmaz and Tasdan, 2009) and job satisfaction on OCB (e.g. Murphy et al., 2002. Other studies have researched perceived organizational justice and OCBs separately (e.g. Skarlicki and Folger, 1997). However, knowing how each independent construct affects the dimensions of OCB helps diagnose opportunities for intervention and improvement to enhance OCB in the workplace. 
Though managers may have little direct control over some employee attitudes and behaviours, the findings suggest that managers can increase OCB, in particular courtesy, through demonstrating interactional justice. By treating employees with dignity and respect, OCB is expected to improve as it affects all dimensions of OCB. As workplace success among other factors depends on respect for people, the findings support that interpersonal justice is indeed important. The way managers treat employees has a significant influence on their attitudes and commitment and, as a consequence, on their performance. Employees generally are more likely to response affirmatively to meet the demands of increased workload if there is perceived equity. Greenberg (1988) contends that actively communicating fairness through interaction rather than merely relying on actual fair behaviour has greater success of improving perceptions of fairness. The findings propose that if managers practice effective and fair communication, there is a probability that OCB would improve. Enhancing informational justice does not cost an organization much, but the absence of it may be a costly affair. The implementation of informational justice is feasible if organizations were to invest in enhancing communication skills of managers to improve perceive fairness in decision-making. Besides, fair personal treatment in decision-making processes is likely to augment affirmative employee behaviours. Therefore, prompt and honest feedback is essential to maintain trust and confidence in managerial decisions. As perception of justice is formed quickly, inadequate information in decision-making may influence the perception of subsequent actions (Klendauer and Deller, 2009). Indubitably, it is of paramount importance that organizations convince employees about management sincerity in ensuring equity in information sharing. Strategic manipulation intentions may generate counterproductive effects (Klendauer and Deller, 2009) that can spiral beyond managerial control.

Moreover, providing adequate explanations for decisions and events that affect them improve job satisfaction. As job satisfaction has a significant influence on all dimensions of OCB, improving job satisfaction is likely to enhance OCB. As "happy" employees are "productive" employees (Katzell and Yankelovich, 1975), it would be beneficial for managers to promote OCB to influence employees to enhance commitment and performance. Intuitively, identification with the organization would reduce employee alienation and enhance collaboration at the workplace. Employees are more likely to cooperate to help achieve organizational goals, devote sincerely to the organization, avoid disapproving behaviours, and increase interest in organizational affairs. These traits are instrumental for gaining competitive advantage in the face of current global challenges.

These findings suggest that organizational justice may have a greater impact on OCB via job satisfaction when compared to the direct effect of organizational justice on OCB. Organizational justice has long been thought to lead to improved OCB, but the results of this study indicate that organizational justice may not play a significant role in enhancing OCB. On the contrary, enhancing job satisfaction may produce better results. Therefore, if organizations were to increase $\mathrm{OCB}$, the focus would be on improving job satisfaction rather than organizational justice. To improve job satisfaction, managers would probably have to focus on providing adequate and honest explanations for decision outcomes. Organizational leaders may improve employee 
perceptions of justice by providing timely information, ensuring equity in distribution of outcomes, enacting fair procedures, and treating subordinates with dignity and respect.

Consequently, the need for organizations to train and educate their managers on the impact of the perceived lack of justice on job satisfaction and OCB is inevitable. In the current era of globalization, increased diversity at the workplace provides more challenges for organizations. A diverse workforce may influence employee perceptions of justice and what used to be the norm at the workplace may no longer be acceptable. Moreover, technological advancement has enable employees to communicate globally, thus, enhancing awareness of global opportunities which may entice employees to leave. Besides, sharing knowledge globally creates awareness on employee rights, and perceived injustice may lead to dissatisfaction, and hence, lower OCB. In essence, appropriate training to enhance managerial competences in ensuring organizational justice is crucial for improving OCB.

\section{Conclusion}

This study presented an integrated analysis of the organizational justice-OCB relationship by including job satisfaction as a mediator to provide a wholesome perspective of the associations between organizational justice and OCB. The study has expounded on the importance of job satisfaction in the organizational justice-OCB relationship, and therefore, the correlation between these constructs must not be overlooked. Practitioners may have to focus on job satisfaction to enhance OCB. Increased job satisfaction together with effective training to improve managerial competence in decision making would likely increase OCBs which ultimately results in better performance. Therefore, organizations would have to improve organizational justice in tandem with job satisfaction to enhance OCB. Among justice factors, interactional justice is important in influencing $\mathrm{OCB}$, in particular interpersonal justice. Concisely, the findings indicate that personal factors are imperative for advancing OCBs.

\section{References}

1. Asgari, A., Silong, A.D., Ahmad, A., Abu Samah, B. (2008): The relationship between transformational leadership behaviours, organizational justice, leader-member exchange, perceived organizational support, trust in management and organizational citizenship behaviours. European Journal of Scientific Research 23(2): 227242.

2. Azman, I., Mohamed, H.A., Hamid, N.S., Sulaiman, A.Z., Girardi, A. Abdullah, M.M. (2011): Relationship between performance based pay, interactional justice and job satisfaction: A mediating model approach. International Journal of Business and Management 6(11): 170-180.

3. Bateman, T.S., Organ, D.W. (1983): Job satisfaction and the good soldier: The relationship between affect and employee citizenship. Academy of Management Journal 26(4): 587-595.

4. Blau, P. (1964): Exchange and Power in Social Life. New York: Wiley.

5. Bluen, S.D., Barling, J., Burns, W. (1990) Predicting sales performance, job satisfaction, and depression by using the achievement strivings and impatience-irritability dimensions of Type A behaviour. Journal of Applied Psychology 75(2): 212-216.

6. Brayfield, A.H., Rothe, H.F. (1951): An index of job satisfaction. Journal of Applied Psychology 35(5): 307311. 
7. Colquitt, J.A., Conlon, D.E. Wesson, M.J., Porter, C.O.L.H., Ng, K.Y. (2001): Justice at the millennium: A meta-analytic review of 25 years of organizational justice research. Journal of Applied Psychology 86(3): 425445.

8. Colquitt, J.A. (2001): On the dimensionality of organizational justice: A construct validation of a measure. Journal of Applied Psychology 86(3): 386-400.

9. DeConinck, J.B. (2010): The effect of organizational justice, perceived organizational support, and perceived supervisor support on marketing employees' level of trust. Journal of Business Research 63(12): 1349-1355.

10. Deutsch, M. (2000): Justice and conflict. In: M. Deutsch and P.T. Coleman (eds.), The Handbook of Conflict Resolution: Theory and Practice. San Francisco, CA: Jossey Bass.

11. Eskew, D.E. (1993): The role of organizational justice in organizational citizenship behaviour. Employee Responsibilities and Rights Journal 6(3): 185-194.

12. Farh, J., Podsakoff, P.M. and Organ, D.W. (1990): Accounting for organizational citizenship behaviour: Leader fairness and task scope versus satisfaction. Journal of Management 16(4): 705-721.

13. Fassina, N. E., Jones, D. A., Uggerslev, K. L. (2008): Relationship clean-up time: Using meta analysis and path analysis to clarify relationships among job satisfaction, perceived fairness, and citizenship behaviours. Journal of Management 34(2): 161-188.

14. Fernandes, C., Awamleh, R. (2006): Impact of organizational justice in an expatriate work environment. Management Research News 29(11): 701-712.

15. Foote, D.A., Tang, T.L. (2008): Job satisfaction and organizational citizenship behaviour (OCB): Does team commitment make a difference in self-directed teams? Management Decision 46(6): 933-947.

16. Giap, B.N., Hackermeier, I., Jiao, X., Wagdarikar, S.P. (2005): Organizational citizenship behaviour and perception of organizational justice in student jobs. Research Study, Psychology of Excellence Instructional Design, Job Analysis and Job Design, 04 July 2005.

17. Greenberg, J. (1988): Cultivating an image of justice: Looking fair on the job. Academy of Management Executive 2(2): 155-157.

18. Hassan, A., Al Jubari, I.H.A. (2010): Organizational justice and employee work engagement: LMX as mediator. Journal of International Business and Entrepreneurship Development 5(2): 167-178.

19. Hassan, A., Hashim, J. (2011): Role of organizational justice in determining work outcomes of national and expatriate academic staff in Malaysia. International Journal of Commerce and Management 21(1): 82-93.

20. Hassan, A., Mohd Noor, K. (2008): Organizational justice and extra-role behaviour: Examining the relationship in the Malaysian cultural context. IIUM Journal of Economics and Management 16(2): 187-208.

21. Homans, G.C. (1961): Social Behaviour: Its Elementary Forms. London: Routledge and Kegan Paul.

22. Hooi, L.W. (2011): The role of leader-member exchange in organizational justiceorganizational citizenship behaviour relationship, Research and Practice in Human Resource Management 19(2): 71-91.

23. Ishak, N.A., Alam, S.S. (2009): The effects of leader-member exchange on organizational justice and organizational citizenship behaviour: Empirical study. European Journal of Social Sciences 8(2): 324-334.

24. Ismail, M.T., Abdul Karim, S.A, Alwadi, S. (2011): A study of structural breaks in Malaysian stock market. African Journal of Business Management 5(6): 2418-2425.

25. Judge,T.A., Thoresen, C.J., Bono, J.E., Patton, G.K. (2001): The job satisfaction-job performance relationship: A qualitative and quantitative review. Psychological Bulletin 127(3): 376-407. 
26. Katzell, R. A., Yankelovich, D. (1975): Work, Productivity, and Job Satisfaction. New York: Psychological Corp.

27. Khalid, S., Ali, H. (2005): The effect of organizational citizenship behaviour on withdrawal behaviour: A Malaysian Study. International Journal of Management and Entrepreneurship 1(1): 30-40.

28. Klendauer, R., Deller, J. (2009): Organizational justice and managerial commitment in corporate mergers. Journal of Managerial Psychology 24(1): 29-45.

29. Lambert, E.G., Cluse-Tolar, T., Pasupuleti, S., Hall, D.E., Jenkins, M. (2005): The impact of distributive justice and procedural justice on social service workers. Social Justice Research 18(4): 411-427.

30. Latham, G., Pinder C. (2005): Work motivation theory and research at the dawn of the twentyfirst century. Annual Review of Psychology 56(1): 485-516.

31. Lazar, A., Zinger, A., Lachterman, B. (2007): The influence of prefeedback selection justice on perceptions of overall procedural justice and organizational attractiveness in a real-life selection procedure. European Journal of Work and Organizational Psychology 16(1): 94-109.

32. Leow, K.L., Khong, K.W. (2009): Organizational Commitment: The study of organizational justice and leader member exchange (LMX) among auditors in Malaysia. International Journal of Business and Information 4(2): 161-198.

33. Lo, M.C., Ramayah, T., Hui, J.K.S (2006): An investigation of leader member exchange effects on organizational citizenship behaviour in Malaysia. Journal of Business and Management 12: 5-23.

34. Meyer, J., Stanley, D., Herscovich, L., Topolnytsky, L. (2002): Affective, continuance, and normative commitment to the organization: A meta-analysis of antecedents, correlates, and consequences. Journal of Vocational Behaviour 61(1): 20-52.

35. Mohd. Nasurdin, A., Soon, L. K. (2011): Organizational justice, age, and performance connection in Malaysia. International Journal of Commerce and Management 21(3): 273-290.

36. Moorman, R.H., Blakely, G.L. (1995): Individualism-Collectivism as an individual difference predictor of organisational citizenship behaviour. Journal of Organisational Behaviour 16(2): 127-142.

37. Moorman, R.H. (1991): Relationship between organizational justice and organizational citizenship behaviour: Do fairness perceptions influence employee citizenship? Journal of Applied Psychology 76(6): 845-855.

38. Murphy, G., Athanasou, J., King, N. (2002): Job satisfaction and organizational citizenship behaviour: A study of Australian human-service professionals. Journal of Managerial Psychology 17(4): 287-297.

39. Nadiri, H., Tanova, C. (2010): An investigation of the role of justice in turnover intentions, job satisfaction, and organizational citizenship behaviour in hospitality industry. International Journal of Hospitality Management 29(1): 33-41.

40. Organ, D. W., Podsakoff, P. M., MacKenzie, S. B. (2006): Organizational Citizenship Behaviour: Its Nature, Antecedents, and Consequences. Thousand Oaks, CA: Sage Publications.

41. Organ, D.W., Moorman, R.H. (1993): Fairness and organizational citizenship behaviour: What are the connections? Social Justice Research 6(1): 5-18.

42. Organ, D.W., Ryan. K. (1995): A meta-analytic review of attitudinal and dispositional predictors of organizational citizenship behaviour. Personnel Psychology 48(4): 775-802.

43. Organ, D.W. (1977): A reappraisal and reinterpretation of the satisfaction-causes-performance hypothesis. Academy of Management Review 2(1): 46-53.

44. Organ, D.W. (1988a): Organizational Citizenship Behaviour: The Good Solider Syndrome. Lexington, MA: Lexington Books.

45. Organ, D.W. (1988b): A restatement of the satisfaction-performance hypothesis. Journal of Management 14(4): 547-557. 
46. Organ, D.W. (1990) The motivational basis of organizational citizenship behaviour. Research in Organizational Behaviour 12(1): 43-72.

47. Organ, D.W. (1997): Organizational citizenship behaviour: It's construct clean-up time". Human Performance 10(2): 85-97.

48. Othman, R. A., Rashida, H., Noor A., Rosmah, M. (2005): Psychological contract violation and organizational citizenship behaviour. Gaja Mada International Journal of Business 7: 325-349

49. Podsakoff, P.M., MacKenzie, S.B., Moorman, R.H., Fetter, R. (1990): Transformational leader behaviours and their effects on followers' trust in leader, satisfaction, and organizational citizenship behaviours. The Leadership Quarterly 1(2): 107-142.

50. Podsakoff, P.M., MacKenzie, S.B., Paine, J.B., Bachrach, D.G. (2000): Organizational citizenship behaviours: A critical review of the theoretical and empirical literature and suggestions for future research. Journal of Management 26(3): 513-563.

51. Price, J.L., Mueller, C.W. (1986): Handbook of Organizational Measurement. Marshfield, Mass: Pittman. Robinson, S.L., Morrison, E.W. (1995): Psychological contracts and the OCB: The effect of unfulfilled obligations on civic virtue behaviour. Journal of Organizational Behaviour 16(3): 289-298.

52. Schaubroeck, J., May, D.R., Brown, F.W. (1994): Procedural justice explanations and reactions to economic hardship: A field experiment. Journal of Applied Psychology, 79(3): 455-460.

53. Skarlicki, D.P., Folger, R. (1997): Retaliation in the workplace: The roles of distributive, procedural, and interactional justice. Journal of Applied Psychology 82(3): 434-443.

54. Skarlicki, D.P., Latham, G.P. (1997): Leadership training in organizational justice to increase citizenship behaviour within a labor union: A replication. Personnel Psychology 50(3): 617-633.

55. Skarlicki, D.P. and Latham, G.P. (1996): Increasing citizenship behaviour within a labor union: A test of organizational justice theory. Journal of Applied Psychology 81(2): 161-169.

56. Smith, C.A., Organ, D.W., Near, J.P. (1983): Organizational citizenship behaviour: Its nature and antecedents. Journal of Applied Psychology 68(4): 653-663.

57. Spector, P.E., Dwyer, D.J., Jex, S.M. (1988): Relation of job stressors to affective, health, and performance outcomes: A comparison of multiple data sources. Journal of Applied Psychology 73(1): 11-19.

58. Sweeney, P.D., McFarlin, D.B. (1993): Workers' evaluations of the 'ends' and the 'means': An examination of four models of distributive and procedural justice. Organizational Behaviour and Human Decision Processes 55(1): 23-40.

59. Tansky, J.W. (1993): Justice and organizational citizenship behaviour: What is the relationship? Employee Responsibilities and Rights Journal 6(3): 195-207.

60. Tyler, T. R., Blader, S. L. (2003): The group engagement model: Procedural justice, social identity, and cooperative behaviour. Personality and Social Psychology Review 7: 349-361.

61. Williams, L.J., Anderson, S.E. (1991): Job satisfaction and organizational commitment as predictors of organizational citizenship and in-role behaviours. Journal of Management 17(3): 601-617.

62. Yilmaz, K. and Tasdan, M. (2009): Organizational citizenship and organizational justice in Turkish primary schools. Journal of Educational Administration 47(1) http://dx.doi.org/10.1108/09578230910928106 



\title{
2.2. QUALITY AND MANAGEMENT - TOOLS FOR CONTINUOUS AND SYSTEMATIC IMPROVEMENT OF PROCESSES
}

\begin{abstract}
Summary
Nowadays, the quality of the company is one of the essential part of the business competitiveness. The realization of quality is drastically changed in the last century. The level of development is depends on the point of view of direction, the possibilities of the organization, the external environment, the age and of the company. Business has also changed radically since the last major revision of ISO 9001 in 2000, as technology development has made substantial changes in working processes. In addition, geographical boundaries are almost insignificant in today's global economy, supply chains are increasingly complex and the information availability has multiplied exponentially. These changes affect the quality control processes and methods. Quality Management Systems shall adopt the changes to follow the requirements of customers and organizations and take the necessary evolutional steps from quality control to the Total Quality Management (TQM). In order to be realized as a management tool, quality principles shall be applied in all levels of operation, and for being successful, businesses have to adapt to the growing needs of customers.
\end{abstract}

Keywords: quality, management systems, TQM, ISO, costs of quality, role of managers

\section{Introduction - definitions of quality}

Nowadays, the quality of the company is an essential factor of business competitiveness. There is a long way taken from F. W. Taylor (1911) when he issued his book "The principles of Scientific Management". Quality takes the necessary evolutionary steps from quality control to the TQM (Total Quality Management). The in-between steps are known as quality control, quality assurance, quality systems and finally, the TQM.

It is very important to check, where is the point from which we can distinguish the difference between organizations: which will be successful and which will not? Some organizations just hang the certification on the wall, while another operates a successful quality system which will bring benefits for the whole company.

There are no general 'recipes' for a success, the correct steps should be established and carried out by leadership and management issues 'on the spot'. The problem is that there are not general measurement methods that could measure the performance of the management. In many companies several developments or projects (e.g. introduction of ISO system, TQM, etc.) are running simultaneously. The benefits of these activities sometimes can hardly be realized, because the introduction of ISO system will require high investment costs, and hardly predictable benefits. As Juran said, senior leaders speak the language of money; workers speak the language of things (machines, tools and products), and middle managers should be able to translate the language of money into language of things and vice versa for the successful performance of organizations (Juran, 1964; Defeo and Juran, 2014). According to Deming (2000), quality is mostly 
connected to the performance of the leaders and top managers, and workers are only responsible for their failures at the production line. Feigenbaum $(2004,2009)$ insisted on that quality should be discussed as a whole, and introduced his Total Quality Control system.

Total quality management is rather a philosophy or leadership attitude, which can be summarized as a management system for a customer-focused organization that involves all employees in continual improvement. It uses strategy, data, and effective communications to integrate the quality discipline into the culture and activities of the organization. The main principles of total quality management are summarized by Figure 1.

Figure 1: Principles of TQM

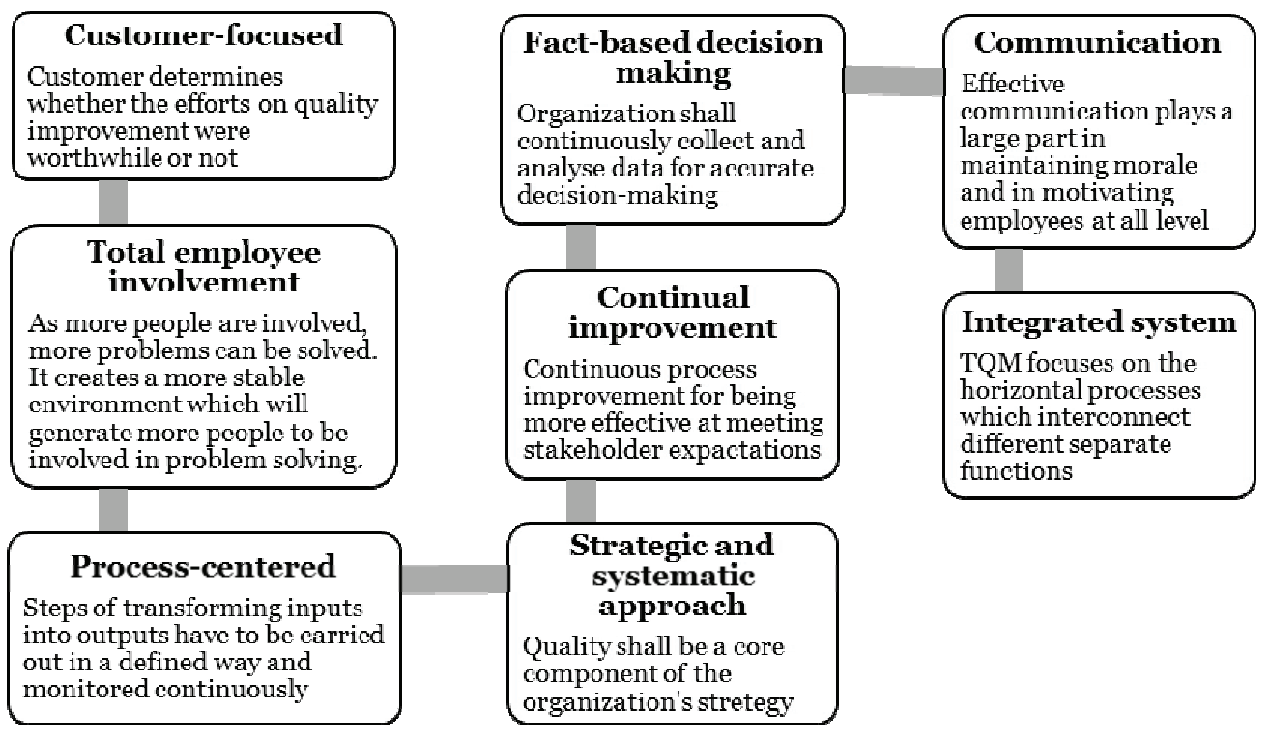

Source: own summary based on Oakland (2014) and Illés and Szuda (2015)

In manufacturing industry, quality traditionally means the continuous inspection especially in companies with Asian origin, but for the real success the company have to move towards operating really efficient quality management tools, which is affect the competitiveness of the company (IATF, 2014).

\section{Costs of quality}

When we define the meaning of quality, we shall state that it is a subjective term, for which each person or sector has its own definition. In technical usage, quality can have two meanings: the first means that he characteristics of a product or service that bear on its ability to satisfy stated or implied needs; the second meaning refers to that a product or service free of deficiencies.

According to Philip Crosby (1979), quality means "conformance to requirements". Quality is related not only to the quality of product, but it means the quality of 
operations, which covers the whole area and processes of manufacturing. In 1979, Crosby published his first business book "Quality Is Free", which became popular at the time because of the crisis in North American quality. During the late 1970s and the 1980s, North American manufacturers were losing market share against Japanese products largely due to the superior quality of the Japanese goods. Crosby's response to the quality crisis was the principle of "doing it right the first time" (DIRFT). He defined four major principles:

1. Quality has to be defined as conformance to requirements, not as goodness (requirements refer to both the product and the customer's requirements);

2. The system for causing quality is prevention, not appraisal. When a defect occurs, discovery and elimination is top priority. Prevention is a knowledge issue for quality-focused workers.

3. The performance standard is zero defects (relative to requirements). Zero defects needs to be a performance standard for everyone in the company, from top management to workers on the line.

The measurement of quality is the price of nonconformance, not indexes.

Cost of quality is also an important communication tool. Crosby demonstrated what a powerful tool it could be to raise awareness of the importance of quality. He referred to the measure as the "price of non-conformance" and argued that organizations choose to pay for poor quality.

Figure 1: Quality-related costs

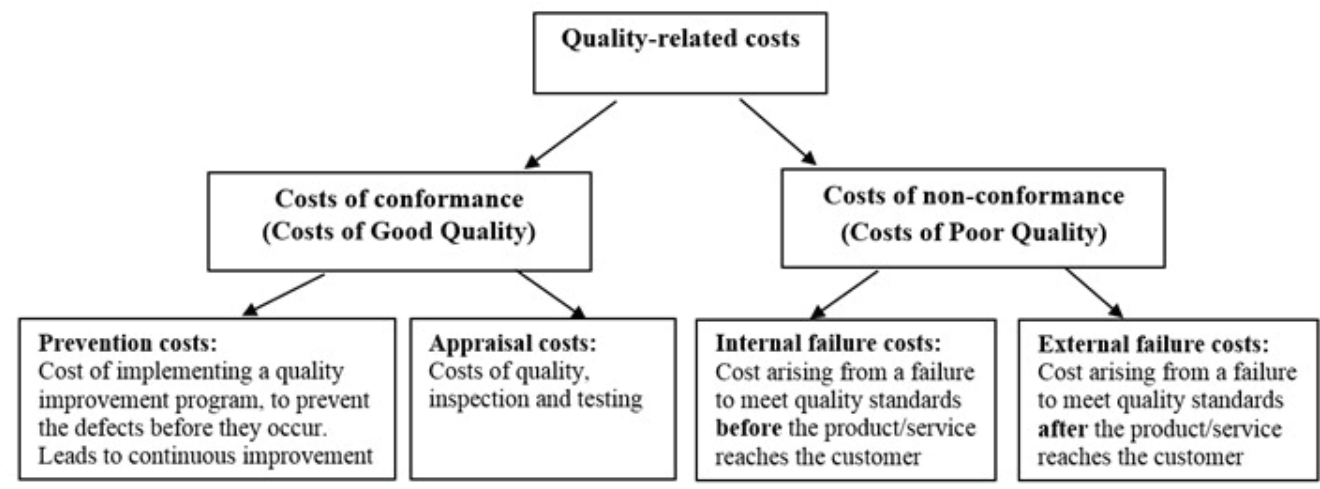

Source: own

Cost of quality is a methodology that allows an organization to determine the extent to which its resources are used for activities that prevent poor quality, that appraise the quality of the organization's products or services, and that result from internal and external failures. Having such information allows an organization to determine the potential savings to be gained by implementing process improvements.

Quality-related activities that incur costs may be divided into prevention costs, appraisal costs, and internal and external failure costs.

Crosby's belief was that an organization, which establishes good quality management principles, would see more savings than they paid for the cost of the quality system, 
which means, "quality is free". It is less expensive to do it in a right way from the beginning than to pay for rework and repairs. For example, in the electronic manufacturing, there was a technological breakthrough in the past decade. The SMT (Surface Mount Technology) became a standard and able to miniaturize the circuits and provide excellent quality even. The environment protection issues such as the Restriction of Hazardous Substances (RoHS) also affected manufacturers, especially who used soldering, that have to introduce lead free soldering. As lead-free and RoHS compliancy fast approaches, it is more important than ever to build it right the first time. Lead-free assembly and RoHS will bring about numerous changes and the number of variables with which to contend is increasing, creating increased risk of defects and reduced product reliability (EU, 2011). Understanding the impacts on the assembly can increase product reliability significantly.

The costs of performing high quality, conducting quality improvements, and achieving goals should be carefully managed so that the long-term effect of quality on the organization is desirable goal. The real value of the quality efforts can be measured by these costs by performing an analysis of the costs of quality. Such an analysis provides a method of assessing the effectiveness of the management of quality and a means of determining problem areas, opportunities, savings, and action priorities.

Traditionally the visible COPQ (Cost of Poor Quality) is representing 4-5\% of the sales and it calls the visible area of the iceberg (Dempsey, 2012)

Figure 2: The cost of quality iceberg

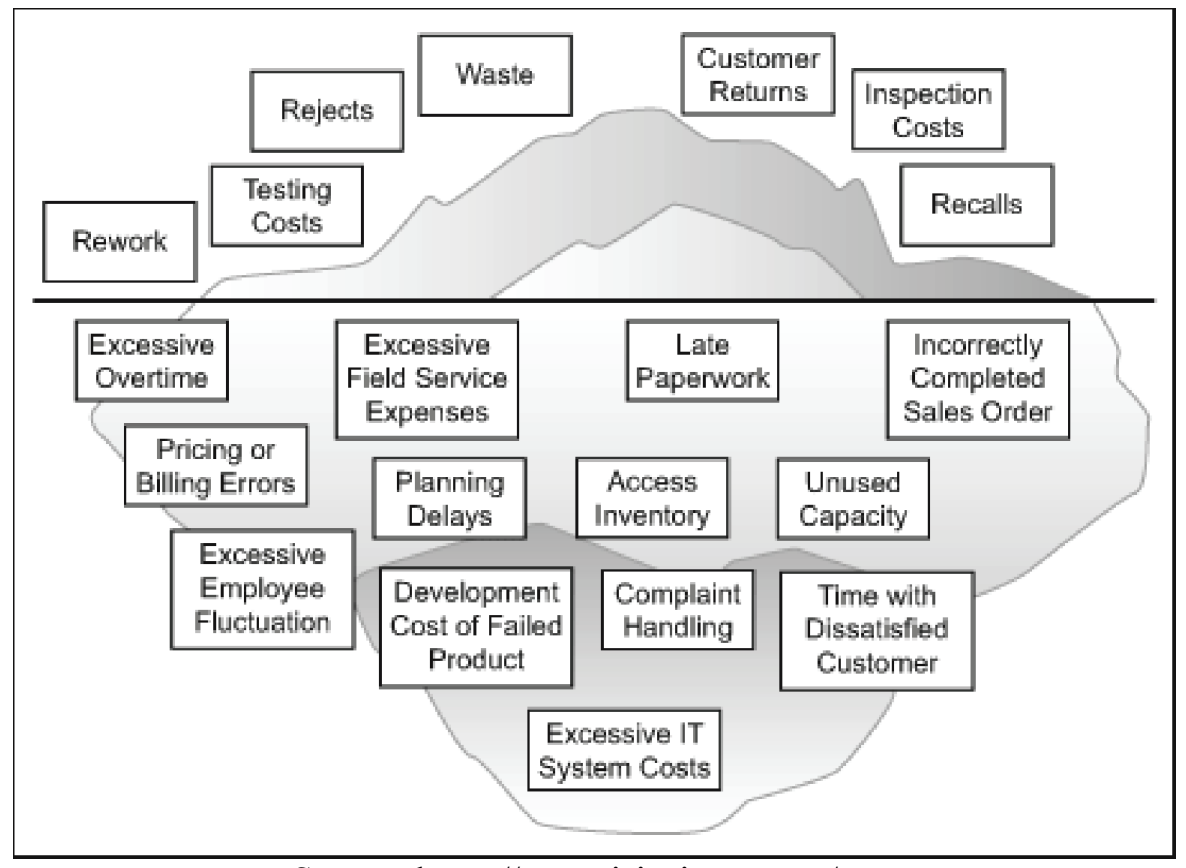

Source: https://www.isixsigma.com/wp-

content/uploads/images/stories/migrated/graphics/767b.gif 
As in case of any iceberg, the hugest and more dangerous part is hidden, as it is beneath the surface of the water and cannot be seen. In general, these "invisible" costs add up to $20-35 \%$ of sales in addition to the "visible" costs. By using COPQ method the company may get a simple and understandable tool for measuring the effects of poor quality and the cost-savings from improvement of the work, and it can be a guidance for top leaders, middle managers and employees as well. Product quality could be a heavy burden if we use the traditional way such as inspection at the end. Quality is coming from the process not from the inspection. Nowadays, due to the automatization and poka-yoke (i.e. mistake proofing) principles the product quality are achievable everywhere.

Many organizations will have true quality-related costs as high as 15 to $20 \%$, sales revenue, sometimes going as high as 40 percent of total operations. A general rule of thumb is that costs of poor quality in a thriving company will be about 10 to 15 percent of operations (Duffy, 2013, pp. 65). Effective quality improvement programs can reduce this substantially, thus making a direct contribution to profits. As Westcott and Duffy (2014) highlighted, the role of managers is crucial in this process, because it will influence the company's performance in the future. The quality cost system, once established, shall be managed in a dynamic way and it will a positive impact on the achievement of the organization's mission, goals, and objectives.

\section{The evolution of quality standards}

The quality standards follow an evolutionary ladder (Rothery, 1997). If we look the ISO 9001:1994 version, it may be seen that it covers the classical quality control requirements. The main requirements are heavy documentation, working based on documented procedures, inspection and permanent product quality.

The next steps are ISO 9001:2000 and 2008 standards (ISO 9001:2000; ISO 9001:2015). These standards introduce the quality objectives, customer satisfaction and process management concept.

The new ISO 9001:2015 standard was released last year. It focuses on the following elements: risk management, use of opportunities, skills (competences) management, and customer satisfaction. It is clearly seen that the new version would like to be a management standard more than before, and wants to eliminate weaknesses of the previous versions such as too much focus on the documentation system or weak risk management. The new ISO focuses on risk management, reduces documentation burden, checks the active participation of the management, performs skill and competence management, and also improves customer satisfaction.

\section{ISO 9001:2015 as a management tool}

The most recent ISO 9001:2015 standard is much more than a standard, it should be the part of a company's strategic plan rather than something to get certified to because it is required. The standard is constructed around seven quality management principles and describes for each part which requirements your products, services and organisation have to meet in order to enjoy the above benefits. The seven principles 
are: customer focus, leadership, engagement of people, process approach, improvement, evidence-based decision making and relationship management (ISO 9000:2015).

To be realized as a management tool, quality principles have to be applied in all operation processes. This concept is realized in the new ISO 9001:2015 standard. The main changes are listed below, which prove that the new ISO 9001 would like to be a "management standard" more than ever.

ISO 9001:2015 has ten clauses instead of eight. The first three clauses are largely similar to the former version, but the new version introduced considerable changes adding seven new clauses, which are arranged according to the PDCA cycle.

Figure 3: Clauses of ISO 9001:2015 in accordance with the PDCA cycle

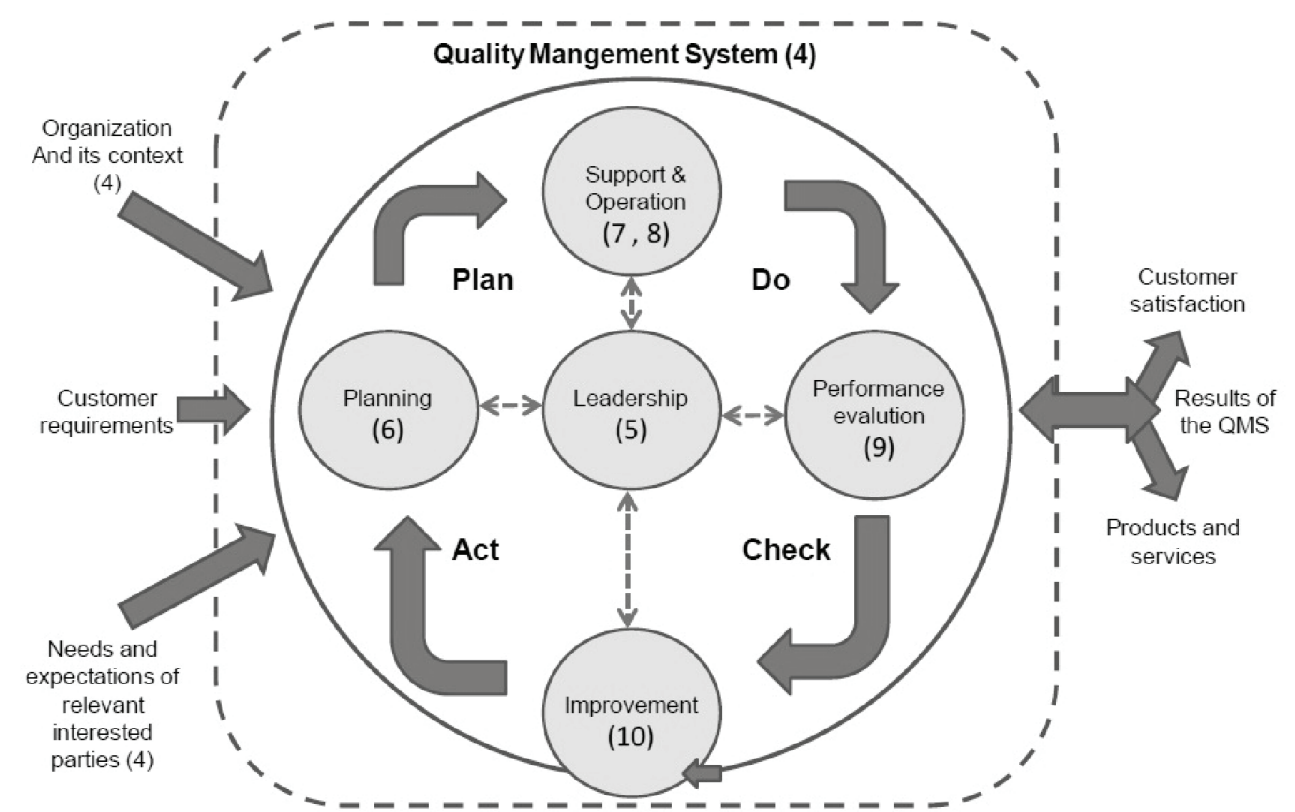

Source: own, based on ISO 9001:2015

Legend: the numbers in brackets refer to the given clause of the new ISO standard

\section{Context of the Organization (Clause 4)}

This is a new concept and relates to the external factors and conditions that affect an organisation (government regulations, sector, competition, technology change etc.). To determine external context, the organisation should consider issues arising from its macroenvironment, i.e. political, social, economic, technological, environmental and legal factors using PESTEL analysis.

The needs and expectations of interested parties (external stakeholders including customers) should also be discussed, as well as internal issues of the organization (shareholders, employees, resources). Internal issues are related to the culture, beliefs, 
values, or principles inside the organization, as well as complexity of processes and organizational structure (Needle, 2004).

Based on the gathered information, a SWOT analysis shall be conducted for combining external and internal issues, which enables the management to define the steps needed for achieving the goals.

\section{Leadership(Clause 5)}

The clause "Management Responsibilities" of ISO 9001:2008 is now addressed in two clauses: "Leadership" and "Planning", it shows clearly that quality management according to the new standard shall strongly rely on the role of leadership, which underlines that quality system should be used as a management tool.

Management is mostly about processes and it relies on tangible measurable capabilities while leadership is mostly about behaviour. Leadership relies on less tangible and less measurable things like trust, inspiration, attitude, decision-making, and personal character. Chapter on Leadership includes three subchapters: 5.1. summarizes general and customer-focused issues of leadership and commitment, 5.2. provides requirements for establishing and communicating quality policy, and 5.3. describes the organizational roles and responsibilities, as well as the relevant authorities. Thus, top management now has greater accountability and involvement in the organization's management system. They shall integrate the requirements of the management system into the organization's core business process in order to ensure that the management system may achieve its intended outcomes and can allocate the necessary resources. Top management is also responsible for communicating the importance of the management system and heighten employee awareness and involvement. (ISO 9001:2015) To be successful, the clear and visible commitment of top management is required and people (employees) should be involved during the whole process. Managers shall lead and manage the change; it is not enough only to support it.

Based on our observations, one of the biggest problem at top management level is the lack of systemic thinking and ensuring the proper allocation of resources is not ideal in most cases. When managers understand this problem, the case cause is won. It should be highlighted that the existence of the efficient management system and the good competence of colleagues will result an effectively working management system, which can highly affect the financial results of the company. Which is encouraging for the future, when top management will adapt quality management system standards they will strive to put more and more emphasis on these requirements. Consequently, we will not talk about hanging certificates just on the wall, but will speak about how a company can manage its risks, so how to avoid losses, damages etc. wherever possible, using the principles of quality management system.

\section{Planning (Clause 6)}

Is a new term introduced to the high level structure, with a requirement to address risks and opportunities and to carefully plan changes within the management system. This new clause brings risk-based thinking to the front. The organization highlighted risks and opportunities in clause 4 , now it needs to define how these will be addressed 
through planning: what actions should be taken to address the risks and opportunities, what are the quality objectives and how to achieve them, and finally, how to plan these changes.

This is an enhanced requirement in the new standard. Risks and opportunities, for example, could relate to the use of electronic systems within the management system. Introducing such systems would require change and transition arrangements, which should be planned within the management system.

\section{Support (Clause 7)}

As a next step, organizations shall define what kind of support is needed to meet their goals and objectives. This includes resources (including infrastructure, environment for the operation of processes, monitoring and measuring resources and organizational knowledge), the targeted communication and documented information that replaces previously used terms such as documents, documentation and records. This new term builds upon the 2008 requirements for competence and awareness, now extended to include persons under the organisation's control, not just employees.

With the increasing use of outsourced providers, this requirement reminds us that this resource must be managed effectively just as internal providers are managed.

\section{Operation (Clause 8)}

The most of the management system requirements are covered by this clause, which is addressed both in-house and outsourced processes. Subchapters deal with operational planning and control, requirements and design of products/services, control of externally provided products/services, production or provision and release of products/services, and control of non-conforming outputs.

\section{Performance evaluation (Clause 9)}

This clause has similar topics to the existing standard, but with a new emphasis on evaluation in addition to the current requirement to measure and analyse.

Evaluation is the interpretation of results and analysis is not new to managers but is made explicit in the standard for the first time. Processes may be well defined and effective, but will they perform optimum results? This may be a new challenge for internal audits.

ISO 9001:2015 is much less prescriptive than previous versions, and incorporates more business management terminology and concepts. Documentation requirements are much less prescriptive and left more to the organisation to judge its own needs. The standard is written for the benefit of organizations. The organization determines what, how and when things are to be monitored, measured, analysed and evaluated adding an internal audit and management review. There are likely to be more challenges to auditors to understand and recognise the extent and type of evidence that would be acceptable to confirm compliance to the 2015 requirements. ISO 9001:2015 auditors will be engaging in dialogue with business leaders, seeking understanding and explanations from them about policy, strategy and quality objectives, and ensuring these are compatible. 


\section{Improvement (Clause 10)}

Improvement has three sub-clauses, in general, it shall discuss product and process improvement and improvement of management practices with a systemic approach. The next step is determination of nonconformities and selecting the corrective actions. The organization must continually improve the suitability, adequacy, and effectiveness of the quality management system, which should be in accordance with the original strategy.

\section{Conclusions and further issues}

Based upon those changes the process approach is more important than ever. The success of the organization is depends on their processes. It is not not enough to develop, produce and sell excellent product, but the organization shall design their business processes to ensure that the realization of product and services, will result the maximum effectiveness, which means the optimal use of the available resources to be met with the customer needs. To improve the business operation and make success, the strategy of the company will help the management if the business processes are considered from the view of process approach.

The concept of modern management places great emphasis on the fact that the company's activities should be smoothly linked together for getting more rapid return on invested capital. Experiences show that it is determined by activities, if they are not linked by function, but are following process approach.

The changes are fasten now, the quick act to the demand of the markets is very important, fast response is the key of success, and companies should be change from reactive approach to proactive.

Business has changed radically since the last major revision of ISO 9001 in 2000; technology has changed our life in many aspects. The Western civilization experienced three industrial revolutions, and now we live in the new, fourth industrial revolution Industry 4.0, when physical objects and machines are connected to an information network and the economy is integrated into a single powerful, intelligent information system.

Europe in the past 20 years lost much of its weight of the industrial production. While in 1991, 36\% of the world's industrial added value was produced in Europe, in 2011, only a quarter. A similar trend has been in Japan and North America, while developing countries have doubled the value-added industrial production.

In the near future, the scale of connected "things" - Internet of Things (IoT), i.e. different inter-networking of physical devices that enable these objects to collect and exchange data. According to Gartner Inc., 6.4 billion connected things will be in use this year and more than 20 billion by 2020 (www.gartner.com). The growth of connected devices and assets has increased concerns about security challenges in IoT. Protecting IoT solutions requires ensuring secure provisioning of devices, secure connectivity between these devices and the cloud, and secure data protection in the cloud during processing and storage. 
Standard organizations should therefore develop and when it is necessary, to adopt these new technologies, reference models, new architectures and open interfaces for IoT. In order to ensure that ISO 9001 continues to serve the business community and maintain its relevance, the standard should be revised and reconsidered continuously, in accordance with the new challenges. One thing remains constant, to be successful, businesses have to adapt to meet the growing needs of customers.

\section{References}

1. Crosby P. (1979): Quality is Free, New York, McGraw-Hill, 270 p.

2. Defeo, J. A.; Juran, J. M. (2014): Juran's Quality Essentials, New York, McGraw-Hill, 280 p.

3. Deming, W. E. (2000): Out of the crisis, MIT-CAES, $510 \mathrm{p}$.

4. Duffy, G. L. (2013): The ASQ Quality Improvement Pocket Guide: Basic History, Concepts, Tools, and Relationships, ASQ Quality Press, pp. 62-65.

5. EU (2011): Directive 2011/65/EU of the European Parliament and of the Council on the restriction of the use of certain hazardous substances in electrical and electronic equipment

6. Feigenbaum, A. V. (2004): Total Quality Control $4^{\text {th }}$ Edition, New York, McGraw-Hill, 896 p.

7. Feigenbaum, A. V. (2009): The Power of Management Innovation: 24 Keys for Accelerating Profitability and Growth, New York, McGraw-Hill, 64 p.

8. IATF (2014): Rules for achieving and maintaining IATF recognition $4^{\text {th }}$ Edition for ISO/TS 16949 , IATF, $16 \mathrm{p}$.

9. Illés, B. Cs., Szuda, Cs. (2015): Quality in manufacturing - is a management tool? In: Dunay, A. (ed.) Proceedings of the 5th International Conference on Management 2015. Management, leadership and strategy for SMEs' competitiveness. Szent István University Publishing House, Gödöllö, pp. 126-129. http://dx.doi.org/10.17626/dBEM.ICoM.P00.2015.p023

10. ISO $9001: 2008$

11. ISO $9001: 2015$

12. Juran, J. M. (1964): Managerial Breakthrough, New York: McGraw-Hill

13. Needle, D. (2004). Business in Context: An Introduction to Business and Its Environment. Thomson Learning, London, $646 \mathrm{p}$.

14. Oakland, J. S. (2014): Total Quality Management, $4^{\text {th }}$ edition, Routledge, $500 \mathrm{p}$.

15. Rothery, B. (1997): ISO 14000 és ISO 9000, Budapest, Panem-McGraw-Hill, 315 p.

16. Taylor, F. W. (1911): The Principles of Scientific Management, Harper \& Brothers

17. Westcott, R. T.; Duffy, G. L. (2014): The Certified Quality Improvement Associate Handbook, Third Edition, ASQ Quality Press, 288. p.

18. http://www.gartner.com/newsroom/id/3165317

19. http://www.isixsigma.com/wp-content/uploads/images/stories/migrated/graphics/767b.gif 


\title{
2.3. EVALUATION OF THE RESULTS OF A PRODUCTION SIMULATION GAME WITH DIFFERENT DEA MODELS
}

\begin{abstract}
Summary
Data Envelopment Analysis (DEA) is a method for comparing the efficiency of decisionmaking units when the output of these units is evaluated based on the amount of inputs used. A special application area of DEA is the evaluation of student groups participating in a production simulation game. This paper shows how DEA is used to compare the performance of student groups in the simulation game, and how their results can be evaluated using the efficiency scores. Several DEA models exist to capture the special characteristics of real life operation. Basic models with radial efficiency measures are used to analyse the effect of input and output weights, and to separate the proportional decrease of inputs from the independent input reduction possibilities. Slack based measure models are applied to study the joint effect of proportional and independent input/output changes. Dynamic models are used to study the change of efficiency over time. This paper compares the results of the applied models and analyses the differences. The results show that the application of an assurance regain model is strongly recommended. The presence of negative outputs requires the application of models which can be adapted to negative data. Dynamic models indicate efficiency problems even if overall performances are acceptable.
\end{abstract}

Keywords: Data Envelopment Analysis, linear programming, performance evaluation, simulation game

\section{Introduction}

Data Envelopment Analysis (DEA) is a mathematical programming approach that is used for comparing the efficiency of decision making units (DMU) such as production and/or service systems. In contrast to other methods (e.g. ratio methods) used for performance evaluation, DEA is capable of handling multiple inputs and multiple outputs as well. DEA was first introduced by Charnes, Cooper and Rhodes for evaluating nonprofit organizations. In the last few decades DEA has been extensively investigated, and it became an important research area. Several applications of DEA are reported in the literature both in the service and in the production sector as well. There is no any single DEA model which is always the best. Different application environments have generated different evaluation problems thus several variants of DEA models have been developed. In this paper DEA is applied in a higher education context to compare the performance of student groups in a production simulation game. Different DEA models are proposed to capture some special characteristics of operation. In the following part of this paper first the DEA models applied in the presented research are introduced. Next, the application environment is presented and the important differences between the suggested DEA models are discussed. Finally, conclusions are drawn and the areas of future research are summarised. 


\section{Basic concept and the applied models}

Charnes, Cooper and Rhodes (1978) suggested a linear programming model which compared DMUs using relative efficiency measures. Based on the suggested model relative efficiency analysis, or data envelopment analysis (DEA) became an important research area and a useful tool for performance evaluation. Several applications of DEA models are reported in the literature in the service and in the production sector as well (see for example Doyle and Green, 1991; Panayotis, 1992; Sherman and Ladino, 1995; Markovits-Somogyi, Gecse and Bokor, 2011). A frequently applied area of DEA is higher education. Johnes (2006) compared more than 100 higher educational institutions in England using a nested DEA model. Sinuany-Stern, Mehrez and Barboy (1994) analysed the relative efficiency of several departments within the same university.

The first model suggested by Charnes, Cooper and Rhodes (1978) can be explained by an intuitive analogy taken from engineering. According to the law of energy conservation, the different types of energies can be transformed, but energy cannot be created. In case of a power plant for example, it is not possible to produce more energy, than the energy content of the fuel used, that is, technical efficiency is always lower than 1. Applying this engineering analogy in the area of performance evaluation in operations management it can be stated, that the measure of output is always smaller than the measure of input. In the best possible case, the ratio of output measure and input measure is equal to 1 . The output and input measures are calculated as weighted outputs and weighted inputs, and the best possible weight values are looked for a DMU, which is called reference DMU $R$. Let us assume that $J$ number of DMUs are evaluated, when $K$ different outputs are observed and $I$ different inputs are used. Notations applied in this paper are listed in Table 1 . If $y_{k j}(k=1, \ldots, K ; j=1, \ldots, J)$ are the observed output values of output $k$, and $x_{i j}(i=1, \ldots, I ; j=1, \ldots, J)$ are the observed input values of input $i$ for DMU $j$, furthermore $v_{k}(k=1, \ldots, K)$ and $u_{i}(i=1, \ldots, I)$ denote the output and input weights then the linear programming formulation for finding the most favorable weights for DMU $R$ is as follows,

$$
\begin{aligned}
& \operatorname{Max}\left(\sum_{k=1}^{K} v_{k} y_{k R} / \sum_{i=1}^{I} u_{i} x_{i R}\right) \\
& \sum_{k=1}^{K} v_{k} y_{k j} / \sum_{i=1}^{I} u_{i} x_{i j} \leq 1 \quad j=1, \ldots, n \\
& u_{i}, v_{k} \geq 0 \quad i=1, \ldots, I ; \quad k=1, \ldots, K
\end{aligned}
$$

If problem (1) is transformed to eliminate the ratio of variables, and the weighted input is fixed (equal to 1) in order to get unique solution for LP problem (1), then the primal version of the input oriented, constant return to scale (CRS) model is obtained, that is, 


$$
\begin{aligned}
& \operatorname{Max}\left(\sum_{k=1}^{K} v_{k} y_{k R}\right) \\
& \sum_{i=1}^{I} u_{i} x_{i R}=1 \\
& \sum_{k=1}^{K} v_{k} y_{k j}-\sum_{i=1}^{I} u_{i} x_{i j} \leq 0 \quad j=1, \ldots, n \\
& u_{i}, v_{k} \geq 0 \quad i=1, \ldots, I ; \quad k=1, \ldots, K
\end{aligned}
$$

Table 1: Notation (1) - Indices and parameters

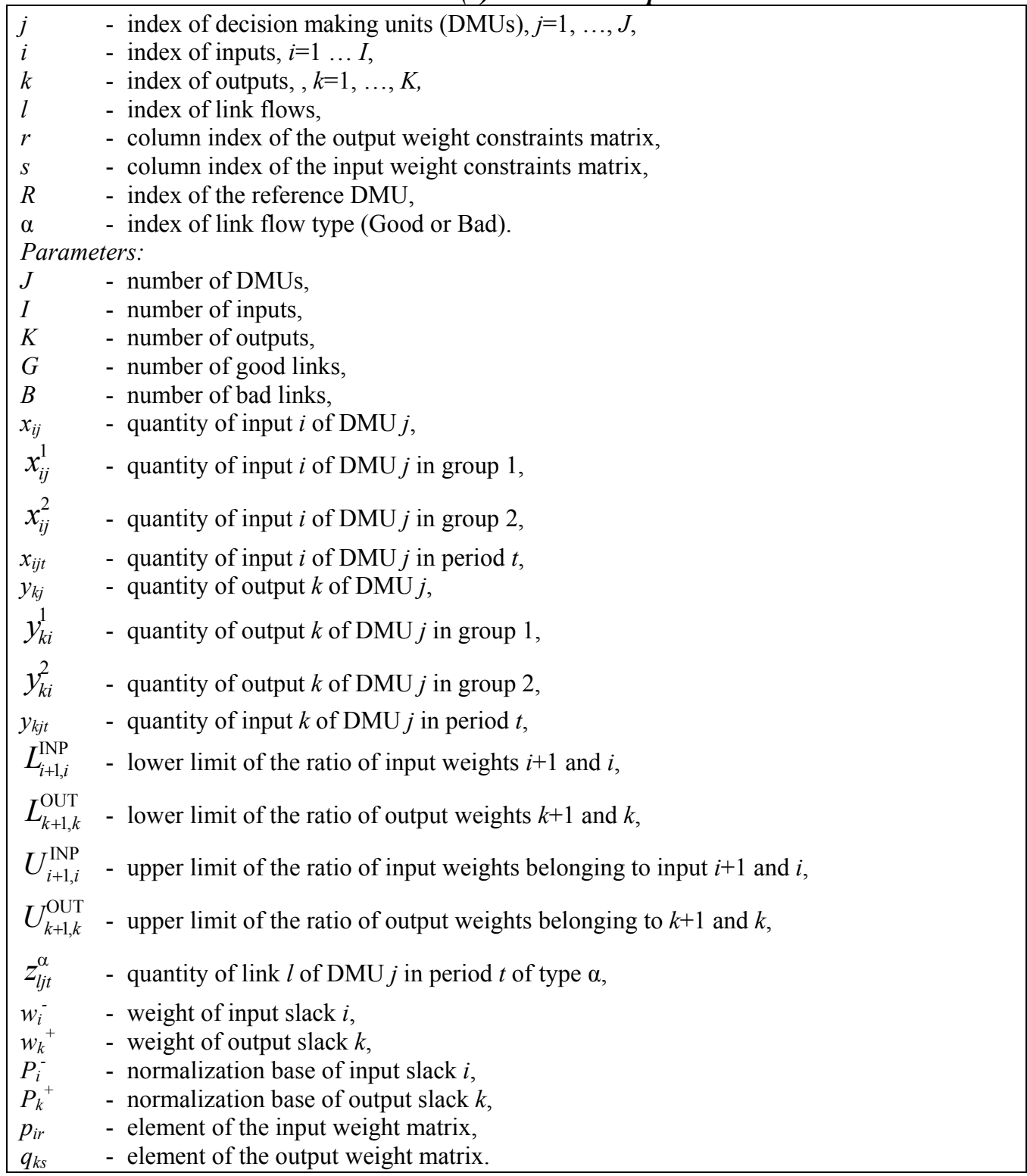


Table 2: Notation (2) - Variables

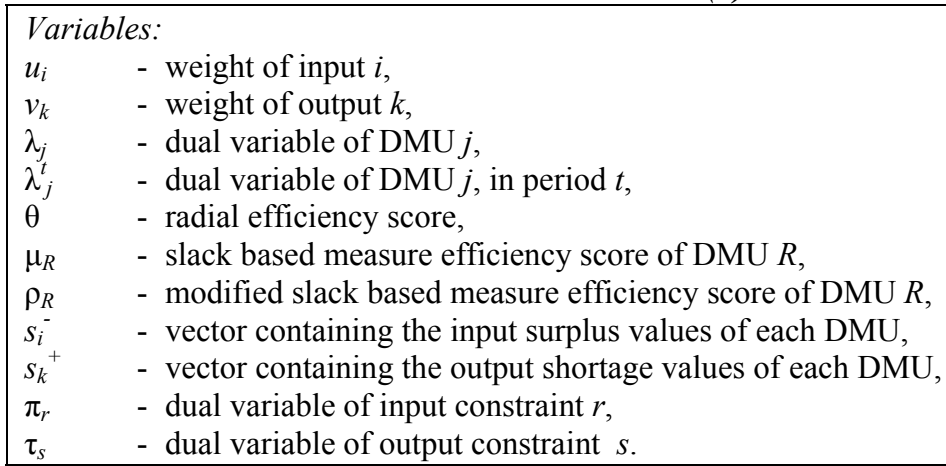

The dual version of problem (2), however, has more practical relevance and leads to another interpretation of DEA. According to the dual interpretation any linear combination of the observed output and input values leads to a new and feasible DMU, which may exist in practice. The production possibility set is determined by all possible linear combinations of the observed outputs and inputs. If $\lambda_{j}(j=1, \ldots, J)$ are the coefficients of the linear combination of output and input values, then the production possibility set of DMU $R$ can be defined as follows,

$$
\begin{array}{rl}
y_{k R} \leq \sum_{j=1}^{J} y_{k j} \lambda_{j} & k=1, \ldots, K \\
x_{i R} \geq \sum_{j=1}^{J} x_{i j} \lambda_{j} & i=1, \ldots, I
\end{array}
$$

If we consider the $\lambda_{j}(j=1, \ldots, J)$ coefficients as variables, and a proper objective function is used to get an optimal combination of the output and input values, then the distance from any existing DMU from the optimal DMUs can be a basis of an efficiency score. The dual version of the input oriented CRS model assumes that all inputs must be decreased to the same proportion $(\theta)$, and efficiency is given by the smallest proportion. Consequently the smallest amount of input necessary to produce the observed output must be determined. The corresponding dual LP model is as follows,

$$
\begin{array}{ll}
\operatorname{Min}(\theta) & k=1, \ldots, K \\
\sum_{j=1}^{J} \lambda_{j} y_{k j} \geq y_{k R} & i=1, \ldots, I \\
\sum_{j=1}^{J} \lambda_{j} x_{i j} \leq \theta x_{i R} & j=1, \ldots, J \\
\lambda_{j} \geq 0 &
\end{array}
$$

In primal problem (2), the optimal value of the weights of inputs and outputs are determined by linear programming. Frequently, the value of some weights is zero, that is, when the efficiency score is calculated, some inputs and outputs have zero weights. Inputs and outputs with zero weights are ignored in the evaluation, which is not always 
acceptable for management purposes. To avoid the problem of zero weights, restrictions which reflect the intention of management can be added to model (2). One possible form of weight restriction is when constraints for all possible pairs of inputs and outputs are introduced, that is,

$$
\begin{array}{ll}
L_{k, k+1}^{\mathrm{OUT}} \leq \frac{v_{k+1}}{v_{k}} \leq U_{k, k+1}^{\mathrm{OUT}} & k=1, \ldots K-1 \\
L_{i, i+1}^{\mathrm{INP}} \leq \frac{u_{i+1}}{u_{i}} \leq U_{i, i+1}^{\mathrm{INP}} & i=1, \ldots I-1
\end{array}
$$

Adding constraints (5) to model (2) and writing the dual form of the resulting model, the input oriented CRS assurance region (AR) dual model is obtained which is as follows,

$$
\begin{array}{ll}
\operatorname{Min}(\theta) & \\
\sum_{j=1}^{J} \lambda_{j} y_{k j}+\sum_{S} \tau_{s} q_{k s} \geq y_{k R} & k=1, \ldots, K \\
\sum_{j=1}^{J} \lambda_{j} x_{i j}-\sum_{r} \pi_{r} p_{i r} \leq \theta x_{i R} & i=1, \ldots, I \\
\lambda_{j}, \tau_{s}, \pi_{r} \geq 0 & j=1, \ldots, J ; \quad \forall s ; \quad \forall r
\end{array}
$$

In model (2), (4) and (6) input and output data can only be semi-positive. In practice, however, sometimes negative inputs and outputs may frequently occur. Several attempts can be found in the literature to cope with negative data when radial efficiency measure is used. In the following part of the paper we use the semi-oriented radial model (SORM) proposed by Emrouznejad, Anouze and Thanassoulis (2010). In the SORM model all inputs and outputs are separated into two groups. Positive data belong to group 1 and the absolute values of the negative data belong to group 2 . The separated input data of the SORM model are as follows,

$$
\begin{aligned}
& x_{i j}^{(1)}= \begin{cases}x_{i j} & \text { if } x_{i j} \geq 0 \\
0 & \text { if } x_{i j}<0\end{cases} \\
& x_{i j}^{(2)}= \begin{cases}0 & \text { if } x_{i j} \geq 0 \\
a b s\left(x_{i j}\right) & \text { if } x_{i j}<0\end{cases}
\end{aligned}
$$

and the separated output data of the SORM model are as follows,

$$
\begin{aligned}
& y_{k j}^{(1)}=\left\{\begin{array}{l}
y_{k j} \text { if } y_{k j} \geq 0 \\
0 \quad \text { if } y_{k j}<0
\end{array}\right. \\
& y_{k j}^{(2)}=\left\{\begin{array}{l}
0 \text { if } y_{k j} \geq 0 \\
a b s\left(y_{k j}\right) \text { if } y_{k j}<0
\end{array}\right.
\end{aligned}
$$


Positive outputs and negative inputs are favorable for the decision maker. Consequently, the ideal DMU is always constrained by these values from below, that is, the production possibility set determined by the positive outputs and negative inputs are as follows,

$$
\begin{aligned}
& y_{k R}^{(1)} \leq \sum_{j=1}^{J} y_{k j}^{1} \lambda_{j} \quad k=1, \ldots, K \\
& x_{i R}^{(2)} \leq \sum_{j=1}^{J} x_{i j}^{2} \lambda_{j} \quad i=1, \ldots, I
\end{aligned}
$$

Negative outputs and positive inputs are unfavourable for the decision maker. Consequently, the ideal DMU is always constrained by these values from above, that is, the production possibility set determined by the negative outputs and positive inputs are as follows,

$$
\begin{array}{rl}
y_{k R}^{(2)} \geq \sum_{j=1}^{J} y_{k j}^{2} \lambda_{j} & k=1, \ldots, K \\
x_{i R}^{(1)} \geq \sum_{j=1}^{J} x_{i j}^{1} \lambda_{j} & i=1, \ldots, I
\end{array}
$$

Based on constraints (9) and (10), the dual form of the SORM model is as follows,

$$
\begin{aligned}
& \operatorname{Min}(\theta) \\
& \sum_{j=1}^{J} y_{k j}^{1} \lambda_{j} \geq y_{k R}^{1} \quad k=1, \ldots, K \\
& \sum_{j=1}^{J} y_{k j}^{2} \lambda_{j} \leq y_{k R}^{2} \quad k=1, \ldots, K \\
& \sum_{j=1}^{J} x_{i j}^{1} \lambda_{j} \leq \theta x_{i R}^{1} \quad i=1, \ldots, I \\
& \sum_{j=1}^{J} x_{i j}^{2} \lambda_{j} \geq \theta x_{i R}^{2} \quad i=1, \ldots, I \\
& \lambda_{j} \geq 0 \quad j=1, \ldots, J
\end{aligned}
$$

Models (2), (4), (6) and (11) are based on a radial measure of efficiency, that is, all inputs are decreased proportionally by the same ratio. The slack based model (SBM) proposed by Tone (1999) uses the difference of the observed values and the best possible linear combination of inputs and outputs. The difference of the actual value and the best possible value is called slack. With the help of production possibility set (3), all possible slack values of DMU $R$ are given by (12) if $s_{k}{ }^{+}$indicate the output increase possibility of output $k$ and $s_{i}{ }^{-}$indicate the input decrease possibility of input $i$, that is,

$$
\begin{array}{ll}
s_{k}^{+}=\sum_{j=1}^{J} \lambda_{j} y_{k j}-y_{k R} & k=1, \ldots, K \\
s_{i}^{-}=x_{i R}-\sum_{j=1}^{J} \lambda_{j} x_{i j} & i=1, \ldots, I
\end{array}
$$


The slack values express the distance of a DMU from the best possible DMU. Based on the slack values the following efficiency measure can be used,

$$
\mu_{R}=\frac{1-\sum_{i=1}^{I} w_{i}^{-} s_{i}^{-} / x_{i R}^{-}}{1+\sum_{k=1}^{K} w_{k}^{+} s_{k}^{+} / y_{k R}^{+}}
$$

The slack based measure of efficiency proposed by Tone (1999) can take any value between 0 and 1 , and it is based on the weighted average of the normalized input and output slacks. The basis of normalization is the actual value of outputs and inputs in expression (13).

The basic DEA concept assumes that all observed inputs and outputs are semi-positive. In case of negative values some modification of the formulation is required to get feasible solution and to keep the efficiency score between 0 and 1. Silva Portela, Thanassoulis and Simpson (2004) proposed a directional distance approach which is based on the range of the possible output and input improvements. Assume that the highest possible output is the highest observed output, and the improvement possibility is defined by the distance between the highest possible value and the observed value. In this case, the output slack may change in the following range for reference DMU $R$,

$$
P_{k R}^{+}=\max _{j}\left(y_{k j}\right)-y_{k R} \quad k=1 \ldots, K
$$

Similarly, assume, that the smallest possible input is the smallest observed input, and the improvement possibility is defined by the distance between the observed value and the smallest possible value. In this case, the input slack may change in the following range for reference DMU $R$,

$$
P_{i R}^{-}=x_{i R}-\min _{j}\left(x_{i j}\right) \quad i=1 \ldots, s
$$

Ranges (14) and (15) are called Silver-Portela (S-P) ranges, and can be used for normalizing the slack values in case of negative outputs and/or inputs. Correspondingly, the modified slack based model (MSBM) proposed by Sharp, Meng and Liu (2007) applies the following efficiency measure,

$$
\rho_{R}=\frac{1-\sum_{i=1}^{I} w_{i} s_{i}^{-} / P_{i R}^{-}}{1+\sum_{k=1}^{K} w_{k} s_{k}^{+} / P_{k R}^{+}}
$$

Solving models (4), (6) and (11) in the first phase, a second phase is required. In the second phase a slack maximization model is solved using the optimal efficiency score of phase 1. Phase 2 is used to check the strong efficiency conditions, and to obtain the independent input decrease and output increase possibilities (Cooper, Seiford and Tone, 2007). In case of the slack based models, this second phase is not required.

Several variations of the radial and slack based models exist in the literature (see for example Sooper, Seiford and Tone, 2007). Depending on the main objective of evaluation, input oriented, output oriented or non-oriented models can be used. If the rate of the use of inputs and the rate of the generation of outputs change, then a 
variable return to scale (VRS) model is appropriate. If information related to input and output weights are necessary, then primal models are preferred. Assurance region models can be used when weight restrictions are introduced by the decision maker. Finally, when the efficiency of several DMUs must be evaluated, and the inputs and outputs of these DMUs are not independent from each other, then network DEA models are recommended (Tone and Tsutsui, 2010).

Dynamic DEA models are special network DEA models. In this case, the performance of the same DMU must be evaluated over several periods; consequently, the production possibility set must be defined for each period. A part of the production possibility set is determined by the observed output and input values of the DMUs in each period $t$, that is, constraints (2) must be completed with index $t$, as follows,

$$
\begin{array}{ll}
y_{k R t} \leq \sum_{j=1}^{J} y_{k j t} \lambda_{j}^{t} & k=1, \ldots, K ; \quad t=1, \ldots, T \\
x_{i R t} \geq \sum_{j=1}^{J} x_{i j t} \lambda_{j}^{t} & i=1, \ldots, I ; \quad t=1, \ldots, T
\end{array}
$$

In dynamic models, the production possibility set of a given period is also determined by the link flows $\left(z_{l j t}\right)$ which connect the neighbouring periods. If a link flow has favourable effect on operation, then it is called "Good" link (Tone and Tsutsui, 2010) and an output type constraints must be determined, that is,

$$
\sum_{j=1}^{J} z_{l j t}^{\text {Good }} \lambda_{j}^{t} \geq z_{R t}^{\text {Good }} \quad l=1, \ldots, G ; \quad t=1, \ldots, T
$$

If a link flow has unfavourable effect on operation, then it is called "Bad" link (Tone and Tsutsui, 2010) and an input type constraints must be determined, that is,

$$
\sum_{j=1}^{J} z_{l j t}^{\mathrm{Bad}} \lambda_{j}^{t} \leq z_{R t}^{\mathrm{Bad}} \quad l=1, \ldots, B ; \quad t=1, \ldots, T
$$

The different periods are connected by the continuity equations in the dynamic models. The optimal linear combination of the link flows is identical in the neighbouring periods, that is,

$$
\sum_{l} z_{l j t}^{\alpha} \lambda_{j}^{t}=\sum_{l} z_{l j t}^{\alpha} \lambda_{j}^{t+1} \quad t=1, \ldots, T-1 ; \quad \alpha=\{\text { Good, Bad }\}
$$

In the following part of the paper the performance of the student groups in the production simulation games are evaluated with several DEA models. Radial efficiency is determined with model (4), (6) and (11). Slack based efficiency is determined with objective functions (13) and (16). Finally, dynamic efficiency is determined using constraints (17), (18), (19) and (20).

\section{Application environment}

We analysed a production simulation game, which is developed by Ecosim to support education and training in the production management area (www.ecosim.hu). The objective of the game is to simulate production management decision making in a car 
engine manufacturing factory. The factory produces three different car engines for five different markets in 7 periods. Each market has its own demand characteristics. The car engines are assembled from parts on assembly lines operated by workers.

For the next production period (year) each student group must make sales and marketing, production, investment and financial decisions. After submitting the decisions, the simulation program generates the results of the actual production period. The results are summarized in a production report and in a financial report. Using the results and experiences of the earlier periods the student groups try to increase operational performance of the next periods.

We used different input oriented DEA models for evaluating the performance of student groups at the end of the seventh period of the simulation game. In all cases we applied a constant return to scale model, because there is not size difference between the DMUs, thus a variable return to scale (VRS) approach is not relevant.

Two outputs and four inputs were considered in the analysis. In our previous papers we presented the evaluation of the performance of student groups using different outputs (Koltai and Uzonyi 2012). In this paper, the results of several DEA models addressing various modelling problems are presented. One of the outputs is cumulated production quantity which reflects the effect of production management decisions related to machine and worker capacity, to material requirement planning and to inventory management. The other output is net profit which integrates the effect of marketing, production and financial decisions. The four inputs - cumulated number of workers, cumulated number of machine hours, cumulated sum of money spent on raw materials and cumulated value of credits - represent the resources used in the production process. Consequently, the performance of the production system based on these decisions reflects student's knowledge in the related areas.

\section{Comparison of the results of the different DEA models}

The performance of 18 student groups is compared using input oriented CRS, CRSAR, SORM, SBM, MSBM and dynamic MSBM model. The results are summarized in Table 2. Column 2 and 3 shows the values of the two outputs applied in the evaluation. These data are properly scaled to avoid numerical problems. Column 4-9 shows the efficiency scores of the different models. In those models, which cannot handle negative data, negative values were substituted by zero.

Using the basic input oriented CRS model, 7 student groups have the highest possible efficiency score. The results show that the operation of almost half of the DMUs is efficient. Furthermore, the value of the efficiency score of inefficient groups is close to 1 , which indicate a low discrimination power of the model. In this case, a large number of input and output weights are zero, consequently, for example, the profit has insignificant effect on the obtained efficiency scores.

Applying weight restrictions (CCR-AR), it can be observed that all groups obtained lower scores. The number of the efficient groups is also reduced, only groups 3,7 and 15 remained efficient. We applied 0.1 for the pairwise relative lower limit of the inputs, and 0.25 for the lower limit of the ratio of outputs. 
Table 2: Efficiency results of DEA models

\begin{tabular}{|c|c|c|c|c|c|c|c|c|}
\hline Team & $\begin{array}{c}\text { Output 1 } \\
\text { Net } \\
\text { profit }\end{array}$ & $\begin{array}{c}\text { Output 2 } \\
\text { Production } \\
\text { Quantity }\end{array}$ & $\mathbf{C R S}$ & $\begin{array}{c}\text { CRS- } \\
\text { AR }\end{array}$ & SORM & SBM & MSBM & $\begin{array}{c}\text { Dyna- } \\
\text { mic } \\
\text { MSBM }\end{array}$ \\
\hline $\mathbf{1}$ & 0,650 & 2,701 & $\mathbf{1 , 0 0 0 0}$ & 0,9281 & $\mathbf{1 , 0 0 0 0}$ & $\mathbf{1 , 0 0 0 0 0}$ & $\mathbf{1 , 0 0 0 0}$ & 0,6141 \\
\hline $\mathbf{2}$ & 0,097 & 2,714 & $\mathbf{1 , 0 0 0 0}$ & 0,8109 & $\mathbf{1 , 0 0 0 0}$ & $\mathbf{1 , 0 0 0 0 0}$ & $\mathbf{1 , 0 0 0 0}$ & 0,5409 \\
\hline $\mathbf{3}$ & 1,874 & 2,911 & $\mathbf{1 , 0 0 0 0}$ & $\mathbf{1 , 0 0 0 0}$ & $\mathbf{1 , 0 0 0 0}$ & $\mathbf{1 , 0 0 0 0 0}$ & $\mathbf{1 , 0 0 0 0}$ & 0,9017 \\
\hline $\mathbf{4}$ & 0,186 & 2,448 & 0,9732 & 0,8750 & 0,9732 & 0,22036 & 0,7033 & 0,5603 \\
\hline $\mathbf{5}$ & $-0,269$ & 2,327 & 0,9579 & 0,7583 & 0,9579 & $\mathbf{1 , 0 0 0 0 0}$ & 0,5192 & 0,5701 \\
\hline $\mathbf{6}$ & 0,046 & 2,573 & 0,9823 & 0,8583 & 0,9823 & 0,07051 & 0,6846 & 0,5242 \\
\hline $\mathbf{7}$ & 1,656 & 2,778 & $\mathbf{1 , 0 0 0 0}$ & $\mathbf{1 , 0 0 0 0}$ & $\mathbf{1 , 0 0 0 0}$ & $\mathbf{1 , 0 0 0 0 0}$ & $\mathbf{1 , 0 0 0 0}$ & $\mathbf{1 , 0 0 0 0}$ \\
\hline $\boldsymbol{8}$ & 1,007 & 2,553 & 0,9917 & 0,9152 & 0,9917 & 0,62730 & 0,6043 & 0,8186 \\
\hline $\mathbf{9}$ & 1,714 & 2,977 & $\mathbf{1 , 0 0 0 0}$ & 0,9999 & $\mathbf{1 , 0 0 0 0}$ & $\mathbf{1 , 0 0 0 0 0}$ & $\mathbf{1 , 0 0 0 0}$ & 0,7370 \\
\hline $\mathbf{1 0}$ & 1,051 & 2,836 & 0,9982 & 0,9351 & 0,9982 & 0,88190 & 0,8757 & 0,6030 \\
\hline $\mathbf{1 1}$ & 0,987 & 2,440 & 0,9982 & 0,9473 & 0,9982 & 0,75962 & 0,7461 & 0,6316 \\
\hline $\mathbf{1 2}$ & 0,183 & 2,466 & 0,9798 & 0,8647 & 0,9798 & 0,19680 & 0,6468 & 0,5510 \\
\hline $\mathbf{1 3}$ & 0,675 & 2,368 & 0,9322 & 0,8020 & 0,9322 & 0,47361 & 0,5573 & 0,5265 \\
\hline $\mathbf{1 4}$ & 1,729 & 2,650 & $\mathbf{1 , 0 0 0 0}$ & 0,9859 & $\mathbf{1 , 0 0 0 0}$ & $\mathbf{1 , 0 0 0 0 0}$ & $\mathbf{1 , 0 0 0 0}$ & $\mathbf{1 , 0 0 0 0}$ \\
\hline $\mathbf{1 5}$ & 0,879 & 2,665 & $\mathbf{1 , 0 0 0 0}$ & $\mathbf{1 , 0 0 0 0}$ & $\mathbf{1 , 0 0 0 0}$ & $\mathbf{1 , 0 0 0 0 0}$ & $\mathbf{1 , 0 0 0 0}$ & 0,7633 \\
\hline $\mathbf{1 6}$ & 0,197 & 2,487 & 0,9508 & 0,8305 & 0,9508 & 0,18356 & 0,5641 & 0,5515 \\
\hline $\mathbf{1 7}$ & 0,667 & 2,964 & 0,9053 & 0,8250 & 0,9053 & 0,42232 & 0,0676 & 0,5696 \\
\hline $\mathbf{1 8}$ & 0,799 & 2,553 & 0,9867 & 0,8731 & 0,9867 & 0,69966 & 0,7184 & 0,5614 \\
\hline
\end{tabular}

It is proved, that the efficiency score of the SBM models is not greater than the CRS efficiency values (Tone, 1999). In addition, a DMU is CCR efficient if it is SBM efficient. Consequently, CCR efficient student groups remained at the efficient status under SBM evaluation. The SBM score of most of the inefficient groups are lower than the CRS scores. Group 5 has higher efficiency score with SBM than with CRS evaluation. This contradiction indicates that the SBM model can not be applied in this case. Note, that group 5 has negative net profit, consequently the output values are not semi-positive, and the efficiency scores are theoretically erroneous. We can also observe large differences between the efficiency scores of the CRS (CRS-AR) and the SBM models. These large differences can be explained by the fact, that slacks are not reflected in the CRS scores. The CRS model calculate the slack values in the second phase, and these values are considered, when the target quantities are calculated, but are not reflected in the scores.

Finally, the last column shows the overall efficiency scores calculated by the dynamic MSBM model. The results show, that only groups 7 and 14 remained efficient. Moreover the efficiency scores of most of the groups are significantly reduced. A detailed analysis of the period efficiencies showed, that some groups which have good overall performance, may have efficiency problems in some periods.

The MSBM and the SORM models can be used to handle negative data. According to Table 2. MSBM and SORM selected the same DMUs as efficient, but different target values are recommended. The target values recommended by the CRS, and the MSBM models for a selected student group (Team 10) is presented in Table 3. It can be seen, 
that the MSBM target values indicate a slightly smaller input reduction, than that of the CRS values, but with a higher production quantity.

Table 3: Target values of Team 10

\begin{tabular}{|l|c|c|c|c|c|c|}
\hline & $\begin{array}{c}\text { Production } \\
\text { quantity }\end{array}$ & $\begin{array}{c}\text { Net } \\
\text { profit }\end{array}$ & $\begin{array}{c}\text { No. } \\
\text { workers }\end{array}$ & $\begin{array}{c}\text { Machine } \\
\text { hours }\end{array}$ & $\begin{array}{c}\text { Raw } \\
\text { materials }\end{array}$ & Debt \\
\hline Original & 2836320 & 1050699 & 13662 & 3284436 & 5608796 & 1632000 \\
\hline CRS & 2836320 & 1050699 & 12489 & 3278483 & 5410413 & 1123659 \\
\hline MSBM & 2841860 & 1050699 & 12514 & 3284436 & 5423519 & 1124375 \\
\hline
\end{tabular}

Source: the authors own table

Note, that the SORM efficiency scores are identical with the CRS efficiency scores in Table 1 . This can be explained by the fact, that Team 5 is the only team with negative output value. In this special case, the constraint belonging to this unfavorable output does not influence the production possibility set, and consequently the efficiency scores.

\section{Conclusion}

This paper compared the results of different DEA models when the performance of student groups in a production simulation game is evaluated. Basic models with radial efficiency measures are used to analyse the effect of input and output weights, and to separate the proportional decrease of inputs from the independent input reduction possibilities. Slack based measure models are applied to study the joint effect of proportional and independent input/output changes. The results show the advantage of the application of the assurance regain model. The presence of negative outputs requires the application of models which can be adapted to negative data.

The evaluation of the groups in the static DEA models uses aggregated input and output values. The inputs and outputs in the 7 production periods are simply cumulated, consequently, the dynamic behaviour of the groups is not reflected in the results. When applying Dynamic DEA models, the progress of groups during the decision making process can be analysed and a more detailed picture about the learning process can be obtained. (Koltai and Uzonyi 2013) Analysing the different results provided by the static and dynamic models and using the information provided by the dynamic models about local efficiency problems are an interesting and promising topic for further research.

\section{References}

1. Charnes, A., Cooper, W.W., Rhodes, A. (1978): Measuring the efficiency of decision making units. "European Journal of Operations Research", 2, pp. 429-444. http://dx.doi.org/10.1016/0377-2217(79)90229-7

2. Cooper, W.W., Seiford, L.M., Tone, K. (2007): Data envelopment analysis. Springer. http://dx.doi.org/10.1007/978-0-387-45283-8

3. Doyle, J.R. and Green, R.H. (1991): Comparing products using data envelopment analysis. “Omega International Journal of Management Sciences", 19(6), pp. 631-638. http://dx.doi.org/10.1016/0305-0483(91)90012-i 
4. Emrouznejad, A., Anouze, A.L., Thanassoulis, E. (2010): A semi - oriented radial measure for measuring the efficiency of decision making units with negative data, using DEA. "European Journal of Operational Research", 200, pp. 297-304. http://dx.doi.org/10.1016/j.ejor.2009.01.001

5. Johnes, J., (2006): Data envelopment analysis and its application to the measurement of efficiency in higher education. "Economics of Education Review", 25(3), pp. 273-288. http://dx.doi.org/10.1016/j.econedurev.2005.02.005

6. Koltai, T., Uzonyi-Kecskés, J. (2012): Data Envelopment Analysis and its Application for Measuring the Performance of Students in a Production Simulation Game. In: Illés, Cs.B. (ED) SMEs' Management in the 21st Century: Challanges and Solutions. Czestochowa: Publishing Section of the Faculty of Management, Czestochova University of Technology, pp. 322-335.

7. Koltai, T., Uzonyi-Kecskés, J. (2013): Analysis of the learning process in a production simulation game with DEA using cumulative data. In: Miskolci Egyetem. Innovációs és Technológia Transzfer Centrum (szerk.). microCAD 2013: XXVII. microCAD International Scientific Conference: Section Q: Economic Challenges in the 21st Century (Gazdasági kihívások a XXI. században). Miskolci Egyetem, Paper Q9. 6 p.

8. Markovits-Somogyi. R., Gecse, G. and Bokor, Z. (2011): Basic efficiency measurement of Hungarian logistics centres using data envelopment analysis. "Periodica Polytechnica Social and Management Sciences", 19(2), pp. 97-101.

http://dx.doi.org/10.3311/pp.so.2011-2.06

9. Panayotis, A.M. (1992): Data envelopment analysis applied to electricity distribution districts. "Journal of the Operations Research Society", 43(5), pp. 549-555. http://dx.doi.org/10.1057/jors.1992.80

10. Sharp, J., Meng, W., Liu, S. (2006): A modified slacks based measure model for data envelopment analysis with 'natural' negative outputs and inputs. "Journal of Operational Research Society" 57(11), pp. 1-6. http://dx.doi.org/10.1057/palgrave.jors.2602318

11. Sherman, H.D. and Ladino G. (1995): Managing bank productivity using data envelopment analysis (DEA). "Interfaces", 25(2), pp. 60-73. http://dx.doi.org/10.1287/inte.25.2.60

12. Sinuany-Stern, Z., Mehrez, A. and Barboy, A. (1994): Academic departments efficiency via DEA. "Computers \& Operations Research", 21(5), pp. 543-556. http://dx.doi.org/10.1016/0305-0548(94)90103-1

13. Tone, K. (1999): A slacks - based measure of efficiency in data envelopment analysis. "European Journal of Operational Research", 130 pp. 498-509. http://dx.doi.org/10.1016/s0377-2217(99)00407-5

14. Tone, K. and Tsutsui, M. (2010): Dynamic DEA: A slack-based measure approach. "Omega", 38, pp. 145-156. http://dx.doi.org/10.1016/j.omega.2009.07.003

15. Silva Portela, M.C.A., Thanassoulis, E., Simpson, G. (2004): Negative Data in DEA: a directional distance approach applied to bank branches. "Journal of Operational Research Society”, 55, pp. 1111-1121. http://dx.doi.org/10.1057/palgrave.jors.2601768 
Anna KARCZEWSKA, Magdalena BSOUL

\title{
2.4. PUBLIC RELATIONS IN THE MANAGEMENT OF A MODERN ENTERPRISE - SOLUTIONS FOR CRISIS SITUATIONS
}

\begin{abstract}
Summary
Public relations and communications management covers wide range of ideas such as media relations, public affairs, community affairs, product publicity, events management, crisis management, lobbing, investor relations etc. The article presents an overview of modern aspects of public relations, its role in management of an enterprise, including crisis management. The perception of public management and its roles are changing. The enterprises face the challenges such as fast technological changes, developing of international relations and growing global competition. What is also changing is the nature and tools of communication, what influences the public relations management. Public relations may be a strategic resource which, when appropriately managed, may contribute to effective realization of the strategy of an enterprise. Modern public relations help to understand the environment of an organization and maintain the relations with groups significant to achieving the strategic goals of an enterprise. What is also important issue for modern public relations is an ethical approach to business, social, and environmental responsibility. The authors of the article mention the main characteristics and challenges of modern public relations and try to highlight its significance to the successful operation of an enterprise.
\end{abstract}

Keywords: public relations, management, communications, enterprise

\section{Public relations - a form of communication in an organization}

Every manager of a modern enterprise should be aware of the significance of a communications management for the activity and competitiveness of his organization. Communication processes are crucial to effective functioning of organizations. They influence the realization of the following functions in managing an organization: planning, organizing, motivating and controlling (Stankiewicz, 1998). Good company management requires highly developed communication skills, both on the individual as well as on the organizational level. One of the most important form of company's communication processes is public relations (ed. Heath, 2005).

There are a large number of definitions of public relation. The Encyclopaedia of Public Relations offers a general description of the term: "public relations is a set of management, supervisory, and technical functions that foster an organization's ability to strategically listen to, appreciate, and respond to those persons whose mutually beneficial relationships with the organization are necessary if it is to achieve its mission and vision" (Kunczik, 1993).

One can distinguish also two general ways of defining PR. It refers to the process of shaping mutual relationship between people in various social situations especially in the political, social and economic life and what is more, it refers to the set of actions of the interdisciplinary, knowledge-requiring nature and covering a number of areas, such as media-relations, strategy counselling, crisis and image management etc. (Bsoul, 2010). It can be divided into internal public relations (the public are the members of an 
organization) and external public relations (the public are various stakeholders outside an organization) (Bsoul, 2005).

It may also be defined as a management communication function, which enables a company to "adopt to the environment, changing the environment or maintaining the status quo, providing that the aims of an organization are reached" (Goban-Klas, 1997). Treating Public Management as a form of communication, one can enumerate its main communication functions: selection of information, presentation of information, performing a role of a mediator, being a leader of public opinion (GobanKlas, Kadracic and Czarnowski, 1997).

The conceptualization of the term public relations often perceive it as a continuous activity connected with an organization's relations with the public: "public relations is a planned, continuous activity, conducted with taking into consideration the results of actions. It means conveying by the company specially prepared various forms of information in order to create its desirable image in the environment of the company, which enables better integration with the environment and facilitates the realization of the main goals of a company. This activity may be conducted by other organizations, including profit-oriented" (Heath, 2005).

Before the $20^{\text {th }}$ century, there were several specializations which later evolved into a structured phenomenon of public relations. These specializations now are treated as functions of the public management. Each public management function is characterized by special set of objectives; they aim at building and maintaining as well as fixing relations with various audiences. The most typical specializations and also functions are: corporate communication, media relations, investor relations, community relations, issues management, employee relations, donor relations, government relations and strategic philanthropy (ed. Heath, 2005). Every function of public management is a form of a dialogue with public, so it has to take into consideration the feedback from the public and be prepared for the cooperation with many - stakeholders.

\section{Public relations - a search for the dialogue with the audiences}

The communication form such as public relations has many different audiences and consequently it is not simple and uniform but complex and diverse. It have to justify organization's activity to not only to internal shareholders, but also to customers, public opinion, government, employees, financial groups and media. The form and content of the message should be adopted to the particular environment. Public relations program, which aims at engaging in the dialogue with different public, should take into consideration and analyse the stakeholder specificity. The goals and obligations in public relations depend on the kind of stakeholders it turns to. Table 1 presents main responsibilities of public management directed to different audiences. 
Table 1: Stakeholders' responsibilities

\begin{tabular}{|c|c|c|}
\hline Stakeholder & & Responsibilities \\
\hline \multirow{3}{*}{ Customers } & Economic issues & $\begin{array}{l}\text { Profitability, competitive products, survival of the } \\
\text { company, product quality }\end{array}$ \\
\hline & Ethical issues & $\begin{array}{l}\text { Honesty, the best possible products and services, } \\
\text { satisfy customer needs }\end{array}$ \\
\hline & Voluntary issues & Long-term business, function development \\
\hline \multirow{4}{*}{ Employees } & Economic issues & Work and income \\
\hline & Legal issues & $\begin{array}{l}\text { Cooperation, following the regulations in dismissal } \\
\text { situations }\end{array}$ \\
\hline & Ethical issues & $\begin{array}{l}\text { Good working conditions, stability and security, } \\
\text { developing possibilities, honesty }\end{array}$ \\
\hline & Voluntary issues & Education, supporting activity and interests \\
\hline \multirow[t]{2}{*}{ Competitors } & Ethical issues & $\begin{array}{l}\text { Truthful information, fair marketing and fair pricing } \\
\text { practices, no use of questionable consistency and } \\
\text { stability, playing the game by the rules }\end{array}$ \\
\hline & Voluntary issues & Good relations, cooperation in industry-related issues \\
\hline \multirow[t]{2}{*}{ Owners } & Economic issues & $\begin{array}{l}\text { Return on assets/investments, securing investments, } \\
\text { maximizing cash flow, solvency, profits }\end{array}$ \\
\hline & Ethical issues & Adequate information \\
\hline \multirow{3}{*}{ Suppliers } & Economic issues & Volumes profitability \\
\hline & Ethical issues & Honesty \\
\hline & Voluntary issues & Sustainable and reliable long-term relations \\
\hline \multirow{4}{*}{ Community } & Economic issues & Taxes employment, influence on trade balance \\
\hline & Legal issues & Following laws and regulations \\
\hline & Ethical issues & Behaving with integrity \\
\hline & Voluntary issues & Supporting local activities \\
\hline \multirow{4}{*}{ Government } & Economic issues & Taxes employment, influence on trade balance \\
\hline & Legal issues & Following laws and regulations \\
\hline & Ethical issues & Behaving with integrity \\
\hline & Voluntary issues & Supporting local activities \\
\hline \multirow{2}{*}{$\begin{array}{l}\text { Financial } \\
\text { groups }\end{array}$} & Economic issues & Profitability, security of investment \\
\hline & Ethical issues & Adequate information \\
\hline \multirow{3}{*}{$\begin{array}{l}\text { The } \\
\text { environment } \\
\text { (e.g. pressure } \\
\text { groups) }\end{array}$} & Legal issues & Compliance with environmental regulations \\
\hline & Ethical issues & $\begin{array}{l}\text { Environmental friendliness, protecting the } \\
\text { environment, product recycling }\end{array}$ \\
\hline & Voluntary issues & Proactive environmental management \\
\hline \multirow{3}{*}{$\begin{array}{l}\text { Old and new } \\
\text { media, e.g. } \\
\text { press, TV, } \\
\text { web }\end{array}$} & Legal issues & Compliance with the law \\
\hline & General issues & $\begin{array}{l}\text { Compliance with guidelines, codes of conduct and } \\
\text { ethics statement }\end{array}$ \\
\hline & Voluntary issues & Internal web pages and chat rooms \\
\hline
\end{tabular}

Source: Olivier (2010), pp 17-18. 
The second important element of public relations activity is planning. The planning process is complex and based on the following key issues. The essential aspects are determined by the answers to six main questions, which the public relations managers are obliged to find the answers:

- "What is the problem? (researching the issue)

- What does the plan seek to achieve? (what are the objectives)

- Who should be talked to? (with which publics should a relationship be developed)

- What should be said? (what is the content or message)

- How should the message be communicated? (what channels should be used for dissemination)

- How should success to be judged? (how will the work be evaluated against the objectives)" (Tench and Yeomans, 2006).

In our modern globalized world, it is crucial to adapt the public relations to the requirements of an international publics. The creation of public relations management strategy in the international dimension should take into account:

1. optimizing communication forms on the international market (choice of the most suitable set of promotion tools),

2. optimizing the message (the possible best preparation of a message through the identification of a culture of an audience in a given country),

3. optimizing the attractiveness of a product (a company is required to upgrade the product, increase its desirability taking into account the values and criteria in a given country),

4. optimizing the personnel qualification in particular branch offices (constant improving of personnel's skills, including the language skills)

5. optimizing the flexibility of actions and adapting to the changing environment (making fast changes of marketing program to adapt to changing conditions) (Witek and Adamczyk 2008).

The main aim of public relations activity is to create and maintain the organization's image and reputation and the favour of the environment as well as informing the public of an organization about its activity. What is more, the public relations management influences the attitudes of an organization and its public, monitor and provide the information about changes in the environment and inform the employees about the situation of the organization. One of the most important aims of the public relations is warning about and solving the problems and crisis situations (Smektała 2005).

Depending on what kind of situation public relations manager deals with, he has got the choice of numerous tools of communication and activities available. The collection of the public management activities is presented in Table 2 .

As it emerges from the analysis of the above table, the public relations activities are very diverse - from media relations, customer and community relations to internal communication with the organization's employees and essential, crisis management.

As it was mentioned before, there are different aims connected with different public and it is important to remember about the stakeholder specificity while choosing the best activity in a given situation. 
Table 2: Public relations' activities

\begin{tabular}{|c|c|}
\hline Media relations & Conferences \\
\hline \multirow{9}{*}{$\begin{array}{l}\text { Press conference } \\
\text { Press release } \\
\text { Articles and features } \\
\text { One-to-one briefings } \\
\text { Interviews } \\
\text { Background briefings/materials } \\
\text { Photography } \\
\text { Video news releases } \\
\text { Website, Email }\end{array}$} & Multimedia \\
\hline & Literature \\
\hline & Hospitality \\
\hline & Community relations \\
\hline & Direct involvement \\
\hline & Gifts in kind \\
\hline & Sponsorship \\
\hline & Donations \\
\hline & \multirow{4}{*}{$\begin{array}{l}\text { Special events } \\
\text { AGMs } \\
\text { SGMs } \\
\text { Special occasions }\end{array}$} \\
\hline Advertising (PR led) & \\
\hline Corporate & \\
\hline Product & \\
\hline Direct mail (PR led) & \multirow{10}{*}{$\begin{array}{l}\text { Customer relations } \\
\text { Media relations } \\
\text { Direct mail } \\
\text { Advertising } \\
\text { Internet } \\
\text { Exhibitions } \\
\text { Retail outlets } \\
\text { Sponsorship } \\
\text { Product literature } \\
\text { Newsletter }\end{array}$} \\
\hline Annual report & \\
\hline Brochures/leaflets & \\
\hline Customer reports & \\
\hline External newsletters & \\
\hline General literature (also multimedia material) & \\
\hline Exhibitions & \\
\hline Trade and public & \\
\hline Literature & \\
\hline Sampling & \\
\hline $\begin{array}{l}\text { Demonstrations } \\
\text { Multimedia }\end{array}$ & \multirow{7}{*}{$\begin{array}{l}\text { Internal communication } \\
\text { Videos } \\
\text { Briefings } \\
\text { Newsletters } \\
\text { Quality guides } \\
\text { Compact disk interactive } \\
\text { Email } \\
\text { Intranet }\end{array}$} \\
\hline Lobbying & \\
\hline One-to-one briefings & \\
\hline Background material & \\
\hline Videos, Literature & \\
\hline Group briefings & \\
\hline Hospitality & \\
\hline CDs, Audio cassettes & \multirow{3}{*}{$\begin{array}{l}\text { Corporate identity } \\
\text { Design } \\
\text { Implementation } \\
\end{array}$} \\
\hline Research & \\
\hline Organisations & \\
\hline Public relations programmes & \multirow{4}{*}{$\begin{array}{l}\text { Sponsorship } \\
\text { Sport } \\
\text { Arts } \\
\text { Worthy causes }\end{array}$} \\
\hline Issues monitoring & \\
\hline Results monitoring & \\
\hline Crisis management & \\
\hline $\begin{array}{l}\text { Planning } \\
\text { Implementation }\end{array}$ & \multirow{2}{*}{$\begin{array}{l}\text { Financial relations } \\
\text { Annual report } \\
\text { Briefing materials, One-to-one briefing } \\
\text { Media relations } \\
\text { Hospitality } \\
\text { Internet } \\
\text { Extranet }\end{array}$} \\
\hline $\begin{array}{l}\text { Liaison } \\
\text { Internal (including counseling) } \\
\text { External } \\
\text { Implementation }\end{array}$ & \\
\hline
\end{tabular}

Source: Tench and Yeomans (2006), p. 198. 


\section{Public relations - solutions for the crisis}

Public relations activity is particularly significant during the crisis situations. We may define a situation of crisis as: "usually sudden and unexpected, undesirable event, destabilizing the balance of a company and being a threat for a certain field of its activity" (Smektała, 2005). Mitroff enumerates the most frequent types of crisis segregated according to the source of the problem:

1. External economic problems (bribery, boycott, extortion, acquisition of assets (also against the will of the owner)

2. External informational problems (loss of data, forgery false rumours personal data breach)

3. Professional factors (health and diseases)

4. Breaks in work (removal from a post, failures, product defects, errors of operators, low level of safety)

5. Human resources (low morale, takeover of the executive power by the successor)

6. Visible damage (false rumours, slander, calumny)

7. Damage on a large scale (accidents, damage to the environment)

8. Psychopathology (illegal copying, tampering within the company and outside the company, sexual harassment, false rumours, hijacking high official) (Smektała, 2005).

A crisis lasts some time, develop and goes through several steps. Fink presents a lifecycle of a crisis composed of four steps: "prodromal, where warning signs appear before a crisis hits; crisis breakout or acute, where the trigger event occurs or what we typically think of as the crisis happening; chronic, the time it takes to attend to the damage and disruption from the crisis; and finally resolution, in which there is evidence that the crisis is over and no longer a factor with stakeholders" (in Heath, 2005, p. 216).

Due to the development of new information and communication technologies and the fast flow of information in the Internet websites, the speed of people's communications increased rapidly.

The company, which aims at being competitive on the market and deal with the potential crises, should react as quickly as possible and use the tools which the Internet provides for the initial response to the crisis. And what is important is to prevent and plan ahead to be prepared for the potential problems.

What is more, the powerful role of media in modern public communication makes the relationships with media very important for the companies. There is a shift towards more open and communicative relationships with the media environment. It has a great influence on corporate image and enables contact with the wide range of audiences (White and Mazur 1998).

Crisis management aims not only at reacting to a crisis. Proactive crisis management attempts to prevent the crisis, fight with it and lessen the possible and actual damage the crisis had caused. It may be divided into four steps: prevention, preparation, response and learning. So it is not only having a plan for crisis, yet planning is the essential element of crisis management. It is important to exercise the plan, prepare the crisis management team to its realization. It is advisable for the crisis management 
team to consist of people who respond to the crisis. It is recommended for the team to be cross-functional, which means that it gathers people from different parts of the organization in order to have various skills and knowledge in the team. Crisis team may include the following membership: operations, legal, public relations, security, facilities management (White and Mazur 1998).

Prevention of the problems and crises conducted by the management should include:

- making aware of the potential for crisis in the organization,

- organization of crisis team and training of the team members,

- preparing the emergency plan,

- preparing the supply base,

- preparing the documentation of previous crisis situations,

- observation of the competitors (Mruk 2002).

According to Simon and Zapala, the effective dealing with crisis situations requires adopting the following features of activity:

- factual view of the problems,

- proper strategy of activity and mobilization of supporting groups,

- presenting engagement and compassion of a company towards the injured party,

- carrying out symbolic actions (declaring help, showing goodwill),

- establishing the direct contact with the injured,

- showing the possibilities of getting a compensation,

- declaring to take instant actions towards liquidation of effects of the event, possibly also concrete prevention solutions for the future,

- having open and factual policy of communication together with the use of emotional arguments (Simon and Zapala 1996).

However, companies adopt several strategies in practice. It may be admitting to guilt and cooperation with the public, as recommended above. Presently one can often find strategies of keeping silence and ignoring the situation or even attacking and opposing to the allegations. Still active and factual informing the public in the situation of crisis prevent more conflicts from occurring and is more beneficial for the company's image and reputation.

\section{Conclusion}

Modern enterprises have to combine economic issues with ethical issues and build relationships with many different audiences. Good use of communication is essential for obtaining a company's strategic objectives. Global business environment, technological changes demand from companies to operate responsibly, maintain relationships with public and react to the crisis as fast as it is possible.

The good external strategy of communication contributes to an effective activity of a company and to preventing problems from occurring or dealing with them successfully. Internal communication (with employees) helps the members of an organization to be more efficient and effective in service or production.

It is advisable to if not appoint special public relation department or a manager responsible for the public relations, then to use the services of a public relations consultancy. 
Otherwise, the company may have bad or inconsistent relationships with the environment and miss the opportunities and benefits which result from conducting the effective public relations activity.

\section{References}

1. Bsoul, M. (2005): Public relations, in: Encyklopedia Pedagogiczna XXI w, Vol. IV, Wyd. Akademickie „Żak”, Warszawa, p. 1294

2. Bsoul, M. (2010): Zasady dobrego Public relations w polityce, in: Public relations w procesie kształtowania relacji z otoczeniem, D. Tworzydło, Z Chmielewski(eds), Wyd.Konsorcjum Akademickie,Kraków-Rzeszów-Zamość, p.11.

3. Heath, R. L. (ed.) (2005): Encyclopedia of Public Relations, Sage Publications, p. 680.

4. Tench, R., Yeomans, L. (eds) (2006): Exploring public relations, Pearson Education, pp 186187.

5. Goban-Klas, T., Kadracic, A., Czarnowski, P. (1997): Public relations czyli promocja reputacji: pojęcia, definicje, uwarunkowania, Ed.2, Business Press, Warszawa, after: Smektała T. (2005): Public relations w sytuacjach kryzysowych przedsiębiorstw, Wyd. Astrum, Wrocław, p. 13.

6. Goban-Klas, T. (1997): Teoria komunikowania jako fundament public relations, „Marketing i Rynek", nr 4, p. 7.

7. Kunczik, M. (1993): Public Relations. Konzepte und Theorien, Böhlau Verlag GmbH \& Cie, Köln, p.10.

8. Mruk, H. (ed.) (2002): Komunikowanie się w biznesie, Wyd. AM w Poznaniu, Poznań, p 139.

9. Olivier, S. (2010): Public relations strategy, Kogan Page, London, pp. 17-18.

10. Simon, R., Zapala, J.M. (1996): Public relations workbook, Writing \& techniques, NTC Business Books, Lincolnwood, Illinois, p.214-215, after: Mruk H. (ed.) (2002), Komunikowanie się w biznesie, Wyd. AM w Poznaniu, Poznań, p 142.

11. Smektała, T. (2005): Public relations w sytuacjach kryzysowych przedsiębiorstw, Wyd. Astrum, Wrocław, pp 68-69.

12. Stankiewicz, J. (1998): Komunikowanie się w organizacji, Wyd. PZ, Zielona Góra, p 15.

13. White, J., Mazur, L., (1998): Strategic Communications Management. Making Public Relations Work, Addison-Wesley Publishing Company, pp 125-127.

14. Witek, L., Adamczyk, J. (2008): Marketing międzynarodowy, Oficyna Wydawnicza Politechniki Rzeszowskiej, Rzeszów, p. 12. 


\title{
2.5. HOW CAN CORPORATE SOCIAL RESPONSIBILITY BE PERCEIVED IN MULTINATIONAL COMPANIES? - A CASE STUDY
}

\begin{abstract}
Summary
First decade of the $21^{\text {st }}$ century can be characterized by rapid development of global society as well as by remarkable growth of global issues, both on environmental and social level. These issues have strengthened the necessity to develop and apply more systematic and sustainable approach towards business activities realized on international and local level. Therefore, Corporate Social Responsibility (CSR) has become an important tool, many companies have decided to apply considering their business activities on local as well as global markets. The aim of this article is to evaluate the perception of corporate social responsibility in the context of business internationalization at the selected company. We will focus on its appraisal in four main areas especially on the area of human resources, the environmental area, the business area and the area of local community. The first part of article includes theoretical knowledge which was obtained by the study of professional home and foreign literature, which delimit the area of corporate social responsibility and its individual parts, international management and business, globalization and internationalization of the business activity, business ethics and the ethics code. To meet the set target, we obtained the primary dates by a questionnaire method. This questionnaire was filled in by the employees of the company in an electronic form. The principal part of this article is a part aiming at the work results which includes a brief characteristic of the parent and subsidiary company, evaluation of the questionnaire including clear tables, graphs and statistical evaluation of the four set research theories. In conclusion, we evaluated the results from the questionnaire in total and suggested recommendations for the oncoming company business activity.
\end{abstract}

Keywords: international management and business, business ethics, internationalization, corporate social responsibility

\section{Introduction}

The main reason for the idea of corporate social responsibility was the question of how to do a business well. This was meant in a way that would bring as many benefits to as many people as possible. Corporate social responsibility therefore means that companies should respect the needs of their stakeholders such as employees, customers, competitors, suppliers, community as well as environment while they also keep focused on profit. The pressure on enterprises towards socially responsible behaviour is reflecting the social, environmental and economic challenges that communities worldwide have to face nowadays. The beginning of modern concept of CSR dates back to 1950 Ss and since then it has become an inseparable part of strategic planning for many companies. In today's globalized world, an increasing number of customers expect to buy products that are not harmful to the environment and are produced in fair conditions for employees. Social responsibility of enterprises is focused on three main areas - economic, social and environmental all together encouraging sustainable development. Many multinational corporations have taken 
part in development of CSR concept. They understand that implementation of CSR activities brings along several benefits such as competitive advantage, improving company' image and reputation in the market, increasing loyalty of employees and customers and in the end also lower costs as a result. In today's competitive environment full of demanding requirements from customers, being a flexible company is crucial. Concept of CSR plays an important role in this environment and represents a great opportunity for companies to become successful while also making world a better place explains Kovácsová (2015). The corporate social responsibility of firms, trying to enter new markets and internationalize their production, is a hot topic, nowadays. Decision makers are solving issues connected to the profit maximization, quality improvement, lowering costs, outsourcing, resources recovery, and satisfaction of stakeholders. Companies, operating on more than one market, have to adapt their production processes and management to the requirements of the several markets. International employees are more than a common thing in multinational corporations and managers have to respond to the constant changes caused by implementation of new technologies and innovations. For this concept, mainly known under the English name Corporate Social Responsibility, there are a number of definitions in the literature, and currently there is no one global definition. One of the most important is the definition by the European Commission, which describes the social responsibility as a "concept whereby companies integrate social and environmental considerations into daily business operations and interactions with corporate stakeholders". (EC, 2011) The European Commission's definition highlights the voluntary nature of this particular concept and the impact on the functioning of the company's stakeholders.

Currently, there is no uniform global definition for the concept of CSR. This is mainly due to the fact that CSR is on voluntary basis and does not have strictly defined boundaries.

The three best-known definition of CSR:

- The EU Green Paper defines CSR as "a concept whereby companies integrate social and environmental concerns in their business operations and in their interaction with their stakeholders on a voluntary basis".

- The World Business Council for Sustainable Development (WBCSD): "Corporate Social Responsibility is the continuing commitment by business to behave ethically and contribute to economic development while improving the quality of life of the workforce and their families as well as of the local community and society at large."

- Business for Social responsibility defines CSR as: "Operating a business in a manner that meets or exceeds the ethical, legal, commercial and public expectations that society has of business." (Pavlík and Bělčík, 2010)

Ubrežiová and Gurská (2013), Mura and Buleca (2014) and Ubrežiová and Horská (2011) explain that corporate social responsibility includes the economic, legal, ethical, and philanthropic expectations placed on organizations by society at a given point in time. Authors mention the concept Carroll's four-part model of CSR.

- Within the economic responsibility, companies have shareholders who demand a reasonable return of their investments, they have employees who want safe and 
fairy paid jobs, they have customers who demand good quality products at a fair price, etc.

- By legal responsibility, we understand demands that business abide by the law and "play by the rules of the game".

- Ethical responsibilities oblige corporations to do what is right, just, and fair even when they are not compelled to do so by the legal framework.

- Philanthropic responsibilities as the fourth level incorporates activities that are within the corporation's discretion to improve the quality of life of employees, local communities, and ultimately society in general.

According Wach (2014), Skýpalová and Kučerová (2014) as well as Mihalčová et. al. (2013), many multinational corporations and small and medium sized enterprises have taken part in development of CSR concept. According to Čierna (2008) corporate social responsibility of companies and individuals is now becoming one of the most serious issues of our planet. It is an area that is increasingly becoming an important part of corporate strategy. The philosophy of corporate social responsibility concerns business development, ethics, morality, nature, and hope for present and future generations. CSR is a concept by which firms admit their co-responsibility for the condition and functioning of the society. Many businesses, regardless of their size, importance and position in the marketplace, are now trying to behave more responsible - ethically, socially and environmentally acceptable to its stakeholders. Such behaviour brings them undoubtedly many effects in the long run, such as better economic performance, the effect of reputation, customer satisfaction and employee loyalty. Responsible behaviour is not a short-term issue; it has to be long-term and consistent business philosophy, overlapping all the business activities. Applying the concept of CSR often requires fundamental changes in thinking of owners, managers and employees. Musová (2013). They understand that implementation of CSR activities brings along several benefits such as competitive advantage, improving company' image and reputation in the market, increasing loyalty of employees and customers and in the end also lower costs as a result. In today's competitive environment full of demanding requirements from customers, being a flexible company is crucial. Concept of CSR plays an important role in this environment and represent a great opportunity for companies to become successful while also making world a better place. Veber et al. (2011) supports the previous statements and adds that companies applying the concept of CSR integrate social and environmental considerations into their business activities in collaboration with their stakeholders on a voluntary basis. Firms complement their traditional economic objectives by the objectives that take into consideration the benefits of society (expansion of the company's strategy by environmental, social, ethical and community aspects). The concept works on the principles of charity, volunteering and partnership. According to Hambalková and Lušnáková (2012), the argument, which is often used against the application of social responsibility, is that companies are simply not able to pay the increased cost of its implementation. Yet corporate responsibility ultimately has a direct effect on reducing the environmental and production costs, to attract and retain a skilled workforce and also to discover new niches or even new markets. One of the benefits of corporate social responsibility is risk management. Enterprise, which perceives the surrounding 
environment and takes into account its interests, is better able to anticipate potential risks and promptly respond to changes that may occur and have an impact on the success of the enterprise based on Hohnen (2007). Other numerous benefits of applying CSR concept according to Hambalková and Lušnáková (2012) include:

- helps to increase profits (consumers prefer to buy products from socially responsible companies);

- helps to reduce costs (resource efficiency);

- increase the long-term potential of the company (the company supports the growth conditions such as goodwill);

- supports innovation (stimulation of innovative thinking and procedure);

- allows better management of human resources (reconciliation of family and working time, training and education, anti-discrimination policy);

- conditions to attract investors (investment funds choose opportunities and economic, social and environmental factors, as CSR criteria mean safety).

According to Kachaňáková (2010), in today's dynamic environment, which is accompanied by the globalization trends, organizations are required to be identified and distinguished from each other at the first glance. Each organization is being presented daily in some way to the surrounding environment. This is happening through its various activities, such as hiring and releasing employees, product manufacturing, service providing, marketing, etc. The ways in which the organization represents itself for the purposes distinguishing from others and becoming well known can be called the identity of the organization or corporate identity. It is significantly influenced by strong, clearly defined and presented organizational culture. The author adds that the identity of the organization is a purposefully shaped strategic concept of the internal structure of the elements, their operation and external presentation of the particular organization. The defining element of identity is the vision of the organization.

\section{Methodology}

The main objective of this article is to evaluate the perception of corporate social responsibility in the context of business internationalization at the selected company. In order to achieve this major objective, it is necessary to create supportive partial objectives. The theoretical part gathers the necessary information about terms such as multinational company, corporate culture and corporate social responsibility and serves as a basis for the practical part. The practical part is dedicated to the analysis of the selected company and its CSR activities, as well as the evaluation of the survey findings in relation to the mentioned issues.

For elaboration of the theoretical part of the article, secondary sources such as books, papers and information available on internet websites were used. Both primary and secondary sources served as the basis for the practical part of the thesis:

- Primary sources: gathered from the survey about CSR understanding taken on the sample of 100 respondents.

- Secondary sources: gathered from the company's internal materials, for instance annual reports, Global Responsibility reports, website and other publications.

The following hypotheses were formulated during the final article elaboration: 
- Hypothesis 1: We assume that there is a relation between the knowledge of CSR concept and education level achieved.

- Hypothesis 2: We assume that there is a relation between the preference of particular CSR aspect and gender of the respondent.

- Hypothesis 3: We assume that there is a relation between the familiarity of the selected company and age of the respondent.

To test if these hypotheses are truthful, we used the statistical method called $\chi^{2}$ test of square contingency. Is a test for nominal data for two independent sets and is used to test hypotheses concerning the existence of dependencies between own questions and classifying variables. For illustration, we will explain the results from evaluation of hypothesis 2 .

The survey included four classification questions about respondents' gender, age, education and nationality. The second part of the questionnaire was focused on the general knowledge of respondents about the concept of CSR using both polytomic questions with multiple choice and trichotomic closed questions. The last part of the survey was oriented on perception of selected company and its CSR efforts by respondents. In this part also scale questions were used to reflect the importance of particular factors. The data acquired from the questionnaire were statistically processed in Microsoft Excel and displayed by using both graphical and numerical means.

As a part of research, we set the following hypotheses in relation to the research in selected company:

- We assume that there is a relation between the knowledge of CSR concept and education level achieved.

- We assume that there is a relation between the preference of particular CSR aspect and gender of the respondent.

- We assume that there is a relation between the familiarity of selected company and age of the respondent.

\section{Results and discussion}

The aim of the research was to analyse the level of knowledge that respondents have about corporate social responsibility in general and at the selected company. For this purpose, the method of anonymous questionnaire was chosen and this was distributed among 100 respondents electronically. The research was conducted between at the beginning of 2015. The survey included four classification questions about respondents' gender, age, education and nationality. The second part of the questionnaire was focused on the general knowledge of respondents about the concept of CSR using both polytomic questions with multiple choice and trichotomic closed questions. The last part of the survey was oriented on perception of the selected company and its CSR efforts by respondents. The questionnaire consists of 18 questions and was anonymous. The first question was aimed to find out the gender structure of the respondents. The questionnaire survey was filled in by 100 respondents, of whom 66 were women and 34 were men. Based on the main goal of article, we wanted to find out which of the three CSR aspects do respondents prefer. Social aspect was chosen as the most important with 62 respondents believing in its importance. 30 respondents think Environmental aspect is the most important of the 
three and only 8 people believe Economic aspect should come first before environmental and social initiatives of a company. Within the selected question for respondents, e.g. "According to your opinion, what is the most important aspect for an organization regarding CSR" we also set the second hypothesis where we assume that there is a relation between the preference of CSR aspect and gender of respondents. We tested the following options:

- H0: There is no relation between the preference of CSR aspect and gender of respondent.

- H1: There is a relation between the preference of CSR aspect and gender of respondent.

Table 1. Relation between the preference of CSR aspect and gender of respondent

\begin{tabular}{|c|c|c|}
\hline \multirow{2}{*}{ Outcomes } & Chi table & Chi calculated \\
\cline { 2 - 3 } & 1,3187 & 5,9915 \\
\hline
\end{tabular}

Source: own processing based on (Kovácsová, 2015)

Based on the outcome of the chi-square test of square contingency (Tab. no.1) we do not reject the zero hypothesis which means that at the significance level of $\alpha=0.05$ there is no relationship between the preference of CSR aspect and gender of respondent. The another question was aimed to find out what are the main reasons for a company to involve in CSR activities. Respondents could choose maximum three of eight answers. Intentions to improve company's image were selected as the most probable reason leading company to social responsibility with 74 respondent choices. The other two highly ranked options were to increase employees' satisfaction and loyalty and to gain competitive advantage. The least probable of all possible reasons for company to adopt CSR activities was cost savings with only was opted by 5 respondents (see Figure 1).

Figure 1: What do you think are the reasons for a company to adopt CSR?

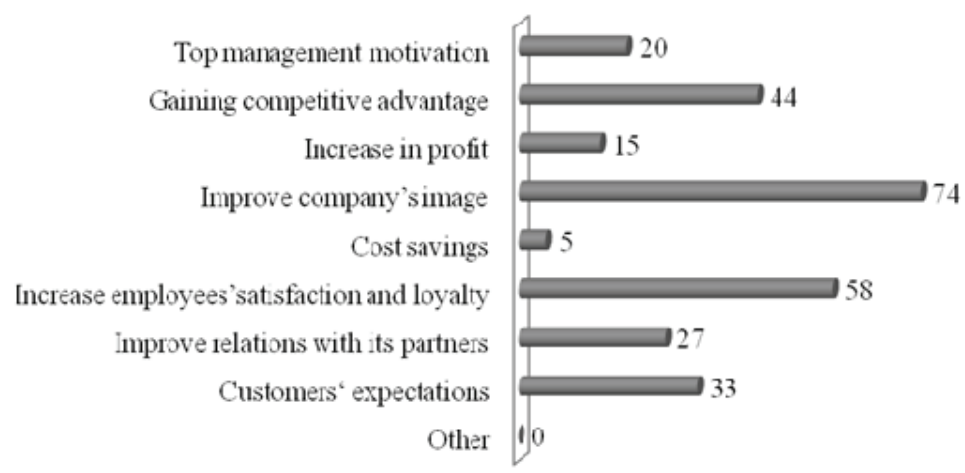

Source: own processing based on Kovácsová (2015)

On the other hand, other question deals with barriers that prevent a company from adoption of responsible behaviour. Two options were selected as the greatest barrier. Equally 30 respondents think that lack of management's motivation and high cost of 
implementation of CSR often hinder enterprises from socially responsible initiatives. $25 \%$ of respondents believe that insufficient knowledge about the topic could be a significant barrier for organizations as well. Two respondents thought of other, not stated, barriers and these were evaluated as simply no interest of a company in CSR and profit preference. As Kovácsová (2015) states, in today's fast changing business environment, companies need to be flexible to adapt to these changes. They should understand that doing business nowadays means more than just generating profit and their activities need to be beneficial for the society as a whole. The concept of corporate social responsibility represents voluntary efforts of an enterprise in following three areas - economic, social and environmental. CSR influences the corporate image of an organization and represents competitive advantage, added value and long-term prosperity for companies that have decided for its application.

On the other hand, the next question deals with barriers that prevent a company from adoption of responsible behaviour. Two options were selected as the greatest barrier. Equally 30 respondents think that lack of management's motivation and high cost of implementation of CSR often hinder enterprises from socially responsible initiatives. $25 \%$ of respondents believes that insufficient knowledge about the topic could be a significant barrier for organizations as well. Two respondents thought of other, not stated, barriers and these were evaluated as simply no interest of a company in CSR and profit preference (Figure 2).

Figure 2: Barriers of Corporate Social Responsibility
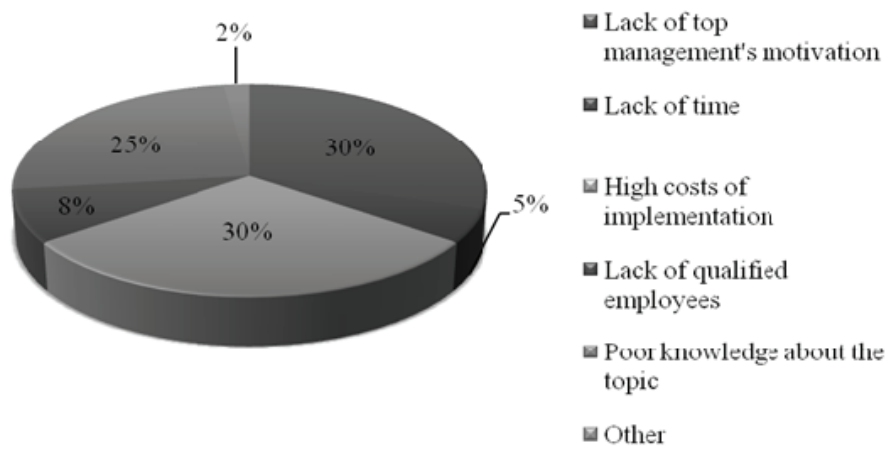

Source: own processing based on Kovácsová (2015)

Following questions are oriented to find out if respondents are familiar with the term of CSR and what do they understand under this concept. In recent years, the concept of corporate social responsibility received awareness and interest of companies and general public around the world. When asked "Have you ever met with the term Corporate Social Responsibility?"

- 51 out of 100 respondents claimed that they are familiar with this term and know what is the concept about.

- 25 respondents have already come in touch with CSR but they are not sure about it significance.

- 6 respondents who do not know whether they have ever met with the term. 
- 18 respondents are not familiar with the concept at all. The results are rather positive and we can assume that socially responsible behaviour of the companies is attracting increasing attention of the public.

Within this question, we set the first hypothesis where we assume that there is a relation between the knowledge of CSR concept and education level of respondents. We tested the following options:

- H0: There is no relation between the knowledge of CSR concept and education level of respondents.

- H1: There is a relation between the knowledge of CSR concept and education level of respondents.

Table 2: Relation between the knowledge of CSR concept and education level

\begin{tabular}{|c|c|c|}
\hline \multirow{2}{*}{ Outcomes } & Chi table & Chi calculated \\
\cline { 2 - 3 } & 16,9190 & 10,5576 \\
\hline
\end{tabular}

Source: own calculations based on Kovácsová (2015)

Based on the outcome of the chi-square test of square contingency (see table 2) we do not reject the zero hypothesis which means that at the significance level of $\alpha=0.05$ there is no relationship between the knowledge of CSR concept and achieved education level of the respondent. Next question provides us with a more detailed information about what do respondents understand under corporate social responsibility.

Figure 3: What do you understand under Corporate Social Responsibility

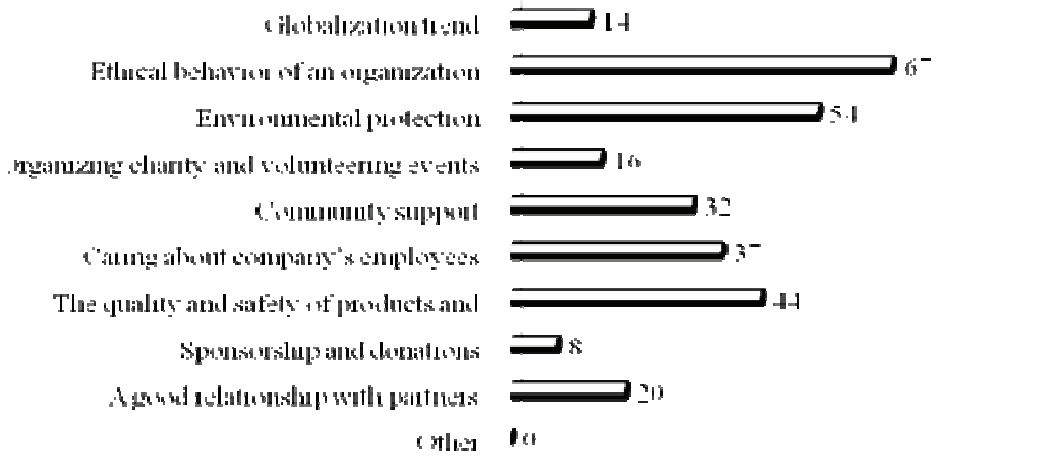

Source: own processing based on Kovácsová (2015)

There were nine specific ideas of perceiving this concept and respondents could choose maximum of three answers. Out of total respondents, 67 think Ethical behaviour of an organization best characterizes the concept of CSR. Environmental protection was placed as second important activity of socially responsible enterprises with 54 respondents 'choices, followed by The quality and safety of products and services provided by a company which ended up with 40 respondents choosing i tas one of the options. 37 respondents understand under CSR Caring about company's employees as one of the relevant explanations, while 32 consider Community support 
as an area that should not be ignored by companies. A good relationship with business partners is understood by as CSR initiative by 20 respondents. 16 of those asked think that Organizing charity and volunteering events is an important activity within the responsible behaviour followed by Globalization trend which is understood with 14 answers and Sponsorship and donations with only 8 respondents considering it as a typical CSR activity as you can see on Fig 3 .

The upcoming set of questions form a part of our survey, too. They were aimed to analyse the perception of selected company within the concept of CSR as well as importance of particular activities company carries out. Question „Do you know the selected company?" unveils whether respondents know the international coffee selected chain . 87\% know selected company and visited the coffee house at least once in their lives while $8 \%$ of respondents have never been in company store but are aware of the company's existence. The remaining 5\% of respondents do not know the company. Results point out the great brand awareness of the company as only $5 \%$ of respondents do not know the company which is not even operating in Slovakia. In connection with globalization trends we can support this fact by theoretical knowledge according to Veber et al. (2011) who explains which factors have supported the globalization trends in recent decades:

- tendency to limit the role of national territories, nationalism, protectionism and seek "borderless world"

- the development of logistics systems and communication systems that significantly "shorten the distance"

- changing political priorities of national governments, which can be characterized as a transition from welfare state to liberal oriented policy

- The introduction of investment incentives for foreign investors in the form of the creation of duty free zones, tax relieves, the provision of appropriate land grants to create jobs etc.

Within this question we set the third and last hypothesis where we assume that there is a relation between the awareness of selected company and age of respondents. We tested the following options:

- H0: There is no relation between the awareness of selected company and age of respondent.

- H1: There is a relation between the awareness of selected company and age of respondent.

Figure 4: Age of respondents

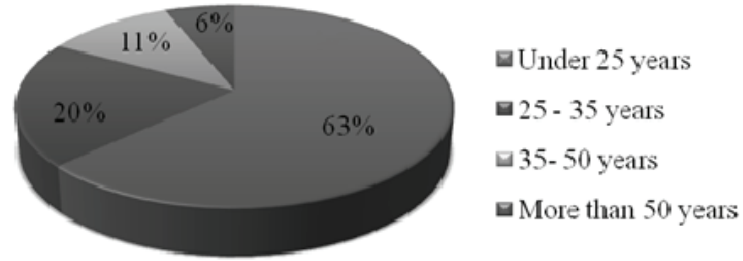

Source: own processing based on Kovácsová (2015) 
The major part is represented by young people aged under 25 years and this was $63 \%$. The second biggest part, $20 \%$, is created by the age group 25-35 years. $11 \%$ of respondents were aged between 35 and 50 years and finally $6 \%$ were people older than 50 years (Figure 4$)$ :

\section{Table 3: Relation between the awareness of selected company and age of respondents}

\begin{tabular}{|c|c|c|}
\hline \multirow{2}{*}{ Outcomes } & Chi table & Chi calculated \\
\cline { 2 - 3 } & 12,5916 & 18,3043 \\
\hline
\end{tabular}

Source: own processing based on Kovácsová (2015)

Based on the outcome of the chi-square test of square contingency we do reject the zero hypothesis and so accept the $\mathrm{H}_{0}$ which means that at the significance level of $\alpha=$ 0.05 there is a relationship between the awareness of selected company and age of respondent. Following, we calculate the Cramer contingency coefficient to find out how strong is this relationship. The coefficient equals 0,5018 pointing out the moderate interdependence between the two factors. Next question deals with frequency with which respondents visit company' stores. The majority of respondents, 65 , answered with occasionally. Other 27 respondents never visit the well-known coffee shop. One of the reasons could be that most of the respondents were of Slovak nationality and selected company does not operate its stores in Slovakia yet. 3 respondents selected company at least are quite regular customers who visit once per month and remaining 5 respondents are considered loyal customers visiting their favourite coffee place one time a week at least.

Question "What is your first thing you image under company?" asks about what does company evoke among respondents. Most respondents, 37\%, imagine high quality coffee while other $31 \%$ would rather Picture a customer oriented enterprise with friendly employees. $18 \%$ of respondents say that selected company represents nice environment to meet with friends and only $3 \%$ would label of selected company as a socially responsible enterprise at first place. There were 11 respondents who connect selected company with something other than provided options. Among these answers we could find opinions about overprices products when customers pay mostly for the famous brand name, American style and good marketing or simply an image of international coffee shop. Moving further, respondents were asked if they consider selected company to be a socially responsible enterprise. The greatest part of respondents do not know while 45 persons believe that the enterprise is involved in some socially responsible activities. Only 3 respondents think that selected company is not a socially responsible company.

Question "Protection environment" was subdivided into eight parts finding out opinions about importance of particular activities that selected company carries out within its CSR commitment. According to results, respondents find environmental protection, high quality of products and good care of employees as activities with the greatest importance to which selected company, according to its business nature, should especially dedicate attention (Figure 5). 
Figure 5: Importance of environment protection

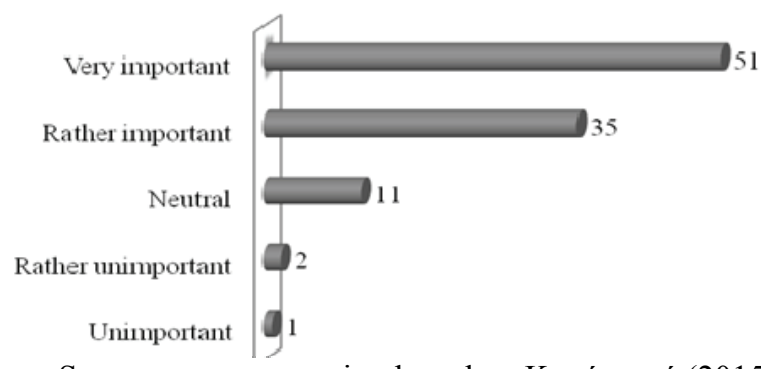

Source: own processing based on Kovácsová (2015)

Fair trade efforts (see Figure 6) of selected company were evaluated somewhere between very important and rather important. Other socially responsible initiatives were recognized as rather important including charity and donations events, interacting with communities, cultural diversity in the workplace and good relationship with stakeholders.

\section{Figure 6: Fair Trade efforts}

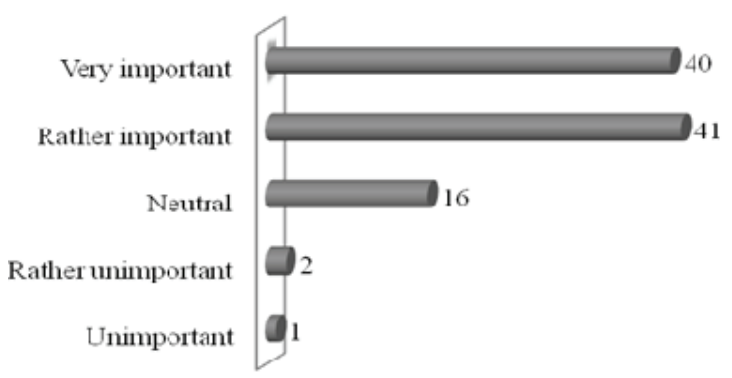

Source: processing based on Kovácsová (2015)

None of the stated activities was ranked of neutral or lower significance. A large multinational corporation such as selected company should put the efforts for environment protection in the first places of its Corporate Social responsibility activities to decrease its negative impact on nature. Similarly, majority of respondents - 51 - chose these activities as very important. Company set ambitious goals to achieve $100 \%$ ethical sourcing of its products in the future meaning that employees have fair conditions and remuneration while working and also no work of children is accepted. Respondents place importance of fair trade efforts of company somewhere between very important and rather important.

Most of respondents consider charity and donation events carried out by the company as rather important. Such activities are also very positive but should take place only after the more important responsible activities are performed such as environmental protection or high quality products etc. The high quality of products should be the in the greatest interest of company according to respondents from who 65 consider this factor very important. Interacting with community, similarly to organizing charity events, should be included within secondary responsible activities and majority of respondents consider such activities as rather important (Figure 7). 


\section{Figure 7: Importance of charity and donations}

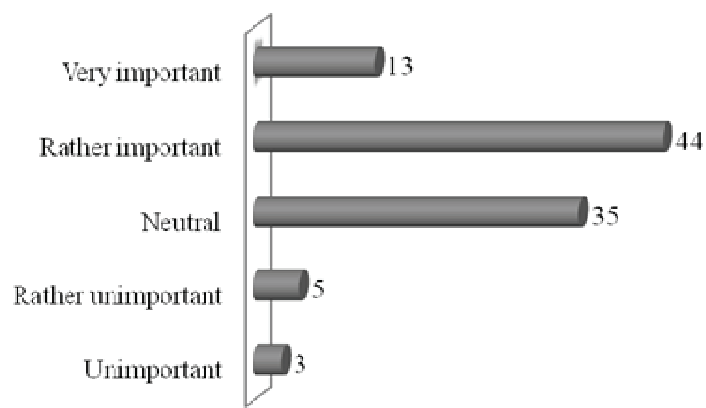

Source: own processing based on Kovácsová (2015)

Multinational enterprise put great emphasis on cultural diversity in the workplace and discrimination avoidance. $39 \%$ of respondents believe cultural diversity is rather important factor within CSR. To have a good relationship with customers, suppliers and other stakeholders included in company's operations a vital factor for every successful company. Respondents consider efforts for maintaining good relationship with these partners as rather important. However, efforts to practice responsible behaviour towards employees is chosen as one of the three most important CSR activities of selected company among environment protection and high quality products.

Question "Do you agree that selected company is one of the leaders company in the terms Corporate Social responsibility in the international market?" was aimed to find out whether respondents agree with the statement: "Selected company is one of the leader companies in terms of CSR in the international market". The majority of respondents do not know if the statement is true, while 36 respondents rather agree with the saying and 12 respondents strongly agree with the statement. 5 respondents do not think the statement about selected company as a leading CSR company is true and answered with rather or strong disagreement.

Last two questions "Do you believe responsible behaviour has helped selected company to build its reputation and firm image?" and "As a customer, would you prefer socially responsible company?" were aimed to find out if respondents believe socially responsible activities have helped selected company to build its image and if respondents themselves would prefer an enterprise which is involved in some of Corporate Social Responsibility activities and cares about the society and environment around it. $52 \%$ of respondents believe that responsible behaviour has probably helped selected company in building its reputation while $26 \%$ are sure about this being true. Other $15 \%$ of respondents do not know the answer for this question (Figure 8 ).

In practice, 64 respondents would surely prefer a socially responsible company and other 29 respondents would probably be of the same opinion (Figure 8). The answers clearly point out that CSR is becoming more familiar and important to customers who would probably sacrifice other factors such as price in order to get products from a socially responsible enterprise. 
Figure 8: Image of Selected Company

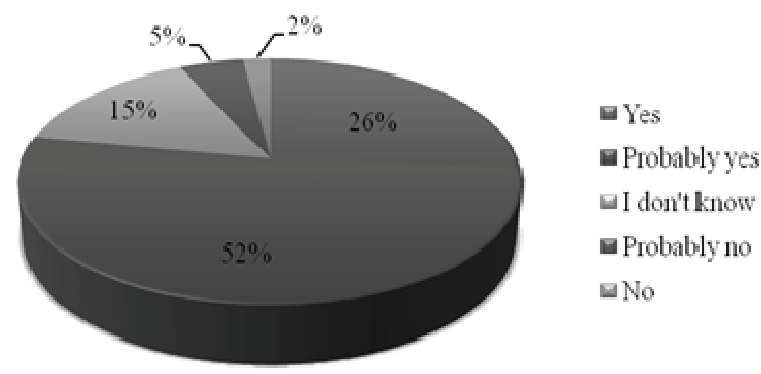

Source: own processing based on Kovácsová (2015)

As a multinational enterprise, selected company put great emphasis on cultural diversity in the workplace and discrimination avoidance. 39\% of respondents believe cultural diversity is rather important factor within CSR (Figure 9). In discussion with Fazekašová, M. (2006) corporate culture is a very complex phenomenon which is difficult to define, but significantly influences the long term success of the company. On the one hand it can be a source of strength for an enterprise and its competitive advantage, on the other hand, a stranglehold of its development. Corporate culture is about everyday life of a company and in particular about the behaviour of managers how they decide, solve conflicts, communicate, reward, motivate.

Hofstede (1991) defines organizational culture as core values, beliefs and assumptions that exist in the organization, patterns of behaviour that result from these shared meanings and symbols that express the connection between the assumptions, values and behaviour of members of the organization. It was confirmed by our research as it is introduced on Figure 9.

\section{Figure 9: Importance of cultural diversity in the workplace}

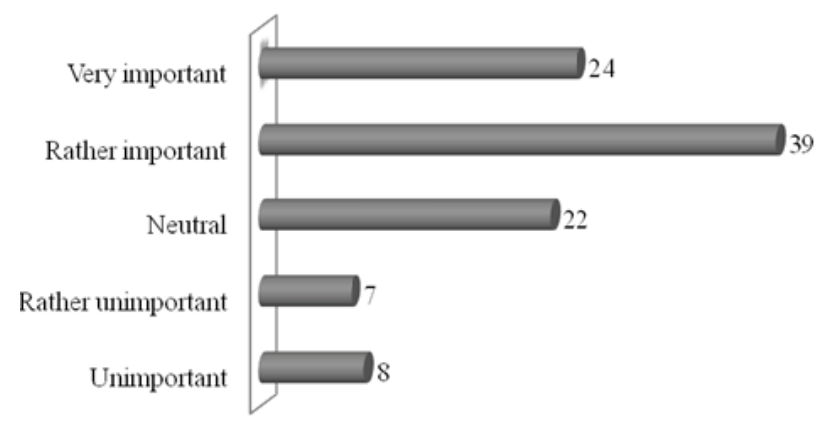

Source: own processing based on Kovácsová (2015)

\section{Conclusion and recommendation for further studies}

In today's fast changing business environment, companies need to be flexible to adapt to these changes. They should understand that doing business nowadays means more than just generating profit and their activities need to be beneficial for the society as a 
whole. The concept of corporate social responsibility represents voluntary efforts of an enterprise in following three areas - economic, social and environmental. CSR influences the corporate image of an organization and represents competitive advantage, added value and long-term prosperity for companies that have decided for its application.

The main objective of this diploma thesis was to analyse corporate social responsibility at the selected company and how these activities influence the firm image. We introduced the characteristics of the company, its corporate culture and responsible behaviour towards society in the practical part. We found out how selected company has become a successful multinational corporation. We focused on efforts of the corporation in terms of CSR in all social, environmental and economic areas. Following, we also analysed the customer awareness of CSR issues and their perception in selected company via questionnaire research and statistical processing of the results.

The survey involved the participation of 100 respondents of whose majority were women in terms of gender (66\%), those younger than 25 years $(63 \%)$ in terms of age, with some university degree $(68 \%)$ and of Slovak roots in terms of nationality. The research has shown that majority of respondents are familiar or has at least heard of term CSR which clearly indicate its increasing popularity and importance. We assumed that there could be a relation between this knowledge and education level of respondents, however, this assumption was incorrect meaning the knowledge of the concept does not depend on the highest education achieved.

The research also studied the customer understanding of CSR and unveiled that people expect companies to act beyond their legal responsibilities and commonly imagine ethical behaviour, environmental protection and high quality of products and services among three most common characteristics of responsible behaviour of enterprises. Majority of customers would prefer the social aspect aspirations however these preference does not depend on the gender of respondents as we assumed. The survey then pointed out in question, that improved corporate image is considered as the most powerful reason for applying the concept of CSR. This result support the overall focus of the thesis, which is the fact that responsible behaviour is perceived positively by the general public and creates better reputation and organizational image. On the other hand, there are several factors that discourage enterprises from doing this including lack of motivation, high cost of implementation or poor knowledge of the issue.

The closing part of the survey research analysed the perception of corporation within its CSR efforts and therefore represents the core and most important piece of the thesis. The vast majority of respondents (together 95\%) know of selected company which only proves the fact that it is the world's most famous coffee retailer. The awareness of company among respondents depends on their age and this assumption proved to be of mediate dependence. The survey also found out that most of the respondents visit Starbucks only occasionally which we suppose is the reason of fact that company is not present in Slovak territory and most of the respondents thus do not have a chance to visit more frequently.

The results of our research confirmed the success of this vision when respondents imagine not only high quality coffee but also customer oriented and friendly enterprise 
or nice environment to meet up with friends and colleagues when it comes to selected company. However, the survey results also pointed out that $52 \%$ of respondents do not know if the company incorporates itself in behaviour that is beneficial for society and environment. Based on the character of the enterprise, people believe that high quality products, good employees' treatment and protection of environment should be at the first place in selected company responsible commitment. Earlier, within the practical part of the thesis, we mentioned main CSR activities selected company tries to pursue. According to this knowledge, we can conclude that ethical sourcing of products, recycling challenges and employees (or "partners" as they are called) satisfaction are really the most important aims within company's responsible efforts. Moreover, 52\% of respondents believe that the CSR concept has probably helped selected company to build its reputation, while other $26 \%$ are absolutely sure about this fact. We can conclude that not only selected company, but every company that applies the corporate social behaviour brings benefits in the end not only for society, but definitely presents itself better in front of the customers and positively influence its corporate image. The results from last question of the survey proved us that $93 \%$ of respondents would quite surely or surely prefer a company that mind the society and environments issues and tries to bring benefits not only for itself.

Based on our findings, we can conclude that concept of CSR is becoming still more important and both people and companies are aware of this importance which opens the door for even greater application in the future. We hope that companies worldwide will understand the advantages of responsible behaviour and will use this sustainable advantage in long terms. There is a strong connection between the responsible attitude and increasing profit and improving image and we hope this fact will assure us brighter and more sustainable future.

\section{Acknowledgements}

This paper was created within the research project VEGA supported by the Ministry of Education, Science, Research and Sport of the Slovak Republic VEGA Corporate Social Responsibility (CSR) of the Slovak Enterprises in the context of Internationalization in Business. Project registration number 1/0044/13

\section{References}

1. Čierna, H. (2008): Spoločensky zodpovedné podnikanie a model výnimočnosti. Banská Bystrica: Univerzita Mateja Bela, 2008. 104 s. ISBN 978-80-8083-585-9

2. Fazekašová, M. (2006): Manažment teórii a praxi. [online]. [cit. 2015-06-27]. Available at: $<$ http://casopisy.euke.sk/mtp/clanky/3-4-2006/fazekasova.pdf $>$.

3. Gurská, S. (2012): Business Ethics in International Environment. In: Ubrežiová, I. - Gurská, S. (2012): International management and entrepreneurship. Nitra: SUA, 2012, pp. 43 - 57, ISBN 978-80-552-0941-8

4. Hambalková, M., Lušnáková, Z. (2012): Manažment obchodnej firmy. Nitra: SPU, 2012, 157p. ISBN 978-80-552-0894-7.

5. Hofstede, G. (1991): Cultures and Organizations: Software of the Mind. London: McGrawHill, Book Company, 1991, 296 p. ISBN 0-07-707474-2.

6. Hohnen, P. (2007): CSR: An implementation guide for business. [online]. [cit. 2015-06-27]. Available at: $<$ http://www.iisd.org/pdf/2007/csr_guide.pdf $>$. 
7. Kachaňáková, A. (2010). Organizačná kultúra. Bratislava: Iura Edition, 2010, 137 p. ISBN 978-80-8078-304-4.

8. Kovácsová, B. (2015): Firm Image in relation to Corporate Social Responsibility. (Diploma Thesis), Nitra: SUA, 2015, 99 p.

9. Mura, L., Buleca, J. (2013): Trends in international business of the Slovak small and medium food enterprises. Procedia-Social and Behavioural Sciences 110, 2014, pp.905-912

10. Obtulovič, P. (2004): Bioštatistika. 3. vyd. Nitra: SPU, 2004. 132s. ISBN 80-8069-432-X.

11. Pavlík, M., Bělčík, M. 2010. Společenská odpovědnost organizace. Praha: Grada Publishing, 2010, 176p. ISBN 978-80-247-3157-5.

12. Skýpalová, R., Kučerová, R. (2014): The Role of the State in Launching Social Responsibility in Small and Medium Enterprises. Acta Universitatis Agriculturae et Silviculturae Mendelianae Brunensis. 2014. sv. 62, č. 6, s. 1407--1415. ISSN 1211-8516.

13. Ubrežiová, A., Horská, E. (2011):. Perception and Approach towards Corporate Social Responsibility in SMEs: Case Study of Slovak and Czech Republic. In: PEFnet 2011 "European Scientific Conference of Ph.D. Students, Brno, 2011, pp. 1-7

14. Ubrežiová, I., Stankovič, L., Mihalčová, B., Ubrežiová, A. (2013): Perception of corporate social responsibility in companies of Eastern Slovakia region in 2009 and 2010. In Acta Universitatis Agriculturae et Silviculturae Mendelianae Brunensis. ISSN 1211-8516, 2013, vol. 61 , no. 7, p. 2903-2910

15. Veber, J. et al. (2011): Management: základy, moderní manažerské přístupy, výkonnost a prosperita. Praha: Management Press, 2011, 734 p. ISBN 978-80-7261-200-0.

16. Wach, K. (2014):.Internationalization and Globalization as the Wider Context of Europeanisation Process from the Macro- and Microeconomic Perspective. Horyzonty Polityki, Vol.5, no.10, pp.11-30 


\title{
2.6. PROBLEMATIC METHODOLOGICAL QUESTIONS OF INVESTMENT PROJECT EVALUATION
}

\begin{abstract}
Summary
There are some scientific questions related to the NPV and IRR which have not been worked up. From these issues, this paper discusses the economic content of the two categories and the questions of usability for project evaluation and ranking. The main research methods are methodological analysis, model editing and examination of the mathematical formulas. The paper proves that the NPV is the discounted amount of the surplus profit generated above the profit requirement, and points out, that content band of the real reinvestment rate assumption is fundamentally different from everything that can be found about this in the literature. Because of the NPVs are not comparable, the paper systematically eliminates the distortion effects. Thus, the NPV transforms into a special kind of rate, namely, the difference between the factual rate and the required rate of return. This NPV rate (with equal required rates of return) gives the same ranking list as the IRR. The aggregate capital needs is a new conception and gives a new viewpoint to analysis of investment projects evaluation. The paper defines the special content of aggregate capital needs and compiles an index number for it.
\end{abstract}

Keywords: NPV, IRR, ranking, aggregate capital needs, reinvestment rate assumption

\section{Literature review}

The paper examines the two main tools of investment project evaluation, i.e. the net present value (NPV) method and internal rate of return (IRR) method. Application appropriateness of the two methods is sharply debated from the first half of the last century. Many writings already were born in the 1950s (see Alchian, 1955; Solomon, 1956; Bierman and Smidt, 1957). Since then the discussion is running.

The literature of finance expresses a very determined preference for NPV. In spite of this, business professionals of developed countries apply the IRR in a large proportion for decision-making. For example Arnold and Hope (1990) cite two surveys done in the 1970s and 1980s, demonstrating that the largest British companies (that are otherwise able to pay the best experts) definitely rank the IRR higher than the NPV in practice. They mention that a lot of American surveys prove that the practice prefers the IRR in the USA as well. The practical method preferences are widely researched. Szücsné Markovics (2012) gives a literature review about the researches on methods which are used by companies throughout the world. Illés and Keszthelyi (1998), Illés (2000) and Daróczi (2004) examined the practical use of different methods based on empirical researches on the complex evaluation of decision-making process. According to my experiences, in business economics literature generally there is not a strong method preference, but the IRR method often seems to be better.

\section{Different disciplinary roots}

According to Volkman's (1997) research, the emergence of method qualification contradiction could be attributed to the fact that finance propagates the more 
advantageous nature of NPV method based on one of Fisher's works (Fisher, 1930) published in the first half of the past century while business economists (and business professionals) prefer the IRR method based primarily on the works of Boehm-Bawerk (1889) and Keynes (1936).

However, this is only the surface. Serious methodological contradictions are caused by the different disciplinary foundations. Finance, namely, is based on standard microeconomics, or as Volkman says "based on orthodox economic theory" (Volkman, 1997, p.75). Problems caused by microeconomic roots are mentioned by Woods and Randall (1989) as well. There is a significant difference between the theorems of finance and business economics as far as the proximity to real-life problems is concerned. Basically, there is no direct passage within microeconomics and business economics because of the very different abstraction level, different category system and different approach.

Microeconomics is not a business practice oriented science. The finance does not take this into account, and uses microeconomic categories and methods. In concerning methodological questions the finance-based findings and conclusions are based on two general assumptions: the investment opportunities are unlimited and the reinvestment rate is equal to the required rate of return. (Although these assumptions are regularly behind the finance models, it is not always stated clearly.) These conditions are never met in reality. That is why these doctrines should be lead through conditions that are close to reality before they are offered for corporate professionals.

The abstraction level of business economics is relatively low and a considerable part of its research results - adjusted to the characteristics of the given company - may be directly used in the corporate practice. The business economics literature often mentions the importance of the professional clarity and practical implications of the suggested methodology (e.g. Garrison, 1988, p. 712; Arnold and Hope, 1990 p. 260; Schmalen, 2002, pp. 602-605). That is, the majority of the business experts can only apply the methodology correctly if they can fit methods to their way of thinking, and if they can somehow connect them to the logic of the economic process.

\section{The arguments for superiority of NPV}

There are no strong and methodically supported arguments to demonstrate the primacy of the NPV over the IRR. The literature puts forward three particularistic arguments to change things around. One of them is that the NPV means also that amount, which will be added to the shareholder value by the project. The second argument is based on the reinvestment rate assumptions. The third one is that there only one NPV can occur as opposed to the opportunity of several IRR.

\section{NPV as a shareholder value surplus}

Among the advantages of NPV, finance literature regularly mentions the theorem according to which the NPV indicates the project's contribution to the shareholder value (e.g. Van Horne and Vachowicz, 2008; Crundwell, 2008). The publications often refer to Fisher's related theorem.

There are also a considerable number of authors who interpret the NPV primarily or simultaneously as the surplus of company (or firm) value (Keane, 1975; Baker and 
Powell, 2005; Laux, 2011). However, in the reality (as it is well known) the shareholder value is not equal with the firm value, and the maximization of the firm value is not the same as the maximization of shareholder value.

The paper of Woods and Randall (1989, p. 85) says that the direct relationship of NPV and shareholder wealth has never been proven:("the links between NPV and shareholder wealth are not made explicit in the literature. Textbooks merely state the equivalence as a general premise without rigorous proof'). The theorem are still alive today, even though it cannot be proven moreover it contains many logical contradictions (Illés, 2012b).

\section{The reinvestment rate assumptions}

According to the main direction of reinvestment rate assumption the NPV method assumes the required rate of return, while the IRR method assumes the IRR as the reinvestment rate of annual yields (as long as the project lasts). The debate about this began in the 1950s (Solomon, 1956; Renshaw, 1957), and is still underway.

The contested conception emerged as a kind of treatment of the ranking conflict which often occurs between the NPV and the IRR. The supporters of the described above reinvestment rate assumption concept ensure automatic priority to the NPV method by emphasizing that reinvestment according to the high IRR is hard enough (a typical example is Laux, 2011).

The debate is slightly one-sided. One of the dominant groups does not argue and does not react to the opposing views, just repeats the validity of the reinvestment rate assumption as a well-known relationship. These views can be considered roughly uniform. The representatives of the significantly smaller group of those who partially or fully reject the reinvestment rate assumption try to prove that this assumption is wrong. They use different logical arguments as well as mathematical or exemplary evidence. Their methodical solutions are also varied (e.g. Dudley, 1972; Carlson et al., 1974; Keane, 1979; Lohmann, 1988; Johnston et al., 2002; Crean, 2005; Rich and Rose, 2014).

In a great number of studies in this topic, many unclear conditions, categories and phrases can be found. For instance, the reinvestment rate assumption itself is interpreted as either an explicit, implicit, or some kind of general assumption. The type of reinvestment amount is not always obvious, either. These amounts can mostly be interpretable as yields coming from a project in different years of its duration, more rarely as differences computed from yields of two examined projects. Sometimes the examined problem is not actually the reinvestment rate assumption, but the critical reinvestment rate (e.g. Alchian, 1955; Dudley, 1972; Meyer, 1979). In the latter cases, references date back to Fisher (1930). Meyer's paper (1979) examines this question according to the system tools and categories of microeconomics.

Several authors point out their disapproval with the one-sided teaching of faulty doctrines. Among them, Johnston et al. (2002) call attention to the fact that a number of finance textbooks completely ignore scientific findings that disprove the reinvestment rate assumption of the two methods. Due to this, they urge reforms. In the introduction of their paper, Walker et al. (2011) give a detailed description of teaching completely controversial materials. Their research joins to the study of Keef and Roush (2001), which draws the attention to the fact that finance textbooks use the 
reinvestment rate assumption higher proportion than textbooks in management accounting. The findings of their own research done a decade later show a similar direction. They make an important statement emphasizing the lack of consistency amongst disciplines: "Finance books fall at one end of the continuum with 64 percent using the assumption while the engineering economics books fall at the other end with just 20 percent using the assumption" (Walker et al., 2011, pp. 11-12).

In my research results, this sort of reinvestment rate assumptions as an automatism of these methods has never proved.

\section{Only one NPV can occur}

The argument that there only one NPV can occur as opposed to the opportunity of several IRR sometimes appears as comprehensive problem (Brealey and Myers, 1988). However it is generally known that, the multiple internal rates of return occur only in cases of unorthodox cash flow patterns. According to the general academic opinion, the NPV method is suitable for evaluation in the case of unorthodox (non-normal) cash flow patterns as well, as there can be only one NPV as opposed to the opportunity of several internal rates of return (e.g. Arnold and Hope, 1990; Bierman and Smidt, 2012). However, there is absolutely no evidence that the NPV of an unorthodox cash flow pattern shows a real economic content.

\section{Literary trends in preferring of NPV method}

In the literature a sort of harmony appears on the issue of project classification, that both the NPV and IRR method will always give the same result, either rejecting or accepting a project (e.g. essentially the same is discussed by Bierman and Smidt, 1986; Brigham and Ehrhardt, 2008; Khan and Jain, 2008; Kinney and Raiborn, 2012). This consistency, however, does not limit the declarations concerning the NPV's superiority. Behind the NPV preference, three main trends with a slight boundaryblurring can be revealed as follows:

1. The NPV method is the best in all aspects. Most of the representatives of the trend according to which the NPV is the best as a selection tool and as a ranking creating tool as well apply the above shareholder value concept as a kind of guiding principle. There is a very interesting "forecast". Laux (2011) says that academics consider the NPV approach is superior and some of them so find that over time practitioners have come to agree.

In fact, the Fisher's intersection was borne on the basis of comparability of NPVs as well (Fisher 1930). The Fisher's intersection is named the point where NPV curves of two investment projects are equal. This intersection is often referred as a decision preparing problem nowadays as well (Baker and Powell, 2005; Hill, 2008; Van Horne and Vachowicz, 2008). Several decades now known that the NPVs are not directly comparable. Generally, the comparability is distorted by the differences of initial investment, durations and the rapidity of payback (Keane, 1975). Despite of this, the one-sided recommendation of NPV has not disappeared.

2. The NPV is the best as a selection tool, but the NPV divided by the initial investment (or the profitability index) is suitable to be a ranking creating tool. The NPV divided by the initial investment and the profitability index gives the same ranking. Namely, 
the profitability index can be written in the following form as well: [1+ NPV divided by the initial investment]. For example Brealey and Myers (1988), Albrecht et al. (2007), Watson and Head (2009) suggest the profitability index for ranking creating. The paper of Damodaran (2010) suggests for this purpose the NPV divided by the initial investment, however, this rate there is named profitability index. By these suggestions only the distortion effect of differences in initial investments is avoided (two of distortion affects are remained).

3. The NPV is the best as a selection tool, however, the equivalent annual average sum of the NPV is suitable to be a ranking creating tool. This ranking tool suggestion often appears - mainly in the financial literature - in the last three decade (e.g. Helfert, 1991; Baker and Powell, 2005; Lee at al., 2009). The way of quantifying the average is NPV divided by the annuity factor, which in business economics means multiplying by the loan repayment factor. (Business economics always uses the loan repayment factor. The financial literature uses the annuity factor, which is the reciprocal of the previous formula.) This solution only eliminates the distortion effect of the differences in duration (two of them are remained).

In the literature, it does not seem ambition to simultaneous eliminate the three distorting factors.

\section{Purpose and method}

The main objectives of this paper are as follows:

- To define the economic content of the NPV and IRR and to diagnose the usability for project evaluation and ranking.

- To present the profit requirement calculation according to required rate of return.

- To define the special content of aggregate capital needs, to compile an index number for it, and to highlight the importance of taking the aggregate capital needs into consideration.

- To show the essentials of the real reinvestment rate assumption in case of orthodox cash flow pattern.

The main research methods are methodological analysis, model editing and examination of formulas. The proving ways of findings are logical and mathematical processes as well. The interests of clarity, the paper uses the following conditions and categories:

1. The traditional concept of the NPV and the IRR methods: The paper interprets and analyses the content background of NPV and IRR methods in the classic sense. Among others, the paper uses the term "capital" as a homogeneous sum in terms of ownership (and as investable or invested money). Profit is interpreted as a pre-tax profit. The interpretation and analysis of methods are related exclusively to investment projects.

2. Business economics approach and system of aspects: The business economics interprets and manages the database as well as the results of calculations according to the conditions in reality. (As featured in the first section finance is inherently built on standard microeconomic foundations.). This study examines the NPV and IRR from the aspect of business economics by using its category system.

3. The calculation logic follows the real process of management and after the close of this, returns to the discounting method: The paper assumes that the management 
relations can be clarified moving forward in time according to the management process. The planning and thinking of corporate executives works the same way. The main and well-known question of strategy making is: "where are we now and where we want to arrive?" It would be difficult to work out backwards this. The moving forward is the only way in which the emergence and realization of return requirements as well as the process of the surplus profit formation can be seen through. Therefore, this study uses a detour to substitute for the classical methods. In order to show the content tally with the classical methodology of project evaluation, after the systematic exploration of content relations, the analysis returns to the classical method. Discounting back to the start time makes the content examination of the return process impossible.

4. The NPV and IRR methods can provide acceptable and economically meaningful outcomes only in case of orthodox cash flow patterns: (This is proved by Illés 2016.) Therefore the analyses and conclusions are only concerning to the cases of investment projects with orthodox cash flow patterns. (The well-known criteria of orthodox cash flow patterns are: a series of the difference of annual revenues and expenditures starts with negative amount or amounts and the sign of these differences changes only once. That is, from a point in time where this difference first turns into positive, this positive sign does not change.)

5. Yield analysis according to the return structure: Examinations and analyses of the return process can be solved by following the formation of internal structure of the yield. The yield is the difference between the annual revenues and annual expenditures. So the yield belongs to the types of annual indicators. A positive amount of yield is surplus sales revenue in terms of financial needs in a given year. Therefore the yield exits from the project at the end of the examined year. The conditions of further utilization of this usually do not affect the evaluation of the analysed project. In the case of orthodox cash flow patterns, the content of the yield with a positive sign can consist of capital return and/or profit. In the NPV method, the profit part of the yield may consist of further two parts: profit according to the required rate of return and surplus profit. Until meeting the return requirements, the yield consists of profit according to the required rate of return and capital return. After the fulfilment of return requirements, the content of the emerging yield is surplus profit. In the IRR method, the yield all along consists of capital return and profit according to the interest rate, there is no surplus profit. In this case, collation with the return requirements takes place after calculations.

\section{The economic contents}

\section{The economic content of IRR}

Earlier in business economics the IRR was named time-adjusted rate of return (Garrison, 1988). IRR calculation means searching for the rate of return which makes the sales revenue line and the expenditure line equal to each other. (IRR is usually determined by a process of trial and error. Using computer the calculation is very quick.) In case of investment projects with orthodox cash flow patterns, the IRR shows the factual time-adjusted profitability rate of the investment. This content is regarded generally known in business economics literature. For instance Garrison (1988) and 
Arnold and Hope (1990) interpret this rate as a true yield percentage. (This sort of content approach is not typical in finance literature.) The acceptability criteria of the project are decided by how large factual profitability rate is generated compared to the required rate of return. The difference shows how large surplus rates (or lack of rates) are generated compared to the required rate of return. Generally, this difference needs not be defined numerically; this becomes visible when writing the two rates next to each other. Where the two rates are equal, that still means that required profitability is exactly achieved.

Having more than one IRR is the characteristic of unorthodox cash flow pattern projects only. It is occurs that financial literature does not handle the distinction of orthodox and unorthodox cash flow patterns and denies the expedience of the IRR (e.g. Brealey and Myers, 1988). It often says that the IRR is without meaning (Hill, 2008). These statements are valid only the case of unorthodox cash flow patterns. In this case the multiple IRRs in reality are only technical factors, and they really are without economic meaning.

\section{The economic content of NPV}

The NPV literature does not deal with economic content clarification. According to my research results, the economic content of the NPV is clear only in case of orthodox cash flow patterns. In this case, the NPV is the sum of the surplus profit generated above the required one, discounted for the present time. This is explicable in logical way and demonstrable mathematically as well (Illés, 1990, 2007, 2012a).

\section{Two basic formulas}

In well-known theory, the NPV is calculated so that the discounted sum of all expenditures is subtracted from the discounted sum of sales revenue that is associated with the examined investment project. The calculation can also be made with the time series of the difference of revenues and expenditures. Then the annual differences are discounted and summarized. Hereinafter, in order to simplify modelling, that sort of model will be examined where the payment of initial investment occurs at the same time as operation is started. This is date zero. The first revenues will occur one year later, by this time the annual revenues exceed the annual expenditures. The two basic formulas of NPV method are used in this paper are as follows:

$$
N P V=\sum_{t=1}^{n}\left(B_{t}-K_{t}\right) \frac{1}{(1+i)^{t}}-E_{0} \quad \mid B_{t}-K_{t}>0
$$

Where

$B_{t}=$ sales revenues in year $t$,

$K_{t}=$ expenditures in year $t$,

$E_{0}=$ initial investment (the investment sum is occurring in the zero point of time),

$i=$ required rate of return,

$t=$ serial number of years,

$n=$ duration of the project.

$$
N P V=-E_{0}+\sum_{t=1}^{n} H_{t} \frac{1}{(1+i)^{t}} \quad \mid H_{t}>0
$$


$H_{t}=$ difference between sales revenues and expenditures in year $\mathrm{t}$ (where $\mathrm{Ht}>0$ for orthodox cash flow pattern projects).

According to NPV method the investment project is acceptable if the NPV is not less than zero. In the following the analysis deals with positive or zero NPV.

\section{General demonstration}

The economic efficiency of investment projects can be examined correctly by several methods, not only by the published ones. Such a no familiar method can be the return calculation based on following up the return process. At the end of this process the output is the sum of surplus profit (according to all of annual surplus profits is charged with the required rate of return by the end of the duration). The essence of the proof is that the discounting of this surplus profit leads to the NPV.

The first stage of the demonstration describes the return process of the cost of capital. The cost of capital is the sum of the return requirement of the capital face value and its required profit according to the required rate of return.

The amount of the cost of capital not yet returned and the return status is

at the end of Year 1: $-E_{0}(1+i)+H_{1}$

at the end of Year 2: $\left[-E_{0}(1+i)+H_{1}\right](1+i)+H_{2}$

at the end of Year 3: $\left\{\left[-E_{0}(1+i)+H_{1}\right](1+i)+H_{2}\right\}(1+i)+H_{3}$

and so on. After the return requirement is met, the formula becomes positive. Assuming that the return status at the end of Year 3 already shows the pattern of the development of the process through time, the simplification is introduced.

Eliminating the curly and square brackets:

$$
-E_{0}(1+i)^{3}+H_{1}(1+i)^{2}+H_{2}(1+i)+H_{3}
$$

The numerical definition of the return status inscribed for the end of Year 3 can be applied further for the full duration of the investment:

$$
-E_{0}(1+i)^{n}+H_{1}(1+i)^{n-1}+H_{2}(1+i)^{n-2}+\ldots+H_{n-1}(1+i)+H_{n}
$$

In the second stage of the demonstration the surplus profits calculated above to the end of duration is transformed into present value. The three steps of it are: prescribing the discounting formula, fulfilling the discounting process, simplifying the resulted formula.

$$
\begin{gathered}
{\left[-E_{0}(1+i)^{n}+H_{1}(1+i)^{n-1}+H_{2}(1+i)^{n-2}+\ldots+H_{n-1}(1+i)+H_{n}\right] \frac{1}{(1+i)^{n}}} \\
-E_{0}+H_{1} \frac{1}{(1+i)}+H_{2} \frac{1}{(1+i)^{2}}+\ldots H_{n-1} \frac{1}{(1+i)^{n-1}}+H_{n} \frac{1}{(1+i)^{n}} \\
-E_{0}+\sum_{i=1}^{n} H_{t} \frac{1}{(1+i)^{t}}
\end{gathered}
$$

The Formula (6) has arrived at one of the basic NPV formula that is the Formula (2). The proof is complete. The deduction proved that in the case of orthodox cash flow 
pattern projects the NPV is the discounted amount of the surplus profit generated above the profit requirement according to the discount rate (Illés, 2012a).

The economic background of the NPV curve

The NPV curve is well known (Figure 1). The plotting of this is a regularly appearing topic within the literature of investment projects evaluation. The authors also consider that this figure is well-known and widely used; therefore do not use any professional reference. The figures and related explanations are introduced from different perspectives: once a general theoretical relationship (Arnold and Hope, 1990), another time as a solution of an exercise or an introduction of a problem through an example (Brealey and Myers, 1988; Van Horne and Wachowicz, 2008).

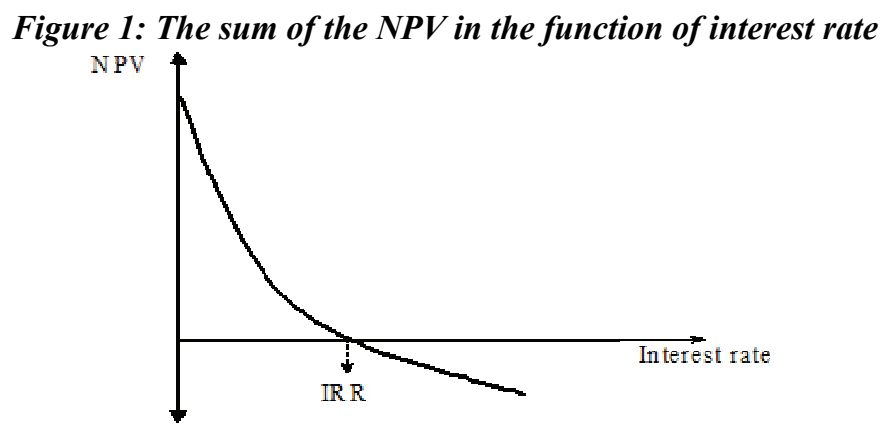

Source: Widely used illustrations of the relationship (e.g. Arnold and Hope, 1990, p.254,

Brealey and Myers, 1988, p. 79; Van Horne and Wachowicz, 2008, p. 329)

Figure 1 shows the NPV curve. By this the higher the interest rate is, the smaller the NPV. As a result of increasing interest rate, this decrease first reaches the zero NPV, then further increasing results in higher and higher negative NPVs. The interest rate that is at the intersection of axis $x$ and that results in zero NPV is the IRR. (This is well known.) As I know, there are no literature sources on the pre-conditions and detailed content background of the illustrated relationship. In order to specify the problem it must be laid down that the curve in Figure 1 is valid for most but not all projects in question. The relationship is only valid for profitable projects with orthodox cash flow pattern. Namely, the NPV is monotonously decreasing, there is only one intersection, and the curve starts in the positive range (Illés, 2014).

The illustrated NPV curve starts from zero percent interest rate. When the required rate of return is zero, then the NPV is calculated by the Formula (1) as follows:

$$
N P V=\sum_{t=1}^{n} B_{t}-\sum_{t=1}^{n} K_{t}-E_{0}=M \quad \mid i=0
$$

$M=$ Total accounting profit that is the difference of the nominal value of total revenues and total expenditures including initial investment arising during the whole duration of the project.

As Formula (7) shows, at zero percent interest rate the NPV is the difference between the nominal value of total revenues and total expenditures including initial investment. 
This difference can also be considered as an accounting profit summed up in nominal value for the total duration of the project. This gives the conclusion that if no profit is gained at nominal value, the starting point of NPV curve cannot be in a positive range. (Because of this, the figure is not valid for projects that do not generate accounting profit.)

The profit calculated at nominal value for the whole duration means the coverage possibilities of the profit requirements. If the profit requirements are not larger than the nominal value of all accounting profits, then the project is acceptable.

\section{Calculation of profit requirement}

The profit requirement is interpretable on the yearly sums of not returned part of initial investment. The not returned capital can be only within the pay off period (when the NPV is not negative). In the remaining years of the duration there is not profit requirement, therefore the yields of these years are surplus profits.

Calculation mechanism of the profit requirements according to the not returned part of initial investment (after the payback period the sum of the not returned capital is zero):

In the first year: $M_{s 1}=E_{0} i$

In the second year: $M_{s 2}=E_{l} i ; \quad$ where $\quad E_{l}=\left|H_{1}-E_{0} i-E_{0}\right|$

In the third year: $M_{s 3}=E_{2} i \quad ; \quad$ where $\quad E_{2}=\left|H_{2}-E_{l} i-E_{l}\right|$

For the $\mathrm{t}>1$ year generally:

$$
M_{s t}=E_{t-1} i \quad ; \quad \text { where } \quad E_{t-1}=\left|H_{t-1}-E_{t-2} i-E_{t-2}\right|
$$

$E_{t}=$ the not returned part of initial investment at the end of year $t$,

$M_{s t}=$ the profit requirement in year $t$ according to the not returned part of capital and required rate of return,

If the yearly profit requirement is larger than the yield in current year, then the difference is automatically added to the capital still to be returned. According to Formula (11) the total profit requirements that arise during the duration of the project can be calculated as follows:

$$
\sum_{t=1}^{n} M_{s t}=\sum_{t=1}^{n} E_{t-1} i \quad \text { where } \quad E_{t-1}=\left|H_{t-1}-E_{t-2} i-E_{t-2}\right|
$$

\section{The calculation of surplus profits and its present value}

In the last ear of pay-off period the economic content of yield consists of three elements: profit return according to required rate of return, capital return and surplus profit. On this basis Formula (13) describes the calculation of surplus profit concerning the final year of the pay-off period.

$$
H_{z}-\left(E_{z-1} i+E_{z-1}\right)=\Delta H_{z} \quad \mid H_{z}>E_{z-1}(1+i)>0
$$

$z=$ number of years of the pay-off period (including the last commenced year).

$\Delta H_{z}=$ sum of the surplus profit in the last commenced year of pay-off period.

The yield occurring in the years after the return totally consists of surplus profit. The 
description of its quantification begins by making formula for the calculation of the annual amounts. The sum of the surplus profit at the end of the first, the second and the third year after the pay-off period:

$$
\begin{array}{ll}
H_{z+1}+\Delta H_{z}(1+i) ; & H_{z+2}+\left[H_{z+1}+\Delta H_{z}(1+i)\right](1+i) ; \\
H_{z+3}+H_{z+2}+\left[H_{z+1}+\Delta H\right. & \text {; }(1+i)](1+i))(1+i)
\end{array}
$$

Considering the third year's formula, the sum of all of annual surplus profits charged with the interest rate can be calculated by the end of the duration as follows:

$$
F V \Delta M=\sum_{j=1}^{s} H_{z+j}(1+i)^{s-j}+\Delta H_{Z}(1+i)^{s}
$$

$F V \Delta M=$ the sum of the surplus profit charged with interest rate at the end of the duration,

$j=$ the ordinal number of the years of operating period after the pay-off,

$s=$ the number of years of the operating period after the pay-off $(s=n-z)$.

Because of the interest rates are charged, Formula (14) contains some false interest income. According to Formula (15) the false interest income falls out during discounting. Surplus profits will be discounted from the year of their occurrence. The present value of the discounted and summed surplus profits is the NPV itself:

$$
N P V=\left[\sum_{j=1}^{s} H_{z+j}(1+i)^{s-j}+\Delta H_{z}(1+i)^{s}\right] \frac{1}{(1+i)^{n}}
$$

$n=$ duration of the project $(z+s)$.

After simplification [using $(\mathrm{n}=\mathrm{s}+\mathrm{z})$ ] there will be a clear formula, according to which the NPV can be reached by discounting and assuming the surplus profits according to the date of occurrence:

$$
N P V=\sum_{j=1}^{s} \frac{H_{z+j}}{(1+i)^{z+j}}+\frac{\Delta H_{z}}{(1+i)^{2}}
$$

Starting from the classical version of the NPV inscription it cannot be seen that only surplus profits remain among the really discounted items.

\section{The real reinvestment rate assumption in the case of orthodox cash flow pattern}

According to the logic of time going forward, firstly the capital and profit requirements should be recovered. These items gradually quit the project and calculations, according to their return. (The method does not charge farther return requirements for these items.) The yields generated after the fulfilment of return requirements are the surplus profit. These sums also leave the project so they cannot be regarded as the organic part of the project. However, these sums remain in the calculations. The NPV method focuses on the quantification of sums interpreted in this paper as surplus profit.

The discounting mechanism related to the surplus profit automatically assumes that the profitability of this surplus will be equal to the required rate of return according to the project. This way the real reinvestment rate assumption will prevail, but only regarding 
the surplus profit appearing above the profit as to the required rate of return.

It is important to emphasize that the this real assumption concerns only the surplus profit and it concerns neither the total yield, nor the yield part for capital return, nor the yield part for return on profit requirement. The content band of the real reinvestment rate assumption is fundamentally different from everything that can be found about this in the literature. The real reinvestment rate assumption exclusively is prevailed for the surplus profit. This does not cause any inconvenience. For orthodox cash flow patterns the IRR method does not enforced any reinvestment rate assumption. The IRR covers the whole profit sum, so technically there is no surplus profit (no lack, either). Accordingly, the automatic reinvestment rate assumption cannot be realized.

It should be noted that in the case of unorthodox cash flow patterns the real reinvestment rate assumption are enforced in both method. Here the significance of this may be very large. In this area there are loss-making projects with positive NPV. However, in the case of orthodox cash flow patterns the loss-making projects are automatically rejected by both methods. The most important point of the problem is as follows: the calculation mechanism of the NPV method handles the false interest incomes of temporary surplus profit as real money. Discounting the unused part of the false interest income leads to a positive NPV. The NPV emerging this way is false as well. Detailed proof and analysis of these are in Illés, 2016)

\section{Comparison of expressive power of the two indicators}

The economic content of the IRR of orthodox cash flow pattern is clear. This is the profitability rate of invested capital. This information is in accordance with an almost commonplace basic truth of economics, that in the competitive market the capital goes where the highest return rate can be achieved at a given risk.

In contrast with this, an NPV with positive sign has the following message for the decision-maker: the profit requirements according to the required rate of return will be fulfilled and surplus profit calculated in present value will also be gained. If the question is whether the profit requirements are fulfilled, this answer is satisfactory. But it is not easy to tell what advantage this amount exactly means.

A quite ordinary example: for an individual who is fixing 300,000 euro in a bank for one year, it is more meaningful to do so at an interest rate of $4.5 \%$ than to be told that he will get 3\% interest on his deposit plus 4,500 euro more. This special sort of deposit is more difficult to see through with a long-term commitment (Illés, 2012b).

\section{The ranking problem}

As it was mentioned in the first section, the comparability of NPVs may distort the differences in initial investments, the durations and the rapidity of capital returns. There are literary sources for suggestion of certain corrections to eliminate of the distortion effects. These suggestions, however, only concern for the first or the second out of the three distortion effects listed above. (There is no visible pursuit of a complex correction.) 
The suggestion for dividing the NPV by the initial investment $\left[\frac{N P V}{E_{0}}\right]$ or using the profitability index $\left[1+\frac{N P V}{E_{0}}\right]$ as a ranking tool, eliminates only the distortion effect of differences in initial investments.

The suggested equivalent annual average sum of the NPV as a ranking creating tool only eliminates the distortion effect of the differences in duration. The formula of this time-adjusted average is: $q_{n} N P V \quad$ (where $q_{n}$ is the loan repayment factor, within the required rate of return and duration of the project).

Another step could be - although I did not find any suggestions for this in the literature - merging of the above two methods, that is, the numerical definition of the equivalent annual average sum of the NPV divided by initial investment, that is $q_{n} \frac{N P V}{E_{0}}$.

In the last formula there are eliminated distortion effects of initial investments and durations, however, there is no eliminated the distortion effect of return rapidity. The methodological elaboration of calculating a coefficient which could measure return rapidity seems to be very complicated in this structure. I believe that the calculation of this coefficient is not necessary, but very important to know its essence.

Fundamental cases: a) Return by years is uniform. Than the coefficient is 1. b) Return is quickly. The larger yields arise at the beginning of the duration. In this case the coefficient is bigger, than 1 (advantageous). c) Return is slow. The larger yields arise at the end of the duration. In this case the coefficient is lesser, than 1 (disadvantageous).

The cleansed formula is as follows:

$$
q_{n} \frac{N P V}{E_{0}} \lambda=(r-i) \varepsilon
$$

$\lambda=$ coefficient of payback rapidity,

$r=$ internal rate of return,

$\varepsilon=$ miscalculation factor.

The cleansed NPV is a special rate-difference between the factual return rate and the required one. This content is followed from exhibited calculating procedure. The ratecharacter has appeared when the NPV was divided by initial investment. The matter of rate-difference is following from that, the NPV is a surplus yield. Multiplying this surplus yield rate with the loan repayment factor it transforms the time-adjusted average of NPV rate. The last step is the correction with the coefficient of return rapidity. This way has formed the modified difference between the IRR and the required rate of return. This method cannot lead to the accurate difference of two rates. This is coming from the special cleaning solution in which are mixing the elements of static and dynamic procedures for investment project evaluation. This is indicated by a calculation error factor (Illés, 2012a).

The surplus profitability over the required rate of return (if the required rate is equal for all examined project) will be the highest for the project where the IRR is the highest. Thus the same projects will gain the first, second, etc. place in both rankings. In this correct way, there is not methodological superiority. 


\section{Aggregate capital needs}

The project's aggregate capital needs means the amount of capital needed for operation of the project during its full duration. This is a new business economics category. Quantification and consideration of it could significantly improve the economic evaluation and comparison of investment projects. The sum of the aggregate capital needs depends on the initial investment, duration of project and the rapidity of capital return. For the calculation it shall be aggregated the yearly tied-up capital that is the not-returned parts of the initial investment for each year (Illés, 2014).

The calculation method of tied-up capital for the first three years and for the $t>1$ year generally are presented in Equitation (8) - (11). Based on all these, the index number of aggregate capital needs $\left(E_{A C N}\right)$ is as follows:

$$
E_{A C N}=\sum_{t=1}^{n} E_{t-1}
$$

Tied-up capital is a state indicator, and therefore the tied-up capitals of different years cannot be summed up from this aspect. However, in consideration the incomeproducing potential needs to take into account simultaneously the tied-up capital and tied-up time. The content of the index-number means a capital amount which is tied up for one year. So the measurement unit of this is one unit tied-up capital for one year. According to the calculation method used above a three-year tie-up of one capital unit is equal to three capital units tied up for one year.

This solution is considered to be correct because the tied-up capital is computed with a database where in the first step the profit requirements are subtracted from the yields of certain years. The remainder is interpreted as a return part of initial investment in a given year.

It is useful to examine how much total capital is used in an investment project, to generate a given NPV and a given IRR. It is favourable if smaller aggregate capital needs result in a higher NPV or greater aggregate capital needs result in a higher IRR. The category of the aggregate capital needs has a significant opinion-forming role. It is advisable to take into account the aggregate capital needs as well.

\section{References}

1. Albrecht, W., Stice, J., Stice, E., Monte Swain, M. (2007): Accounting: Concepts and Applications. Cengage Learning Thomson South-Western

2. Alchian, A.A. (1955). The Rate of Interest, Fisher's Rate of Return over Costs and Keynes' Internal Rate of Return. American Economic Review, 45(5), 938-943.

3. Arnold, J., Hope, T. (1990): Accounting for Management Decisions. Prentice Hall International (UK) Ltd.

4. Baker, H. K., Powell, G. E. (2005): Understanding Financial Management: A Practical Guide. John Wiley \& Sons. USA, UK, Australia

5. Bierman, H., Smidt, S. (1957): Capital Budgeting and the Problem of Reinvesting Cash Proceeds, The Journal of Business, 30, No. 4: 276-279.

6. Bierman, Jr. H., Smidt, S. (1986): Financial Management for Decision Making. Macmillan, New York 
7. Bierman, H., Jr., Smidt, S. (2012). The Capital Budgeting Decision: Economic Analysis of Investment Projects (9th ed.) Routledge.

8. Boehm-Bawerk, E.V. (1889): Positive Theorie des Kapitales. Jena: Fisher.

9. Brealey, R. A., Myers, S. C. (1988): Principles of Corporate Finance. (Third edition.) McGraw-Hill Publishing Company, New York, St. Louis, San Francisco etc.

10. Brigham E. F., Ehrhardt M. C. (2008): Financial Management: Theory \& Practice. Thomson South-Western, Mason, USA

11. Brigham, E. F., Houston J. F.(2009): Fundamentals of Financial Management. South-Wesern Gengage Learning, Mason, USA

12. Carlson, C.R., Lawrence, M.L., Wort, D.H. (1974): Clarification of the Reinvestment Assumption in, Capital Analysis. Journal of Business Research. Volume 2, Number

13. Crean, M. J. (2005): Point of View. Revealing the True Meaning of the IRR via Profiling the IRR and Defining the ERR. Journal of Real Estate Portfolio Management. Volume 11, Number 3, pp. 323-330.

14. Crundwell, F. K. (2008): Finance for Engineers. Evaluation and Funding of Capital Projects. Springer, London.

15. Damodaran, A. (2010): Applied Corporate Finance. John Wiley \& Sons Inc. Hoboken.

16. Daróczi, M. (2004): Mezőgazdasági beruházások komplex döntés-elökészítése. Doktori (Phd) disszertáció. 139 p. Szent istván Egyetem, Gödöllő

17. Dudley, C. L., Jr. (1972): A Note on Reinvestment Assumptions in Choosing between Net Present Value and Internal Rate of Return. The Journal of Finance. Volume 27, Number 4 (Sep.), pp. 907-915.

18. Fisher, I. (1930): The Theory of Interest. Macmillan, New York.

19. Garrison, R. H. (1988): Managerial Accounting. Concepts for Planning, Control, Decision Making. Business Publications, Inc. Plano, Texas.

20. Helfert, E. A. (1991): Techniques of Financial Analysis. Business One Irwin. USA.

21. Hill, A. R. (2008): Strategic Financial Management. available at: www.bookboon.com

22. Illés, B. Cs. (2000): A beruházás-gazdaságossági elemzés alapjai. In: Agrárgazdasági élelmiszerelőállító üzem (eds.: Berszán G.-Várszegi T.), Agroinform Kiadó, Budapest, pp. 344-359.

23. Illés, B. Cs., Keszthelyi, Sz. (1998): Mezőgazdasági kis- és középvállalkozások beruházásainak gazdaságossági-, és kockázatelemzése; Tudományos Közlemények - Gödöllöi Agrártudományi Egyetem Gazdaság- és Társadalomtudományi Kar 3: pp. 105-109.

24. Illés, M. (1990): A gazdaságossági és jövedelmezőségi számítások alapjai. (Fundamentals of investment project evaluations and profitability calculations.) Szakszervezetek Gazdaság- és Társadalomkutató Intézete, Budapest.

25. Illés, M. (2007): Scientific problems of modern approach of net present value. Theory, Methodology, Practice. Club of Economics in Miskolc. Volume 4.Number 1, pp. 29-35.

26. Illés, M. (2012a): Transforming the Net Present Value for a Comparable One. Theory, Methodology, Practice. Club of Economics in Miskolc. Volume 8 Number 1, pp. 24-32.

27. Illés, M. (2012b): Links Between Net Present Value and Shareholder Value form a Business Economics Perspective. Theory Methodology Practice. Club of Economics in Miskolc. Volume. 8, Number 2, pp. 31-36.

28. Illés, M. (2014) Fisher's Rate and Aggregate Capital Needs in Investment Decisions. Theory Methodology Practice. Club of Economics in Miskolc. Volume 10, Number 1, pp. 21-32.

29. Illés, M. (2016): The Real Reinvestment Rate Assumption as a Hidden Pitfall. Theory Methodology Practice. Club of Economics in Miskolc. Volume 12, Number 1, pp. 47-60. http://dx.doi.org/10.18096/TMP.2016.01.06 47

30. Johnston, K., Forbes, S., Hatem, J. J. (2002): Reinvestment Rate Assumptions in Capital Budgeting: A Note. Journal of Economics and Finance Education. Vol. 1, No 2, pp. 28-29.

31. Khan, M.Y, Jain, P.K. (2008) Financial Management. Tata McGrow-Hill, New Delhi 
32. Keane, S. M. (1975) Investment selection criteria: an examination of the theory of the internal rate of return and of the investment discount rate under conditions of uncertainty. $\mathrm{PhD}$ thesis. University of Glasgow.

33. Keane, S.M. (1979): The Internal Rate of Return and the Reinvestment Fallacy. Abacus Vol.15, No. 1, pp. 48-55.

34. Keef, S.P., Roush, M.L. (2001): Discounted Cash Flow Methods and the Fallacious Reinvestment Assumption: A Review of Recent Texts. Accounting Education. Volume: 10 Issue: 1 (Mar), pp.105-116 10 (1) pp. 105-116.

35. Keynes, J.M. (1936): The General Theory of Employment Interest and Money, Harcourt, Brace \& Company, New York,

36. Kinney, M., Raiborn, C. (2011) Cost Accounting: Foundations and Evolutions. SouthWestern, Cengage Learning.

37. Laux, J. (2011): Topics in Finance Part VI - Capital Budgeting. American Journal of Business Education - Volume 4, Number 7 pp. 29-38

38. Lee, A. C., Lee, J. C., Lee, C. F. (2009): Financial Analysis, Planning, and Forecasting: Theory and Application. World Scientific Publishing Co. Pte. Ltd.

39. Lohmann, J.R. (1988): The IRR, NPV and the Fallacy of the Reinvestment Rate Assumptions. The Engineering Economist. Volume 33, Issue 4 pp. 303-330

40. Meyer, R.L. (1979): A Note on Capital Budgeting Techniques and the Reinvestment Rate. The Journal of Finance. Vol. 34, No. 5 (Dec.), pp. 1251-1254.

41. Renshaw, E. (1957): A Note on the Arithmetic of Capital Budgeting Decisions. Journal of Business. Vol. 30, No. 3 (July), pp. 193-201.

42. Rich, S. P., Rose, J. T. (2014): Re-Examining an Old Question: Does the IRR Method Implicitly Assume a Reinvestment Rate? Journal of Financial Education. Vol.10, No.1, pp. 105-116

43. Schmalen, H. (2002): Általános üzleti gazdaságtan. (Universal Business Economics) AxelSpringer Budapest Kiadó.

44. Solomon, E. (1956): The Arithmetic of Capital Budgeting Decisions. Journal of Business. Vol. 29, No. 2 (April), pp. 124-29.

45. Szűcsné Markovics K. (2012): A beruházásgazdaságossági számítások gyakorlatban alkalmazott módszerei (Applied Methods of Investment Project Evaluation in Practice) . Vezetéstudomány, Különszám, pp 97-106.

46. Van Horne, J. C. , Wachowicz, J. M., Jr. (2008): Fundamentals of Financial Management. Pearson Education Limited. Harlow.

47. Volkman D. A. (1997): A consistent yield-based capital budgeting method. Journal of Financial and Strategic Decisions. Volume 10 Number 3, pp. 75-88.

48. Walker, J. S., Check, H. F., Jr., Randall, K. L. (2011): Does the Internal Rate of Return Calculation Require a Reinvestment Rate Assumption? - There Is Still No Consensus, West Chester University: Pennsylvania Economic Association Proceedings Annual Conference, June 3-5, 2010. pp. 118-130.

49. Watson, D., Head, A. (2009): Corporate Finance: Principles and Practice. Pearson Education Limited, Harlow

50. Woods J.C., Randall M. R. (1989): The Net Present Value of Future Investment Opportunities: Its Impact on Shareholder Wealth and Implications for Capital Budgeting Theory. Financial Management, Vol. 18, No. 2, pp. 85-91 


\title{
2.7. THE EVOLUTION OF E-RECRUITMENT: THE INTRODUCTION OF ONLINE RECRUITER
}

\begin{abstract}
Summary
The evolution of e-recruitment in the last 15 years has led to the emergence of new techniques of recruitment for the traditional recruiter. These techniques can change the function of a simple recruiter in an online recruiter. In this paper we have identified new tasks, skils and qualifications for the online recruiter function. "Recruitment is, in reality, job marketing" (Maurer and Liu, 2007), and this is the reason why online recruiter must constantly emphasize "the creation of a virtual recruiting environment" to attract talented employees which can provide long-term competitive advantage to organization. This virtual recruitment environment includes the company website that can be used in recruitment process, social networks and professional recruitment sites. Another online recruiter task is to create the opportunity and to motivate the colleagues in the organization, to participate in the recruitment process by posting and distributing available jobs in the virtual environment (social networks). The online recruiter must "cultivate a strong employment brand in online environment" (Ollington, Gibb and Harcourt, 2013). All these tasks require new skils and qualifications for recruiter.

The purpose of this paper is to create a job description for online recruiter. This job description suggests new tasks, skils and qualifications for traditional recruiter. It defines the scope of this new job, the duties and the responsibilities. The purpose of all these is the transformation of traditional recruiter in online recruiter.

The article ends with recommendations in terms of improving recruitment techniques and online practices.
\end{abstract}

Keywords: e-recruitment, job description, online recruiter

\section{Introduction}

E-recruitment is a subject often discussed in the specialized literature. In the mid of 1990s the Internet appears for the first time as a recruitment tool, giving rise to a phenomenon called in that time recruiting revolution (Boydell, 2002 quoted by Dhamija, 2012). Over the years, several synonymous terms describing the notion of erecruitment were identified: e-recruitment, web-based recruiting, online recruiting, web recruiting, recruiting online, recruiting on the internet, electronic resume, internet recruiting, etc. (Wolfswinkel, Furtmueller and Wilderom, 2010).

Recently at this list we can add other terms such as social media recruiting or social recruiting, which also falls under the scope of e-recruitment. More and more organizations are using their social media pages for recruitment purposes. Acikgoz 
(2013) presents a study conducted by Jobvite where „Ninety-two percent of organizations were using or planning to use social media for recruitment in 2012".

To the transformation of human resources recruitment function in e-recruitment, the evolution of technology information also contributed significantly by using information systems for the collection, storage, processing and the use of information in the field of human resources.

E-recruiting experienced a strong development in a short time. Given the current context, the evolution of technology has made its mark in recruitment due to the large number of companies looking for candidates using the Internet, but the large number of candidates applying to a job using online tools. Finding a talented candidate that fits the job has become more difficult. E-recruitment represents a solution for companies that are trying to find the ideal candidate to generate them competitive advantage, helping also the candidate.

Dhamija (2012) shows that "e-recruiting revolutionized the complete recruiting process" and the Internet is "acting as a link between employers and job seekers". These major changes in the recruitment filed, besides having greatly improved the work methods, they have created new work tasks for the recruiter.

Until now, many studies were focused on explaining the phenomenon of e-recruitment point of view of job seekers or employers. Over the years the studies regarding erecruitment were made from several angles of various management-oriented subdisciplines such as information systems, marketing, psychology, and human resources, giving the field of its interdisciplinary slant (Wolfswinkel, Furtmueller and Wilderom, 2010). Wolfswinkel et al (2010) realized a study of the specialized literature and selected 45 articles when they discovered three important perspectives. Most articles were conceived from the perspective of the applicant (19 items) then in terms of organization, several articles from different perspectives and only a recruiter perspective article. In this paper we will focus on the recruiter and its new tasks and responsibilities that appeared with the emergence and development of e-recruitment.

The ultimate goal is to propose a new job, moving from the traditional recruiter to online recruiter.

\section{E-recruiting evolution and design}

Recruitment function occupies an important role in the organization because companies are always looking to attract the most talented employees on a job that can them generate competitive advantage. As the psychologist and physician George Crane said "There is no future in any job. The future lies in the man who holds the job ". Deillon (2014) explain very simple that e-recruitment "is a new technological mean for selecting one of the companies' most crucial resources, i.e. human resource ".

Deillon (2014) quotes also Malinowski, Keim, \& Weitzel when he is describing the four different phases of e-recruitment evolution. They found two dimensions "degree of process integration" and "time" to determine the four phases (Figure 1).

Phase 1: The introduction of isolated solutions in the e-recruitment process for single activities such as the applicant data storage in computer systems. With the using of 
Internet appeared the possibility to post vacancies on the company's website or on the job portals, but also the possibility to search of a job and CV databases of these portals. Phase 2: In this phase appears the integrated applicant management system. This system wants to attract potential candidates, post vacancies, and receive applications from those who are looking for a job and even the final selection.

Phase 3: The information systems ensure compatibility of external service providers with company information systems providing a continuous flow in the recruitment process.

Phase 4: It involves a final solution that covers the entire recruitment process, integrating computer systems but also web-based tools that allow data transfer between the company and other external parties.

Figure 1: The Recruitment Phase Model

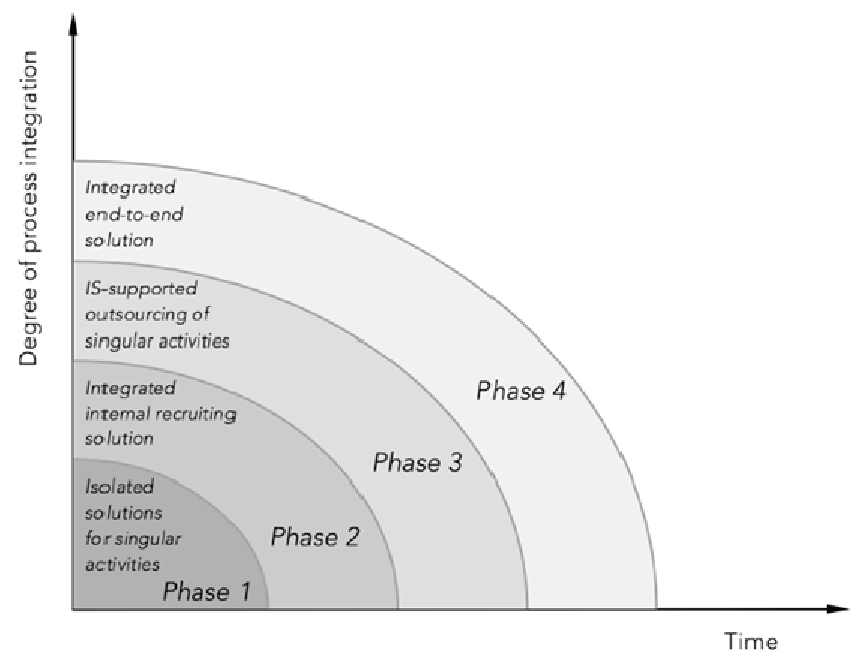

Source: Malinowski, Keim, \& Weitzel, 2005 quoted by Deillon Céline, 2014

These four phases are not generally available, but offers an itinerary and organizations tend to follow this model in integrating new techniques and methods of recruitment. Follow these four phases can highlight also the e-recruitment progress, from the simply use of a PC (from 1980s) for data storage, to the use of Internet and tools that rely on web for attracting, selecting and hiring the suited candidates.

Wolfswinkel et al. (2010) identifies three important directions of e-recruitment: "adding recruiting pages to an existing organization site, using websites specialized in recruiting, and using electronic advertisements on media sites". They define erecruiting as "the online attraction and identification of potential employees using corporate or commercial recruiting websites, electronic advertisements on other websites, or an arbitrary combination of these channels including optional methods such as remote interviews and assessments, smart online search agents or interactive communication tools between recruiter and applicant.

For several years, the phenomenon of social networks stands out in the recruitment process. Ollington Nickolas et al. (2013) bring us into account several studies showing 
that recruiters and companies are increasingly using online social networking to attract and screen candidates as part of the hiring process. They present a study realized by Careerbuilder.com in which $45 \%$ of companies use social recruiting. Another more recent study made by Jobvite.com (2014) shows that employers plan to increase their investment in a range of recruiting methods and on top (73\%) of these methods, social networks can be found. This study of Jobvite.com also shows which social sites are preferred by recruiters: Linkedin is on top with 94\%, then Facebook with 66\%, Twitter with $52 \%$ and the list goes with Google plus $21 \%$, etc. Although these social networks were not specifically designed for recruiting, they became tools for recruitment. For example Linkedin was not designed specifically for the recruitment industry, but it has become the preferred tool of recruitment of more recruiters and companies (Vick and Walsh, 2008).

These changes in the recruitment procedure lead to the need to manage some specific challenges for the recruiter. Once identified these challenges transform the traditional recruiter in an online recruiter who owns new skills, tasks and responsibilities.

\section{The online recruiter - Job Description}

With the advent of recruitment has been much talk about reducing costs and time spent in the recruiting stage. As e-recruitment has evolved, a transfer from the traditional recruitment to e-recruitment took place. This new way to attract candidates for a job also brought with it new tasks and responsibilities that change the traditional recruiter's activity. These tasks and responsibilities require a new set of skills and qualifications that can create a new profession: "online recruiter".

Companies need an online recruiter to adapt the recruitment process to the information age with the aim of "cultivated a strong employment brand in the online environment" (Ollington, Gibb and Harcourt, 2013). Another purpose for which we need the online recruiter is to attract applicants by building an online social network (Ollington, Gibb, Harcourt, 2013). Another online recruiter task is to create the opportunity and to motivate the colleagues in the organization, to participate in the recruitment process by posting and distributing available jobs in the virtual environment (social networks).

Maurer and Liu (2007) say that "recruitment is, in reality, job marketing" and this is the reason why online recruiter must constantly emphasize "the creation of a virtual recruiting environment" to attract talented employees which can provide long-term competitive advantage to organization. This virtual recruitment environment includes the company website that can be used in recruitment process, social networks and professional recruitment sites.

Some tasks and responsibilities are similar to those of traditional recruiter. Table 1 shows the traditional recruiter's job description.

We took a traditional recruiter job description from a company with over 1,600 employees in Romania and we modified it only to highlight the duties and responsibilities of an online recruiter (Table2.) The way these tasks are executed and finalized change the traditional recruiter's work, in fact all the developments of erecruitment based on "Internet, has completely changed the role of the traditional recruiter" (Dhamija, 2012). 
Table 1: Traditional Job Description

\begin{tabular}{|c|c|}
\hline JOB DESCRIPTION & G ANALYST / INTEGRATION EMPLOYEES \\
\hline Internal function & HR SPECIALIST \\
\hline DEPARTEMENT & Human resources \\
\hline STUDIES & specialized higher education \\
\hline hierarchical relations & $\begin{array}{l}\text { hierarchically subordinate to the head of } \\
\text { department }\end{array}$ \\
\hline DUTIES, RESPONSIBILITIES & \\
\hline 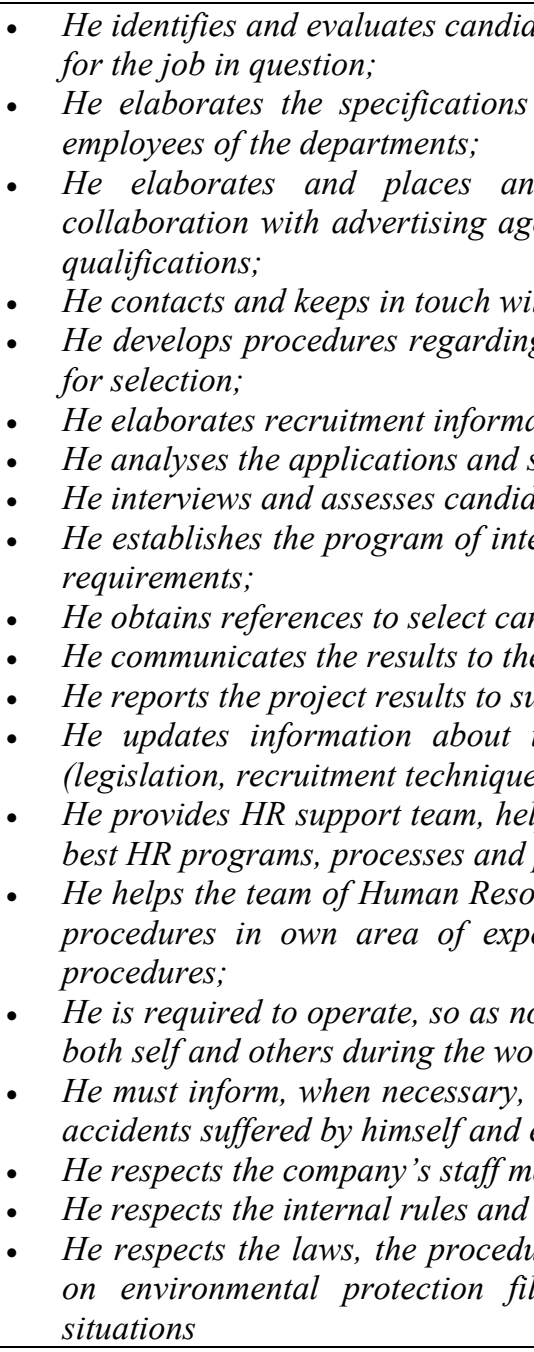 & $\begin{array}{l}\text { es for available jobs and proposes the most suitable } \\
\text { f the available job in discussion with officers or } \\
\text { uncements in newspapers and magazines (in } \\
\text { cy) in order to attract candidates with appropriate } \\
\text { the recruitment agency; } \\
\text { the selection of candidates and goes at universities } \\
\text { ve materials specific to the organization; } \\
\text { ects the appropriate ones; } \\
\text { es by applying psychological tests and knowledge; } \\
\text { views and informs he candidate about the future job } \\
\text { idates; } \\
\text { ejects candidates; } \\
\text { eriors, getting feedback from internal client; } \\
\text { e legislation and informs the other departments } \\
\text { procedures) } \\
\text { ing to analyse the employees requests to provide the } \\
\text { ocedures; } \\
\text { ces to implement and develop programs, processes, } \\
\text { tise, in accordance with company processes and } \\
\text { to expose to danger, injury or occupational disease, } \\
\text {; supervisor and / or employer, about occupational } \\
\text { vironmental accidents; } \\
\text { ork procedures; } \\
\text { l, security and occupational health, emergency } \\
\text { os indications; }\end{array}$ \\
\hline Name and surname of the employee & Complied by \\
\hline Signature & \\
\hline Date: 16.04 .2015 & Date: 16.04 .2015 \\
\hline
\end{tabular}

Source: a company with over 1,600 employees in Romania 
Table 2: Online recrutier - Job Description

\begin{tabular}{|l|c|}
\hline JOB DESCRIPTION & Online Recrutier / INTEGRATION EMPLOYEES \\
\hline Internal function & HR SPECIALIST \\
\hline DEPARTEMENT & Human resources \\
\hline STUDIES & specialized higher education \\
\hline Hierarchical relations & hierarchically subordinate to the head of department \\
\hline DUTIES, RESPONSIBILITIES & \\
\hline
\end{tabular}

- He identifies and evaluates candidates for available jobs and proposes the most suitable for the job in question;

- He elaborates the specifications of the available job in discussion with officers or employees of the departments;

- He elaborates and place online ads to attract candidates with appropriate qualifications for the job;

- He contacts and liaises with other external recruitment factors such as specialized recruiting sites social sites;

- He elaborates online procedures and motivates colleagues to participate in the recruitment process by distributing job offers and cultivating an employer brand on the social networks.

- He creates a virtual environment by building and maintaining an online social network structure;

- He adapts recruitment informative materials specific to the organization using the online environment;

- He manages the company's career page or website and also the social media pages.

- He deals with management database and analyses the applications by choosing the appropiate ones.

- He obtains references about the selected candidates;

- He reports the projects results to superiors, getting feedback from internal client;

- He updates information about the legislation and informs the other departments (legislation, recruitment techniques, procedures;

- He provides HR support team, helping to analyse the employees requests to provide the best HR programs, processes and procedures;

- He helps the team of Human Resources to implement and develop programs, processes, procedures in own area of expertise, in accordance with company processes and procedures;

- He is required to operate, so as not to expose to danger, injury or occupational disease, both self and others during the work;

- He must inform, when necessary, his supervisor and / or employer, about occupational accidents suffered by himself and environmental accidents;

- He respects the company's staff management indications;

- He respects the internal rules and work procedures;

- He respects the laws, the procedures in the area of responsibility and company policy on environmental protection filed, security and occupational health, emergency situations

\begin{tabular}{|l|l|} 
Name and surname of the employee & Complied by \\
\cline { 1 - 1 } Signature & Date: \\
\hline Date: &
\end{tabular}


Another online recruiter's task is to create the opportunity to motivate and the colleagues in the organization, to participate in the recruitment process by posting and distributing available jobs in the virtual environment (social networks).

\section{Recommendations for improving online recruitment techniques and practices}

Regarding the techniques and methods used in online recruitment, it should be noted that there is no formula for success, they have to be adapted and specifically selected for each recruitment action. All these techniques and methods show both advantages and disadvantages, the online recruiter's role is to select the much more suited methods depending on job and the company he represents.

For example the advantages of an organization career sites are: candidate relationship management, high interest in jobs by job applicants and integration with existing systems. The disadvantages are the needs for IT specialists and high up front development cost (Lee, 2007). The situation of these disadvantages could be changed by creating an online job recruiter that must have the necessary IT skills to maintain the career site, and thus the company will not need an IT specialist for maintenance.

A future research direction would be to measure the level of satisfaction of the online recruiter and applicant, as a result of experiences during the various stages of online recruitment process. An analysis about e-satisfaction can be influenced by the websites and online service quality (Constantin, 2012). This analyse can differentiate in an emerging economy the online recruitment tools that promise lower margins and no higher profits. (Boşcai, 2015).

Figure 2 below shows the results from an exploratory study of an online recruitment company (job board) that illustrate consumer evaluations (Liljander, 2002).

Figure 2: Service elements of a job board and customer's cognitive and affective reactions

$$
\text { E-service offering - a job board }
$$

Customer evaluation

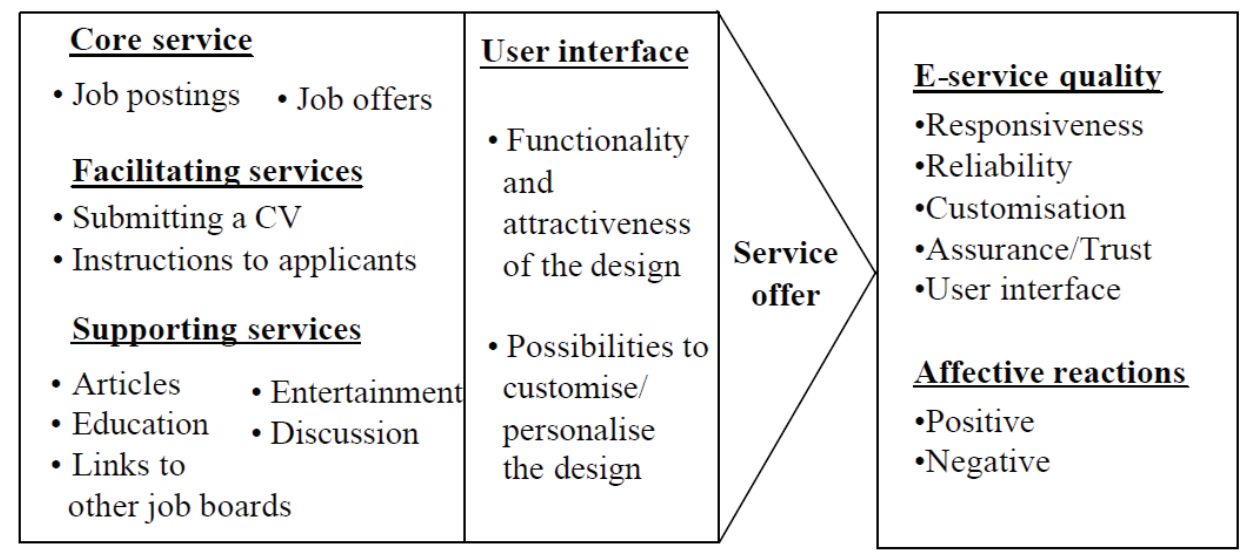

Source: Liljander, van Riel and Allard (2002) 
The above guidance can be used to study the changes that take place when the traditional recruitment process turns into online recruitment, the study of these changes can lead to the improvement of online recruitment tools. The figure below illustrates four elements offered by an online recruitment tool, with examples of procedures. Then it suggests five dimensions about the quality of services that an online recruitment tool provides.

These approaches indicate the necessity of continuous research and improvement of factors to attract future applicants but also to meet the needs of the organization by attracting those candidates that can generate value to the company (Constantin, 2012).

"A recent trend is for employers and recruiters to utilize social networking sites to screen candidates as part of the hiring process" (Vicknair et al., 2010). In this article, Vicknair et al. propose additional studies conducted from the perspective of the employer/ recruiter's attitude to answer questions about how often these tools are used and what would be the industries that use them. In this way the online recruiter can choose when it is relevant to use tools provided by social recruiting and when is not the case.

Vicknair et al. quotes Jacobs (2009) which defines the term social recruiting as "harnessing Web 2.0 technology developments and social media tools to communicate, employ, inform, and recruit our future talent,,The use of such social networking websites allows recruiters to connect to a broad array of talented and capable candidates in niche communities" (Vicknair et al., 2009). A disadvantage of these social networking websites is that applicants usually controls what they post and they would not post something that the employers would not like to see.

Future candidates must be prepared "for the new era of social recruitment" (Faliagka et al., 2012), they must have a profile on LinkedIn which they must update and invest time to have an extensive list of contacts, also the participation in online discussion in communities or blogs can give them greater visibility and thus can increase job offers. Parry and Tyson (2008) after an analysis of the use and success of online recruitment identify some steps that employers must take in order to improve their success in using online recruitment methods. They identified four such steps: (1) driving traffic to a corporate website, (2) use of back-office functionality, (3) creation of a talent pool and (4) branding and the provision of information to candidates.

- Driving traffic to a corporate website. If a company does not have a strong employment brand in the online environment and is not well known then it is very difficult to bring job seekers to their website. Such companies must adopte other "advertising channels such as jobs boards or print media to drive people to the site" and ,jobs boards were used to drive traffic to a company's corporate website through the use of a web link" (Parry and Tyson, 2008)

- Use of back-office functionality. Technological developments have created the opportunity to reduce the number of initial screening activities by using IT systems ("use of the back-office system") that automate certain functions for managing the recruitment process and reduce costs significantly.

- Creation of a talent pool. Applicant's data can be automatically recorded on a system without manual input. Data storage of some talented candidates within the organization and subsequent search in this database when a new vacancy appears, 
can bring several benefits to recruitment process such as reducing initial costs and reducing the time spent with screening activity.

- Branding and the provision of information to candidates. Candidates can learn more about the company and the future job through career information on the website, information that can be read, viewed through videos or listened to audio files. In this way, future candidates can do a better selection. These online recruitment technologies can easily be used to promote employer brand.

\section{Conclusions}

The Internet and the development of e-recruitment functions have changed the way the traditional recruiter perform his duties and responsibilities. These changes have led to the shaping of new jobs as "online recruiter," which besides the fact that he has new tasks and responsibilities, he must possess certain qualifications that traditional recruiter does not have. These qualifications might be for database management, skills and web designer abilities, qualifications and skills to use and select the appropriate softwear in order to solve specific recruitment problems, etc.

It is necessary to built analytical methods for online recruitment tools, so that online recruiter can choose the tools that attract the most talented people with minimal resources.

Online recruitment methods can be improved by increasing the corporate career site traffic, by using a back-office system, creating a talent pool and an employer branding with a lot of specific information available to future job candidates.

\section{Acknowledgement}

This work was supported from the European Social Fund through Sectorial Operational Programme Human Resources Development 2007-2013, project number POSDRU/159/1.5/S/134197 , project title "Performance and Excellence in Postdoctoral Research in Romanian Economics Science Domain"

\section{References}

1. Boşcai G. B. (2015): Niche Websites and online tools used in recruitment, SEA - Practical Application of Science, Volume III, Issue 1 (7) pp. 113-120., http://www.sea.bxb.ro/Article/SEA 7 18.pdf

2. Constantin, A-M. (2012): The antecedents of e-satisfaction and e-loyalty and the relationship between them, Timisoara Journal of Economics, eISSN: 1844-7139, volume 5, Issue 18, p. 236- 252, http://www.tje.uvt.ro/index.php/tje/article/view /163/ pdf.

3. Deillon, C. (2014): The advantages and challenges of turning towards e-recruitment for small and medium sized businesses (SME). Thesis avaible at https://diuf.unifr.ch/main/is/sites/diuf.unifr.ch.main.is/files/documents/student-project $\quad$ s/S2014_Celine_Deillon_0.pdf

4. Dhamija, P. (2012): E-recruitment: a road map towards E-human Resource Management, Researchers World: Journal of Arts, Science and Commerce Vol. 3, Issue: 3(2), pp. 33-39. 
5. Faliagka, E., Tsakalidis, A., Tzimas, G. (2012): An integrated e-recruitment system for automated personality mining and applicant ranking, Internet Research, Vol. 22 Iss: 5 pp. 551568, http://dx.doi.org/10.1108/10662241211271545

6. http://www.goodreads.com/quotes/140173-there-is-no-future-in-any-job-the-future-lies

7. https://www.jobvite.com/wp-content/uploads/2014/10/Jobvite_SocialRecruiting_Survey 2014.pdf

8. Lee In (2007): An Architecture for a next - Generation Holistic E-recruiting System, Comunications of the ACM, July 2007/Vol.50, No. 7.

9. Liljander, V.; van Riel C.R.; Allard, P. M. (2002): Customer satisfaction with e-services: The case of an online recruitment portal, Electronic services, http://citeseerx.ist.psu.edu/viewdoc/download?doi=10.1.1.199.2974\&rep=rep1\&type=pdf

10. Malinowski, J.; Keim, T.; Weitzel, T. (2005): Analyzing the Impact of IS Support on Recruitment Processes: An E-Recruitment Phase Model, AIS Electronic Library (AISeL), PACIS 2005 Proceedings Paper 81, http://aisel.aisnet.org/pa cis20 05/81

11. Maurer, D. S.; Liu, Y. (2007): Developing effective e-recruiting websites: Insights for managers from marketers, Business Horizons (2007) 50, 305-314. Available at: http://www.yupingliu.com/files/papers/maurer_liu_recruiting.pdf

12. Ollington, N.; Gibb, J.; Harcourt, M. (2013): Online social networks: an emergent recruiter tool for attracting and screening, Personnel Review, Vol. 42 No. 3, 2013, pp. 248-265, Emerald Group Publishing Limited, 0048-3486, DOI 10.1108/00483481311320390

13. Parry, E.; Tyson, S. (2008): An analysis of the use and success of online recruitment methods in the UK, Human Resource Management Journal, Vol. 18, Iss. 3, Pages 257-274, https://dspace.lib.cranfield.ac.uk/bitstream/1826/4228/1/Ana nalysis_of the use and success_of \%20online recruitment methods in the UK.pdf

14. Vick, B.; Walsh, D. (2008): Happy about LinkedIn for recruiting, available at: www.happyabout.info/linkedin4recruiting.php.

15. Vicknair, J.; Elkersh, D.; Yancey, K.; Budden, C. M. (2010): The use of social networking websites as a recruiting tool for employers, American Journal of Business Education, Volume 3, Number 117, http://dx.doi.org/10.19030/ajbe.v3i11.57

16. Wolfswinkel, J.; Furtmueller, E.; Wilderom, C. (2010): Reflecting on e-recruiting research using grounded theory, 18th European Conference on Information Systems, ECIS20100477.R1.

17. Acikgoz, Y. (2013): Social Media and Employee Recruitment: Too Much Pain For Not Much Gain, Thesis, Cranfield University 


\section{CHAPTER 3}

\section{Applications and innovative methods}



Anna DUNAY, Zoltán T. NAGY, Csaba Bálint ILLÉS

\title{
3.1. ORGANIZATIONAL CULTURE ASSESSMENT - A CASE STUDY OF HUNGARY AND AUSTRIA
}

\begin{abstract}
Summary
In this study, we compared the organizational culture of two companies of similar size, which are both working in the chemical equipment manufacturing market. The comparison is based on interviews of the corporate executives and the analysis of the data gathered by questionnaire of Competing Values Model. Based on these data we observed that the Hungarian company's organizational culture shows duality, because at the manufacturing departments of the company a dominantly hierarchical organizational culture may be found, while among white-collar workers the market structure is typical. The organizational culture of the Austrian company is uniformly hierarchical in the entire organization. Both company's organizational culture is significantly different when compared to those structures which are described in the literature sources characterizing the two countries. We clearly found the different effects of the Austrian and Hungarian national cultures in the organizations, however, the effects and influence of the strict and uniform EU regulations of the investigated industrial sector were represented even more strongly. These regulations seem to drive the two company's organizational culture in the same direction.
\end{abstract}

Keywords: national culture, organizational culture, Competing Values Framework

\section{Introduction}

Nowadays, under the increasing competitive circumstances, the achievement of the desirable organizational efficiency attracts the interest of researchers and market players as well, and organizational culture is one of the key factors. Organizational culture is important to the practitioners, because it affects all aspects of interrelationship both intra-organizational and inter-organizational.

In the daily operation of small and medium sized enterprises (SMEs), especially in Eastern Europe, most managers are not able to find enough time to deal with organizational culture issues, but this does not mean that organizational culture does not exist. Organizational culture develops from the foundation of a company and it is influenced by external factors like national culture, industrial sector and technology and by internal circumstances such as company size, management strategies, decisions and leadership style. It is a continuously changing aspect of an organization, in which managers can instantiate changes to better suit their business strategy (Bakacsi, 2004, p. 223). However, organizational culture is difficult to modify as it is developed during a long period. Companies must think critically about that how they will run their business, because initiatives should be consistent with the organizational culture (Abbett, Coldham and Whisnant, 2010).

Many researchers and leaders underline that organizational culture as an important factor of the successful operation. However, only a few researches on organizational studies were resulted by the findings of case studies, most of them are based on 
empirical evidence. Applying a practical framework to this issue would contribute to a valuable insight into the real organizational culture issues, by which our existing theoretical and empirical knowledge could be complemented. Therefore, in our research, we compared the organizational culture of two companies: one from Hungary and one from Austria.

\section{Literature review}

According to Hofstede and Hofstede (2005), national culture is the collective programming of the mind distinguishing the members of one group or category of people from others. The six dimensions of national culture are individualismcollectivism; uncertainty avoidance; power distance (strength of social hierarchy); masculinity-femininity (task orientation versus person-orientation); long-term orientation and indulgence versus self-restraint.

It has been proven in previous researches that national culture has a strong influence on the organizational culture of an enterprise (Kertai-Kiss, 2014). National cultures were studied extensively in the past decades. Based on the information of the Hofstede Centre (2015) one can summarize the differences and similarities of the national cultures in Hungary and Austria. Based on this model, we found that the two cultures are quite similar in three aspects: Masculinity, Uncertainty Avoidance and Long Term Orientation. There is a gap between the Optimism of the two countries, Austria being explicitly more optimistic. Individualism is more typical in Hungary and particularly Power distance is much higher. These differences may derive from the historical differences of the $20^{\text {th }}$ century: Austria was among Western countries, while Hungary was a part of the Eastern bloc. Interestingly, while according to the Hofstede model, Austria has the lowest Power Distance Index globally and Hungary is in the middle range.

According to Dittrich et al. (1996), national cultures of Western Europe and the former socialist countries are getting closer and closer to each other owing to globalization and of course, the fall of the Iron Curtain.

Dimitratos et al. (2011) examine how national culture values affect strategic decisionmaking processes of internationalized firms. The findings of the study prove that the national culture of the focal firm may have a strong influence among internationalized small and medium-sized firms. It verifies that the examination of the national culture cannot be ignored.

Cheng et al. (2007) pointed out that evidence suggests that the encountered problems of companies mostly are not technical in nature; they are usually 'soft' problems, such as having an organizational culture that is not implicitly or explicitly supportive. Therefore, it is essential to deal with organisational culture issues.

In the international literature, there are many definitions for organizational culture. According to Aktas et al. (2011, p. 1561.) it is 'a model of norms, values, beliefs and attitudes which affects organizational behaviour'. According to Kordshouli et al. $(2013$, p. 2840) 'organizational culture can be defined as values, beliefs, principles observed as a framework for systems and managerial activities'. One can agree with the authors that 'one of the essential factors on reaching success within organizations 
is to learn more about organizational culture, to direct and to improve it towards favourite organizational culture' (Kordshouli et al., 2013, p. 2840).

The Competing Values Framework (CVF) of Cameron and Quinn (1999) now is one of the most influential and widely adopted model by both academicians and practitioners, and used to understand better the relationship between organizational culture and the company's performance. The main idea behind the theory is that when all leaders, managers and staff within an organization have a perspicuous sense of their culture, it creates order, continuity, collective identity, commitment, and common vision while reducing organizational uncertainties. This leads to improved organizational effectiveness (Cameron and Quinn, 2006).

CVF describes the organizational cultures in two main dimensions: the internal vs. external orientation, and the flexibility and dynamism vs. stability and control. The different approaches of a given organization towards these values allow the categorization of the companies into four culture types, which are called Clan, Adhocracy, Market and Hierarchy. The main characteristics of the four types are summarized in Table 1.

Table 1: Characteristics of organizational culture types

\begin{tabular}{|c|c|c|c|c|}
\hline & Clan & Adhocracy & Hierarchy & Market \\
\hline $\begin{array}{c}\text { Dominant } \\
\text { character- } \\
\text { istics }\end{array}$ & $\begin{array}{l}\text { Personal, family- } \\
\text { like }\end{array}$ & $\begin{array}{l}\text { Entrepreneurial, } \\
\text { risk taking }\end{array}$ & $\begin{array}{l}\text { Controlled and } \\
\text { structured }\end{array}$ & $\begin{array}{l}\text { Competitive, } \\
\text { achievement- } \\
\text { oriented }\end{array}$ \\
\hline $\begin{array}{l}\text { Leadership } \\
\text { style }\end{array}$ & $\begin{array}{l}\text { Mentoring and } \\
\text { supporting, } \\
\text { parental role }\end{array}$ & $\begin{array}{l}\text { Creative, } \\
\text { innovative, risk } \\
\text { taking }\end{array}$ & $\begin{array}{l}\text { Coordinating, } \\
\text { organizing, } \\
\text { efficiency oriented }\end{array}$ & $\begin{array}{l}\text { Aggressive, } \\
\text { result-oriented } \\
\text { hard drivers }\end{array}$ \\
\hline $\begin{array}{l}\text { Manage- } \\
\text { ment of } \\
\text { employees }\end{array}$ & $\begin{array}{l}\text { Teamwork, } \\
\text { consensus and } \\
\text { participation }\end{array}$ & $\begin{array}{l}\text { Individual risk- } \\
\text { taking, innovative } \\
\text { entrepreneurs }\end{array}$ & $\begin{array}{l}\text { Security, } \\
\text { conformity, } \\
\text { predictability }\end{array}$ & $\begin{array}{l}\text { Competitiveness } \\
\text { and achievement }\end{array}$ \\
\hline $\begin{array}{l}\text { Organiza- } \\
\text { tional glue }\end{array}$ & $\begin{array}{l}\text { Loyalty, tradition } \\
\text { and mutual trust }\end{array}$ & $\begin{array}{l}\text { Commitment to } \\
\text { innovation, } \\
\text { development }\end{array}$ & $\begin{array}{l}\text { Formal rules and } \\
\text { policies }\end{array}$ & $\begin{array}{l}\text { Emphasis on } \\
\text { achievement and } \\
\text { goal accomplishing }\end{array}$ \\
\hline $\begin{array}{l}\text { Strategic } \\
\text { emphasis }\end{array}$ & $\begin{array}{l}\text { Human } \\
\text { development, high } \\
\text { trust, openness }\end{array}$ & $\begin{array}{l}\text { Acquisition of } \\
\text { resources, creating } \\
\text { new challenges }\end{array}$ & $\begin{array}{l}\text { Permanence and } \\
\text { stability }\end{array}$ & $\begin{array}{l}\text { Competitive actions } \\
\text { and winning }\end{array}$ \\
\hline $\begin{array}{l}\text { Criteria for } \\
\text { success }\end{array}$ & $\begin{array}{l}\text { Development of } \\
\text { human resources, } \\
\text { teamwork, concern } \\
\text { for people }\end{array}$ & $\begin{array}{l}\text { Unique and new } \\
\text { products and } \\
\text { services }\end{array}$ & $\begin{array}{l}\text { Dependable } \\
\text { delivery, efficient, } \\
\text { scheduling, low } \\
\text { cost }\end{array}$ & $\begin{array}{l}\text { Winning in the } \\
\text { marketplace, market } \\
\text { penetration }\end{array}$ \\
\hline
\end{tabular}

Source: own compilation based on Aitken and Higgs (2010), www.ocai-online.com, Cameron and Quinn, (1999)

Several research aimed to measure the differences in the national cultures and organizational cultures of Hungarian and Austrian companies (Szöke, 2014), but all of these use data from different industrial sectors, from manufacturers to service and consulting companies. The information on the cultural aspects of these companies is therefore also influenced by the differences of the organizational cultures, which can be attributed to different industrial sectors. In addition, these researches considered 
only the cultural aspects based on the answers of the general managers and not that of the different managerial levels or departments of the organization.

In these general researches of the organizational cultures of Hungarian companies, we found that the Hierarchy culture type is dominant, Clan and Market culture types are equally represented and Adhocracy culture type can be found only in $10-16 \%$ of the investigated companies. (Costa and Bogdány, 2013; Gaál et al., 2010)

In the literature concerning the Austrian companies an interesting comparison was made between the Austrian and Australian construction firms, which showed that in this sector the dominant organizational culture type is Market (Lorenz and Marosszeky, 2004).

Acikgoz and Gunsel (2011) investigated the interrelationship between organizational climate and team innovativeness. The findings provide empirical evidence in support of the relationship between innovative vision and managerial support dimensions of climate and team innovativeness. Moreover, the study showed that there is a greater relationship between innovative vision, management support and team innovativeness when environmental uncertainty is greater. Aktas et al. (2011) concluded that organizational culture has an impact on job satisfaction, job efficiency, employee commitment and cooperation. Reimann et al. (2012) also argued that employees are among the forces that drive firms to superior performance.

Koufteros et al. (2007) also found strong positive relationship between level of customer orientation and supported values relating to beliefs on management control, beliefs on working with others, and beliefs on making decisions, which are global. Regarding the increases in customer expectations and competition, the authors stated that manufacturers might need to be responsive and flexible in order to stay competitive. Their findings are consistent with the literature on innovation and organizational theory.

The lack of adequate climate of organization will have negative and strong effects for both employees and organizations. According to Erdil and Ertosun (2011) managers generally take competitiveness of employees into consideration and they believe that this will increase productivity. This attitude is beneficial in the short term but in long term may create decrease in productivity, as employees may feel loneliness in work. Managers should not think in short terms. In addition to this, authors highlighted that synergy among employees will increase willingness to learn and creativity, and a result of this, productivity is another important and related component. Summarizing the authors' findings, positive social relationships should be supported by managers, by the help of positive work life experience for both employees and organizations, much positive outputs can be gained (Erdil and Ertosun, 2011).

The theoretical proposition of Pernot and Roodhooft (2008) was that the organizational cultural resemblance of suppliers is positively associated with the speed at which the management control system changes in case of changing circumstances. Their longitudinal data provided evidence supporting this theoretical proposition. For example, the higher level of management control immediately fitted the risks increase at the start of production and contributed to sustaining good performance. Thus, manufacturers need to be aware of the own values and should be aware of the influence of supplier cultural resemblance. 
However, in his study he presented a behavioural perspective on organizational culture and contributed to its emerging dynamic aspect. Thus, changing environment conditions, internal and external should be examined.

Linnenluecke and Griffiths (2010) tried to examine whether there are links between organizations that emphasize a certain organizational culture type - characterized by one or more of the four different culture types of the Competing Values Framework and the adoption of corporate sustainability principles. They could not provide links.

\section{Research methods}

The empirical research was carried out by comparing the organizational cultures in different management levels of two similar companies. Both of these companies are medium-sized enterprises which supply specialized equipment for chemical-, mainly pharmaceutical manufacturers. Although they are similar in size, turnover and number of employees, they are not competitors, as they operate mainly in their homeland markets. Due to these similarities, we expected the results of the comparison of the organizational cultures to be less influenced by other factors than national culture. Of course, the differences between the management styles and historical development of the two investigated companies are remaining to be influencing factors.

The cultural diagnosis was started with structured interviews with the managers of each company, which provided qualitative indications of the similarities and the differences of the organizational cultures.

In order to provide a quantitative approach, we have chosen to diagnose of the organizational cultures of the enterprises also by the Competing Values Framework of Cameron and Quinn. (Cameron and Quinn, 1999, 2006), because this model provides means of quantifying culture and has a strong and well-established empirical basis for cultural diagnosis.

Figure 1: The Competing Values Framework

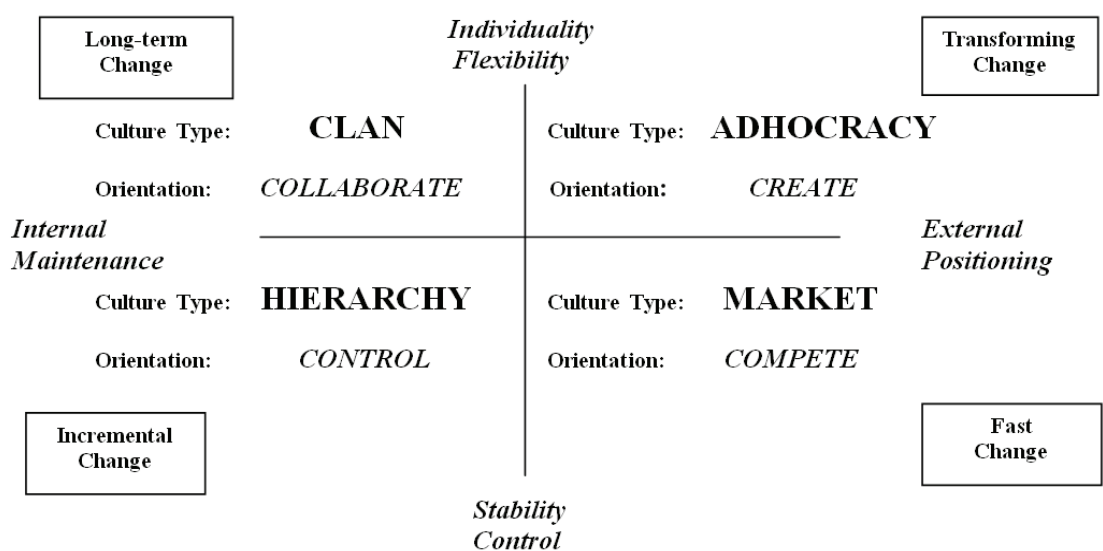

Cameron and Quinn (2006) also published the questionnaire of the Competing Values Framework, which they called Organizational Culture Assessment Instrument, which was used in Hungarian and German translation in our study. Cameron and Quinn (1999) applied an ipsative response scale in which participants must share 100 points 
among the four alternatives describing each cultural dimension. This type of scale could emphasize the differences between the cultural orientations. The peculiarity of this instrument is that it measures the currently experienced and also the preferred culture dimensions, culture types. This allows managers to express if they are not aware, as in most cases, to define the right cultural dimensions for their business strategy systematically.

\section{Research results}

The investigation started with structured interviews of both companies' general managers. The relevant answers showed that the Hungarian company is externally oriented. The results also supported the data of the Hofstede Center (2015) that in Austria Power Distance is lower as in Hungary. The first findings of the research were described by Nagy et al. (2015).

The questionnaire was filled in by $43 \%$ of the employees of the Hungarian and $26 \%$ of the employees of the Austrian company. In both organizations the general managers and all of the middle managers answered, which allowed a distinction of the answers based on management level, therefore we analysed the data in 4 groups: general manager level, middle management level, office workers' level (engineers and administrative staff) and among blue-collar workers.

Firstly, we examined the organizational culture in the different levels of the Hungarian company (Fig. 2).

Figure 2: Perception of organizational culture at different levels of the Hungarian company

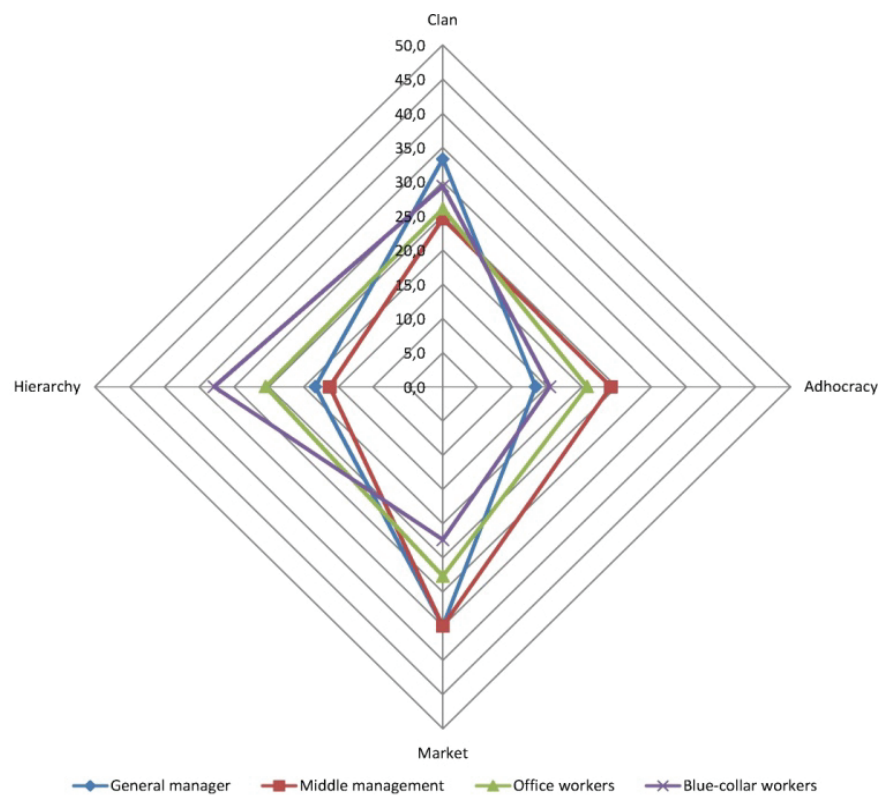

Source: own study, 2015 
In the Hungarian company, we found that Market and Clan culture is dominant in the perception of the general manager and the Hierarchy type is more and more important in the lower levels of the organizational structure. At the level of the blue-collar workers, the Hierarchy becomes the dominant culture.

In the research of Aktas et al. (2011), the culture of Clan was found as negatively related to the organizational environment factor, which emphasizes organizational structure, work in organization, and external competition. The importance of cohesion observed as high for the employees in the Market culture. This implements the significance to the institutional policies and human resources practices, which assure employees to be market oriented and to identify themselves with the institution for this.

Secondly, we moved on the examination of the organizational culture in the different levels of the Austrian company (Fig. 3).

Figure 3: Perception of organizational culture at different levels of the Austrian company

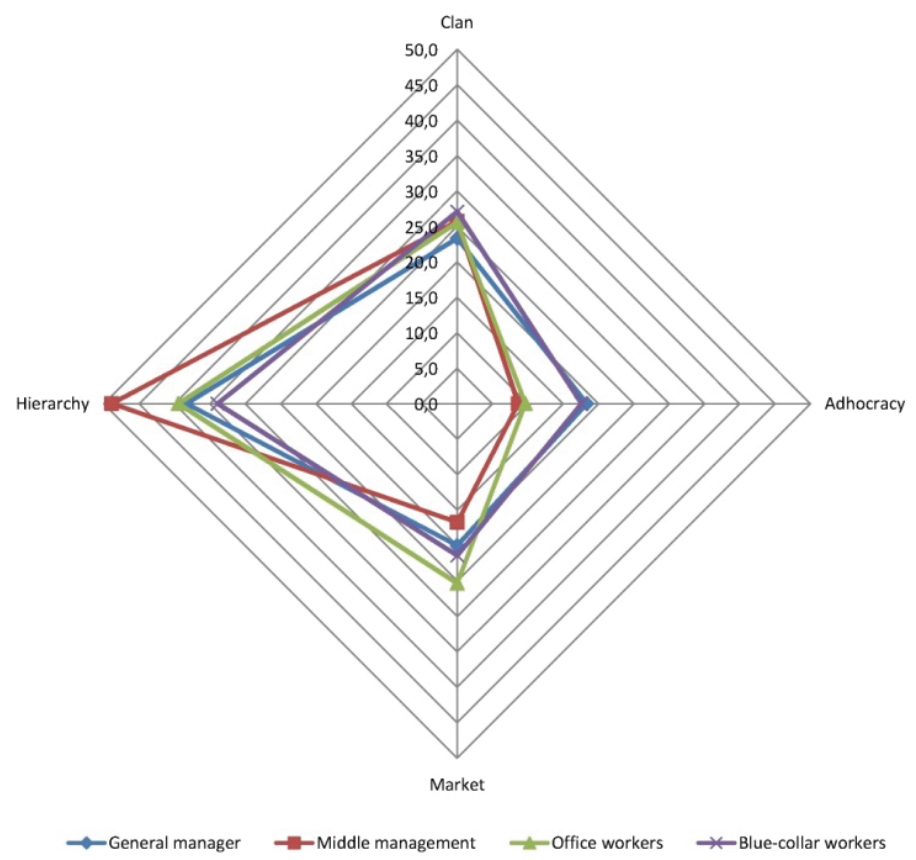

Source: own study, 2015

In the Austrian company, we found that Hierarchy is the dominant culture throughout the entire organization. According to Aktas, Cicek and Kiyak (2011) Hierarchy (and also Market) culture have a strong influence on organizational efficiency.

Richard et al. (2009) examined the role of psychological contracts of the organizational culture to affective commitment as a mediator. They found that Clan cultures positively affected relational contracts and negatively influenced transactional contracts. Hierarchical cultures had a reverse effect. Psychological contract types (relational and transactional) mediated the relationship between organizational culture 
and organizational commitment. Their findings show that a Clan culture is essential for the creation of relational contracts while a Hierarchy culture contributes to the creation of transactional contracts. Their research suggests that if violations of psychological contracts are perceived by employees, the results can have negative effects on the organization. According to the authors, these negative results can then lead to, for example, lower performance. Therefore, it is important that organizations and managers should understand these relationships and how could they manage them most effectively.

Thirdly, we analysed the 'preferred' culture types in both companies (Figure 4.)

Figure 4: Comparison of the preferred culture dimensions

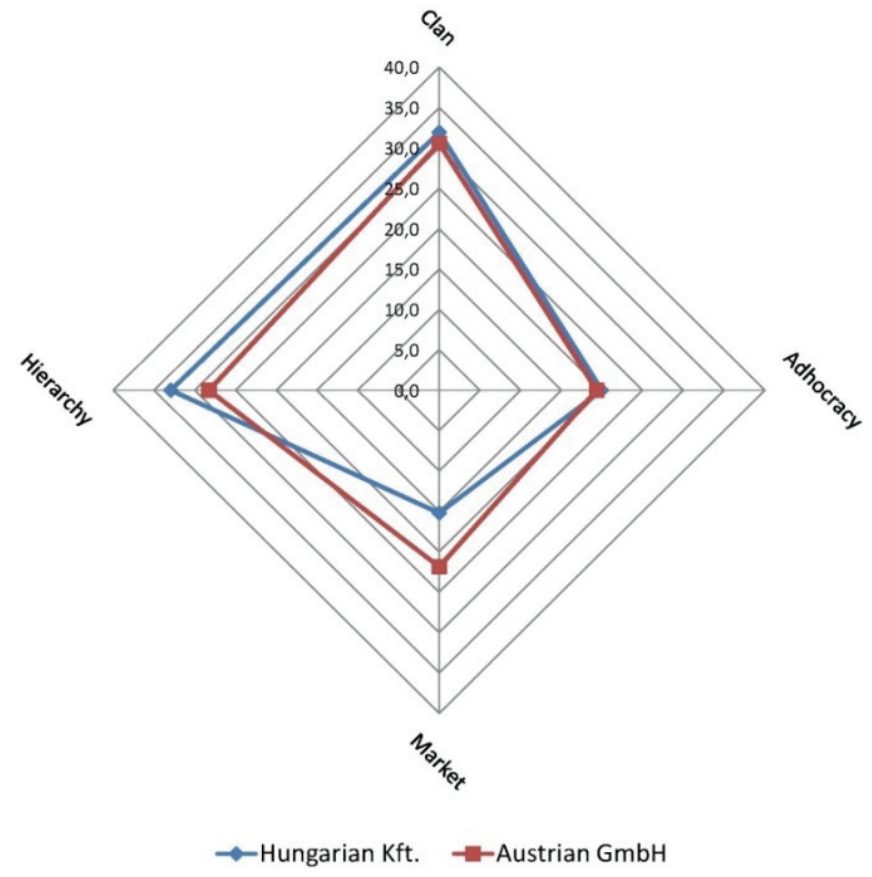

Source: own study, 2015

Based on the results of the comparison of 'preferred' culture types it could be realized that in the Austrian company is more market oriented and in Hungarian company has a more internal orientation where the control would be ideal according to the employees. This means that the differences in cultural dimensions of the two companies might be reduced to a minimum, if the desired changes would take place.

According to the results of Aktas et al. (2011) organizational arrangement, work in organization and external competitiveness, organizational structure and determined job also have a moderator effect on the relationship between organizational culture types and organizational effectiveness, especially for three types of culture: Hierarchical, Clan and Adhocracy. 


\section{Conclusions}

Drawing the conclusions it can be stated that based on literature, it is clear that investigating the effects of organisational culture on the efficient performance of companies is inevitable, because organisational culture has an impact on job satisfaction, job efficiency, employee commitment and cooperation and also on organizational changes, learning, climate, security, motivation, innovation, development etc. Summing up, it has strong impact on effectiveness, profitability and competitiveness of modern industrial organizations. Therefore, business leaders cannot ignore the organizational culture issue.

Although our research is in progress with partial results, these results may allow some speculation and inferences. Firstly, it is interesting to note that the investigated two companies do not show the dominant culture types, which would be characteristic of similar companies in their countries, although a hierarchy type of organizational culture is typical in German speaking countries.

Secondly, it is important to note that these companies have a quite simple organizational structure. Considering that the studied companies are partially owned by their general managers, it is expected that the influence of the managers' personal character is even more influential than in bigger organizations.

The most important finding is, however, that in this uniformly regulated sector, where EU regulations should be strictly kept, Hierarchy type of culture is imposed on the manufacturing departments and this sectorial character is more influential than the differences in the national cultures of Hungary and Austria.

Further investigations in similar companies, possibly in other, - culturally more diverse - countries, would reveal more evidence of the influence of national cultures on the organizational culture.

\section{References}

1. Abbett, L., Coldham A., Whisnant R. (2010): Organizational Culture and the success of corporate sustainability initiatives: An empirical analysis using the Competing Values Framework. University of Michigan, pp. 1-68.

2. Acikgoz, A., Gunsel, A. (2011): The effects of organizational climate on team innovativeness. Procedia Social and Behavioural Sciences 24, pp. 920-927. http://dx.doi.org/10.1016/j.sbspro.2011.09.102

3. Aktaş, E., Çiçek, I., Kıyak, M. (2011): The Effect of Organizational Culture on Organizational Efficiency: The Moderating Role of Organizational Environment and CEO Values. Procedia Social and Behavioural Sciences, 24, pp. 1560-1573.

4. Bakacsi, Gy. (2004): Szervezeti magatartás és vezetés. Aula Kiadó, Budapest

5. Cameron, K. S., Quinn, R. E. (1999). Diagnosing and changing organizational culture: Based on the competing values framework. Addison-Wesley Publishing Company, Reading, Mass.

6. Cameron, K. S., Quinn, R. E. (2006): Diagnosing and changing organizational culture: based on the competing values framework. Revised ed. John Wiley and Sons, San Francisco

7. Cheng T. C. E., Lai K-H, Koufteros X., McDermott C. (2007): Special issue on organizational structure, culture and operations management: An empirical missing link, 106(2), pp. 321-322.

8. Costa, J. P. M., Bogdány, E. (2013): The relationship between organizational culture and the transfer of management, functions and roles in the SMEs succession: A case study between Hungary and North of Portugal. Tourism \& Management Studies, Vol. 9, Issue 1, pp. 121-128. 
9. Dimitratos, P., Petrou, A., Plakoyiannaki, E., Johnson, J.E. (2011): Strategic decision-making processes in internationalization: does national culture of the focal firm matter? Journal of World Business, 46 (2). pp. 194-204. http://dx.doi.org/10.1016/j.jwb.2010.05.002

10. Dittrich, E., Makó, C., Stojanov, C. (1996): Unternehmenskultur, Nationalkultur und Transformation. In: Lang, R. (1996), Wandel von Unternehmenskulturen in Ostdeutschland und Osteuropa, München/Mering, pp. 73-91.

11. Erdil, O., Ertosun, Ö.G. (2011): The Relationship between Social Climate and Loneliness in the Workplace and Effects on Employee Well-Being. 7th International Strategic Management Conference. Procedia Social and Behavioural Sciences 24 (2011) pp. 505-525.

12. Gaál, Z., Obermayer-Kovács, N., Csepregi, A., Antonova, A., Jenei, E. (2010): Clan, Adhocracy, Market, Hierarchy? Investigating Organizational Culture Types and Knowledge Sharing in Bulgaria, Hungary and Serbia. pp. 52-61. In: Uden et al. (eds.) KMO 2010 - Roles and Challenges of Knowledge Management in Innovation for Services and Products. 5th International Knowledge Management in Organizations Conference. Veszprém, Hungary

13. Hofstede, G., Hofstede, G. J. (2005): Cultures and Organizations: Software of the Mind. Revised and expanded $2^{\text {nd }}$ Edition. McGraw-Hill, New York, USA, p. 436

14. Kordshouli, H. R., Baneshi E., Rezaei B. (2013). Depicting favorite organizational culture: An empirical case study. Management Science Letters, 3(11), pp. 2839-2846.

15. Koufteros X. A., Nahm A. Y., Cheng T. C. E., Lai K. (2007): An empirical assessment of a nomological network of organizational design constructs: From culture to structure to pull production to performance. International Journal of Production Economics 106(2), pp. 468492. http://dx.doi.org/10.1016/j.ijpe.2006.08.001

16. Kertai-Kiss, I. (2014): The Fit of National and Organisational Cultures in International Scientific Literature. Management, Enterprise and Benchmarking in the $21^{\text {st }}$ Century, Óbudai Egyetem, Budapest, pp. 301-314.

17. Linnenluecke, M. K., Griffiths, A. (2010): Corporate sustainability and organizational culture. Journal of World Business 45/2010. pp. 357-366. http://dx.doi.org/10.1016/j.jwb.2009.08.006

18. Lorenz, K., Marosszeky, M. (2004): Intercultural Management for International Construction Projects - A Comparison of Austria and Germany with Australia. In: Khosrowshahi, F. (ed.), Proceedings 20th Annual ARCOM Conference, Edinburgh, UK, Vol. 1, pp. 427-436.

19. Nagy, T. Z., Hurta, H., Dunay, A. Illés, Cs. B. (2015) The comparison of the organizational culture of an Austrian and a Hungarian chemical engineering company. In: Proceedings of the 5th International Conference on Management 2015. Management, leadership and strategy for SMEs' competitiveness. Szent István University Publishing House, Gödöllő, pp. 35-39. http://dx.doi.org/10.17626/dBEM.ICoM.P00.2015.p007

20. Pernot, E., Roodhooft F. (2008). The impact of cultural resemblance on management control of supplier relations: Longitudinal evidence in the automotive industry. Vlerick Leuven Gent Management School Working Paper Series 2008/18. pp. 1-58.

21. Reimann, F., Ehrgott, M., Kaufmann, L., Carter, C. R. (2012). Local stakeholders and local legitimacy: MNEs' social strategies in emerging economies, Journal of International Management, 18(1), pp. 1-17. http://dx.doi.org/10.1016/j.intman.2011.06.002

22. Richard, O. C., McMillan-Capehart, A., Bhuian, S. N., Taylor, E. C. (2009): Antecedents and consequences of psychological contracts: Does organizational culture really matter? Journal of Business Research Vol. 62, pp. 818-825. http://dx.doi.org/10.1016/j.jbusres.2008.04.001

23. Szöke, J. (2014): Kis- és középvállalatok határon átnyúló gazdasági kapcsolatai kulturális aspektusból. Doktori értekezés, Széchenyi István Egyetem, Győr

24. The Hofstede Center (2015): National culture, Hungary and Austria http://geerthofstede.com/countries.html, Downloaded: 28/12/2015 


\title{
3.2. KNOWLEDGE SHARING BEHAVIOUR - IMPACTS OF TRUST CLIMATE AND ATTACHMENT TO KNOWLEDGE
}

\begin{abstract}
Summary
Knowledge sharing is considered vital for the success of the organisations as the knowledge driven economy demands knowledge specific asset building rather than physical asset building). In this study, the role of trust environment, the perceived benefits, Expected reciprocation and the sense of attachment to knowledge affecting the knowledge sharing behaviour of employees in Knowledge centric organisations are assessed. A structural model fit of the variables involved in the study revealed that expected reciprocation and a trust based environment is positively affecting the knowledge sharing behaviour. Attachment to knowledge will strongly hinder the knowledge sharing initiatives whereas perceived benefits will not have any direct impact on knowledge sharing. This study suggests that Organisations can not encourage knowledge sharing amongst its employees by merely providing incentives and benefits. It requires a trust based environment which can strongly encourage knowledge sharing and simultaneously mitigate the employee's attachment to knowledge (perceived loss of knowledge power) which emerged as a strong detractor of knowledge sharing behaviour.
\end{abstract}

Keywords: knowledge sharing, knowledge attachment, trust

\section{Introduction}

Knowledge is considered to be a source of competitive advantage (Chennamaneni, 2006) and it represents rare, inimitable and non-substitutable assets (Liebeskind, 1996). With the purpose of improving the efficiency, effectiveness and competitiveness Organisations build its ability to acquire, organise and diffuse knowledge through its knowledge management initiatives. Knowledge sharing is considered to be the key enabler of knowledge management (Alavi and Leidner, 2001). Jackson et al (2006) argue that primary means through which employee can contribute to application of knowledge, innovation and finally competitive advantage to an organisation is through knowledge sharing.

Although knowledge sharing is recognised as one among the important factors which facilitate the survival of the organisation, the factors which encourage or discourage knowledge sharing behaviour in organisations are not well understood (Bock et al, 2005). To date several authors have studied the antecedents to knowledge sharing including organisational factors like a culture of trust and innovation, management and supervisor support, rewards and incentives, team characteristics etc. and individual factors like attitude, ownership of knowledge, reciprocation, etc. (Wang and Noe, 2010). Uniqueness in knowledge will be a source of power and personal gains in terms of cash bonuses and promotion (Husted and Michailova, 2002). This power source may act as a deterrent to knowledge sharing because employees fear losing their distinctiveness. Only a few studies have been made on the impact of power on knowledge sharing (Liao, 2008; Renzl, 2008). 
Perceived loss of knowledge power is considered to be a detractor of knowledge sharing (Chennamaneni, 2006) whereas perceived benefits, Reciprocation and trust climate is considered to be a facilitator of knowledge sharing as identified in the earlier studies (Wang and Noe, 2010). The role of the afore-mentioned factors is not assessed through a Structural Equation Model which will be the unique contribution of the study. No documented research has studied the role of trust climate as an antecedent to the knowledge sharing behaviour with the perceived benefits and the perceived loss of knowledge power as mediators. This is warranted because trust plays a major role in balancing a psychological contract between employers and employees and it has the potential to provide employee satisfaction and commitment (Atkinson, 2007). The ability of trust as an antecedent in reducing the perceived loss of knowledge power and increasing the perceived benefits before having a positive impact on knowledge sharing has to be tested.

\section{Hypotheses Development}

Trust as an antecedent: In the knowledge sharing context, trust is considered to be very effective in reducing the perceived costs of knowledge sharing (Kankanhalli, Tan and Wei, 2005). Equally, trust is considered to be an important antecedent to knowledge sharing (Butler et al., 1999; Chowdhury, 2005). This premise leads to the hypothesis on the antecedent role of trust on the knowledge sharing behaviour of employees.

H1. Trust climate has a significant positive impact on the knowledge sharing behaviour of employees.

Mayer and Gavin (2005) proposes through their study on the need to investigate the mechanism through which the trust has an impact on the knowledge sharing. Therefore, measuring the direct and indirect effects of trust on knowledge sharing carries significance. Renzl (2008) proposes that trust can facilitate knowledge sharing by reducing the perceived loss of unique value by holding on to the power. This is measured as perceived loss of knowledge power (Grey, 2001). This sense of holding on to knowledge as a source of power and fearing to lose that power leads to knowledge attachment which could act detrimental to knowledge sharing. This premise leads to the second and third hypotheses.

H2. Trust climate significantly reduces the sense of attachment to knowledge

H3. Attachment to knowledge will significantly reduce the knowledge sharing behaviour

Knowledge sharing by individuals is evaluated based on the perceived ratio of benefits to costs and their knowledge sharing decisions are based on perceived respect, reputation and incentives. This leads to the following hypotheses. The norm of reciprocity refers to the expectations that knowledge sharing should be mutual and considered fair by both the sharing and receiving parties. Prior studies suggest that individuals share knowledge with an expectation that the others will oblige to the individual's future knowledge requests (Kankanhalli et al., 2005; Bock et al., 2005). No relevant studies have identified the impact of the perceived benefits on the reciprocity. It can be hypothesised that the higher the perceived extrinsic benefits from knowledge sharing, higher the reciprocal expectations for fair exchange of knowledge between two parties. 
H4: Perceived benefits (measured in terms of perceived reputation and incentives) have a profound positive impact on the knowledge sharing behaviour.

H5: Perceived benefits of knowledge sharing positively influences the expected knowledge reciprocity

H6: Knowledge Reciprocity significantly increases the knowledge sharing behaviour.

\section{Figure 1: Conceptual framework}

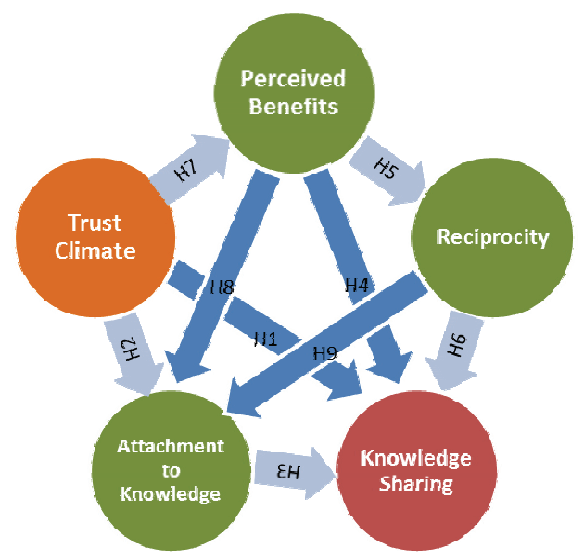

Beyond these the role of trust climate and its impact on the perceived benefits also need to get assessed because employees may expect benefits from knowledge sharing aided by a climate of trust. Moreover, the perceived benefits may reduce the sense of attachment to the knowledge because the incentives and reputation associated with knowledge sharing will encourage the individuals to give up their knowledge. Meanwhile, the reciprocity associated with knowledge sharing may increase the sense of attachment to knowledge because expectations to share knowledge are influenced by other's intentions to reciprocate. This leads to the following hypotheses:

H7: The trust climate has a significant positive impact on the perceived benefits of knowledge sharing

H8: The perceived benefits of knowledge sharing will significantly reduce the attachment to knowledge

H9: The reciprocity will have a positive effect on the attachment to knowledge.

Based on the above hypotheses, a conceptual framework (Figure 1) is developed so as to assess the model using structural equations.

The respondents for this study are representing knowledge workers who are predominantly from software development and Information Technology industry. As reaching a sample size of above 425 is considered robust to represent the population, a snowballing sampling procedure is followed but very much restricted to the knowledge industries.

\section{Results}

The Structural Equation analysis is carried out on the data using AMOS 21.0 through a two-stage approach. The measurement properties of the constructs are initially assessed before analysing the structural relationships between the constructs. Several 
nested models are tested for fit and through examining the changes in Chi-Square of the several nested models, the theoretical model turned out to be a good fit with CFI= 0.96 . The theoretical model turned out to be significant with Chi-square/degrees of freedom ratio at 2.142 and $\mathrm{P}$ value showing significant difference (as the sample size and number of variables are larger, this significant difference in the overall model fit is expected). The RMSEA value and SRMR value stood at .049 and .0588 respectively, indicating parsimonious model fit. The goodness of fit indices equally are in acceptable limits $(\mathrm{GFI}=0.931$, AGFI $=0.908)$.

Figure 2: Theoretical Model Fit

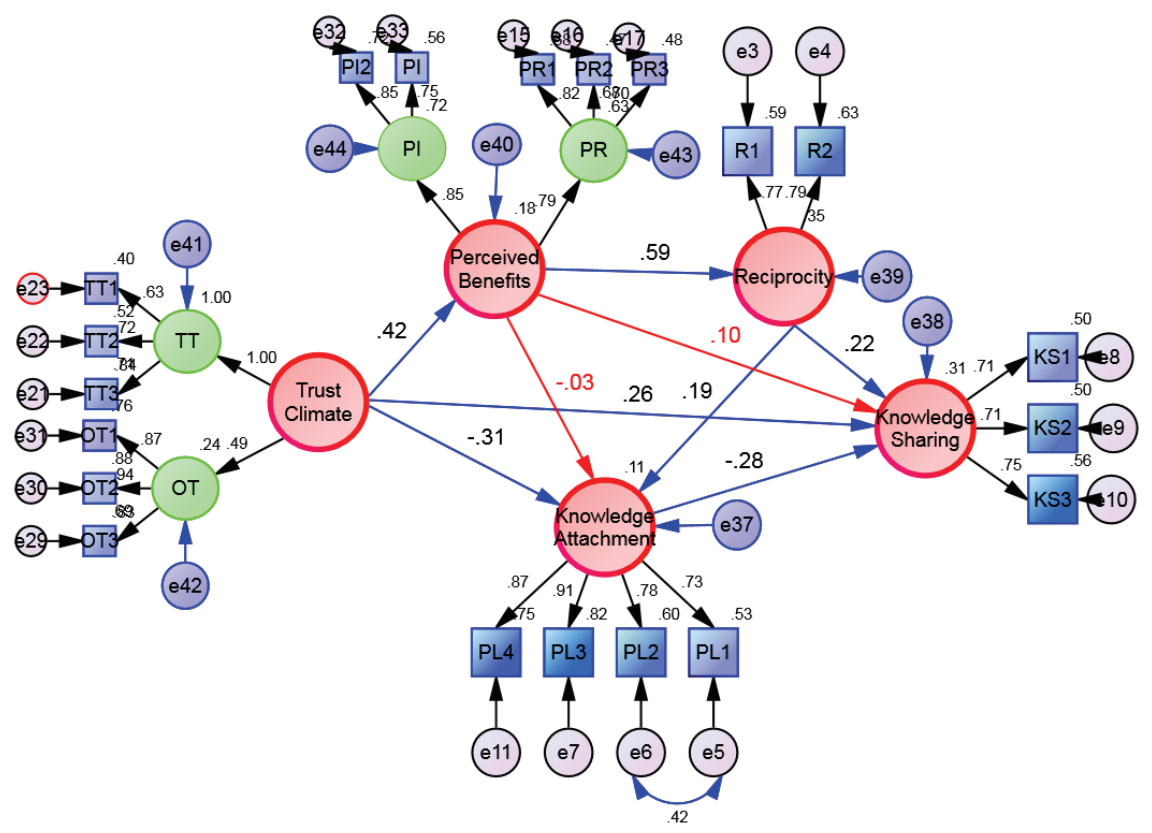

The standardised path estimates (Table 1) reveal that the knowledge sharing behaviour of employees is highly influenced by the organisation's trust climate (H1 supported with beta estimate at 0.256 and $\mathrm{p}<0.01$ ). On the other hand the attachment to knowledge has a significant negative effect on the knowledge sharing behaviour as hypothesized ( $\mathrm{H} 3$ supported with standardised beta estimate at -0.280 and $\mathrm{p}<0.01$ ). Both are almost equal in effect on the individual's knowledge sharing intentions but in opposite directions. But it is interesting to observe that the trust climate can significantly reduce the negative intentions associated with knowledge attachment $(\mathrm{H} 2$ supported very strongly with standardised beta estimate at -0.311 and $\mathrm{p}<0.01$ ). This underscores the mitigating role played by the organisational trust climate in reducing the fear of losing knowledge power. The perceived benefits in terms of incentives and reputation do significantly influence knowledge sharing behaviour ( $\mathrm{H} 4$ not supported: as evident from the beta estimate with 0.104 and $p>0.05$ ). This showcases the insignificant role played by the organisational benefits on determining the knowledge sharing behaviour in comparison to the role played by trust or knowledge attachment. 
The perceived reciprocity in knowledge sharing has a strong positive relationship with knowledge sharing behaviour (H6 supported: as evident from the beta estimate with 0.221 and $\mathrm{p}<0.01)$. Quid pro quo expectations in knowledge sharing logically have a strong impact on the actual knowledge sharing behaviour. One of the strongest positive relationship is the impact of perceived benefits on reciprocity (H5 supported: with beta estimate 0.593 and $\mathrm{p}<0.01$ ). This is quite logical in its explanation that extrinsic benefits encourage quid pro quo transactions in knowledge sharing.

Table 1: Results of Structural Equation Analysis

\begin{tabular}{|l|c|l|l|l|}
\hline Hypotheses/ Relationship & $\begin{array}{l}\text { Esti- } \\
\text { mate }\end{array}$ & $\begin{array}{l}\text { Signi- } \\
\text { ficance }\end{array}$ & Sign & Support \\
\hline H1- Trust Climate $\rightarrow$ Knowledge Sharing & 0.256 & $* *$ & + & Yes \\
\hline H2- Trust Climate $\rightarrow$ Knowledge Attachment & -0.311 & $* *$ & - & Yes \\
\hline H3- Knowledge Attachment $\rightarrow$ Knowledge Sharing & -0.280 & $* *$ & - & Yes \\
\hline H4- Perceived Benefits $\rightarrow$ Knowledge Sharing & 0.104 & $X$ & & No \\
\hline H5- Perceived Benefits $\rightarrow$ Reciprocity & 0.593 & $* *$ & + & Yes \\
\hline H6- Reciprocity $\rightarrow$ Knowledge Sharing & 0.221 & $* *$ & + & Yes \\
\hline H7- Trust Climate $\rightarrow$ Perceived Benefits & 0.422 & $* *$ & + & Yes \\
\hline H8- Perceived Benefits $\rightarrow$ Knowledge Attachment & -0.031 & $X$ & & No \\
\hline H9- Reciprocity $\rightarrow$ Knowledge Attachment & 0.190 & $*$ & + & Yes \\
\hline
\end{tabular}

$* * \mathrm{p}<0.01 \quad * \mathrm{p}<0.05 \quad \mathrm{X}-$ Not Significant

Further analysis reveals that trust climate has also a very strong impact on the perceived benefits from knowledge sharing (H7 supported: with beta estimate 0.422 and $\mathrm{p}<0.01)$. This is contextually revealing in its meaning because the increased trust levels can naturally enhance the perceived benefits from knowledge sharing. But the perceived benefits share no relationship with attachment to knowledge (H8 not supported: as evident from the beta estimate with -0.031 and $\mathrm{p}>0.05)$. This is also surprising because when individuals perceive to get benefits from knowledge sharing it is expected that the tendency to hoard the knowledge can come down significantly. This means that extrinsic benefits do not have the power to reduce the attachment to knowledge and it cannot be able to decrease the fear of power loss due to knowledge sharing. The role of reciprocity in determining the attachment to knowledge tendencies is also significant (H9 supported, but with a weaker impact with beta estimate 0.190 and $\mathrm{p}<0.05)$.

\section{Discussion}

Supporting the views of Kankanhalli et al., (2005), this study reveals that the trust climate in the organisations play a key role in enhancing the knowledge sharing behaviours in organisations. Equally trust plays a major role in reducing the fear attached to the loss of knowledge power. The sense of attachment to knowledge can be a great impediment to knowledge sharing as Schepers and Van den Berg (2007) found out that individual competition in the work place hindering the knowledge sharing initiatives. Chennamaneni (2006) and Renzl (2008) in their studies established the negative role of fear of loss of knowledge power on the knowledge sharing behaviour. 
This study also reinforces the high impeding power of attachment to knowledge on the knowledge sharing behaviours of individuals in organisations.

The quid pro quo expectation in knowledge sharing (reciprocity) can also encourage the attachment to knowledge. This in turn can prove detrimental for the knowledge sharing initiatives of the organisation. The presence of cooperative team perception can lead to enhanced knowledge sharing (Willem and Scarbrough, 2006). The significance of team cooperation is ratified in this study as the organisational trust climate is composed of both the organisation wide trust and team based trust. Organisations which want to reap a significant advantage from knowledge sharing should focus their energies in establishing organisation wide trust and equally on encouraging team level trusts. This is vital in increasing knowledge sharing behaviour and simultaneously reducing negative effects associated with knowledge attachment.

Although earlier studies have highlighted that the perceived benefits in terms of incentives have a profound impact on knowledge sharing (Beer and Nohria 2000), in professional level settings, the advantage of perceived benefits is overcome by the perceived usefulness to others by giving knowledge. This underscores the fact that in some settings perceived benefits may fail to encourage knowledge sharing. This study reflectively reveals the insignificant role of perceived benefits in encouraging knowledge sharing because it is carried out in a similar professional knowledge workers setting. One unique value addition from this study is that the perceived benefits cannot reduce the attachment to knowledge. This is surprising given the extrinsic role of benefits as a motivator. Individuals may not come forward to give up their knowledge power seeing the material benefits or reputation from knowledge sharing initiatives.

This further validates the previous findings that when organisations merely focus on giving benefits to encourage knowledge sharing, it may not likely happen. Unless the organisations invest in building a trust climate their knowledge sharing initiatives may miserably fail, even when it is backed up by a strong incentives, reputation or benefits scheme aiming at knowledge sharing.

The trust climate also will create a significant increase in perceived benefits expectation from knowledge sharing. This means that management can expect the employees' benefit expectations to go up naturally when they start facilitating a trust based climate. Therefore the organisations have to provide benefits to knowledge sharing as a hygiene factor. Although the perceived benefits may not play a major role directly in increasing the knowledge sharing tendencies, it does have a significant say on the reciprocal expectations inn knowledge sharing. This is noteworthy because for encouraging knowledge sharing a well-designed benefit programme in terms of incentives and recognition may play an indirect role because such benefit programmes can develop strong reciprocal intentions among knowledge workers.

This study in concurrence with earlier studies re-iterates the role of reciprocity in enhancing knowledge sharing (Lerner and Triole, 2000; Kankanhalli,et al., 2005). Therefore, perceived benefits seem to have a strong indirect role in encouraging knowledge sharing by establishing the reciprocity expectations. This study's q value addition is that reciprocity expectation can also lead to increased attachment to knowledge. This means that reciprocity expectations can logically lead to a sense of 
fear in losing the knowledge power on the one side (although on a smaller scale) which is considered detrimental and at the same time significantly increasing the knowledge sharing behaviour which is considered positive. Practitioners should emphasise care while they encourage reciprocity because it can increase both the knowledge sharing and knowledge attachment.

\section{Limitations and Future Directions}

This study involves knowledge workers across various organisations. Although there is a consistency across the choice of the respondents they belong to various industries, proving external validity requires greater care in sampling from a single industry to emphasise homogeneity of samples. This work is purely quantitative in nature and is exposed to the inherent vulnerabilities of any quantitative research. Future qualitative studies should be carried out to triangulate these findings.

This study didn't consider any new variables and in a sense has repeated earlier studies with minor modifications to the relationships. In future, the role of conflicting intentions to knowledge sharing has to be tested as the individual's mind is not always consistently tuned towards knowledge sharing. This means that employees will go through a flux during which on some occasions feel encouraged to knowledge sharing and in some other occasions feel not to share knowledge. Such conflicting intentions and their impact on knowledge sharing behaviour need to be studied in the future.

\section{Conclusion}

Organisations while taking initiatives to encourage knowledge sharing behaviour has to facilitate a trust climate as a primary antecedent. While the trust can encourage knowledge sharing it can significantly allay down the fear of individual's loss of knowledge power. The organisations should also design incentives and recognition programme which can indirectly encourage knowledge sharing through creating necessary reciprocity platforms. The above measures will help organisations to encourage knowledge sharing and reducing the knowledge attachment tendencies.

\section{References}

1. Alavi, M., Leidner, D. E. (2001): Review: Knowledge management and knowledge management systems: Conceptual foundations and research issues. MIS Quarterly, 25(1), 107-136. DOI: $10.2307 / 3250961$

2. Atkinson, C. (2007): Trust and the psychological contract. Employee Relations, Vol. 29 Iss: 3, pp. $227-246$

3. Beer, M., Nohria, N. (2000): Cracking the Code of Change. Harvard Business Review 78(3):133-41, 216

4. Bock, G. -W., Zmud, R. W., Kim, Y-G., Lee, J. -N. (2005): Behavioural intention formation in knowledge sharing: Examining the roles of extrinsic motivators, social-psychological forces, and organizational climate. MIS Quarterly, 29(1), 87-111.

5. Butler, J. K., Cantrell, R. S., Flick, R. J. (1999): Transformational leadership behaviors, upward trust, and satisfaction in self-managed work teams. Organization Development Journal, 17, 13-28. 
6. Chennamaneni, A.(2006): Determinants of Knowledge Sharing Behaviors: Developing and Testing an Integrated Model.(PhD. diss., University of Texas)

a. Chowdhury, S.D. (2005): The Dominant perspective, instituitional ownership, and corporate efficiency: An empirical investigation, International Journal of Commerce and Management, Vol. 15 Iss: 3/4, pp.255 - 271. http://dx.doi.org/10.1108/10569210580000201

7. Grey, C., Garsten C. (2001): Trust, control and postbureaucracy. Organization Studies 22: 229-250.

8. Husted, K., Michailova, S. (2002): Diagnosing and fighting knowledge-sharing hostility. Organizational Dynamics, 31(1), 60-73.

9. Jackson, S. E., Chuang, C-H., Harden, E. E., Jiang, Y., Joseph, J. M. (2006): Toward developing human resource management systems for knowledge-intensive team-work. In: in Martocchio J. (ed.) Research in Personnel and Human Resources Management (Research in Personnel and Human Resources Management, Volume 25) Emerald Group Publishing Limited, pp. 27 - 70

10. Kankanhalli, A., Tan, B. C. Y., Wei, K-K. (2005): Contributing Knowledge to Electronic Repositories: An Empirical Investigation, MIS Quarterly, 29(1).

11. Lerner, J., Triole, J. (2000): The Simple Economics of Open Source. NBER Working Paper Series No. 7600. National Bureau of Economic Research. Cambridge, Ma., DOI: $10.3386 / \mathrm{w} 7600$

12. Liao, L-F. (2008): Impact of manager's social power on R\&D employees' knowledge-sharing behaviour. International Journal of Technology Management, 41(1/2), 169-182.

13. Liebeskind, J. P. (1996): Knowledge. Strategy, and the Theory of the Firm, Strategic Management Journal (17:Special Issue), pp. 93-108

14. Mayer, R., Gavin, M. (2005): Trust in management and performance: Who minds the shop while the employees watch the boss? Academy of Management Journal, 48(5), 874-888

15. Renzl, B. (2008): Trust in management and knowledge sharing: The mediating effects of fear and knowledge documentation. Omega, 36(2), 206-220.

16. Schepers, P., Van den Berg, P. T. (2007): Social factors of work environment creativity. Journal of Business and Psychology, 21, 407-428. doi:10.1007/s10869-006-9035-4

17. Wang,S., Noe, S.R. (2010): Knowledge sharing: A review and directions for future research Human Resource Management Review 20 (2010) 115-131

18. Willem, A., Scarbrough, H. (2006): Social capital and political bias in knowledge sharing: an exploratory study. Human Relations 59(10). p.1343-1370. http://hdl.handle.net/1854/LU357890 


\subsection{KNOWLEDGE MANAGEMENT IN INNOVATIVE AND SOCIAL PROCESSES OF ENTERPRISES}

Summary: The aim of the paper is to indicate the significance of the processes of knowledge management in the functioning and development of enterprises. Different models of knowledge management have been illustrated while simultaneously emphasizing the impact of innovativeness on the level of competitiveness of enterprises. Moreover, the impact of corporate social responsibility on the level of competitiveness has been presented as one of the most important categories of the intangible values of enterprises.

Keywords: knowledge management, innovations, social value

\section{Introduction}

The issues of knowledge management are undertaken relatively frequently due to the significance of this matter in terms of theory and economic practice. Every enterprise searches for the mechanisms of knowledge management in order to ensure the improvement of its level of competitiveness on the market. Competitiveness may be ensured in various ways. One of the significant ways is to select the model of knowledge management that is directed at the innovativeness of enterprises. A second method is to adopt corporate social responsibility as the category determining the current level of competitiveness of enterprises.

The methods illustrated indicate the prevalence of knowledge management, innovativeness and corporate social responsibility in the group of intangible values. The said values consequently enable the improvement of the level of competitiveness of enterprises.

\section{Models of knowledge management in terms of the innovativeness of enterprises}

The issue of knowledge management currently constitutes significant aspects of economic theory and practice. Enterprises in turbulent surroundings search for knowledge that constitutes a set of "experience, value, understanding or even the probing of data and information that constitutes the basis for new knowledge, new experience, while also the need to gain new information" (Gierszewska, 2013, p. 231). Based on the knowledge in possession, it is possible to undertake various decisions. Then the base for knowledge management is created, namely the process of "creating value from the intangible resources in the possession of the organization. This process relates to providing access to and utilization of knowledge within the confines of the organization and externally in the direction of the clients and partners of the organization" (Rzemieniak, 2013, p.87). The aim of knowledge management is the improvement of the competitiveness of enterprises, particularly by means of innovations. The context of innovativeness is to be found in the models of knowledge management among which the following may be distinguished (Jakubiec, 2014): 
- the model of "knowledge spiral", that classifies knowledge as explicit and implicit that is characteristic of the Japanese approach;

- the resource model, determining the effectiveness of knowledge management, the existence of the sources of knowledge;

- the model of process approach, basing on the direction of knowledge management as a consequence of the experiences of consulting firms.

The aforementioned models confirm the potential of knowledge management, which leads to the innovativeness of enterprises (Table 1).

\section{Table 1: Competitive potential of an enterprise and its pro-innovative activities}

\begin{tabular}{|c|c|}
\hline & \\
\hline o of research and dovelonment activitios & \multirow[b]{2}{*}{$\begin{array}{l}\text { An area of wide-ranging and novel tasks as the } \\
\text { effort put into the development of innovation is } \\
\text { usually associated with technological research. } \\
\text { Frequently, R\&D activities are directly } \\
\text { connected with the creation of a new product } \\
\text { and is particularly useful as product innovations } \\
\text { contain a high degree of novelty. }\end{array}$} \\
\hline $\begin{array}{l}\text { lev } \\
\text { kn } \\
\text { abi } \\
\text { abi } \\
\text { deg }\end{array}$ & \\
\hline Sph & \multirow[b]{2}{*}{$\begin{array}{l}\text { Technological innovations relate to both the } \\
\text { sphere of production, and service activities. } \\
\text { Service innovations are based on modern tech- } \\
\text { nologies. In production and technical depart- } \\
\text { ments prototypes are developed and the possible } \\
\text { ways of production on a mass scale are analysed. }\end{array}$} \\
\hline $\begin{array}{l}\mathrm{kn} \\
\mathrm{tec} \\
\mathrm{de} \\
\mathrm{pr}\end{array}$ & \\
\hline & \multirow{2}{*}{$\begin{array}{l}\text { Quality is one of the key areas of developing the } \\
\text { innovativeness of a firm due to its significance } \\
\text { of the quality factor (product/services, customer } \\
\text { service, etc.) in terms of consumer decisions. }\end{array}$} \\
\hline $\begin{array}{r}-\mathrm{de} \\
\mathrm{me} \\
-\mathrm{kn} \\
\text { for }\end{array}$ & \\
\hline & \multirow[b]{2}{*}{$\begin{array}{l}\text { Innovative way of treating cooperating firms, } \\
\text { suppliers and clients enables the acquisition of a } \\
\text { competitive advantage in the sphere of logistics, } \\
\text { among other aspects thanks to the } \\
\text { informatization of the logistic processes and the } \\
\text { individualization of the client service in the area } \\
\text { of the whole supply chain. }\end{array}$} \\
\hline & \\
\hline Sphe & \multirow[b]{2}{*}{$\begin{array}{l}\text { Key roles are played by: information about } \\
\text { consumer and market research, marketing } \\
\text { communication relating to the novelties on the } \\
\text { market, building the values of a product and } \\
\text { development of trademarks, innovations in } \\
\text { marketing tools and research. The preparation } \\
\text { and implementation of innovations encompass } \\
\text { among other aspects, the definition of aims, } \\
\text { types and directions of innovations, while the } \\
\text { phase of implementation and diffusion of } \\
\text { innovations - market analysis, product policy, } \\
\text { prices, sales and promotion. }\end{array}$} \\
\hline $\begin{array}{l}\text { familiarity } \\
\text { served, } \\
\text { ability to fo } \\
\text { and in beha } \\
\text { needs and be } \\
\text { possibility o } \\
\text { on formulati } \\
\text { knowledge, } \\
\text { managerial } \\
\text { distribution, } \\
\text { degree of inf }\end{array}$ & \\
\hline
\end{tabular}


Table 1 (continued)

\begin{tabular}{|c|c|}
\hline$S p h$ & \multirow[b]{2}{*}{$\begin{array}{l}\text { Regarding the low public outlays in R\&D, and } \\
\text { the restrictions in the financing of innovation } \\
\text { with personal resources, the acquisition of other } \\
\text { funds for this purpose, e.g. subsidies, or } \\
\text { technological credit loans is becoming a key } \\
\text { condition in undertaking innovative processes. }\end{array}$} \\
\hline $\begin{array}{l}\text { of financing, } \\
s \text { of financial and } \\
\text { of sphere of finance. }\end{array}$ & \\
\hline spn & \multirow[b]{2}{*}{$\begin{array}{l}\text { The most valuable features of employees } \\
\text { capable of the realization of innovative } \\
\text { processes in an enterprise include the following: } \\
\text { skill of adjusting to the changes and functioning } \\
\text { in unstable conditions. The role of a firm is to } \\
\text { create pro-innovative organizational culture } \\
\text { with an emphasized acceptance of development, } \\
\text { learning, sharing knowledge and openness. }\end{array}$} \\
\hline 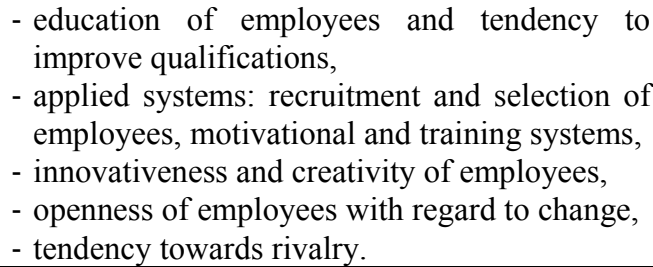 & \\
\hline
\end{tabular}

Source: Jakubiec (2014) pp. 183-184.

The content of Table 1 reveals that every sphere of competitive potential remains in direct ties with the pro-innovative activities of enterprises and knowledge management. (Pachura, 2014, p.44)

An interesting aspect of innovativeness is the phenomenon of the effect of suppression as a particular reference to knowledge management.

Empirical research enabled Lewandowska to distinguish five models that were subsequently placed under analysis in terms of the effect of suppression. Analysis of the first model reveals that the resources of enterprises, namely the internal sources of knowledge have become the mediator of ties between such barriers as the following: factors relating to the knowledge possessed by enterprises and the realization of cooperation with foreign partners.

Among the internal sources of knowledge of enterprises, the research and development facilities are of significant importance, as well as the potential of the managerial staff and the competences of the marketing department. The aforesaid internal structure of the sources of knowledge designates the level of foreign cooperation in spite of the existence of factors that hinder innovations in enterprises. Relations occurring at this level are confirmed by classical suppression.

In the second model, resources that are identified with the internal sources of knowledge were taken into account. This fact caused the increase in relations between the market barriers and cooperation with foreign partners, which by way of consequence was decisive in terms of the occurrence of the cooperative suppression.

Analysis of the third model reveals that the internal sources of knowledge in the area of innovations designate the position of a mediator in terms of the relations between the market barrier and the process of undertaking cooperation with foreign enterprises and those integrated in the supply chain.

A similar nature of dependency exists in the fourth model. Internal sources of knowledge designate a mediator between the market barriers and cooperation for the partners of the supply chain, both within the borders of the country and outside of its borders. As a result of cooperation of this type, cooperative suppression exists. 
Likewise, the fifth model encompasses the phenomenon of cooperative suppression as the sources of internal knowledge lead to the increase in relations between the market barrier on the one hand and the cooperation with the foreign entity on the other hand. Simultaneously, it is necessary to emphasize that cooperation of this type relates to the supply chain. (Lewandowska, 2013, p.22)

The model illustration of the problems of knowledge management and the models of effects of suppression in the context of the processes of knowledge management identify the essence, scope and relations occurring in the aforesaid area. These models also constitute the basis for the expansion of the analysis to other areas of activities of enterprises.

\section{Corporate social responsibility in the activities of enterprises}

Knowledge management directs the activities of enterprises. Economic units, by adapting new categories of knowledge ensure the growth of innovativeness and consequently improvement of the level of competitiveness.

The competitiveness of enterprises determine the changing premise of their functioning. This change relates to the acknowledgement of corporate social responsibility as one of the most important premises that facilitates the improvement of the competitive position of enterprises. The problem of CSR is however subject for debate. In subject-related literature, both the positive and negative consequences of adapting CSR are stipulated.

In the arguments of the proponents of CSR, the following is first and foremost illustrated (Sokołowska, 2014, p.135, 136):

- shaping the new socio-economic reality within the framework of which the models based on the pro-social basis are defined,

- responsibility of enterprises within the framework of the freedom of management,

- pro-market mechanisms constitute an important decision-making element of the market due to their restricted regulatory nature,

- opportunities of the enterprises realizing the principles of social responsibility over a longer term time perspective are always higher in the area of positive financial results; balancing their economic and social aims are the result of the impact of clients,

- public opinion creates the image of enterprises from the viewpoint of ethical attitudes,

- an enterprise of really great economic significance simultaneously incurs a high level of social responsibility,

CSR indicates the close correlative and complementary relation with organizational culture, indication of CSR by an enterprise results from the essence of the concept itself.

It is also claimed that "human activity within the framework of an organization determines it in a way that excludes moral responsibility" (Sokołowska, 2014, p.134.). By way of justification, the following positions are presented:

- in the liberal approach to the results of an enterprise, only profit is expected as other spheres are unimportant, 
- the principles of the market economy cause the situation whereby the only responsibility of an enterprise is to concentrate on the effectiveness of the utilization of resources,

- evaluation of the level of social responsibility is of a superficial and minimalist nature due to the lack of possibilities to carry out a thorough analysis,

- social responsibility is identified in a more methodical sense in terms of resolving the problems of society in a complex manner than the concept of the multidimensional activities of enterprises,

- the lack of appreciation for the long-term social benefits exists which is concentrated around the social balance of improving the image of an enterprise and the growth of social capital,

- the concept of M. Friedman identifies social responsibility with charity and bypasses the really valuable initiatives of a local nature that are created by businesses, but executed first and foremost as social aims,

- an enterprise is not attributed responsibility due to the lack of unequivocal scope and relations of the tasks executed and their effects with reference to the particular employees. (Fudaliński, 2013, p.43,46)

The consequence of activities is a social enterprise in which there is an accumulation of a certain type of antinomy. Its source constitutes the category of an enterprise that is identified with business activities with the simultaneous reference to the social nature of the tasks executed. Likewise, the problems of social management in terms of its bases, concentrates on the self-realizing societies as an entity creating the ability of self-organization.

In the view of Duraj (2011, p.151), the important features of social enterprises are:

- nobility of the mission of an enterprise with the aim of creating and developing the social categories of value,

- integrational unity in the area of the aims and activities of a commercial and social nature in the context of the principles of complexity and variability in terms of the social and commercial activities,

- possession of the potential of creating the opportunities for the social values for stakeholders,

- predisposition for taking decisions while indicating their risk in the areas of proactivity and innovativeness.

The aforementioned features indicate the dualism in terms of the business activities of social enterprises that integrate the areas of commercial and social activities (Figure 1). Analysis of the aforesaid relations reveals that in spite of the common area of activity, there is a separation of the commercial and social activities.

Nevertheless, in the integrating processes we receive a common set that connects the commercial and social activities. This activity has its foundation in capital within the framework of which an increasingly greater significance is being attached to social capital (Glińska-Newes, 2014, p.667). 
Figure 1: Decision-making structure of commercial and social activities of enterprises

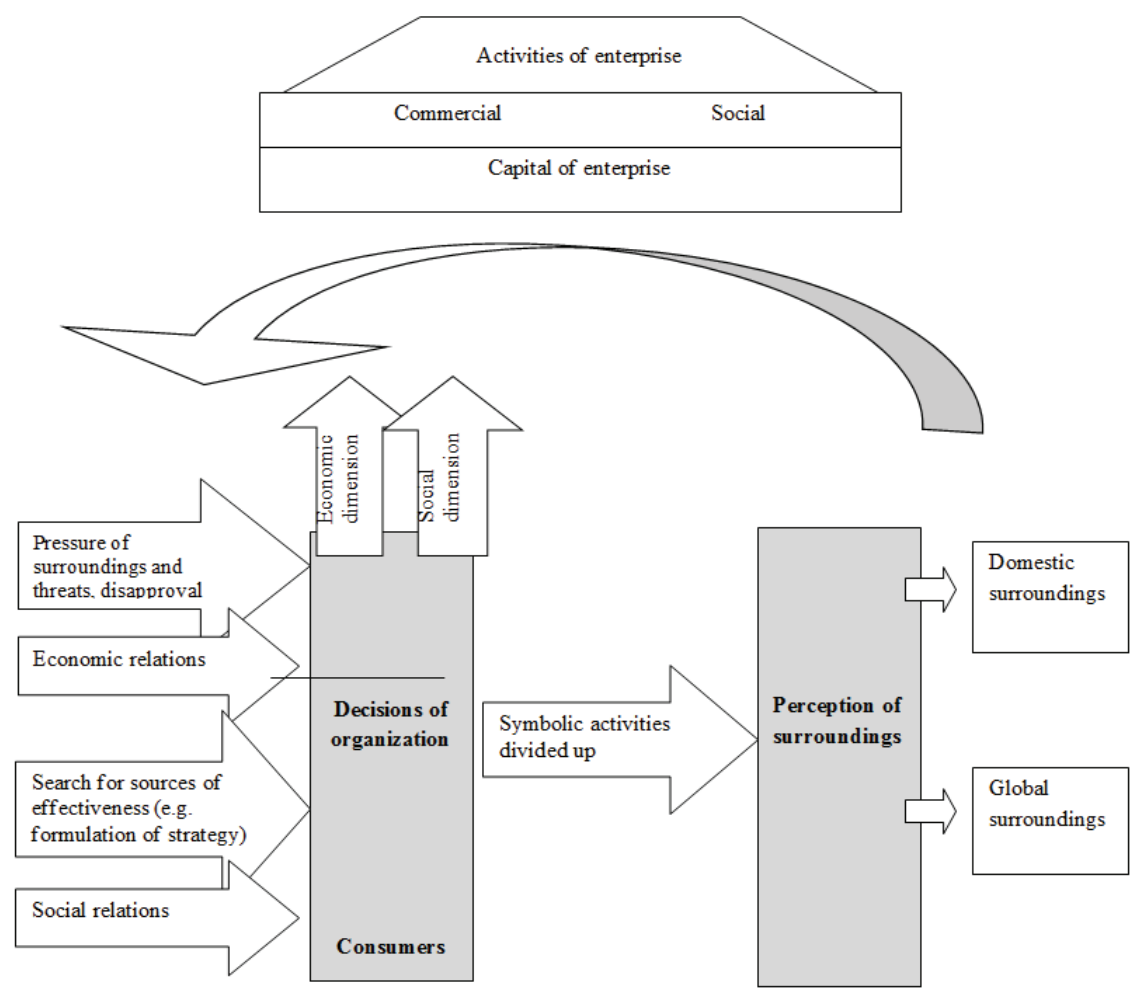

Source: Self-analysis on the basis of Mazur (2014)

Social capital remains in direct ties with social value, namely the economic category that occurs as a consequence of expanding the intangible values. Simultaneously, this is the same type of value that is included in the group of intangible values that also includes knowledge. Hence, it is becoming justified to undertake the problem of social value and organizational culture in the context of knowledge management.

\section{Social values and the organizational culture of enterprises}

The problem of creating values in an enterprise has been undertaken by a multitude of authors (Kaplan and Norton, 2008, p.47). The aforesaid authors indicate the necessity to perceive and define the social approaches of enterprises in terms of the built-up and updated strategies. The aspects of the social approaches of enterprises are reflected in the category of social value (Table 2). The social value is referred to a multitude of illustrated concepts, while the level of comparisons is stipulated by the business activity, inspiration or methods of approach towards the planning and strategies of enterprises. The set presented reveals that the organizational culture in an enterprise is a significant issue. In order to illustrate this issue, empirical research in terms of enterprises has been utilized. 
Table 2: Social value in concepts of CSV, CSI, HVC and CCI

\begin{tabular}{|c|c|c|c|}
\hline $\begin{array}{l}\text { Level of } \\
\text { compari- } \\
\text { son }\end{array}$ & $\begin{array}{c}\text { Premise of undertaking } \\
\text { business and social } \\
\text { activities by an } \\
\text { enterprise }\end{array}$ & $\begin{array}{c}\text { Source of inspiration for } \\
\text { commencing business and } \\
\text { social activities in the case } \\
\text { of enterprises }\end{array}$ & $\begin{array}{c}\text { Way of approaching } \\
\text { planning activities oriented } \\
\text { towards the realization of } \\
\text { socio-economic values }\end{array}$ \\
\hline $\begin{array}{l}\text { CSV } \\
\text { Creating } \\
\text { Shared } \\
\text { Value }\end{array}$ & $\begin{array}{l}\text { Achieving common } \\
\text { values as a benefit with } \\
\text { relation to costs }\end{array}$ & $\begin{array}{l}\text { Inextricably involved with } \\
\text { competing and } \\
\text { maximization of profit by } \\
\text { means of reformulation of } \\
\text { products and markets, as } \\
\text { well as the redefinition of } \\
\text { productivity with reference } \\
\text { to the supply chain }\end{array}$ & $\begin{array}{l}\text { Plan of action that is } \\
\text { appropriate for the given } \\
\text { enterprise stems from its } \\
\text { internal need for the } \\
\text { projection of the creation of } \\
\text { an "alliance" with various } \\
\text { groups of stakeholders in } \\
\text { the form of local }\end{array}$ \\
\hline $\begin{array}{c}\text { CSI } \\
\text { Corporate } \\
\text { Social } \\
\text { Investment }\end{array}$ & $\begin{array}{l}\text { Perceiving social needs } \\
\text { as the possibility of } \\
\text { developing and demon- } \\
\text { strating new notions, } \\
\text { searching for and } \\
\text { finding new markets. }\end{array}$ & $\begin{array}{l}\text { Social needs existing in } \\
\text { zones of poverty and } \\
\text { exclusion, better education } \\
\text { of the young generation, } \\
\text { care for the elderly etc. }\end{array}$ & $\begin{array}{l}\text { Plan of action based on the } \\
\text { convergence of economic } \\
\text { and social aims, strong } \\
\text { partners involved in the } \\
\text { notion of long-lasting social } \\
\text { change. }\end{array}$ \\
\hline $\begin{array}{l}\text { HVC } \\
\text { Hybrid } \\
\text { Value } \\
\text { Chain }\end{array}$ & $\begin{array}{l}\text { Exerting impact on the } \\
\text { social environment } \\
\text { while availing of busi- } \\
\text { ness benefits by means } \\
\text { of cooperation and } \\
\text { satisfying the needs of } \\
\text { clients who are included } \\
\text { in the lower levels of } \\
\text { the "social pyramid". }\end{array}$ & $\begin{array}{l}\text { Profitable growth on an } \\
\text { untapped market, more } \\
\text { effective management of } \\
\text { the supply chain and } \\
\text { development of } \\
\text { innovations. }\end{array}$ & $\begin{array}{l}\text { Aims associated with } \\
\text { employees and conscious } \\
\text { consumers based on trust } \\
\text { and familiarity with the eco- } \\
\text { system at the base of the } \\
\text { social pyramid thanks to } \\
\text { social organizations. }\end{array}$ \\
\hline $\begin{array}{l}\text { CCI } \\
\text { Corporate } \\
\text { Community } \\
\text { Involve- } \\
\text { ment }\end{array}$ & $\begin{array}{l}\text { Undertaking activities } \\
\text { that develop the civic } \\
\text { approach that favours } \\
\text { the resolution of social } \\
\text { problems. }\end{array}$ & $\begin{array}{l}\text { Feeling of moral } \\
\text { obligation, aid for the } \\
\text { needy, solving of social } \\
\text { problems and social } \\
\text { marketing. }\end{array}$ & $\begin{array}{l}\text { Plan of action encompass- } \\
\text { ing a wide spectrum of } \\
\text { various undertakings from } \\
\text { the areas of philanthropy, } \\
\text { charity, development of } \\
\text { corporate volunteering and } \\
\text { support, social campaigns. }\end{array}$ \\
\hline
\end{tabular}

Source: Kroik et al. (2014) and own

Empirical research relating to the organizational culture of Polish enterprises facilitates the formulation of a multitude of conclusions. Of particular importance are those results that are the basis of indicating the features of Polish organizational culture. These features include the following (Czarzasty, 2014, p.105):

- large distance of authorities - a feature of this type results from the functioning of the hierarchical society that transfers hierarchical behaviour to enterprises, thus the preference for centralization and autocracy,

- individualism - displaying the individual features of entities with the hierarchical society requires the building of a two-level communication system, the so-called supplementing of formal and informal contacts; within the framework of such relations, the feeling of the personal values of employees are strengthened, which are to be found at the lower levels of the organizational structures, 
- masculinity - such a defined nature results from the prevalence of the view that work is essential in life, hence managers should display resoluteness and assertiveness; the most rated values are acknowledged to be those of income, while also social and professional recognition.

- low tolerance of uncertainty - avoiding uncertainty indicates strong tendencies that by way of consequence cause a sense of suspicion with regard to dissimilarity, fear of risk, as well as resistance in terms of relations towards innovative solutions,

- normativism - cultural tradition indicates that the experience from the past constitutes a significant decision-making point with regard to the present and the future;

- abstinence - displayed by the entity which is illustrated in terms of repression of the natural impulses and pursuits; preferred attitudes are controlled behaviour and strong pressure to adhere to the social norms.

A similar type of research was carried out in the company known as Eurosoft. Within the framework of organizational culture, the relations with a client were acknowledged to be a priority. With reference to the impact of clients on the generation of profit, the employees set the good of the client above all the other values. Second place is taken by the acquisition of new competences that are the premise for effective work. Undertakings associated with job security and innovativeness are worthy of emphasis.

Further conclusions rating the importance of organizational culture in an enterprise relate to the indication of the significant role fulfilled by the owner of the firm in question. This person by ensuring the good organization of work facilitates the appropriate execution of duties by his/her employees who in such a way create the development of the enterprise. The survey reveals that innovativeness is perceived as an element which requires improvement. A similar nature is illustrated by the feeling of the sense of belonging with relation to the enterprise. The high staff turnover has an impact on the risk of the scarcity of experienced personnel who identify with the enterprise.

The necessity of improving the relations between the employees was commented on by the personnel of the enterprise. The existing conflicts, particularly between the departments confirm the conclusion with regard to the improvement of inter-personal relations, within the framework of the organizational culture of the enterprise.

Furthermore, it has been illustrated that the greatest neglect relates to the quality of work. This fact is the result of assigning excessive duties (Gajewska and Kubański, 2014).

The theoretical deliberations and the results of empirical research indicate the growth in the significance of the organizational culture (Lukasik and Brendzel-Skowera, 2014; Baskiewicz, 2014; Dziwiński and Barcik, 2014) and social values in the group of intangible values in enterprises. The evaluation of intangible values in the resources of enterprises is noticeable, in terms of those first and foremost based on knowledge. Knowledge management is the possibility of adapting a specific model into an enterprise that by means of the growth of innovativeness ensures the competitive position of the economic unit, which is the fundamental aim of every economic organization. 


\section{Summary}

The aforementioned theoretical deliberations, as well as the quoted results from the empirical research reveal that knowledge management determines the development of an enterprise by means of in particular, the implementation of innovative solutions. The innovativeness of enterprises constitutes the basis of the increase in the level of their competitiveness. Innovativeness creates one of the most important categories of intangible values that leads to the appropriate development of an enterprise.

In the past few years, the development of an enterprise has also been facilitated by the inclusion of social value among the group of intangible values. This category of values for enterprises is one of the significant resources of economic units, which is created as a result of knowledge management. Thus, the processes of knowledge management constitute the basis for defining the innovative and social activities of enterprises.

\section{References}

1. Baskiewicz N. (2014): OPT Method as an Example of Process Optimization in an Enterprise, [in:] Management and Managers Facing Challenges of the 21st Century. Theoretical Background and Practical Applications. Monograph, Eds. F. Bylok, I. Ubreziova, L. Cichobłaziński, Szent Istvan Egyetemi Kiado Nonprofit Kft. Gödöllö Hungary.

2. Czarzasty J. (2014): Kultura organizacyjna przedsiębiorstw sektora MSP w Polsce. [in:] Raport o stanie sektora małych i średnich przedsiębiorstw w Polsce w latach 2012-2013, PARP, Warszawa.

3. Duraj J. (2011) Determinanty trwałości i wartości działania przedsiębiorstw społecznych. [in:] Restrukturyzacja. Teoria i praktyka w obliczu nowych wyzwań. Eds A. Jaki, J. Kaczmarek, T. Rojek, Uniwersytet Ekonomiczny w Krakowie, Kraków.

4. Dziwiński P., Barcik A. (2014): The compliance mechanism in management of the company in terms of European Competition Policy [in:] Management and managers facing challenges of the $21^{\text {st }}$ Century. Eds: F. Bylok, J. Ubrežiova, L. Cichobłaziñski, Szent Istvan Egyetemi Kiado, Gödöllö Hungary,

5. Fudaliński J. (2013): Koncepcja zarządzania społecznego organizacjami trzeciego sektora (zarys problematyki), Przeglad Organizacji No1, p.42-47.

6. Gajewska P., Kubański M. (2014): Wpływ kultury organizacyjnej na efektywność przedsiębiorstwa. [in:] Etyka, kultura organizacyjna i społeczna odpowiedzialność biznesu w kształtowaniu potrzeb i relacji z klientami, Eds. H. Howaniec, Z. Malara, W. Waszkielewicz, Akademia Techniczno-Humanistyczna. Bielsko-Biała.

7. Glińska-Newes A., (2014): Rola kapitału społecznego organizacji w kształtowaniu jej kapitału intelektualnego. [in:].Nowe kierunki w zarządzaniu przedsiębiorstwem - wiodące orientacje, Eds. J. Lichtarski, S. Nowosielski, G. Osbert -Pociecha, E. Tobaszewska-Zajbert, Prace naukowe Uniwersytetu Ekonomicznego we Wrocławiu Nr 340, Wrocław.

8. Gierszewska, G. (2013): Zarządzanie wiedzą - wyzwania dla przedsiębiorstw, [in:] Paradygmat sieciowy. Wyzwania dla teorii i praktyki zarządzania. ed A. Karbownika. Politechnika Śląska, Gliwice.

9. Jakubiec M. (2014): Rola zarządzania wiedzą w kształtowaniu proinnowacyjnego działania kadr przedsiębiorstw. The intelectual and innovative potencial In management of organization. ed: J. Dudzik -Lewicka, H. Howaniec, J. Klisiñ ski, W. Waszkiewicz. University of BielskoBiała.

10. Kaplan R. S., Norton D. P. (2008): The Execution Premium. Linking strategy to Operations for Competitive Advantage Harvard Business School, USA. 
11. Kroik, J., Malara, Z., Skonieczny, J., Swida, A. (2014): Innowacje społeczne z perspektywy wartości ekonomiczno-społecznej. In: Dudzik-Lewicka, Howaniec, Klisiński, Waszkielewicz (Eds): Potencjał intelektualny i innowacyjny w zarządzaniu organizacją. Akademia Techniczno-Humanistyczna. Bielsko-Biała

12. Lewandowska M. Ś. (2013): Bariery innowacji a kooperacje przedsiębiorstw. Efekt supresji. Przeglad Organizacji No 4, p.20-27.

13. Łukasik K., Brendzel-Skowera K.. (2014): Research on Entrepreneurial Organizational Culture, [in::] Management and Managers Facing Challenges of the 21st Century. Theoretical Background and Practical Applications. Monograph. Eds. F. Bylok,I . Ubreziova, L. Cichobłaziński, Wyd. Szent Istvan Egyetemi Kiado Nonprofit Kft, Godollo.

14. Mazur, K. (2014): Zjawisko zarządzania symbolicznego a otoczenie organizacji. Przegląd Organizacji No 1 p. 9.

15. Pachura A. (2014): System dimension of creativity in innovativeness of enterprises. Epistemological remarks, [in:] Innovation of logistics processes. Ed. B. Skowron-Grabowska VSB Technical University of Ostrava.

16. Rzemieniak M. (2013): Zarządzanie niematerialnymi wartościami przedsiębiorstw. TNOiK, Dom Organizatora, Toruń.

17. Sokołowska A. (2014): Teoretyczno-metodologiczne dylematy związane ze społeczną odpowiedzialnością przedsiębiorstwa, [in:] Nowe kierunki w zarządzaniu przedsiębiorstwem wiodące orientacje. Ed. J. Lichtarski, S. Nowosielski, G. Osbert - Pociecha, E. Tabaszewska Zajbert, Prace naukowe Uniwersytetu Ekonomicznego we Wrocławiu nr.340. Wrocław. 


\title{
3.4. INNOVATION - THE IMPORTANCE OF KNOWLEDGE NETWORKS
}

\begin{abstract}
Summary
The global social and economic changes that could be felt in the past decade forced the players of the public and private sector to base their decision making mechanisms on information of better quality while reacting to the challenges of the era. The actuality of our paper lies in the fact that the need to have punctual information disclosed about the single organisations, sectors of the national economy and the innovation activity as well as the features of the entire economy is more and more underpinned by recognising the economic role of innovation. In our paper we present the role of knowledge networks activity of the Hungarian agricultural machinery manufacturers in the innovation process efficiency. The conclusions of our paper are based on the examination results of questionnaires and in-depth interviews that were carried out at 58 Hungarian agricultural machinery manufacturing companies.
\end{abstract}

Keywords: innovation, marketing, knowledge networks, key factors of innovations

\section{Introduction and objectives}

The current production of the Hungarian agricultural machinery manufacturing sector, which used to see better days, lags behind the production of the previous years to a great extent. The general financial, organizational and structural poblems of the Hungarian agriculture can be detected in this sector as well (Borbély et al., 2011). The organisational structure of the Hungarian agricultural machinery production has been transformed, primarily regarding its ownership structure. The general problem of this sector is that they can only spend slight amounts on development an innovation relative to foreign-owned concerns. The extent of market loss and the general situation of the Hungarian agricultural machinery manufacturers justify that the present of this sector must be dealt with by searching the ways-out of the crisis and make steps to develop. Before the political and economic changes in the 1990s, only 27 agricultural machinery plants operated mostly "embedded" in the system of the Hungarian "agribusiness". Due to this fact (among others), 60 percent of the requirements for agricultural machinery in the country were covered by these plants at a more advanced standard than the average of the former socialist countries. During the past 15-20 years the organisational structure of the Hungarian agricultural machinery production has totally been transformed (Losoncz, 2008; Fenyvesi, 2005). Generally, the machine manufacturers operating as small-or medium-sized enterprises appear on the market with "separate" products usually not developed by themselves. Consequently, they are not price-setters, rather price takers. The product line of the companies that are successful in the international competition primarily consists of mass-produced and highly automated products. The Hungarian agricultural machinery manufacturerspartly due to their size- are not able to mass-produce in such an extent that they could compete with the West-European, American and Asian companies of huge capital power either in productivity, price or product range. A drastic innovation wave could 
mean a break out of this situation. Regarding innovation, the Hungarian agricultural machinery manufacturers also significantly lag behind as they can only spend slight amounts on development relative to foreign-owned concerns. As a consequence, loss of market is not surprising as a bit more than one-quarter (26-27\%) of the current total domestic market turnover comes from domestic manufacturers. The success of the innovation is decided on the market, therefore it is important that the product development how it is prepared and followed by knowledge networks. It is possible that the earlier phases deficiency can be corrected by networking activity, but it can also happen that previous good results can be destroyed by a wrong market activity. Therefore, the harmonization of agro-technological innovation processes is essential (Magó, 2011). Innovation and R\&D activities are supported by different tools, some of them are connected to the tax system. The relations between R\&D\&I activities and tax allowances are different in different sectors of the national economy. Illés et al. (2013a; 2013b) examined how different agricultural companies could utilize these allowances, while Hustiné et al. (2014) focused on car traders. Their findings underlined that the innovation activities are lather low, companies with profitability problems cannot utilize the available support tools, which will affect their R\&D\&I activities as well.

The technical advantage of the innovation can only be realized if adequate networking skills can support and complement the new products and technologies (Husti, 1990). The innovation processes have been described by the first linear models that product ideas are born, based on these new product is planned, produced, and sold. However is more effective when the process starts out from the market needs, the new products are planned, manufactured based on these, and during the selling process the satisfaction of the needs is controlled. Nowadays it is essential, that the networking has to link all the processes, including the innovation too.

The task of the innovation networking is not just selling the novelty, but to acquaint the expectations of the relevant stakeholders and with this to help for the management to increase the support of the strategy by satisfying the market demands on a reasonable and legitimate way, and on the other hand, to promote the acceptance (diffusion) of planned and implemented results of the innovations as well.

Strategy in the competitive market is such a guideline of corporate function that defines the long-term goals and the system of means and methods that are necessary to reach them. Strategic planning plays an important role at all types of companies especially in the case of the innovative ones as it is they who dare to enter an uncertain area in its technical and economic sense due to their special activities (Edquist, 1997). A thoroughly planned conscious strategy is the basis for creating innovations and operating an innovative organisation. Innovation strategy has to derive from and serve corporate strategy. The main point of innovation strategy is how the company can reach the market starting from research and development via product/service/ technology production in the easiest way. An effective innovation strategy is implemented in a simple, concentrated way to a small extent so at the beginning scarce resources (funds, labour) are used and, simultaneously, the way out is also considered (Bak, 2013). 
Our research objectives are summarised in the following points:

1. Reviewing and evaluating the relevant national and international literature on the topic with special regards to the features of agricultural technological innovations.

2. Preparing and improving a questionnaire and a method of examination that can be used to collect primary data on the innovation activities of agricultural machinery manufacturers.

3. Preparing a thorough picture of the present situation and performance of agricultural machinery innovations as well as the direction of developments on the basis of the empiric research and methodology.

4. What are the main indicators, decisive trends and narrow cross sections of the innovation performance of the national agricultural machinery manufacturers?

5. How can the effects of the global economic climate be felt by the enterprises with special regards to their innovation activities?

6. What is the cooperation activity of enterprises like, what are the characteristics of their social network and how can they affect innovation activities?

\section{Material and method}

The basic objective of the research is to explore and analyse the innovation activity of the Hungarian agricultural machinery manufacturers, its results and influencing factors. Finally our objective is to have a picture of the innovation activity of the organisations involved, the special features of innovations, the partners taking part in the processes and the impact of innovation on the general situation of the companies through our examinations. Besides the brand-new or significantly developed products and technological procedure innovations, organisational features, marketing activity and the environment of the innovation are also considered. The questionnaire serving as the basis of primary research embraces three years, from 2007 to 2009. According to the estimations of experts the number of agricultural machinery manufacturing companies is between 160 and 170 in Hungary. (A great part of the enterprises are involved in more than one activity: a lot of predominantly small enterprises are also engaged in other activities besides machinery production so that is why it is difficult to define the actual number of 'agricultural machinery manufacturers' exactly). Most of the organisations that are subject to our analysis are small enterprises whose annual revenue does not reach one billion HUF. As there was not an available list on all the companies on the basis of which a pattern of probability could have been compiled, the companies that could be drawn into the research had to be defined in another way. To find the companies necessary for carrying out the questionnaire, the address list of MEGOSZ (National Association of Agricultural Machinery Manufacturers) served as a basis and the heads of this professional organisation were also consulted.

Basically our research is based on primary research within the framework of which a questionnaire was compiled. When drafting the questions the results of our secondary research data on this industry were considered and also the 2005 edition of 'Oslo Handbook' was consulted that formulates OECD guidelines for collecting and interpreting technological innovation data. According to the general methodological requirements some pilot interviews were made a first and afterwards the questionnaire was finalised on the basis of our experience. 
In compliance with the general methodological requirements first of all some pilot questions were asked on the basis of which the questionnaire was finalised. Data recording took place between March 2010 and September 2010.

The duration of in-depth interviews was various, typically 90-100 minutes per interview. A positive feature of them was that data providers mainly come from the senior management (chief executive officer, head of production or technical manager). In this way first-hand information on the general situation, actual projects and strategic plans of the organisation involved was gained besides the reliability of data. The atmosphere of the interviews was typically of honesty and intimacy. Some of our interviewees have already expressed their enquiry in our results. The questionnaires compiled on the basis of the interviews and sent out by post were also accompanied by a guide to filling in. A kind of evaluation of our preliminary work is that all the responding organisations gave answers that could be assessed.

The statistical processing of data recorded by the questionnaires was carried out by using SPSS 13.0 programme.

The multi-channel approach was used when recording the data of the research whose main points are the following:

- 15 machine manufacturers were interviewed personally.

- Questionnaires were sent to 25 organisations by post asking them the send it back after filling in the questionnaire.

- The electronic version of our questionnaire was sent to organisations incorporated in the MEGOSZ database. Altogether 18 questionnaires were returned.

Issues of sampling, reliability and precision level of infinitive population from equation:

$$
\Delta=\mathrm{z} \cdot \sqrt{\frac{\mathrm{p}(1-\mathrm{p})}{\tilde{\mathrm{n}}}}
$$

where: $\mathrm{z}=$ quantile of the standard normal distribution,

$\mathrm{p}=$ reliability,

$\Delta=$ level of accuracy,

$\tilde{\mathrm{n}}=$ size of population.

The next equation corrects an infinite population size ( $\tilde{\mathrm{n}})$ to the finite population size (n):

where: $\tilde{\mathrm{n}}=$ size of population (for the infinite)

$$
\mathrm{n}=\frac{\tilde{\mathrm{n}}}{1+\frac{\tilde{\mathrm{n}}}{\mathrm{N}}}
$$

$\mathrm{n}=$ size of population (for the finite)

$\mathrm{N}=$ the number of elements in the population.

The same questionnaire was used in all three approaches so figures can be compared. Fifty eight organisations supplied data in the examination. An approach based on proportion estimate was selected to ensure the reliability and accuracy of the research. The accuracy level of the entire sample is $\pm 7,7$ per cent points with fixed 95 per cent reliability on the basis of the statistical calculations that were carried out.

\section{Results}

Table 1 shows the aggregated revenue of the enterprises concerned. Seventy five percent of the revenue derives from agricultural machinery manufacturing. 
Table 1: Correlations of revenue data $(n=58)$

\begin{tabular}{|c|c|c|c|c|c|c|c|}
\hline $\begin{array}{c}\text { Revenue (million } \\
\text { HUF/year) }\end{array}$ & 2007 & 2008 & 2009 & $\begin{array}{l}\text { Enterprise size by } \\
\text { revenue }(\%)\end{array}$ & 2007 & 2008 & 2009 \\
\hline Total revenue & 5370 & 5920 & 5500 & Small $(<700)$ & 51,7 & 48,3 & 44,8 \\
\hline Average & 1094,9 & 1285,7 & 1140,1 & Medium $(700-4000)$ & 41,4 & 44,8 & 48,3 \\
\hline Median & 692,5 & 708,6 & 665,2 & Large $(4000<)$ & 6,9 & 6,9 & 6,9 \\
\hline Maximum & 8273 & 9752 & 6101 & & & & \\
\hline Minimum & 28 & 25 & 20 & & & & \\
\hline
\end{tabular}

Seventy two percent of the examined organisations sell on the Hungarian market and in the past three years there was no significant change in this respect. The average revenue was approximately 1 billion Ft. Median helps formulate a clearer picture about the situation as a revenue of 700 million Ft is typical of the SME sector in Hungary. Within the examined period 34,5 percent of enterprises had a separate $R \& D$ division, which can be regarded as favourable when compared to surveys in other industries.

Regarding organisational form, an interesting finding is that 48,2 percent of the enterprises operate in a linear while 37,9 percent of them in a simple organisational form, i.e. they do not have functionally separate organisational units while 13,8 percent have functional organisational forms.

\section{Inputs of innovations}

According to the results the examined enterprises realised the necessity of development and the figures show an increasing tendency in this respect. Enterprises tend to have spent more on innovation as of revenue (Table 2).

Table 2: Innovation, $R \& D$ and marketing expenditure as of percentage of revenue $(n=58)$

\begin{tabular}{|l|c|c|c|l|c|c|c|}
\hline \multicolumn{1}{|c|}{ Average (\%) } & $\mathbf{2 0 0 7}$ & $\mathbf{2 0 0 8}$ & $\mathbf{2 0 0 9}$ & Median (\%) & $\mathbf{2 0 0 7}$ & $\mathbf{2 0 0 8}$ & $\mathbf{2 0 0 9}$ \\
\hline R\&D expenditure & 2,6 & 3,38 & 4,1 & R\&D expenditure & 0,9 & 1,7 & 2,1 \\
\hline Innovation expenditure & 3,0 & 4,3 & 5,3 & Innovation expenditure & 1,3 & 2,7 & 3,9 \\
\hline Marketing expenditure & 1,3 & 1,6 & 1,8 & Marketing expenditure & 0,7 & 0,9 & 1,4 \\
\hline
\end{tabular}

When examining the median, again a clearer picture can be obtained. $1-2 \%$ of the revenue is spent on research and development while $3-4 \%$ is used for innovation.

\section{Outputs of innovations}

According to my examinations 65,6 percent of enterprises during the period of examination launched a new product to the market or modified some and 68.9 percent carried out technological innovation. Fifty nine percent started to be implementing an innovation project at the time of the survey. The development of a new product of global standard is, unfortunately, very limited (5,3\%). 34,2 percent of the implemented product developments by the enterprises can be regarded as a novelty under Hungarian circumstances. At the same time a significant part, namely 60,5 percent are only about innovations of modifying-developing nature. With respect to modernity, manufacturers seem to concentrate on rather technological development as 48,7 percent of the examined sample developed/introduced new technologies not applied so far in Hungary. 
Another aspect of research-development and innovation activities consists of publications and patents. In this aspect the performance of Hungarian agricultural machinery manufacturers is rather weak. During the examined period regardless of one or two examples patents and publications were not typical of the enterprises in the industry.

\section{The characterisation of the market environment}

Technological and market uncertainties have a profound impact on the operation of the company and makes a decisive influence on innovation processes-that is why their analysis is of high importance. In the following part we publish the results of our questionnaire in connection with the market environment. An answer was intended to find what changes the management think were made in the sector regarding market and technological uncertainties in the past three years. Also, the main reasons for this were also searched.

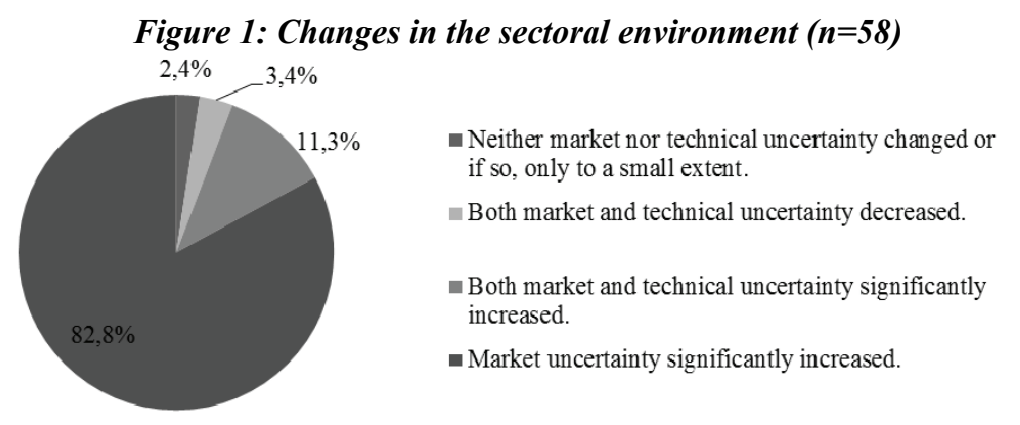

Figure 1 shows that nearly $83 \%$ of the companies think that market uncertainties can strongly increase during the examined period. It is not surprising as due to the global financial crisis all the sectors of the Hungarian economy have had to tackle serious issues and pessimism has also become general. Almost all respondents expressed their pessimistic opinions even during the small talk after the interviews had taken place.

Technical uncertainties have had a significantly slighter impact. One of the reasons for this can be that the sector does not change in a quick and predictable way when taking the basic technical considerations into account. Also, our results reflect that the main direction of innovations is developing the existing products so enterprises do not really dare to enter areas of uncertainties from technological point of view (except one). Some respondents made a complaint about spare parts of bad quality purchased from Chinese sources as a technical uncertainty.

If we examine the reasons for environmental uncertainties (Figure 2) the fact that organisations are aware of market and technical risks to a different extent is justified. The strongest environmental uncertainty is increasing competition (4.19) while the rapidly outdating nature of technologies (1.75) has the slightest impact. As mentioned earlier, the national producers are not price setters, rather price followers. So the stronger competition from the cheaper producers (3.68) as well as the rising energy (3.4) and base material prices (3.31) result in limited opportunities for the national 
agricultural machinery producers. Its direct impact on innovation activity is that producers cannot make funds /savings for development and very frequently they even lack the capital necessary for the project application. The complexity of the products and the needs of the customers for development can be characterised by medium values regarding the other factors of uncertainty. However, it can be seen that the expectations of the clients for development have been growing in the past few years.

Figure 2: Reasons for uncertainties in the sectoral environment $(n=58)$

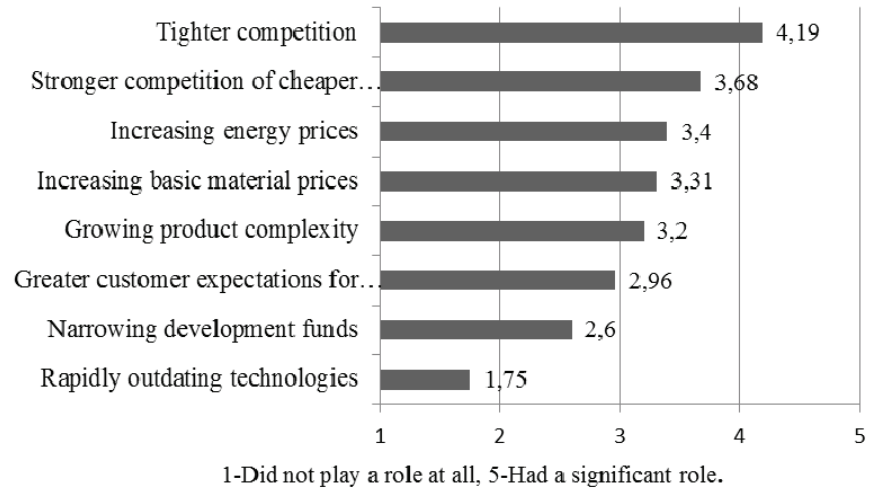

An interesting result is that of the reasons for uncertainty narrowing development sources (2.6) play a minor role. According to the producers financing innovations typically takes place mainly from own capital by channelling back the profit without the inclusion of an external source (credit). That is why it is felt to a smaller extent that the risk taking role of the banks has significantly been decreasing and consequently made the financing of less predictable innovations more expensive. The rate of changing technologies can differ in the market of certain products. In line with the results above, the rapidly outdating technologies (1.75) in the case of agricultural machinery are not the factor of technical uncertainty.

\section{The innovation knowledge networks of agricultural machinery manufacturers}

According to our survey almost 87 percent of the companies concerned in researchdevelopment cooperation have already taken part in a form, which can be regarded a fairly good proportion.

Table 3: Correlations between $R \& D$ cooperations and product- and process innovations

\begin{tabular}{|c|c|c|c|c|c|c|}
\hline \multirow{2}{*}{$\begin{array}{c}\text { The proportion of } \mathrm{R} \& \mathrm{D} \\
\text { cooperation }(\%)\end{array}$} & \multicolumn{2}{|c|}{ Product inn.(\%) } & \multirow[t]{2}{*}{ Total \% } & \multicolumn{2}{|c|}{ Procedure inn. (\%) } & \multirow[t]{2}{*}{ Total \% } \\
\hline & No & Yes & & No & Yes & \\
\hline Never & 75,0 & 25,0 & 13,8 & 100,0 & 0,0 & 13,8 \\
\hline Sometimes & 34,8 & 65,2 & 79,3 & 30,4 & 69,6 & 79,3 \\
\hline Always & 12,5 & 87,5 & 6,9 & 0,0 & 100,0 & 6,9 \\
\hline Total $(\%)$ & 34,5 & 65,5 & 100,0 & 31,0 & 69,0 & 100,0 \\
\hline $\mathrm{n}$ (item) & & & 58 & & & 58 \\
\hline Significance & & & 0,016 & & & 0,008 \\
\hline Cramer V & & & 0,377 & & & 0,406 \\
\hline
\end{tabular}


Results show that for those who have never taken part in cooperation (although their proportion is slight, 6,9\%) the number of successful innovations is low. In this aspect the most active ones are who have always incorporated a partner in their innovation processes. A decisive part of the sample, i.e.79 percent occasionally participate in cooperations. In this case a significant difference can also be noticed as the ratio of the active ones is approximately 70 percent. There is a significant correlation between product, process innovation and $\mathrm{R} \& \mathrm{D}$ cooperation and the strength is the correlation is close to satisfactory.

The extent of R\&D activity (Figure 3) reflects the most decisive directions of knowledge flow. These results illustrate the demand-driven nature of innovations in the agricultural machinery sector. Companies are trying to cooperate closely with their customers in order to know their needs. Sixty percent of the sample examined has already taken part in a common research-development project with a university research institute.

Figure 3: Proportion of R\&D cooperation agreements of agricultural machinery manufacturing companies (Relative frequency, more than one answer could be given) $(n=58)$

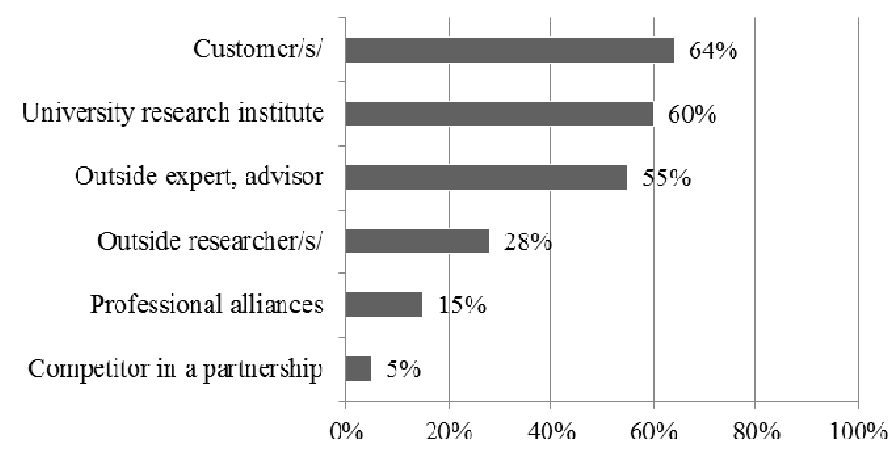

In order to get to know the typical groups and alliances the information managing habits of enterprises were also considered in the multidimensional scaling. The fitting of the model is good $(\mathrm{RSQ}=0,95413)$ and the quality of solution can also be regarded good (Stress $=0,09959$ ). When analysing the MDS map of information managing habits (Figure 4) we can find the typical groups that were described alongside two dimensions. The first dimension is the preferred-not preferred information on the horizontal axis while information (primary/secondary) is included on the vertical axis.

Typical groups:

- Preferred primary information: customers' needs, national and international machine exhibitions, and a further preferred source is the information of competitors and other machine manufacturers.

- Slightly preferred information: development experience of tool manufacturers, basic material manufacturers and of their own, information deriving from corporate R\&D specialists and marketing experts.

- Less preferred secondary information: The use of national and international professional literature can be described as a less preferred secondary source. 
Another less preferred group is the one of counselling, technological transfer organisations and professional alliances.

Figure 4: MDS map showing the information managing habits of enterprises

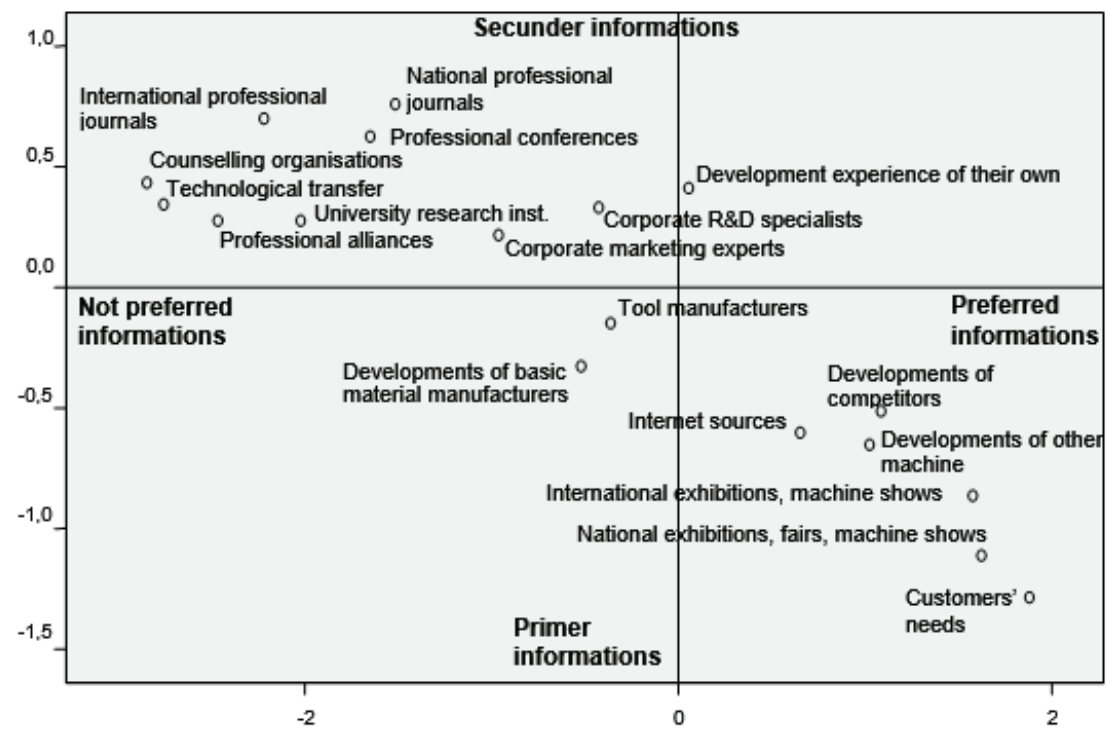

On the basis of the cross table and Chi-square analyses a positive connection can be observed between the two variables, i.e. different cooperations promote the innovation activities of agricultural machinery manufacturers in Hungary. According to the examination on the use of information sources we can state that of the information for their innovation activities enterprises prefer market like information sources most such as their customers and different professional exhibitions.

\section{Conclusions and suggestions}

The characteristics of the Hungarian agricultural machinery manufacturers drawn in the examination illustrate the situation of the sector in the country. A decisive part of the organisations (about $90 \%$ ) are small-and medium-sized enterprises. All in all, only about $26-27 \%$ of the national need for machinery derives from national manufacturers. Their attitude in development is reflected by the fact that more than 70 percent of their products are sold on the domestic market. Among the examined indicators of innovation performance the following ones must be highlighted:

- Organisations were spending more and more on R\&D in the examined years, in 2009 it comprised $4.1 \%$ of their average revenue. This value means a nominal increase of $154 \%$ relative to the one in 2007.

- More than $80 \%$ of the companies concerned have already been taking part in R\&D cooperation. In these forms of cooperation, the proportion of the relationship with the customers is the highest, which indicates the priority of demand-driven innovations. It is also important to note that $60 \%$ is the proportion of partnerships with university research institutes. 
- We stated that of the innovation used for innovation activity the national agricultural machinery manufacturers mostly prefer primary like sources. With the help of a multidimensional map information managing habits connected to innovation activities were divided into three groups along two dimensions: preferred primary like, slightly preferred and less preferred secondary information.

- We proved that for the Hungarian agricultural machinery manufacturers there is a positive significant $\left(\mathrm{Sig}_{1}=0,016 ; \mathrm{Sig}_{2}=0,008\right)$ correlation of medium strength between innovation activity and cooperation $\left(\mathrm{CramerV}_{1}=0,377\right.$; $\mathrm{CramerV}_{2}=0,406$ ). Our further examinations explored that in innovation cooperation it is typically the customers (64 percent) and university research institutes ( 60 percent) who are the preferred partners.

Manufacturers must show a greater interest in exploring and applying the new knowledge accumulated outside their organisational boundaries. In order to keep pace with market and technological changes as well as integrate new scientific results cooperation with professional alliances and specialist universities must be prioritised in their innovation processes. I would also highlight the role of strategic behaviour in the success of innovation processes. The management has to make decisions on investment and development on the basis of a strategic approach in line with systematic innovation objectives.

\section{References}

1. Bak, Á. (2013): A magyar mezőgazdasági gépgyártók innovációs aktivitása. Doktori $(\mathrm{PhD})$ értekezés. Gödöllő, 145 p.

2. Borbély, K.; Pataki, L.; Vágyi, F. R. (2011): Examination of the financial position of Hungarian agricultural enterprises between 2002 and 2009, Agrár és Vidékfejlesztési Szemle, 6:(1) pp. 33-37.

3. Edquist, C. (1997): Systems of Innovation. Technologies, Institutions and Organisations. Pinter, London \& Washington.

4. Fenyvesi, L. (2005): Gondolatok az agrármüszaki fejlesztésről, Mag, Kutatás, Fejlesztés és Környezet, 4:(19) $25 \mathrm{p}$.

5. Illés, B. Cs.; Dunay, A.; Hustiné Béres, K. (2013a): Tax system and innovation activities a case study on Hungarian small and medium enterprises, Gazdaság és Társadalom, 5:(4) pp. 45-66. http://dx.doi.org/10.21637/GT.2013.4.03

6. Illés, B. Cs.; Töröné Dunay, A.; Hustiné Béres, K. (2013b): Relations between the tax system and innovation - Az adózási rendszer és az innováció kapcsolata, Szent István Egyetemi Kiadó, Gödöllö, 82 p.

7. Husti, I. (1999): Technological development in Hungarian Agriculture. Hungarian Agricultural Research, 8:(4) pp. 14-16.

8. Hustiné Béres, K.; Tatár, E.; Turzai-Horányi, B. (2014): Relations between R\&D Activities and Tax Allowances in Hungarian Car Trade Companies. Theory Methodology Practice, 10:(2) pp. 37-47.

9. KSH (2010): Kutatás fejlesztés 2009. Statisztikai tükör, 4:(89)

10. Losoncz, M. (2008): Az EU-csatlakozás és a magyar kutatás-fejlesztési és technológiai stratégia. Közgazdasági Szemle, 54:(2) pp. 169-182.

11. Magó, L.: (2011) Agricultural Machine Distribution in the Hungary in Past Ten Years, Agricultural Engineering Scientific Journal, Belgrade-Zemun, Serbia, 36:(4) pp. 77-82. 
Adrienn HEGYI, Tünde KUTI, Zsófia KERTÉSZ, András SEBÖK,

Sara De PELSMAEKER, Xavier GELLYNCK, József LEHOTA

\title{
3.5. CONSUMER BEHAVIOUR AT THE IMPULSE PRODUCT WITH PRODUCT DEFECT
}

\begin{abstract}
Summary
The aim of the research was to understand and describe the praline consumption behaviour and effect of the product defect, blooming on the behaviour by using Theory of Planned Behaviour model in Hungary. The extended TPB model was used in the experiment. The whole experiment on extended Theory of Planned Behaviour model was also used in Belgium led by University of Ghent. The TPB model was extended with a new contrast as desire and the impact of negative experience on consumer behaviour was also examined via tasting session (N: 120). Totally 400 consumers were involved in the survey. The instruction from Ajzen was followed in the evaluation. As a part of it, the regression analysis was used to define the main factors having impact on the behaviour of the consumers. Based on the results we could conclude that the factor desire was influencing the behaviour together with behaviour intention. A positive desire to eat pralines pushed the consumer to actually eat pralines. The explanation of the variances increased when introducing the desire factor. Results also showed that however, the attitude effected greatly the Hungarian consumers, especially after a negative experience (e.g. eating pralines with product defect), the influence of the perceived behaviour control was stronger than the attitude or subjective norm and the effect of desire decreased.
\end{abstract}

Keywords: consumer behaviour, desire, impulse products,

\section{Introduction}

Chocolate is the most craved food in the world and has long been thought of as a pleasurable, hedonistic comfort food (Rodin et al. 1991; Rozin, Levin and Stoess, 1991). Comparing the food items apple and chocolate eating were found to improve mood but chocolate's effect was stronger (Macht and Dettmer, 2006)

Chocolate eating reduced negative mood after watching sad film; no effect was identified on positive mood Bad mood alleviated after eating palatable chocolate (up to $70 \%$ cocoa)-but the effect was very short-lived. Generally chocolate and filled chocolate are known for the arousal of sensory pleasure due to the specific melting behaviour, aroma and taste (Januszewska and Viaene, 2002; Mela, 2000; Parker et al., 2006, Pelsmaeker et al., 2014). Several authors indicate that the popularity of chocolate is closely related to the emotions it evokes with the consumer (Macht and Dettmer, 2006; Parker et al., 2006). Researchers have tried to define the negative emotion related to chocolate and the factor was named guilty (Fletcher et al. 2007; Frijters, 1993). Gaining weight and absence of self-control, negative effect on skin were proven to be beliefs triggering the guilty feeling (Dean et al. 2008; Lawless and Claassen, 1993)

However, the result is that the craving will eventually overwhelm the craver until the person experiences a breakdown of their efforts to diet in order to manage or lose weight (Cartwright et al. 2007). Such breakdowns have been shown to lead to an 
eating binge in which the person has eaten much more chocolate than desired (Gendall, et al. 1997). Martin (2010) stated that the chocolate effected the consumers in the following way: $73 \%$-puts me in a good mood; 60\%-makes me happy; 50\%-makes my temper disappear; 53\%-makes me feel better; 37\%-makes me feel relaxed; $63 \%$-the smell makes me crave/want it more; $67 \%$-seeing somebody else eat makes me want it and $70 \%$-preferred the smell to cakes/sweets. According to the previous statement Macht and Dettmer (2006) found that a significant effect exists with the emotions joy and guilt after eating a chocolate bar in everyday life. Joy was related to sensory pleasure whereas guilt appeared to be induced by negative thoughts associated with eating chocolate. The consumption of chocolate is thus difficult to identify as it is possibly related to specific emotional beliefs. Several studies (Ajzen, 1991; Fishbein, 1975; Perugini, 2001; Sparks, 2001); aimed to investigate the aspects which has and influence on the consumers' behaviour.

In one approach, the consumer behaviour refers to the selection, purchase and consumption of food for the satisfaction of their wants. Rossi et al., 2005 stated that initially the consumers try to find and select only those products which promise greater utility. After selection, the consumers estimate the available amount of money which they can spend. Lastly, the consumer analyses the prevailing prices of the products and taking the decision. Another point of view, not only the utility and the price of the product influence the consumers, but social, personal and cultural aspects as well. Furthermore, the consumption is not the only purpose to satisfy the basic needs, rather to achieve self-actualization and reach higher stages of Maslow-pyramid. This is why consumption also form the identity of the consumers and provide a social status as well.

The TPB (Ajzen, 1991; Fishbein, 1975; Perugini, 2001; Sparks, 2001) is applied to investigate the cognitive influences by which the rational behaviour of consumers is for prediction.

Januszewska and Viaene (2001) and Osman and Sobal (2006) studied the consumers' behaviours towards chocolate eating with Polish and Belgian consumers and Spanish and American ones. The chocolate craving was significantly different between Spanish and American consumers. Based on this studies we can conclude that different population have different behaviours towards eating chocolate as impulse product.

The evaluation of the product defects is a very complex problem, because the presence of the product defects in terms of quantity and qualitative aspects is well defined in the various legal requirements, but the consumers' opinions; understandings and behaviours on product with defects are slightly investigated in the different researches. The fat bloom and cracking are common problems in pralines leading to significant reduction of shelf-life and rejection of the products by consumers. It is a physical defect that is characterized as a whitish layer on the outer surface (Tisoncik, 2013). It is estimated that 143000 ton chocolate is affected by quality problems like fat bloom and cracks, which costs the European chocolate industry up to EUR 1.2 million a year (ProPraline, 2011).

Based on the literature review including the different cognitive models the models of Ajzen and Fishbein was used to investigate the consumers' behaviour aspects in our survey. The primary objective of this research is to investigate consumer behaviour 
towards filled chocolate consumption in Belgium and Hungary using the extended theory of planned behaviour (TPB) as a conceptual framework, including the emotional factor, desire. The second objective of our trial in Hungary was to examine the negative experience on the behavioural intention and behaviour of chocolate consumers. This article mainly focused on the Hungarian data.

\section{Theory of Planned Behaviour}

Ajzen and Fishbein (1980) developed the Theory of Reasoned Action (TRA) in order to identify the mechanisms of human behaviour in decision processes when this decision is based on free will. According to this theory, individuals are rational and motivation-based in their decision-making processes, and make a reasoned choice among various alternatives. TRA suggests that behaviour intention of a consumer is based on attitude (ATT) and subjective norm (SN). ATT are evaluative reactions to performing instrumental actions and are thought to be motivating the consumer to respond in a positive or negative manner to a certain action. They are modelled as functions of a decision maker's beliefs about the actions and the evaluation of these actions. The second predictor of behavioural intention, SN, captures the interpersonal aspects of behaviour which are largely based on the need for approval and is also referred to as compliance. The Theory of Planned Behaviour (TPB) is an extended version of the TRA. This theory considers not only volitional control (i.e. if a consumer can decide at will to perform or not perform a certain behaviour) but also non-volitional control (i.e., non-motivational factors such as time or money are important in performing behaviour) in explaining an individual's behaviour (Ajzen, 1991). Next to ATT and SN, it states that perceived behaviour control (PBC) is a third factor that helps explaining behaviour intention. PBC reflects the decisions maker's sense of control over performing the chosen actions in the decision enactment. It incorporates aspects of self-regulation, therefore it is a cognitive determinant for behavioural intention as well as behaviour. Further, Ajzen (1991) states that the stronger the intention to perform behaviour, together with perceived behaviour control, accounts for a major part of the variance in behaviour.

The TPB presumes that behaviour is a function of three types of salient beliefs relevant to the behaviour. The first type of beliefs are behavioural beliefs which influence attitudes towards behaviour.

These beliefs represent the subjective probability that the behaviour will produce the outcome in question. Second, the normative beliefs constitute the underlying determinants of subjective norms. These beliefs are concerned with the possibility that important individuals or groups will approve or disapprove the behaviour in question. The third ones are control beliefs that provide the basis for perceptions of behavioural control. Control beliefs can be based on several factors, e.g. past experience, secondhand information about the behaviour, experiences of other individuals and any other factor that increases or decreases the perceived difficulty of performing the behaviour in question.

Ajzen's model has been applied extensively in food studies to reveal and understand the drivers for consumer behaviour and behavioural intention (Mazzocchi et al., 2006; 
Perugini and Bagozzi, 2001). Literature indicated that desires have an influence on behaviour intention and behaviour of the consumer towards food products. This knowledge was translated into an extension of the TPB. Desire was introduced as a new construct that influences a consumer's behaviour (Hoppe. et al., 2013; Perugini and Bagozzi, 2001). This gave a tool to differentiate the Belgian and Hungarian consumer.

\section{Method}

An on-line survey was conducted in Hungary which structure was based on literature review, results of focus group studies and elicity studies.

The three parts of the on-line survey included questions to comprehend personal characteristics, intrinsic product characteristics and consumer behaviour. 400 consumer participated in the study. They were divided into 3 groups. Group A included 120 consumers who tasted the praline samples and filled the on-line survey as well. Consumers in Group B did not participate in the tasting session, but on their second test occasion they also filled the questionnaire again. Group $\mathrm{C}$, similar to Group B did not taste the model pralines, and they only answered questions related to the intrinsic product characteristics (Table 1).

Table 1: The construction of the research

\begin{tabular}{|l|c|c|c|c|c|c|}
\hline $\begin{array}{c}\text { Steps of the } \\
\text { research }\end{array}$ & $\begin{array}{c}\text { On-line } \\
\text { survey }\end{array}$ & $\begin{array}{c}\text { Taste } \\
\text { sensitivity of } \\
\text { target group }\end{array}$ & $\begin{array}{c}\text { Tasting } \\
\text { session }\end{array}$ & $\begin{array}{c}\text { Tasting } \\
\text { session }\end{array}$ & $\begin{array}{c}\text { Tasting } \\
\text { session }\end{array}$ & $\begin{array}{c}\text { Repeated } \\
\text { on-line } \\
\text { survey }\end{array}$ \\
\hline & Step 1-2. & Step 3. & Step 4. & Step 5. & Step 6. & Step 7. \\
\hline $\begin{array}{l}\text { General part } \\
\text { (on-line survey) }\end{array}$ & $\begin{array}{c}\text { N:400 } \\
\text { (HU) }\end{array}$ & & $120 / 459$ & $120 / 459$ & $120 / 459$ & \\
\hline $\begin{array}{l}\text { Group A: Sight+ } \\
\text { tasting }\end{array}$ & 400 & $120 / 400$ & $120 / 400$ & $120 / 400$ & $120 / 400$ & $120 / 400$ \\
\hline Group B: Sight & & & & & & $120 / 400$ \\
\hline $\begin{array}{l}\text { Group C: Sight+ } \\
\text { methodology } \\
\text { (like, dislike) }\end{array}$ & & & & & & $120 / 400$ \\
\hline Group D & & & & & & $40 / 400$ \\
\hline
\end{tabular}

Source: own research

The traditional TPB was built to understand the behaviour intention (BI) of a consumer to purchase a product. Three constructs are important to explain BI: attitude towards product (ATT), subjective norm (SN), perceived behaviour control (PBC). The model was analysed through several interrelated components. Behaviour (B) was predicted by intention to perform this behaviour. Subsequently, behavioural intention (BI) was predicted from three components as follows.

First, there was an attitude (ATT), explained as evaluation whether the individual sees the behaviour as bad or good, unpleasant or pleasant, harmful or beneficial. Attitudes were calculated from 'behavioural beliefs' that performing a certain behaviour leaded to a particular outcome and the 'outcome evaluation' of behaviour, i.e., the evaluation of desirability of that outcome. 
The second component stood for subjective norm (SN). This was the perception by an individual of social pressure from important other people to perform a particular behaviour. The subjective norms were computed from 'normative beliefs' concerning the influence of a referent (e.g. family or friends), and 'motivation to comply' with this referent. The third construct was called perceived behavioural control (PBC). The PBC component could also be explained as the degree to which a person felt that she/he was in control of her/his own behaviour.

Regression analysis was done to determine how much the behaviour intention of a consumer was related to ATT, SN and PBC. Additionally, the correlation coefficients between the three constructs and behaviour intention were calculated.

A second regression analysis determined how behaviour intention is explaining the actual behaviour of a consumer.

A third regression was done to reveal how the behaviour intention and the perceived behaviour control together explain the behaviour. The calculation was done with perceived behaviour control and with attitude and subjective norm. This method could indicate what constructs influence not only behaviour intention but together with behaviour intention, the actual behaviour of the consumer.

Desire as a new construct was added to the model. The influence of desire was calculated with regression analysis. Desire was then put as an extra construct when defining behaviour intention. It also was used to explain actual behaviour together with behaviour intention.

The impact of the negative experience with blooming praline was also investigated.

\section{Results}

\section{Consumer behaviour towards filled chocolate consumption in Hungary using the extended theory of planned behaviour (TPB)}

Firstly reliability with Cronbach's alpha was checked on the main elements (ATT, SN, PBC) of the TPB model. The reliability for attitude and perceived behavioural control were rather low but sufficient, for subjective norm the Chronbach's alpha was very high. After the reliability check, the values for the different constructs were calculated. These new variables were defined as direct_att, direct_sn and direct_pbc. The correlations between the construct and the questions were calculated. All the correlation coefficients were significant which indicated that none of the questions should be left out of the calculation. A next step was defining the value for behavioural intention (BI) and behaviour (B). A reliability analysis was first executed. Both constructs had a high Chronbach's alpha (0.879). Correlation coefficients were calculated to indicate which question was highly correlating with the construct. All the correlation coefficients were significant and the values were high. done for the Hungarian consumers to explain the behavioural intention and the behaviour of the consumers (Table 2). The beta coefficients were the regression coefficients of the independent variables. For behavioural intention, attitude and perceived behavioural control were significant with $\mathrm{p}<0.001$. Subjective norm was also significant but with $\mathrm{p}<0.01$. This indicated that the Hungarian consumer was influenced by the three constructs attitude, subjective norm and perceived behaviour control. 
Table 2: Regression analysis of theory of planned behaviour for the Hungarian consumers

\begin{tabular}{|l|l|l|l|l|l|}
\hline Dependent variable & Independent variable & Beta & Sign. & Correlation & Sign. \\
\hline Direct_bi & Direct_att & 0.406 & 0.000 & 0.407 & 0.000 \\
$\mathbf{R}^{2}=\mathbf{0 . 2 2 3}$ & Direct_sn & 0.123 & 0.008 & 0.238 & 0.000 \\
& Direct_pbc & -0.185 & 0.000 & -0.157 & 0.001 \\
\hline Direct_b & Direct_bi & 0.792 & 0.000 & 0.792 & 0.000 \\
$\mathbf{R}^{\mathbf{2}=\mathbf{0 . 6 2 7}}$ & & & & & \\
\hline Direct_b & Direct_bi & 0.781 & 0.000 & 0.792 & 0.000 \\
$\mathbf{R}^{\mathbf{2}=\mathbf{0 . 6 3 3}}$ & Direct_pbc & -0.074 & 0.017 & -0.196 & 0.000 \\
\hline Direct_b & Direct_bi & 0.795 & 0.000 & 0.792 & 0.000 \\
$\mathbf{R}^{2}=\mathbf{0 . 6 2 8}$ & Direct_att & -0.008 & 0.807 & 0.316 & 0.000 \\
\hline Direct_b & Direct_bi & 0.786 & 0.000 & 0.792 & 0.000 \\
$\mathbf{R}^{2}=\mathbf{0 . 6 2 7}$ & Direct_sn & 0.024 & 0.447 & 0.211 & 0.000 \\
\hline
\end{tabular}

Source: own research

The regression coefficient of attitude was the highest coefficient and positive $(\beta=0,406)$. This meant the behaviour of the Hungarian consumer was highly depended on the attitude of the consumer towards the product. It can be stated that a positive attitude was positively influencing the behaviour intention of the Hungarian consumers. The beta value for subjective norm was low but positive $(\beta=0.123)$. A Hungarian consumer was influenced by his/her partner, family and friends to eat or reject pralines. Again a positive influence from these people increased the behaviour intention of the consumer. Perceived behavioural control had a negative beta value $(\beta=-0.185)$. The explained variance, $R^{2}$, was low which indicated that these were only a few factors that explained the intention to buy a product $\left(\mathrm{R}^{2}=0.223\right)$.

The correlation coefficients represented the same trends. However, these coefficients were all significant, which meant that there was a correlation between all constructs and behavioural intention.

Behaviour could be constructed in different ways. When the regression analysis was done with only behaviour intention, the explained variance was almost $63 \%$. When including perceived behaviour control, the results indicated that the regression coefficient was significant with $\mathrm{p}<0.05$ but the increase of the explained variance was low. Identical to the explanation of the behaviour intention, the perceived behaviour control had a negative regression coefficient. When explaining behaviour with behaviour intention and attitude, the results indicated that attitude was not significantly relevant in explaining this construct. The same result was found when including subjective norm in the regression analysis. The conclusion here was that Hungarian consumers were only influenced by their perceived behavioural control in actual behaviour of eating pralines and not by attitude or subjective norm.

In the Extended Theory of Planned Behaviour, the extra construct desire (direct_d) was included. Before calculating the value for this construct, the internal validity was checked. These Chronbach's alpha was high, so no problems occurred in calculating the value for desire. Again the correlation coefficients were calculated to indicate if the questions were correlating to the construct. These results indicated that the coefficients were significant. The correlation with the construct score was high.

The regression analysis was then executed to indicate how big the influence of this construct was on behavioural intention and behaviour (Table 3 ). 
Table 3: Regression analysis of extended TPB for Hungarian consumers

\begin{tabular}{|c|c|c|c|c|c|}
\hline Dependent variable & Independent variable & Beta & Sign. & Correlation & Sign. \\
\hline Direct_bi & Direct_att & 0.244 & 0.000 & 0.407 & 0.000 \\
\hline \multirow[t]{3}{*}{$R^{2}=0 . \overline{444}$} & Direct sn & 0.058 & 0.143 & 0.238 & 0.000 \\
\hline & Direct_pbc & -0.070 & 0.081 & -0.157 & 0.001 \\
\hline & Direct d & 0.516 & 0.000 & 0.620 & 0.000 \\
\hline Direct_b & Direct_bi & 0.681 & 0.000 & 0.792 & 0.000 \\
\hline$R^{2}=0 . \overline{647}$ & Direct $\mathrm{d}$ & 0.180 & 0.001 & 0.602 & 0.000 \\
\hline
\end{tabular}

Source: own research

The regression analysis to explain behavioural intention gave other results than in the traditional TPB. The construct desire resulted in a higher explained variance namely from an $\mathrm{R}^{2}$ of 0.223 to 0.444 . Further, only the regression coefficients of attitude and desire were significant. Subjective norm stayed non-significant but perceived behavioural control was now also non-significant. The coefficient for attitude was a little lower than before. The regression coefficient of desire was high and almost equal to the beta value for attitude. The correlation coefficients were all significant, which indicated that they were all correlated to the behaviour intention.

The regression analysis to define the behaviour of the consumer indicated that the factor desire was influencing the behaviour together with behaviour intention. A positive desire to eat pralines pushed the consumer to actually eat pralines. The explanation of the variances increased when introducing the desire factor.

\section{The negative experience on the behaviour of filled chocolate consumers}

The impact of negative experience, $2^{\text {nd }}$ occasion can be presented through the results. The people in the $2^{\text {nd }}$ occasion not just were introduced with the pralines, but the pralines with products defects, blooming as well.

Table 4: Regression analysis of 1st and 2nd occasions

\begin{tabular}{|c|c|c|c|c|c|c|c|c|c|}
\hline $\begin{array}{c}\text { Dependent } \\
\text { variable }\end{array}$ & $\begin{array}{c}\text { Independent } \\
\text { variable }\end{array}$ & Beta & Beta_2 & Sign. & $\begin{array}{c}\text { Sign. } \\
2\end{array}$ & $\begin{array}{l}\text { Corre- } \\
\text { lation }\end{array}$ & $\begin{array}{c}\text { Corre- } \\
\text { lation_2 }\end{array}$ & Sign. & $\begin{array}{c}\text { Sign. } \\
2\end{array}$ \\
\hline Direct_bi & Direct_att & 0,406 & 0,236 & 0,000 & 0,002 & 0,407 & 0,198 & 0,000 & 0,01 \\
\hline $\mathrm{R}_{1}^{2}=0.223$ & Direct_sn & 0,123 & 0,112 & 0,008 & 0,099 & 0,238 & 0,127 & 0,000 & 0,027 \\
\hline $\mathrm{R}_{2}^{2}=\mathbf{0 , 1}$ & Direct_pbc & $-0,185$ & $-0,071$ & 0,000 & 0,364 & $-0,157$ & 0,015 & 0,001 & 0,409 \\
\hline Direct_b & Direct_bi & 0,792 & 0,659 & 0,000 & 0,000 & 0,792 & 0,659 & 0,000 & 0,000 \\
\hline $\begin{array}{l}R_{1}^{2}=\mathbf{0 . 6 2 7} \\
R_{2}{ }_{2}=\mathbf{0 , 4 3 5}\end{array}$ & & & & & & & & & \\
\hline Direct_b & Direct_bi & 0,781 & 0,658 & 0,000 & 0,000 & 0,792 & 0,659 & 0,000 & 0,000 \\
\hline $\begin{array}{l}R_{1}^{2}=0.633 \\
R_{2}^{2}=0,442\end{array}$ & Direct_pbc & $-0,074$ & 0,083 & 0,017 & 0,095 & $-0,196$ & 0,093 & 0,000 & 0,080 \\
\hline Direct_b & Direct_bi & 0,795 & 0,67 & 0,000 & 0,000 & 0,792 & 0,659 & 0,000 & 0,000 \\
\hline $\begin{array}{l}R_{1}^{2}=0.628 \\
R_{2}{ }_{2}=0,438\end{array}$ & Direct_att & $-0,008$ & $-0,055$ & 0,807 & 0,276 & 0,316 & 0,077 & 0,000 & 0,120 \\
\hline Direct_b & Direct_bi & 0,786 & 0,685 & 0,000 & 0,000 & 0,792 & 0,659 & 0,000 & 0,000 \\
\hline $\begin{array}{l}R_{1}^{2}=0.627 \\
R_{2}{ }_{2}=0,476\end{array}$ & Direct_sn & 0,024 & $-0,205$ & 0,447 & 0,000 & 0,211 & $-0,118$ & 0,000 & 0,037 \\
\hline
\end{tabular}

Notes: the bottom index (2) means the second occasion.

Source: own research 


\begin{tabular}{|c|c|c|c|c|c|c|c|c|c|}
\hline $\begin{array}{c}\text { Dependent } \\
\text { variable }\end{array}$ & $\begin{array}{c}\text { Independent } \\
\text { variable }\end{array}$ & Beta & Beta_2 & Sign. & $\begin{array}{c}\text { Sign. } \\
2\end{array}$ & $\begin{array}{c}\text { Correla } \\
\text {-tion } \\
\end{array}$ & $\begin{array}{c}\text { Correla- } \\
\text { tion_2 }\end{array}$ & Sign. & $\begin{array}{c}\text { Sign. } \\
2\end{array}$ \\
\hline Direct_bi & Direct_att & 0,244 & 0,132 & 0,000 & 0,08 & 0,407 & 0,198 & 0,000 & 0,001 \\
\hline \multirow{3}{*}{$\begin{array}{l}R^{2}{ }_{1}=0.444 \\
R^{2}{ }_{2}=0,148\end{array}$} & Direct_sn & 0,058 & 0,03 & 0,143 & 0,66 & 0,238 & 0,127 & 0,000 & 0,017 \\
\hline & Direct_pbc & $-0,070$ & 0,044 & 0,081 & 0,577 & $-0,157$ & 0,015 & 0,001 & 0,409 \\
\hline & Direct_d & 0,516 & 0,319 & 0,000 & 0,000 & 0,620 & 0,336 & 0,000 & 0,000 \\
\hline Dir & Direct bi & 0,681 & 0,71 & 0,000 & 0,000 & 0,792 & 0,659 & 0,000 & 0,000 \\
\hline $\begin{array}{l}R_{1}^{2}=0.647 \\
R_{2}{ }_{2}=0,455\end{array}$ & Direct_d & 0,180 & $-0,151$ & 0,001 & 0,004 & 0,602 & 0,087 & 0,000 & 0,094 \\
\hline
\end{tabular}

Notes: the bottom indexx (2) means the second occasion.

\section{Source: own research}

Firstly, reliability with Cronbach's alpha was checked on the main elements (ATT, $\mathrm{SN}, \mathrm{PBC}$ ) of the TPB model. The reliability for attitude, subjective norm and perceived behavioural control were low but sufficient.

After the reliability check, the values for the different constructs were calculated. These new variables were again defined as direct_att, direct_sn and direct_pbc in the same way as it presented in 4.1. A reliability analysis was executed on behaviour and behaviour intention that was sufficient for the further analysis.

Regression analysis was done for the Hungarian consumers to explain the behavioural intention and the behaviour of the consumers (Table 4). For behavioural intention, attitude was significant with $\mathrm{p}<0,05$, but the subjective norm, the perceived behavioural control were not significant. This indicated that the Hungarian consumer was influenced by mainly the construct, attitude and not as much by perceived behaviour control, subjective norm. Based on the results we can conclude that behavioural intention (BI) still influenced the consumer's behaviour mainly.

In the $2^{\text {nd }}$ occasion the extended TPB with the use of the new construct, desire was used. As a results of the second occasion, the negative impact the desire and the attitude have significant impacts on behaviour intention. Subjective norm, perceived behavioural control stayed non-significant.

The regression analysis to define the behaviour of the consumer indicated that the factor desire was influencing the behaviour together with behaviour intention. However a positive desire to eat pralines pushed the consumer to actually eat pralines. Desire (D) stayed significant on behaviour, but it seemed that negative experience had a negative effect on the desire.

\section{Conclusion}

In the literature, the Theory of Planned Behaviour (TPB) has proven to be effective in understanding the consumer behaviour towards food, chocolate and the praline in particular. The TPB was applied to investigate the cognitive influences by which the rational behaviour of consumers may be predicted. The model was analysed through several interrelated components, behaviour (B), attitude (ATT), subjective norm (SN) and perceived behaviour control (PBC). Later, the model was extended with desire as a new construct. The behaviour of Hungarian consumers was influenced by behaviour intention and desire according the extended TPB model. 
Behaviour intention was affected by the negative perceived behaviour control, the attitude and the subjective norm in terms of traditional TPB. Behaviour intention was affected significantly by attitude and desire, non-significantly by subjective norm and negatively perceived behaviour control at the extended TPB. The behaviour was explained by behaviour intention. The behaviour was explained better with the use of desire, with the extended TPB. The impact of the knowledge of product defect, blooming, negative experience had negative effect on desire.

\section{References}

1. Ajzen, I., (1991): The Theory of Planned Behaviour. Organizational behaviour and human decision processes, 50(2), 179-211. DOI: 10.1016/0749-5978(91)90020-T

2. Ajzen I.; Fishbein M. (1980): Understanding Attitudes and Predicting Social Behaviour. Prentice Hall: Englewood Cliffs, NJ, p. 50-57.

3. Anonymous (1975): Minutes of Division Business meeting. In: Institute of Food Technologists -Sensory Evaluation Division, IFT Chicago, IL.

4. Cartwright, F.; Stritzke, W. G. K.; Durkin, K.; Houghton, S.; Burke, V.; Beilin, L. J. (2007): Chocolate craving among children: Implications for disordered eating patterns. Appetite, 48(1), 87-95. http://dx.doi.org/10.1016/j.appet.2006.07.081

5. Dean, M.; Raats, M. M.; Shepherd, R. (2008). Moral Concerns and Consumer Choice of Fresh and Processed Organic Foods. Journal of Applied Social Psychology, 38(8), 2088-2107.

6. Fletcher, B. C.; Pine, K. J.; Woodbridge, Z.; Nash, A. (2007): How visual images of chocolate affect the craving and guilt of female dieters. Appetite, 48 (2), 211-217p.

7. Fishbein, M.; Ajzen, (1975): Belief, attitude, intention and behaviour: an introduction to theory and research. Addison-Wesley, 578p.

8. Frijters, J. E. R. (1993): Functional measurement in the study of mixture percepts. 626 Chemical Senses, 18(2), 93-100 p.

9. Gendall, K. A.; Joyce, P. R.; Sullivan, P. F. (1997): Impact of definition on prevalance of food cravings in a random sample of young women. Appetite, 28, 63-72.doi: 10.1006/appe.1996.0060.

10. Hoppe, A.; Vieira, L. M.; Barcellos, M. D. (2013): Consumer behaviour towards organic food in porto alegre: an application of the theory of planned behaviour. Rev. Econ. Sociol. Rural vol. 51, pp. 69-90. http://dx.doi.org/10.1590/S0103-20032013000100004

11. Januszewska, R.; Viane, J, (2002): Acceptance of chocolate by preference cluster mapping across Belgium and Poland. Journal of Euromarketing, 11 (1), 61-86p.

12. Lawless, H. T.; Claassen, M. R. (1993). Application of the central dogma in sensory evaluation. Food Technology, 47(6), 139-146

13. Macht, M.; Dettmer, D. (2006): Everyday mood and emotions after eating a chocolate bar or an apple. Appetite, 46(3), 332-336p. http://dx.doi.org/10.1016/j.appet.2006.01.014

14. Martin, N. G. (2009): Chocolate psychology: what science tells us about its effect on behaviour. In: London International Confectionery Conference,, 1st-2nd December 2009, British Museum, London.

15. Mazzocchi, M.; Lobb, A. E. W.; Traill, B. (2006): Food Scares and Consumer Behaviour: A European Perspective. Presentation at the International Association of Agricultural Economists Conference, Gold Coast, Australia, August 12-18, 2006.

16. Mela, D. J. (2000): Why do we like what we like? Journal of the Science of Food and Agriculture, 81, 10-16. 
17. Osman, J. L.; Sobal, J. (2006): Chocolate cravings in American and Spanish individuals: Biological and cultural influences. Appetite, 47, 290-301. http://dx.doi.org/10.1016/j.appet.2006.04.008

18. Perugini, M.; Bagozzi, R.P., (2001): The role of desires and anticipated emotions in goaldirected behaviours: Broadening and deepening the theory of planned behaviour. British Journal of Social Psychology, 40, 79-98p.

19. Parker, G.; Parker, I., Brotchie, H. (2006): Mood state effects of chocolate. Journal of Affective Disorders, 92(2-3), 149-159.

20. Parker, D.; Manstead, A. S. R.; Stradling, S. G.; Reason, J. T.; Baxter, J. S. (1992): Intention to Commit Driving Violations: An Application of the Theory of Planned Behaviour. Journal of Applied Psychology, 77(1), 94-101p.

21. Pelsmaeker, S.; Gellynck, X.; Delbaere, C.; Declercq, N.; Dewettinck, K. (2014): Consumerdriven product development and improvement combined with sensory analysis: A case-study for European filled chocolates. Food quality and preference ,41, pp. 20-29. http://dx.doi.org/10.1016/j.foodqual.2014.10.009

22. Propraline (2011): URL:_www.propraline.eu.com

23. Rodin, J., Mancuso, J., Granger, J., Nelbach, E. (1991): Food cravings in relation to body mass index, restraint and estradiol levels: A repeated measures study in healthy women. Appetite, 17, 177-185. doi: 10.1016/0195-6663(91)90020-S

24. Rozin, P., Levine, E. Stoess, C. (1991): Chocolate craving and liking. Appetite, 17(3), 199212. http://dx.doi.org/10.1016/0195-6663(91)90022-K

25. Rossi, P. E.; Allenby, G.M.; Mcculloch, R. (2005): Modeling interdependent consumer behaviour. Bayesian Statistic and Marketing, John Wiley \& Sons. Ltd. ISBN: 0470863676.

26. Shepherd, R.; Sparks, P.; Guthrie C.A. (1995): The Application of the Theory of Planned Behaviour to Consumer Food Choice", in E - European Advances in Consumer Research Volume 2, eds. Flemming Hansen, Provo, UT : Association for Consumer Research, Pages: 360-365.

27. Tisoncik, M (2013): Chocolate fat bloom. http://www.blommer.com/ documents/ChocolateFat-Bloom-article.pdf 


\title{
3.6. SHORT COMMUNICATION: THE EFFECT OF SOCIAL MEDIA ON CUSTOMER BEHAVIOUR AND FIRMS' ACTIVITIES
}

\begin{abstract}
Summary
One of the most important marketplace for the transactions of goods and services is the internet. The internet usage has been increasing and so does the transactions through internet. It is important to consider, that the internet buyers have different approaches to buying and their responses to marketing from the traditional offline consumers. In fact, in these digital era days marketing needs to change. It needs to adapt in developing brands and improving customer relationship through online marketing channels. The firms need to engage more in social media, since, more customers are engaging in social media. Thus, in this paper, we want to demonstrate the effect of social media on consumer behaviour and firms' activities. This outcome of the study can be utilized by the firms to enhance their output.
\end{abstract}

Keywords: social media, consumer behaviour, firms' activities, E-commerce

\section{Introduction:}

Nowadays, it is really appreciating to witness the wealth of new digital technologies. Direct marketers can communicate with consumers, anywhere, at any time and about anything. E-commerce became one of the most controversial topics in most of the business journals. Actually, web and the new advances have turned into a coordinated part of our lives and making easier for research and buying any sort of items. Also, the online transactions are getting to be more easier and quicker, for example people can buy most of goods through internet through online retailers (Bighiu, Manolica and Roman, 2015).

On one hand, research by Emarketer.com (2014) depicts that the usage of the internet for buying goods or services is increasing as shown in Table 1. Therefore, companies need to adopt their strategies to this trend, otherwise they face challenges in the future.

Table 1: B2C E-commerce Sales World Wide by Region (Billions Us Dollar)

\begin{tabular}{|l|c|c|c|c|}
\hline Regions & $\mathbf{2 0 1 3}$ & $\mathbf{2 0 1 4}$ & $\mathbf{2 0 1 5}$ & $\mathbf{2 0 1 6}$ \\
\hline Asia-Pacific & 383.9 & 525.2 & 681.2 & 855.7 \\
\hline North-Amerika & 431 & 482.6 & 538.3 & 597.9 \\
\hline Western Europe & 312 & 347.4 & 382.7 & 414.2 \\
\hline Central \& Eastern Europe & 49.5 & 58 & 64.4 & 68.9 \\
\hline Latin Amerika & 48.1 & 57.7 & 64.9 & 70.6 \\
\hline Middle East \& Africa & 27 & 33.8 & 39.6 & 45.5 \\
\hline World Wide & 1251.5 & 1504.7 & 1771.1 & 2052.8 \\
\hline Change & $18.25 \%$ & $20.23 \%$ & $17.70 \%$ & $15.90 \%$ \\
\hline
\end{tabular}

Source: Emarketer.com (2014)

On the other hand, people are more engaged in social media. For example, Facebook's users are increasing about 271 million in just two years (Table 2). Engaging in social 
media and has had an effect on e-commerce, consumer behaviour and firms activities (Darban and Li, 2012), therefore it seems necessary to have an in-depth look in the new phenomena.

Table 2: Facebook Daily Active Users

\begin{tabular}{|c|c|c|c|c|c|}
\hline \multicolumn{7}{|c|}{ From 2013 to 2015 - in millions } \\
\hline $\begin{array}{c}\text { Geographic } \\
\text { Regions and } \\
\text { Time Periods }\end{array}$ & $\begin{array}{c}\text { FB Users in } \\
\text { USA \& } \\
\text { Canada }\end{array}$ & $\begin{array}{c}\text { FB Users } \\
\text { in Europe }\end{array}$ & $\begin{array}{c}\text { FB Users } \\
\text { in Asia- } \\
\text { Pacific }\end{array}$ & $\begin{array}{c}\text { FB Users in } \\
\text { Rest of } \\
\text { World }\end{array}$ & $\begin{array}{c}\text { FB Users } \\
\text { Total } \\
\text { World }\end{array}$ \\
\hline 2013 Q1 & 139 & 179 & 167 & 180 & 665 \\
\hline 2013 Q2 & 142 & 182 & 181 & 195 & 699 \\
\hline 2013 Q3 & 144 & 188 & 189 & 208 & 728 \\
\hline 2013 Q4 & 147 & 195 & 200 & 216 & 757 \\
\hline 2014 Q1 & 150 & 203 & 216 & 233 & 802 \\
\hline 2014 Q2 & 152 & 206 & 228 & 244 & 829 \\
\hline 2014 Q3 & 155 & 212 & 242 & 256 & 864 \\
\hline 2014 Q4 & 157 & 217 & 253 & 263 & 890 \\
\hline 2015 Q1 & 161 & 225 & 270 & 280 & 936 \\
\hline
\end{tabular}

Source: Internetworldstats.com (2015)

Also, reports show that the companies' home pages, email, and social media are mostly used these days. However, most organizations produce under $5 \%$ of their deals on the web, e-commerce is an upsetting power having a significant effect in changing business models. More recent research proved that social media and mobile applications will be penetrating in our everyday life. Therefore, it seems important to have a specific view to both of them and usage of them in marketing to not drop behind the new trend (Leeflang, Verhoef, Dahlström and Freundt, 2014).

The overwhelming internet recognition has brought in various online social networks or web communities. social networks radically change consumers' behaviour and their brand preferences. Numerous autonomous and commercial web sites have increased, giving consumers a medium for congregate, socialize, and exchange views and information.

There are two ways how marketers can engage in online communities: taking part in existing web communities or by setting up their own. The best would be to join an existing network. However, there are challenges while participating in the existing online social network. Firstly, the effective use of the existing online social network is on experimenting stage, and the results are hard to measure. Secondly, these online networks are largely user controlled. The company's aim is to promote their brand. However, it is not so simple for the marketers to start interacting with consumers, since they need to earn the trust (Kotler and Armstrong, 2012).

This paper begins with an explanation of terminology that defines social media and social media marketing. In addition, it will analyse literature on social media and present its effect on consumer behaviour, firms' activities, and will highlight the advantages and disadvantages of these effects. 


\section{Social media and marketing}

\section{Social media}

From the standpoint of an idea, social media are the websites which bring millions of users with the same interest from the globe. Some examples of most popular social media are Blogs, YouTube, myspace, Facebook. There are various reasons people use social media (Sin, Nor and Al-Agaga, 2012).

From technical point of view, social media are gathering of Internet-based applications that fabricate in light of the ideological and innovative establishments of "Web 2.0", and that permit the creation and exchange of "User Generated Content" (Kaplan and Haenlein, 2010). According to Chaffey (2009), "Web2.0, is a collection of web services that facilitate interaction of web users to create cite user generated content and encourage behaviours such as community or social network participation, mashups, content rating, use of widgets and tagging" (p.55).

Mostly, the people want to maintain their relationship with relative or friends/colleagues. The online users of social media have gained social support, friendship and intimacy from establishing and maintain contact with other users (Dholakiaa, Bagozzia and Pearo, 2004).

Kaplan and Haenlein (2010) believe that for creating a classification scheme for social media, and to do so in a systematic manner, it's better to rely on a set of theories in the field of media research (social presence, media richness) and social processes (selfpresentation, self-disclosure). Probably social presence and media richness terms are not clear, therefore we try to define and explain them. Social presence is defined as the acoustic, visual, and physical contact that can be accomplished. Media vary in the level of richness they possess. It measures the amount of data that social media permit to be transmitted in a given time interval. Accordingly, some media are more effective than others in determining vagueness and uncertainty. Table 3 presents the result of their research.

Table 3: Classification of Social Media

\begin{tabular}{|c|c|c|c|c|}
\hline & \multicolumn{3}{|c|}{ Social presence/ Media richness } \\
\hline & & Low & Medium & High \\
\hline \multirow{2}{*}{$\begin{array}{c}\text { Self- } \\
\text { presentation/ } \\
\text { Self- } \\
\text { disclosure }\end{array}$} & High & Blogs & $\begin{array}{c}\text { Social networking sites } \\
\text { (e.g., Facebook) }\end{array}$ & $\begin{array}{l}\text { Virtual social worlds } \\
\text { (e.g., Second Life) }\end{array}$ \\
\hline & Low & $\begin{array}{c}\text { Collaborative } \\
\text { projects } \\
\text { (e.g., Wikipedia) }\end{array}$ & $\begin{array}{c}\text { Content communities } \\
\text { (e.g., YouTube) }\end{array}$ & $\begin{array}{l}\text { Virtual game worlds } \\
\text { (e.g., World of Warcraft) }\end{array}$ \\
\hline
\end{tabular}

Source: Kaplan and Haenlein(2010), p.62

\section{Social Media Marketing}

There is one thing common with the successful companies nowadays. These companies are strongly customer focused and heavily committed to marketing. In fact, these companies are ready to understand and fulfil the customer needs. Marketing 
deals with the customers, similar to any other business function. In every marketing definition, the significance of customer relationship and firms can be noted. For instance, Kotler and Armstrong (2012) define marketing as the process by which firms create good relationship with customers, to lure value from customers in return.

In addition, the social media website has provided a platform for the businesses to connect and network with the potential consumers, and build relationship with them (Mersey, Malthouse ans Calder, 2010). Social Media speak to a progressive new pattern that ought to be of enthusiasm to organizations working in online space (Kaplan and Haenlein, 2010). E-commerce can be built through social media, which in turn can connect to more potential buyers.

The online shopping is a process of electronic commerce, as, customer directly contact e-vendors and purchase goods and services from an online store (Chaffey, 2009). The process of gaining attention through social media sites is called social media marketing (Trattner and Kappe, 2013). For instance, social network such as, Facebook advertise with information about the likes and dislikes of the customers and assist the firms to learn more about customer needs. In the following section, we will discuss six types of social media from Kaplan and Haenlein's point of view.

\section{Social media and consumer behaviour}

The social network affects people through complex interpersonal influences. These can be conscious or unconscious, active or passive, normative or informative. These social networks provide an opportunity for consumers to advertise their perceptions of the purchased products and create a network of communication. Actually, Kohli, Suri and Kapoor (2015) believe that the communication model from the traditional model has been changed to the social media model as you can see in figure 1 .

Figure 1: Communication Model
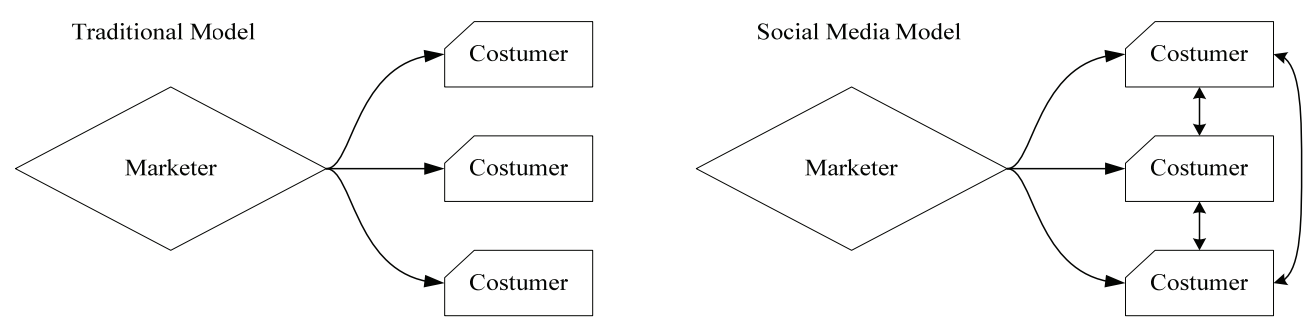

Source: Kohli, Suri and Kapoor (2015, p.37)

Consumers get information through their peers, thus, limiting the power of advertising, and making it challenging for the companies to justify large upfront investments. Social media has made consumers more demanding and discriminating. This shows the power has shifted in their favour, and they can insist marketers to provide their specific needs. Also, communication built by the consumers influences the target market and creating of the product and its delivery. Consumers would most likely respond if their 
specific needs are met and social media acts as a medium for sharing information about brands that best suits ones needs (Kohli et al., 2015).

It is important for the retailers and marketers to know about the factors affecting the consumer attitudes and motives, since, consumers are aware about the brands (Heinonen, 2011). These days there is a vast change in communication technologies and has been related to user participation. Thus, more customers engaging with social media should encourage firms to engage with social media as well. The marketing communications are incorporating with digital space, marketers can link with the customers using social media (Tiago and Verissimo, 2014).

This century is the age of social commerce and it has two most important potential challenges for firms: 1.) The ability to generate and leverage deep customer insights; and 2.) Managing brand and reputation in a marketing environment where social media plays an important role.

In this digital era, large data have become the norm. Large data provide more chance to follow customers, for instance, following customer from the orientation on a product to purchase and even to becoming loyal to the product. Following of the customer journey efficiently is a key component to perfect advertising campaigns and budgets. The most important benefits that companies wish to obtain from the customer data analysis are that; these data drive sales volume, induce innovation, and enhance customer engagement also through the creation of stronger brand loyalty.

Creating brand fans and investing in social media by managers, have a positive effect on the firm word of mouth and loyalty. The brand reputation of companies is controlled by the social media, though, they are struggling to measure its real impact. One of the most important tension perceived, is that the role of social media playing in managing brand health and reputation (Leeflang et al., 2014).

There are four key components of e-commerce which have effect on online purchasing; information, design, security and privacy (Vos et al., 2014). Building consumer trust is the main factor to achieve success against competitors (Pavlou and Fygenson, 2006). Nowadays, there are a lot of advertisements on the internet, also lots of comments criticizing brands and products, so it is hard for people to decide and trust. Social media can play an important role here, where firms can build consumer trust and advertise their products.

According to Edelman (2010), two-thirds of respondents from 2100 companies, were using social media, many perceived that it was still an experiment with blurry future. Only 7\% successfully integrated social media into their marketing activities. Social media can improve the design and promote of brands and has the capability to do this on an enormous scale, as, the consumers are skilful in controlling and influencing marketers through its use. Consumers not only control the information, but, also pass information to others if they find useful or interesting. Furthermore, social media has the potential to provide information very easily, and to move it, and to magnify it.

Shopping has always been a social experience and social media provides an opportunity for consumers to communicate with individuals, many of whom are likely to be strangers. The informational society influences affects the consumer decision processes and product evaluations. Social media give a chance to organizations to draw in and interface with potential customers, support an expanded feeling of 
closeness with them, and fabricate exceptionally imperative relation with potential buyers. As discussed earlier, social media provides the power to the consumers to influence other buyers through the evaluation of the products or the services. Social networks can play a key role in influencing the behaviour of consumers in the digital environment. The social sites are considered as valuable and reliable source for researching products and services (Ioanăs and Stoica, 2014).

\section{Social media and firms' activities:}

In the previous section, we have discussed about the effects of social media on consumer behaviour, in this section we would be discussing about the effect of the social media on firms' activities. Firms ought to try to create advanced connections utilizing special methods that underscore the co-creation of substance and importance (Tiago and Verissimo, 2014). Picking the right medium for any given reason relies on the target cluster to become to and the message to be conveyed. In the following section we summarize Kaplan and Haenlein's research.

\section{Low in social presence \& media richness}

From a corporate viewpoint, firms must be mindful that collaborative projects are slanted toward turning into the primary wellspring of data for some buyers. All things considered, albeit not all that matters composed on Wikipedia might really be genuine, it is accepted to be true by more web clients. Also, customers who end up being disappointed with or frustrated by the organization's offerings may choose to take part in virtual grumblings in blogs, which brings about the accessibility of possibly harming data in the online space.

\section{Medium in social presence \& media richness}

From a corporate perspective, on the negative side, content communities convey the danger of being utilized as web sites for the sharing of copyright-protected materials. On the positive side, the high prevalence of them leads to be extremely alluring channel. Nowadays, a few organizations are utilizing long range social network to bolster the creation of brand communities or for marketing research or distribution channel.

\section{High in social presence \& media richness}

Virtual social/game worlds offers a huge number of chances for organizations in marketing and human resource and internal process management. Also, the high fame of them can change traditional communication campaigns.

\section{Conclusion}

First, it seems necessary for firms to enter e-commerce, also using social media marketing and establish an internet marketing campaign to decrease the likelihood of collapse in the digital era. Secondly, social media sites are a great platform for the retailers to create an experience and the information stored on the sites can be used to 
enhance user experience with their brand. Also, the awareness of the retailer's brand can be achieved by being creative when engaging customers on the social media sites. In addition, retailers must go beyond the advertising aspects of social media sites and need to be more creative to communicate with consumers. Also, retailers need to enter their brand into the people's conversation instead of just one way communication.

Furthermore, people rely more on information from the other people who leave a comment on social media. Thus, firms should follow the customers' comments about their product and when they notice many people complain about a specific issue, try to solve the problem and sometimes ask the customers to give them some solutions or comments.

Moreover, firm contribution must stretch out reacting to negative remarks and shielding item offerings. Actually, members of social networks have the longing to connect effectively with and to end up both makers and buyers.

As a point, trust is a vital element with respect to the development and improvement of e-trade. Also, for having a long-term connection with customers in e-commerce, trust can play a significant role. Through social media, firms can build trust, have a connection with their customers and show them their truth.

Last but not least, the consumers buying behaviour through the internet has changed, since, the advent of social media. People are searching for product's information and features through social media before purchasing. It seems useful that firms provide adequate information about their products before other companies and people talk about them and criticize them.

\section{References}

1. Bighiu, G.; Manolica, A.; Roman, C. T. (2015). Compulsive buying behaviour on the internet. Procedia Economics and Finance, 20, 72-79. http://dx.doi.org/10.1016/S22125671(15)00049-0

2. Chaffey, D. (2009). E-business and e-commerce management strategy, implementation and practice (4 ed.). Harlow: Pearson Education.

3. Darban, A.,; Li, W. (2012). The impact of online social networks on consumers' purchasing decision: The study of food retailers. (Master), Jönköping, Jönköping University.

4. Dholakiaa, U. M.; Bagozzia, R. P.; Pearo, L. K. (2004). A social influence model of consumer participation in network- and small-group-based virtual communities. Intern. J. of Research in Marketing, 21, 23.

5. Emarketer.com. (2014, 28/09/2015). Global B2C e-commerce sales to hit $\$ 1.5$ trillion this year driven by growth in emerging markets. from http://www.emarketer.com/articles/results.aspx?t=1047

6. Heinonen, K. (2011). Consumer activity in social media: Managerial approaches to consumers' social media behaviour. Journal of Consumer Behaviour, J. Consumer Behaviour, 10, 356-364. DOI: $10.1002 / \mathrm{cb} .376$

7. Internetworldstats.com. (2015, 9/28/2015). Facebook users in the world. from http://www.internetworldstats.com/facebook.htm

8. Ioanăs, E.; Stoica, I. (2014). Social media and its impact on consumers behaviour. International Journal of Economic Practices and Theories, 4(2), 295-303. 
9. Kaplan, A. M.; Haenlein, M. (2010). Users of the world, unite! The challenges and opportunities of Social Media. Business Horizons, 53, 59-68. http://dx.doi.org/10.1016/j.bushor.2009.09.003

10. Kohli, C.; Suri, R.; Kapoor, A. (2015). Will social media kill branding? Business Horizons, 58, 35-44. http://dx.doi.org/10.1016/j.bushor.2014.08.004

11. Kotler, P.; Armstrong, G. (2012). Principles of marketing (14 ed.). New Jersey: Pearson Education.

12. Leeflang, P. S. H.; Verhoef, P. C.; Dahlström, P.; Freundt, T. (2014). Challenges and solutions for marketing in a digital era. European Management Journal, 32, 1-12. http://dx.doi.org/10.1016/j.emj.2013.12.001

13. Mersey, R. D.; Malthouse, E. C.; Calder, B. J. (2010). Engagement with Online Media. Journal of Media Business Studies, 7(2), 18. http://dx.doi.org/10.1080/16522354.2010.11073506

14. Pavlou, P. A.; Fygenson, M. (2006). Understanding and predicting electronic commerce adoption: An extension of the theory of planned behaviour. MIS Quaterly, 30, 115-143.

15. Sin, S. S.; Nor, K. M.; Al-Agaga, A. M. (2012). Factors affecting malaysian young consumers' online purchase intention in social media websites. Procedia - Social and Behavioural Sciences, 40, 7. http://dx.doi.org/10.1016/j.sbspro.2012.03.195

16. Tiago, M. T. P. M. B.; Verissimo, J. M. C. (2014). Digital marketing and social media: Why bother? Business Horizons, 57, 703-708. http://dx.doi.org/10.1016/j.bushor.2014.07.002

17. Trattner, C.; Kappe, F. (2013). Social stream marketing on facebook: A case study. Int. J. of Social and Humanistic Computing, 2, 86-103. http://dx.doi.org/10.1504/IJSHC.2013.053268

18. Vos, A.; Marinagi, C.; Trivellas, P.; Eberhagen, N.; Skourlas, C.; Giannakopoulos, G. (2014). Risk reduction strategies in online shopping: E-trust perspective. Procedia - Social and Behavioural Sciences, 147, 418-423. http://dx.doi.org/10.1016/j.sbspro.2014.07.122 


\title{
3.7. APPLYING ALTERNATIVE METRICS IN QUANTIFICATION OF NEWS
}

\begin{abstract}
Summary
Using a common definition, we can define news analysis as the measurement of the various qualitative and quantitative elements of textual news stories. These elements include sentiment, relevance and novelty. By quantifying news stories, we can gain a useful way to manipulate and use everyday information in a mathematically concise manner. In this article, a framework for news analytics techniques used in finance is provided. Various news analytic methods and software are discussed, and a set of metrics is given that may be applied to assess the performance of analytics. Various directions for this field are discussed. The proposed methods can help the valuation and trading of securities, facilitate investment decision making, meet regulatory requirements, or manage risk.
\end{abstract}

Keywords: textual news stories, finance, alternative metrics, software, investment decision making

\section{A brief assessment of the acquisition of INA by MOL}

\section{Corporate background}

The INA Privatization Act was accepted by the Croatian Parliament in 2002 to transform INA from a state-owned company to a privatized enterprise which would be controlled by independent private investors in order to boost its development and increase its operational efficiency and save the company from bankruptcy.

An open public tender was used to sell $25 \%+1$ share of INA in May 2002. The winner was the Hungarian Oil Company (MOL) who offered a higher bid (\$505) than the competing Austrian oil company, ÖMV who offered (\$420M). Soon afterwards, MOL became an official strategic investor in INA. This is coupled by the Croatian government's veto power and special rights.

Following up on the potential offered by the new legislation the Hungarian Oil Company (MOL), built its equity in INA progressively, and in 8 years from 2003 it became the largest shareholder of the company with a share of $49.1 \%$ of the total equity. The Croatian government remained the second largest investor with a share of $44.84 \%$. This increase in shares was undertaken through open market manoeuvres where a beneficially high price was offered for small shareholders.

From its entry onwards MOL always clearly stated its intentions to gain strategic control rights over INA. This was aided by its decisive position achieved by 2008 which allowed MOL to secure a majority in the Supervisory Board due to the terms laid down in the Shareholders Agreement in 2003 (which stated that the Croatian Government's stake in INA fell below $50 \%$, it only had the right to nominate two members). The de facto acquisition of INA by MOL was approved by the Croatian Competition Agency and later by the European Commission. 
The economic crisis of 2008 found INA in a quasi-bankrupt situation. In the following two years MOL provided a $330 \mathrm{M} €$ funding to help the Croatian company. This was augmented by the support from the domestic government which contributed to the stabilisation of INA's financial status.

The reasons for the severe impact of the crisis were multiple. A primary reason was the plunge in energy demand resulting in a direct decrease of revenues. For example, demand for diesel stayed $10 \%$ below the 2008 level even in 2012, for gasoline the drop was $14 \%$. The aggregate effect was a $28 \%$ reduction in the size of the oil product market. Matching these figures with the refinery capacities, this would be equivalent to $70 \%$ of the Sisak plant's capacity.

Another impact was the change in gas price regulations which enforced a rate well under the market price generating a loss of approximately $325 \mathrm{M} €$ in the years 2007 and 2008.

As INA struggled with financing its investment projects due to the drying out of international financing sources. This was problematic because in the years preceding the crisis INA started significant investments designed to reach their maximum levels by 2010 . A good indication for these investments would be that on average the average operating cash-flow was only about $60 \%$ of the investments. This practically meant that these investments could not be financed from the company's cash flow but funds had to be borrowed from external sources.

This was the reason why bankruptcy loomed over INA right when its investment programs were at their highest intensities. In the turmoil following the crisis the company had to satisfy its obligations towards banks, states hosting its projects and even to its suppliers. Key assets like the Syrian international oil and gas field development, the Adriatic fields, and the refinery modernisation all were at risk together with INA's role as a regional supplier.

In the followings, we give the dedicated steps taken to enhance liquidity and avoid default.

- Separation and sale of INA's gas business;

- Delayed tax payment: INA owed more than $204 \mathrm{M} €$ to the Croatian state at that time, and was given a temporary derogation.

- MOL's loan of approximately 330M $€$ provided to INA during 2009 and 2010, at a time of frozen international financial markets. INA used part of this to cover salaries and oil purchases, and partially to repay debts towards the state.

Overall, borrowing the loan from MOL allowed INA to cover its operating expenses, and fully pay its taxes to the state by the Autumn of 2010

\section{Investment details}

The appearance of MOL as a major investment started a period which was earmarked by a period of intensive investments, this is underlined by the doubling of the annual investments. This beneficial change improved INA's core competences (explorationproduction, refinery and distribution) and boosted its performance.

It is interesting to note that the average annual investment of INA after its privatisation surpassed pre-privatisation values with a factor of more than two. From an annual average value of $135 \mathrm{M} €$ it more than doubled to reach an average value of $365 \mathrm{M} €$ per 
annum. This was facilitated by a higher-than-the-industry's average reinvestment rate of approximately $80 \%$.

Investment in upstream oil and gas production reached 2.35 billion euros, while targeted field investments in the northern Adriatic topped at 525 million euros, this brought about a historical high in gas production from this region in 2010-2011.

The proven reserves of natural gas increased with 3 billion $\mathrm{m} 3$ in the past ten years due to increased exploration and development activities in the Adriatic areas. This was according to the initial agreement made and approved by the Croatian government which also focused on international projects. The overwhelming part of the allocated funds went to international targets (cca. 207M€), while only a minor share was assigned to Croatian plays.

Exploration activities were supported by MOL after its appearance as an owner of INA, this is confirmed by the discovery of three quite significant sites with one which turned out to be significant on the country level.

Joining forces also resulted in a cross-border geological research initiative between Croatia and Hungary in 2006-2007. Both of these drillings were successful and highlighted the operative potential in future cooperation. The research and exploitation of national hydrocarbon resources are also beneficial for improving regional energy security.

As of today upstream operations range from inland sites (land and off-shore in Croatia) to outland sites in Egypt and Angola. The Syrian location is blocked due to the conflict and sanctions placed on Syria's energy sector by the EU.

The downstream industry (refining and retail) faced a severe challenge with the upsurge of the economic crisis. This is highlighted by the plunge of diesel oil demand $(-10 \%)$ in Croatia from 2008 to 2012 , for gasoline the respective contraction was $14 \%$. With the disappearance of fuel oil demand the total market loss reached $28 \%$. With the parallel reduction of regional demand in Slovenia and Bosnia, the drop amounted to $70 \%$ of the Sisak refinery's capacity.

This however did not prevent management to successfully tackle the decline in the regional market share and penetrate other markets. The domestic share reached $70 \%$ by 2014 and even the crisis could not bring down motor fuel sales which showed continuous growth. To further ensure its strong market presence and improve competitiveness in the region, INA has taken the following steps:

- Modernisation of retail network, with 160 gas updated stations surpassing all competitors

- Investments targeted at improving fuel quality (EURO V)

- Increased investment in gas stations, reaching 30M€ in 2012

- Introduction of premium fuels

By the end of 2012, the retail network boasted with almost 400 gas stations in Croatia, 45 in Bosnia, 6 in Slovenia and one in Montenegro.

The total direct investment undertaken by MOL in Croatia reached 1.4 billion $€$ making MOL the second largest foreign investor. With its entry on the Croatian market, MOL promotes economic development and transformation and aids the evolution of an environment which ensures INA's leading position in the South 
Eastern European market. This was also supported by the construction of the CroatianHungarian gas interconnector.

\section{Strategic investments}

Numerous projects of strategic importance were undertaken and investment projects were launched in upstream, midstream and downstream. The initial agreement set during the privatisation process were surpassed in all areas with respect to investment levels, reaching an annual average of $365 \mathrm{M} €$ which is more than double of the respective figure before the privatisation.

Regarding the upstream segment investments reached 2.25 billion $€$ which is multiple times higher than a decade earlier. At the time of takeover no upstream projects were ready to launch so the new executive board decided to revise earlier project ideas and design new projects. A good example is INA's EOR project which targeted the improvement of oil and gas recovery from existing locations.

Important projects realised include the overwhelming share of investments in the Northern Adriatic and the Syrian plays, the cross-border exploration (in Zalata-Dravica and Novi Gradac-Potony), onshore projects and seismic scanning of the Southern Adriatic region.

It is strongly thought that the upstream segment is the core competence and key asset of INA and thus MOL is quite eager to develop this segment.

\section{Investment in refineries}

Modernisation of outdated refinery capacities were necessary as the competition also upgraded its facilities and Croatia accessed the EU. With the acquisition of the community legislation, the new fuel standards also required the refurbishment of refining. The first phase was finished in 2011, until 2013 altogether around 1.1 billion $€$ was invested in the refineries. The investments were slowed down by slow administration, this delayed a coker investment in Rijeka resulting in 300-350M $€$ investment lost. The coker would have allowed for a large scale of improvement, however the permits were not issued by the end of 2013. The new EU standards require a low sulphur content in fuels. INA could not by itself reach the required 10 PPM level thus requiring the addition of a significant desulphurisation capacity in order to remain on the market.

The desulphurisation units in Sisak were contracted by the end of 2005 to decrease sulphur in end-of-pipe emissions significantly, moreover to reduce benzene emissions and $\mathrm{CO} 2$ emissions (flaring) from the refinery. This investment also enabled the sales of sulphur to the chemical industry. After the conclusion of the investment, a large isomerization unit was launched. The Sisak refinery was further refurbished with a combined Hydrodesulphurization \& Fluid Catalytic Cracker (FCC) which permitted the production of low sulphur fuels.

Other investments targeted the Rijeka refinery's tank farm, sewage system and gas leakage. Further contracts involved a hydrocracking complex, a sulphur recovery unit and a hydrogen generation unit. 
By 2009 INA has already spent $350 \mathrm{M} €$ on the modernisation programme, which grew to $520 \mathrm{M} €$ by the end of 2010. All the above-mentioned modernisation investments were operational and online by January 2012.

\section{Development of the retail segment}

INA's retail network is presently the most update in the Croatian market and among the leading ones in the region. This is due to the Blue Concept, a modernisation program undertaken by INA with the support of MOL starting from 2010. Beforehand only minor upgrades were accomplished thus jeopardising competitiveness and falling behind other market participants.

With the introduction of premium brand fuels which incorporated biofuel components a new line of gas stations became necessary to ensure the appropriate market reception, this project was named Blue Concept and targeted the rejuvenation of INA's retail. This was coupled with a doubling of capital investment in this segment by the company and resulted in the modernisation of more than 130 gas stations by the end of 2012 with a new design and a facelift. Infrastructure, equipment, catering and services were improved and by the end of 2014, already 160 stations boasted with the new image. It can be stated without hesitation that this rate of improvement cannot be matched with earlier periods' developments.

All these abovementioned developments helped INA to retake its leadership in its markets and successfully increase its overall operational efficiency. It has to be noted that these processes were achieved in a market with an ongoing recession and the contemporary accession to the EU unified internal market where no trader barriers (therefore no protectionist measures) are allowed thus rendering INA suddenly one of the many participants in a competitive environment.

Later in 2013 following the European trends a pilot project was launched which basically is renting the gas stations management rights to the entrepreneurs who seems to be most fit managers, and maintains INA as the owner of capital assets like concessions, buildings, and infrastructure.

The franchise allow for the highest quality service and exploitation of the potential turnover of the station ensuring profitable operation for both INA and the individual holder of the franchise rights.

\section{Oil and gas exploration in Croatia}

Starting from 2003 approximately 2.35 billion $€$ was invested into oil and gas extraction, and about 525 million $€$ in the Northern Adriatic fields allowing for a record production from 2010. The exploration activities added an additional proven reserve of more than 3 billion $\mathrm{m}^{3}$ to INA's reserve base assets.

This was in line with the Initial Business Plan which shifted the focus of exploration to offshore Adriatic and allocated more than $200 \mathrm{M} €$ but less than $10 \mathrm{M} €$ to inland exploration.

As mentioned earlier, cross border explorations with Hungary were also very successful and helped INA's proven and probable reserves to reach $267 \mathrm{MMboe}$, and a daily production of $48.6 \mathrm{Mboe}$. Extensive upstream operations in Croatia are still a key to the country's energy security. 


\section{Operational development of INA}

As the strengthening and improved profitability of INA is aligned with MOL's long term objectives, MOL initiated the restructuring of INA's operative profile by starting rationalisation programmes and efficiency improvement which resulted in significant improvement, doubling of operational profit and a decrease in its debts. This helps INA further play a vital role in the country's energy security.

Concerning energy security a major step was the construction of the gas interconnector with Hungary. The construction of the Croatian-Hungarian gas connection began in 2009 by FGSZ, a daughter company of MOL. This significantly improved the security of energy supply in Croatia. Financing was partially supported by EU, and Hungary also invested $275 \mathrm{M} €$ on their side. The pipeline is $205 \mathrm{kms}$ long in Hungary and $88 \mathrm{kms}$ long in Croatia, carrying a maximum $19.2 \mathrm{M} \mathrm{m}^{3}$ per day.

The interconnection supports the priorities of the EU energy policy as it strongly promotes CEE region's connectivity to mobilise energy supplies and contributes to the North-South gas corridor. It is considered as an important step towards the unified transparent community gas market.

Practical life brought a real stress test to this enhanced connectivity, as in February 2012 a very cold weather was coupled with a unscheduled disruption of gas production in the Northern Adriatic gas fields. The interconnector securely allowed for the resupplying of the Croatian gas system from Hungary amounting to one-third of the daily gas consumption. In this case, households and industrial consumers remained undisturbed in their consumption and the supply was secured.

Despite the intergovernmental agreement between Croatia and Hungary, this interconnector is still unidirectional, from Hungary towards Croatia. As this was a significant investment this limitation strongly jeopardises MOL's investments return and undermines the security of energy supply in the broader region.

\section{Conflicts with the Government of Croatia}

As the Government's accordance outlined in the Gas Master Agreement the state owned company Plinacro purchased the gas storage business subsidiary (PSP Okoli) from INA at a price which was set by an internationally renowned accountancy. This was coupled with an agreement which stated that INA rents this facility for five years for an annual fee of approximately $20 \mathrm{M}$ Euros thus ensuring a return of the investment in 5-6 years. This agreement also contained a clause that the Croatian government would take over Prirodni Plin, the gas retail company of INA.

There was no disaccord on the leasing back of the gas storage facility but the part on the purchase of Prirodni Plin was not respected by Croatia.

Additional unfriendly steps included the Croatian Government adding important amendments to the Gas Market Act without allowing the market actors to prepare for the changes. It was not declared who would be the supplying wholesales gas to households from 2014 Spring, although this obligation was of INA for the past 30 years. With the approach of the end of the five-year agreement for the gas storage plant (PSP Okoli) it became obvious that a complete change was about to happen on the Croatian gas market. This was problematic because the in order to ensure the security 
of gas supply Prirodni Plin has store a significant amount of gas in its storage facility (e.g. to be able to provide gas in the winter period, etc.)

As it was published, HEP, the power provider of Croatia was appointed as the official gas wholesales agency and was granted access to $70 \%$ of the storage capacity of PSP Okoli, all this happened without any prior notice on denouncing Prirodni Plin from its role.

This was harmful not only for the gas company but for INA, as INA's production and sales portfolio relies on being able to sell its gas, if this is strictly limited than a large amount of gas will be either not produced or will be flared.

This step was taken without prior consultation and resulted in INA being forced to sell a large amount of gas stored in the facility in a very short period of time, notably one month. This was not possible due to low seasonal demand and the limited daily pumping capacity of the storage containers.

Besides a prohibitive (and probably non EU-compatible) regulation disallowing the export of domestic gas, a large amount of gas was locked in the storage facility. Although the company tried to reason with the state regulators and stakeholders to be permitted to remove gas gradually over a timespan of several months, the requests were denied and the possibility of a forced auction was raised for the unsold and unwithdrawn amount.

Despite numerous attempts to resolve the situation and an open letter published by the management board of INA to stop the sales, the gas content was auctioned and sold for about one quarter of the market price.

The losses in terms of total revenue might be as high as $20 \%$ of INA's investment spent in Croatia, currently the figures show a loss of approximately $25 \mathrm{M} €$ for the 109 $\mathrm{m} 3$ gas sold below market price. The buyers were HEP and Plinacro, both state owned companies.

The restructuring of the gas market resulted in direct losses to Prirodni Plin since it trusted that the regulatory changes would be neutral and it tried to maintain its responsibility as a gas supplier. The situation is well characterised by Želimir Sikonja, a director of INA, who admitted that ".. we are disappointed with a lack of reaction from all institutions whose goal is supposed to be the protection of market supply security and ensuring of equal terms for all participants in the gas business in Croatia." The problems with INA and the conflict with the Croatian government also adversely effected MOL. Its shares fell to historical low level in 2013 when it first announced that it is ready to sell its equity in INA, the trade on the Hungarian stock exchange reacted strongly to the announcement which mentioned the debate over management right.

The plunge in share prices is well characterised by the drop of the BUX, the benchmark stock index of the Budapest burse of $1.1 \%$.

As a reaction, the management board started preparations for the sale of MOL's share in INA in November, 2013. This demonstrates the deterioration of the connection and negotiations between the Hungarian oil company, and the Croatian government. The Croatian government's main point is that INA is operated as a subsidiary or daughter company to MOL rather than as an independent company. Experts agreed that the 
management's steps were considered as an escalation of the situation. Croatia's macroeconomic situation does not allow for the buyout of the company, however.

As INA is considered to be one of the driving forces and success stories in MOL's recent acquisitions and there is no obvious project on the horizon to invest should proceeds be paid for INA by the Croatian state meaning there is no likely good outcome if selling INA occurred.

An interesting but shocking episode in the INA-MOL story is that the CEO of MOL, Zsolt Hernádi is put under an Interpol arrest warrant by the Croatian state with the accusation of bribery.

As a resolution to the case, where MOL is accused of contractual non-performance, MOL has asked for arbitration. In its statements MOL has referred to its legal obligations to represent shareholder's interests and thus in good faith negotiate. However, discussions have not led to any agreement to date.

\section{Introduction to the research}

Quantitative analysis of text (news, tweets, articles, etc) can provide additional information for financial analysis. First of all text contains an additional emotional content (called sentiment) which provide valuable input for further conjectures on a given topic. Another important factor is the opinions and links found in the text to other sources. Third the quantification of some intrinsically qualitative information can be difficult and results in ,signal loss”. Fourth, textual information contains some additional value over aggregated and composite quantitative information (Loughran, McDonald, 2014).

Evolution of computer hardware, computing power and storage capacity allowed for the birth and fast evolution of data mining. In addition to the vast amount of data generated every day and every hour it is possible to rely on large databases for analysing information. Dictionaries are used for providing a quick assessment of sentiments found in an article by quickly comparing the contents of the respective text with the built-in words and developing a score. One example is the Harvard Inquireer (http://www.wjh.harvard.edu/ inquirer/) which allows for deciding on the optimistic or pessimistic nature of an article. Associative dictionaries are also a novelty, they basically function as a thesaurus and allow for establishing the proper context of a text. To visualise context some webpages offer online graphics to provide an eycatching clue, see e.g. Visuwords or other pages.

Advantage of using such dictionaries is that they provide an unbiased fundament for evaluation, an objective basis which can be referenced and referred in research.

Many techniques exist to reduce the enormous amount of textual input to process thus simplifying analytical work. One interesting and important element is text summarisation. A simple form of summarisation is when we select the sentence(s) with the largest commonality index; that is, a number which represents the similarity beween the text and other elements. One of the basic measures used is the Jaccard formula (Jaccard, 1901), which allow for the composition of the Jaccardi matrix. The 
(i,j) element of the Jaccardi matrix is given as follows $J_{i j}=\left|\frac{s_{i} \cap s_{j}}{s_{i} \cup s_{j}}\right|=J_{j i}$. Similarity is calculated by calculating row sums, $S_{i}=\sum_{j} J_{i j}$, and a natural ranking according to the significance of a sentence can be starting from the lowest values (e.g. highest information content or novelty).

After having done some analysis and editing tasks and having trimmed the text to our needs the next task is to analyse the text. One important step is to extract sentiments and decide about the message of the text (e.g. optimistic, pessimistic, neutral).

One method for this process is the Bayesian classification, where we use a training set to "teach" the computer to classify documents based on the occurrence of typical terms (so called prior probabilities) and use the definition of the conditional probability to calculate posterior probabilities to classify new documents in the given classes of sentiments.

Another method frequently applied is the support vector model, which spearates the datasets using a distance maximisation method (e.g. distance between data groups is maximised by fitting (a) separating hyperplane(s)) between).

A simple way can be the word count method where we simple count the number of words with positive and negative sentiment and get a net balance of the text.

\section{Applying metrics text analysis assessment}

When trying to establish the quality of an algorhitm in text minig, it is important to apply certain metrics. Originally metrics mean a measurement of distance in mathematics, in the current context they provide a means to test for the goodness of the text mining algorithm. Here we present only a few examples from the literature (see e.g. Das, 2014 and Das and Chen, 2007).

One important element is the confusion matrix, which describes the goodness of classification using a matrix form. Simply put, assuming a $k$ categories, we have a quadratic K x K matrix, where the rows represent actual categories, columns represent assigned categories, and any cell $(i, j)$ represents a text which is category $i$ and was assigned to category $j$. Obviously only elements in the diagonal of the matrix represent well classified elements, all other elements which are non-zero represent classification error (thus the notation confusion matrix).

The test is based on a $\chi^{2}$ critical value, the null hypothesis that in the case of random guessing (a completely useless algorithm) the rows and columns would be independent. Denote with $\mathrm{O}(i, j)$ the actual elements of the confusion matrix and $\mathrm{E}(i, j)$ the expected element under the assumption of no classification (uniformly distributed random values, e.g. the number of observations in the $i^{\text {th }}$ row and $j^{\text {th }}$ column divided by the total number of observations).

$$
\chi_{(K-1)^{2}}^{2}=\sum_{i} \sum_{j} \frac{(O(i, j)-E(i, j))^{2}}{E(i, j)}
$$


Depending on this test statistics we can decide about accepting the algorithm.

Based on the elements of the confusion matrix accuracy can also be tested with the following metrics using the previous notations

$$
A=\frac{\sum_{i} O(i, i)}{\sum_{j} M(j)}=\frac{\sum_{i} O(i, i)}{\sum_{i} M(i)}:
$$

This is simply the sum of the diagonal elements divided by the sum of all elements of the matrix.

Incorrect classification can be sometimes more harmful than no classification at all. Incorrect classification can be simply counted as the percentage of elements which are not correctly assigned (this can be weighted). A logical assumption is that the categories are arranged in a manner where neighbouring categories have proxmitiy in their sentimental content, too. Under such arrangement it is expected that a classification which puts a given category to a category with distinctively different meaning causes much more harm than a misclassification to a category in the "vicinity". In our proposition below we try to give a way to resolve this issue by introducing a vicinity factor in misclassification.

\section{Proposed new metrics in text analysis}

One important element in text analysis is classification of text. Besides that, in our proposed method it is possible to identify the main market tendencies according to the followings.

Assume that the information from the market is organised into $n$ documents (sources) and that at most $k$ distinctive terms are

\section{Suggestion for systemic error testing}

If a classification algorithm is completely precise, we would only receive elements in the main diagonal, that is, the rank of the matrix would be full (equalling the number of rows). If on the other hand we have a systemic error in the algorithm, this would mean a tendency of false classification. In this case, a category could be replaced by one or more other categories and the classification would not suffer any loss. For this we suggest a rank probe, that is to calculate the rank of the confusion matrix. If the rank is lower than the order of the matrix $(k)$ that means that one category can be reproduced as a linear combination of other (one or more) categories. In that case, the algorithm is generating systemic, inherent errors. If the rank of the confusion matrix is full, then the algorithm contains only random errors.

\section{Communality matrix and determination of principal vectors in news}

Concerning miscategorisation as a grave error it is logical to identify a measure to deal with this problem. Assume that categories are assigned in a logical order (e.g. decreasing sentiment, etc.) and that the the algorithm is not degenerative, that is the $K$ confusion matrix is full rank. In that case it is possible to apply linear transformation and gain the Jordan canonical form (Molnár and Szidarovszky, 2002). In that case 
there exist at least one real eigenvalue of the matrix, but more importantly the basis of the Jordan-form matrix is composed of the eigenvectors of the original matrix (transformation, or in our case classifying algorithm).

A measure for the degree of miscategorisation can be a simple euclidean distance of the standardised eigenvectors. If the distance is less than a given threshold, then the categorisation can be accepted. If the distance is very large than the algorithm can be considered risky from the aspect of miscategorisation.

\section{Empirical results of news analytics}

Some elements of the theoretical results were applied to a specific case along the following lines. The Hungarian Oil Companies (MOL) and the Croatian Industrianafte (INA) formed a strategical alliance in 2003 and MOL became the owner of almost $50 \%$ of the INA shares. In our short analysis we analysed approximately 850 articles from Hungarian websites (primarily, portfolio.hu). These articles were grouped into three categories based on keyword assessment: bearish (pessimistic), bullish (optimistic) and neutral, and were scored accordingly. In many cases the articles were of political nature and thus had additional layers of information. In cases where multiple messages (perhaps of mixed positive and negative nature) were found the overall aggregate value was considered for that day. This was matched with the daily movement of MOL share prices on the Budapest Stock Exchange (BUX).

These results were combined in simple difference values as follows. If the information gained from news analytics (three discrete values were possible) were matching the daily movement of prices then we assigned $\mathrm{a}+0.5$ value to the forecast.

If the information derived from the analysed news were different from the share price movement we generated $\mathrm{a}+1$ or -1 value depending on the direction of share price change compared to the forecast. The information is summarised in Figure 1.

Figure :. Differences between information of analysed news and share price movements, no lag

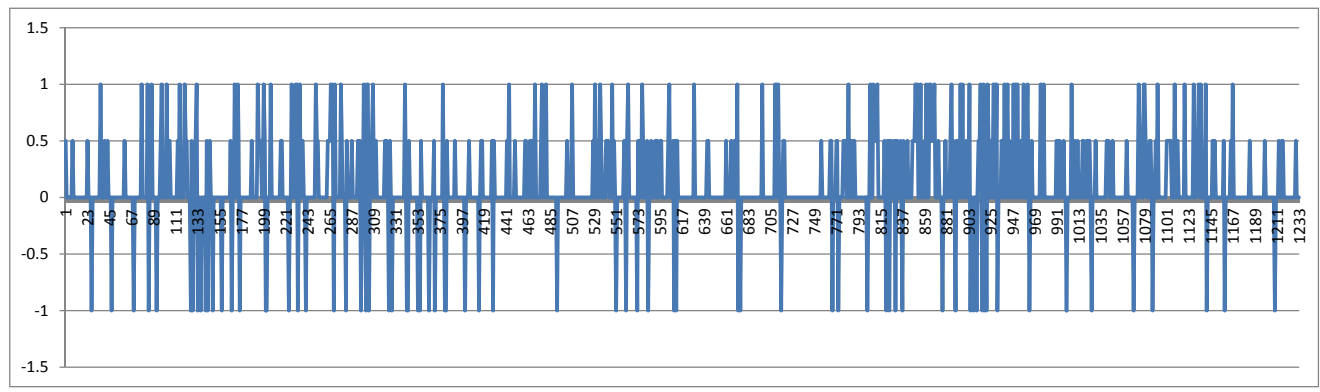

(1=share price increase $w$. negative forecast, 0.5 identical movement, correct forecast, $1=$ share price decrease with positive forecast)

Source: own calculations

It is well visible that the news analytics performed only partially well in forecasting price movements. As this was the contemporaneous (daily change) it is worth to check for the lag phase behaviour of the forecast. This is shown in Figure 2. 
Figure 2: Differences between information of analysed news and share price movements, one day lag

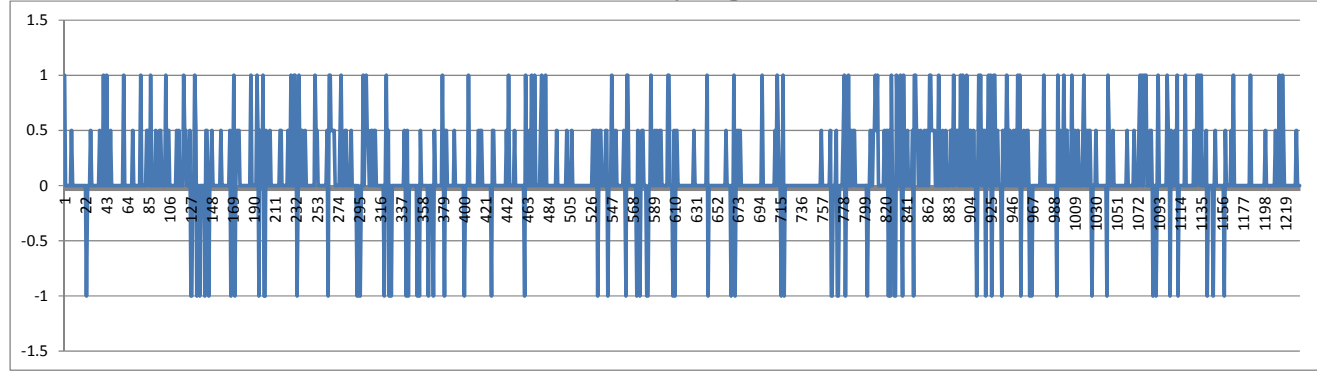

(1=share price increase $w$. negative forecast, 0.5 identical movement, correct forecast, $1=$ share price decrease with positive forecast)

Source: own calculations

From this chart it can also be observed that a given day prediction from news analysis typically resulted in the next day share price movement following the sentiment of the news text.

\section{Remarks}

Although the above results are of limited scope they show that news analytics require increased attention both from the theoretical view and from the view of technical analysis. There is evidence that the market is not fully informed, at least that that full information principle only holds in a weaker form as news analysis is able to provide additional predictive abilities.

\section{References}

1. Das S. R. Text and Context (2014): Language Analytics in Finance. Foundations and Trends R in Finance, vol. 8, no. 3, pp. 145-260.

2. Das S. ; Chen M. (2007): Yahoo for amazon! sentiment extraction from small talk on the web. Management Science, 53:1375-1388.

3. Jaccard P (1901). Étude comparative de la distribuition florale dans une portion des Alpes et des Jura. Bull. Soc. Vaudoise Sci. Nat. 37: 547-579.

4. Loughran T.; McDonald W. (2014): Measuring readability in financial disclosures. Journal of Finance, 69:1643-1671.

5. Molnár S., Szidarovszky F. (2002): Introduction to Matrix Theory with Applications to Business and Economics, World Scientific, London.

6. http://www.bloomberg.com/news/articles/2013-11-26/mol-seeks-arbitration-over-ina-asdispute-escalates

7. http://molincroatia.com/inas-investments

8. http://molincroatia.com/mols-investment-in-ina

9. http://www.bloomberg.com/news/articles/2013-11-11/mol-dives-as-sale-plan-escalates-inadispute-budapest-mover 


\section{AUTHORS}

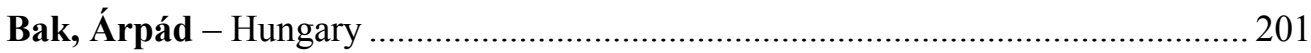

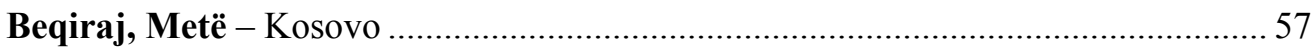

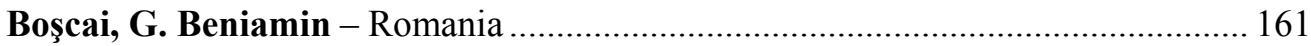

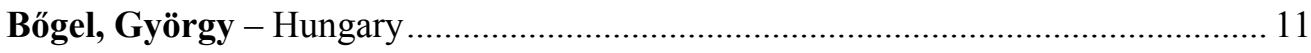

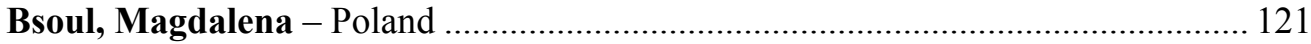

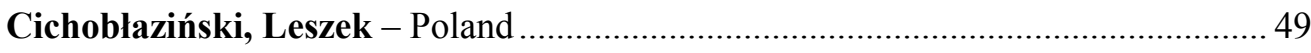

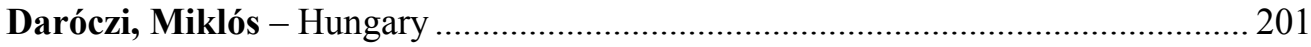

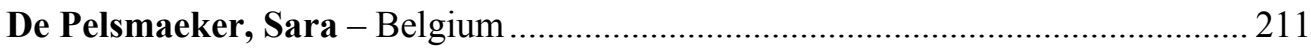

Dunay, Anna - Hungary ……………........................................................ 99, 173

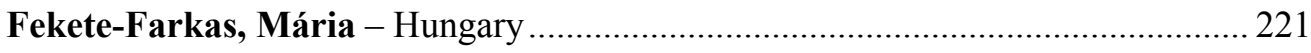

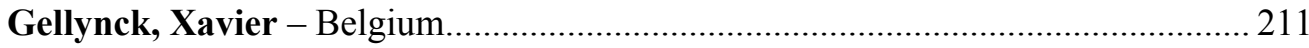

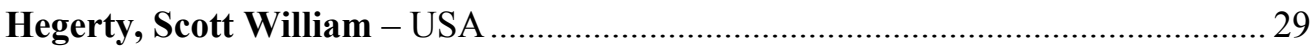

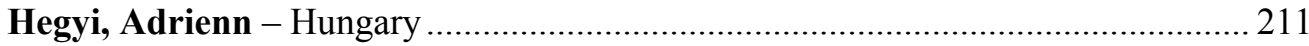

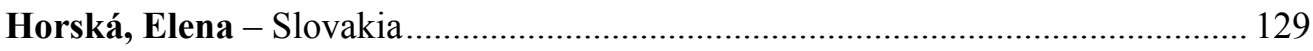

Illés, Bálint Csaba - Hungary ……………………………........................ 99, 173

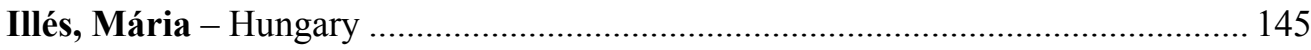

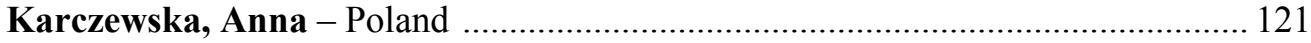

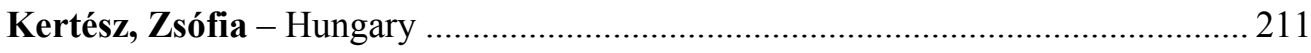

Koltai, Tamás - Hungary ...................................................................................... 109

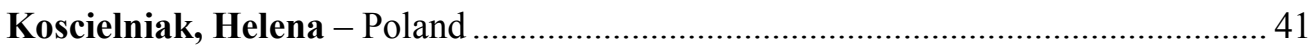

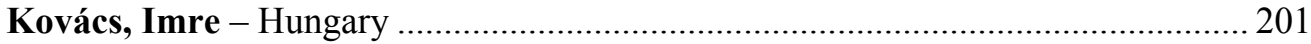

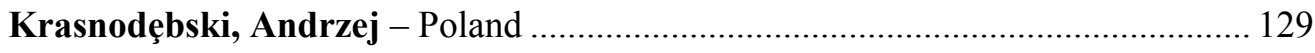

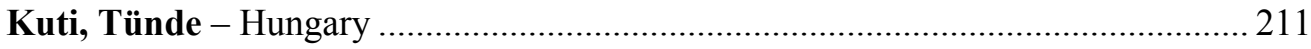

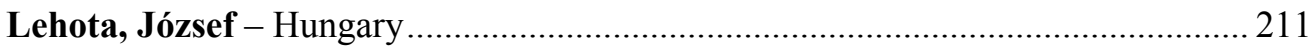

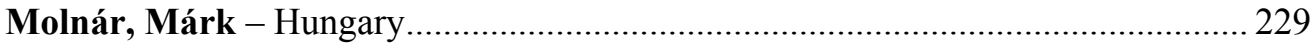

Naár-Tóth, Zsuzsanna - Hungary .................................................................... 229

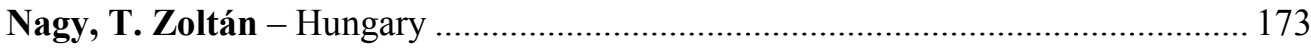

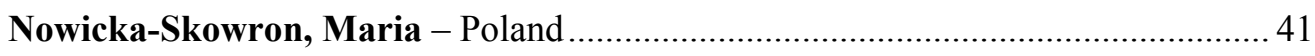




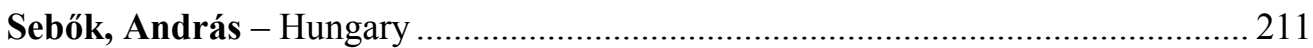

Sivaprakasam, Sathya Narayanan -United Arab Emirates................................... 183

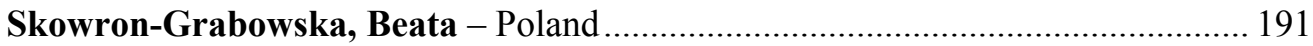

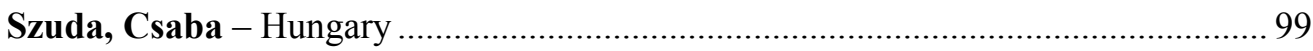

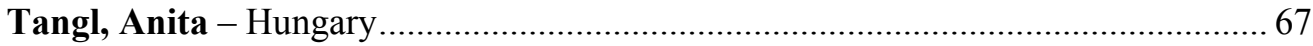

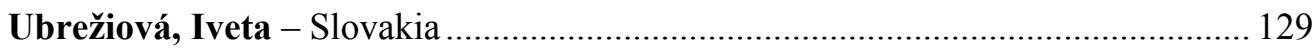

Uzonyi-Kecskés, Judit - Hungary ........................................................................ 109

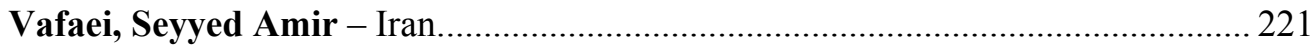

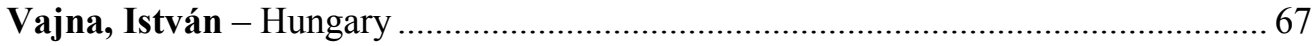

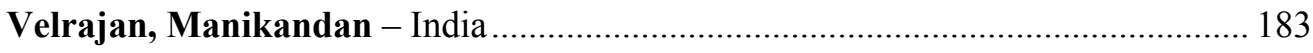

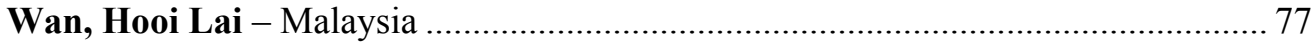


At Pearson, we have a simple mission: to help people make more of their lives through learning.

We combine innovative learning technology with trusted content and educational expertise to provide engaging and effective learning experience that serve people wherever and whenever they are learning.

We enable our customers to access a wide and expanding range of market-leading content from world-renowned authors and develop their own tailor-made book. From classroom to boardroom, our curriculum materials, digital learning tools and testing programmes help to educate millions of people worldwide - more than any other private enterprise.

Every day our work helps learning flourish, and wherever learning flourishes, so do people.

To learn more, please visit us at: www.pearson.com/uk 